\title{
CUSTO, RISCO E MARGEM DE COMERCIALIZAÇÃO DE ARROZ E DE FEIJÃO NO ESTADO DE SÃO PAULO: ANÁLISE DINÂMICA E TESTE DE MODELOS ALTERNATIVOS
}

\author{
DANILO ROLIM DIAS DE AGUIAR \\ Engenheiro Agrônomo
}

Orientador: Prof. Dr. GERALDO SANT'ANA DE CAMARGO BARROS

\begin{abstract}
Tese apresentada à Escola Superior de Agricultura "Luiz de Queiroz", da Universidade de São Paulo, para obtenção do título de Doutor em Agronomia, Área de Concentração: Economia Agrária.
\end{abstract}

PIRACICABA

Estado de São Paulo - Brasil

Abril - 1994 
Aguiar, Danilo Rolim Dias de

A282c Custo, risco e margem de comercialização de arroz e de feijão no Estado de São Paulo: análise dinâmica e teste de modelos alternativos. Piracicaba, 1994. $185 \mathrm{p}$.

Tese - ESALQ

Bibliografia.

1. Arroz - Comercialização - Custo 2. Arroz - Pre ço - São Paulo (Estado) 3. Comercialização agrícola Margem - Modelo 4. Feijão - Comercialização-Custo 5. Feijão - Preço - São Paulo (Estado) I.Escola Superior de Agricultura Luiz de Queiroz, Piracicaba

CDD 338.17318

338.175652 
CUSTO, RISCO E MARGEM DE COMERCIALIZAÇÃO DE ARROZ E DE FEIJÃO NO ESTADOO DE SÃO PAULO: ANÁLISE DINÂMICA E TESTE DE MODELOS ALTERNATIVOS

DANILO ROLIM DIAS DE AGUIAR

Aprovada em 16.05.1994

Comissão julgadora:

Prof. Dr. Geraldo S. A. de Camargo Barros ESALQ/USP

Prof. Dr. Pedro Valentim Marques ESALQ/USP

Profa. Dra. Ana Lúcia Kassouf ESALQ/USP

Prof. Dr. Carlos A. Moreira Leite DER/UFV

Dr. Flávio Condé de Carvalho IEA/SAASP

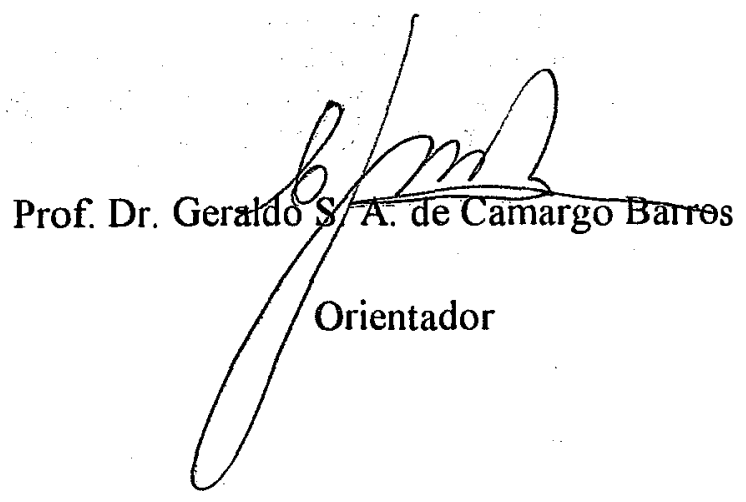


Para

Bel

e Marília 


\section{AGRADECIMENTOS}

Ao Prof. Geraldo S. A. de Camargo Barros, por minha formação como professor e pesquisador.

Aos professores Ana Lúcia Kassouf, Pedro V. Marques e Carlos A. Moreira Leite, e ao pesquisador Flávio Condé de Carvalho, pelas inúmeras sugestões.

Ao Departamento de Economia Rural da Universidade Federal de Viçosa (DER/UFV), pela liberação integral de minhas atividades para conclusão do curso de doutorado e pelas facilidades materiais oferecidas.

Ao Centro de Pesquisa em Economia Agrícola da Fundação de Estudos Agrários Luiz de Queiroz (CEPEA/FEALQ) e à Universidade Estadual Paulista (UNESP) - Campus de Ilha Solteira, pela liberação parcial durante parte do curso de doutorado.

Ao Departamento de Economia e Sociologia Rural (DESR) da Escola Superior de Agricultura "Luiz de Queiroz" (ESALQ), Universidade de São Paulo (USP), pela oportunidade de cursar o doutorado.

Aos colegas do curso de pós-graduação e aos professores e funcionários do DESR, pela agradável convivência durante o curso.

A Adelaide M. Cunha Lopes, pelas sugestões lingüísticas.

Ao professor Michael K. Wohlgenant, por ter gentilmente enviado separata de seu artigo.

À CAPES, pela bolsa de doutorado. 


\section{SUMÁRIO}

\section{Página}

LISTA DE TABELAS.

viii

LISTA DE FIGURAS.

xi

RESUMO

xii

SUMMARY

xiv

1. INTRODUÇÃO

1.1. O problema

1.2. O conceito de margem de comercialização.

1.2.1. Definição.

1.2.2. Interpretação: abordagem preliminar.

1.3. Os mercados de arroz e de feijão e o custo de comercialização.

1.4. Delineamento do trabalho.

2.1. Modelo competitivo de GARDNER (1975).

2.1.1. Efeito de uma variação na demanda primária.

2.1.2. Efeito de uma mudança na oferta agrícola. 
2.1.3. Efeito de uma mudança na oferta

de insumos de comercialização

2.1.4. Elasticidade de transmissão de preços $\mathrm{e}$

elasticidade-preço da demanda derivada

2.2. Modelo de markup de HEIEN

2.3. Modelo de BARROS (1990).

2.4. Modelo de margem com risco de preço

de BRORSEN et al. (1985).

3. MODELOS EMPÍRICOS DE MARGEM

DE COMERCIALIZAÇÃO.

3.1. Modelo de BUSE \& BRANDOW (1960).

3.2. Modelo de markup: WAUGH (1973) -

GEORGE \& KING (1971)

3.3. Modelo relativo: WOHLGENANT \& MULLEN (1987)

3.4. Modelo do custo de comercialização.

3.5. Comparação entre os modelos.

3.6. Deficiências dos modelos.

4.1. Aspectos gerais.

4.2. Modelo proposto

4.2.1. Modelo com causalidade produtor $\rightarrow$ varejo.

4.2.2. Modelo com causalidade varejo $\rightarrow$ produtor. 
4.3. O modelo dinâmico e os mercados de arroz e de feijão..................... 73

5. DADOS E PROCEDIMENTOS..................................................... 74

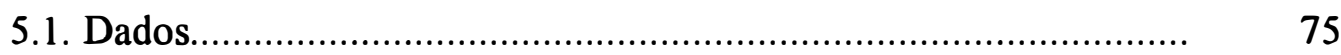

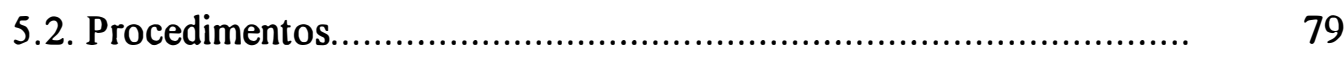

5.2.1. Comparação entre modelos alternativos................................ $\quad 79$

5.2.2. Efeito estático do risco de preço e do custo de comercialização........................................................ 82

5.2.3. Efeito dinâmico do risco de preço e do custo de comercialização................................................ 83

6. ANÁLISE DOS RESULTADOS....................................................... 97

6.1. Comparação entre modelos empiricos.......................................... 98

6.2. Efeito estático do risco e do custo de comercialização......................................................... 108

6.3. Efeito dinâmico do risco e do custo de comercialização.

6.3.1. Multiplicadores de THEIL.............................................. 113

6.3.2. Modelo VAR não-identificável.............................................. 118

6.3.3. Modelo VAR identificável................................................. 136

7. RESUMO E CONCLUSÕES.............................................................. 146

REFERÊNCIAS BIBLIOGRÁFICAS ............................................... 151

APÊNDICE 1: Figuras da análise de auto-regressão vetorial com modelo não-identificável. 
APÊNDICE 2: Figuras da análise de auto-regressão vetorial

com modelo identificável 


\section{LISTA DE TABELAS}

Tabela $\mathrm{n}^{\circ}$

Página

1 Definições de margens de comercialização para os níveis de produtor, atacado e varejo

2 Descrição das variáveis e estatísticas utilizadas na análise

3 Estimações dos modelos alternativos de margem de comercialização de feijão no Estado de São Paulo, dados anuais de 1975 a 1992

$4 \quad$ Valores dos testes $\mathbf{J}$ das estimações anuais dos modelos de margem de comercialização de feijão

5 Estimações dos modelos alternativos de margem de comercialização de arroz no Estado de São Paulo, dados anuais de 1975 a 1992

$6 \quad$ Valores do teste $\mathbf{J}$ das estimações anuais dos modelos de margem de comercialização de arroz

7 Estimações dos modelos dinâmico e de markup para feijão, dados mensais de 1975 a 1993

8 Estimações dos modelos dinâmico e de markup para arroz, dados mensais de 1975 a 1993

9 Valores dos testes $\mathbf{J}$ das estimações mensais dos modelos de markup e dinâmico para arroz e para feijão

10 Estimações do modelo dinâmico de margem de comercialização para feijão, dados mensais de 1975 a 1993 
11 Estimações do modelo dinâmico de margem de comercialização para arroz, dados mensais de 1975 a 1993.

12 Efeito de choques nas variáveis exógenas sobre a margem de comercialização de arroz - multiplicadores de THEIL.

13 Efeito de choques nas variáveis exógenas sobre a margem de comercialização de feijão - multiplicadores de THEIL..........

14 Valores dos testes F para o mercado de arroz, dados de 1975 a 1993

15 Elasticidades de impulso sobre a margem de comercialização de arroz no modelo VAR não-identificável, dados de 1975 a 1993.

16 Decomposição da variância dos erros de previsão da margem de comercialização de arroz no modelo VAR não-identificável, dados de 1975 a 1993, em porcentagem

17 Decomposição da variância dos erros de previsão do preço de arroz ao varejo no modelo VAR não-identificável, dados de 1975 a 1993, em porcentagem.

18 Decomposição da variância dos erros de previsão do preço de arroz ao produtor no modelo VAR não identificável, dados de 1975 a 1993, em porcentagem

19 Valores dos testes F para o mercado de feijão, dados de 1975 a 1993

20 Elasticidades de impulso sobre a margem de comercialização de feijão no modelo VAR não-identificável, dados de 1975 a 1993. 
21 Decomposição da variância dos erros de previsão da margem de comercialização de feijão no modelo VAR nãoidentificável, dados de 1975 a 1993, em porcentagem

22 Decomposição da variância dos erros de previsão do preço de feijão ao produtor no modelo VAR não-identificável, dados de 1975 a 1993, em porcentagem

23 Decomposição da variância dos erros de previsão do preço de feijão ao varejo no modelo VAR não-identificável, dados de 1975 a 1993, em porcentagem

24 Matriz de interações contemporâneas $\left(A_{0}\right)$ para arroz.

25 Elasticidades de impulso sobre a margem de comercialização de arroz no modelo VAR identificável, dados de 1975 a 1993

26 Decomposição da variância dos erros de previsão da margem de comercialização de arroz no modelo VAR identificável, dados de 1975 a 1993, em porcentagem

27 Matriz de interações contemporâneas $\left(A_{0}\right)$ para feijão

28 Elasticidades de impulso sobre a margem de comercialização de feijão no modelo VAR identificável, dados de 1975 a 1993

29 Decomposição da variância dos erros de previsão da margem de comercialização de feijão no modelo VAR identificável, dados de 1975 a 1993, em porcentagem 


\section{LISTA DE FIGURAS}

Figura $n^{\circ}$

Página

1 Exemplo de determinação da margem de comercialização

na produção de queijo, sendo: Od = oferta derivada;

$\mathrm{Op}=$ oferta primária; $\mathrm{Dp}=$ demanda primária;

e $\mathrm{Dd}=$ demanda derivada....

2 Margem absoluta de comercialização de arroz em São Paulo, 1975-1993.

3 Evolução dos preços de arroz ao produtor e varejo

e do risco de preço em São Paulo, 1975-1993

4 Margem absoluta de comercialização de feijão em São Paulo, 1975-1993

5 Evolução dos preços ao produtor e varejo e do risco de preço de feijão em São Paulo, 1975-1993

6 Margens relativas de comercialização de arroz e de feijão em São Paulo, 1975-1993

7 Evolução dos preços dos fertilizantes (Fert), óleo diesel e salário-mínimo (SM), 1975-1993.

8 Evolução do risco de 4 meses (risco4) e de 12 meses (riscol2) de feijão no Estado de São Paulo, 1975-1993

9 Evolução do custo efetivo real m ensal do capital de giro, 1975-1993. 


\title{
CUSTO, RISCO E MARGEM DE COMERCIALIZAÇÃO DE ARROZ E DE FEIJÃO NO ESTADO DE SÃO PAULO: ANÁLISE DINÂMICA E TESTE DE MODELOS ALTERNATIVOS
}

\author{
Autor: DANILO ROLIM DIAS DE AGUIAR
}

Orientador: PROF. DR. GERALDO SANT'ANA DE CAMARGO BARROS

\section{RESUMO}

O objetivo principal deste trabalho é examinar o impacto do risco de preço e dos custos de comercialização na formação da margem de comercialização de arroz e de feijão no Estado de São Paulo. Desenvolveu-se e estimou um modelo teórico que foi comparado com modelos que vêm sendo empregados em estudos similares. Esse modelo foi também submetido à análise dinâmica por meio dos multiplicadores de Theil e da estimação de modelos auto-regressivos vetoriais.

Para ambos os produtos, os melhores ajustamentos do modelo desenvolvido foram observados pelos dados mensais. A análise estática mostrou que a variável risco de preço é importante na explicação da margem de feijão, mas não o é na explicação da margem de arroz; em ambos os casos, o sinal positivo dos coeficientes indicou aversão ao risco por parte dos intermediários. As variáveis salário e preço do óleo diesel foram importantes no mercado de feijão, mas o coeficiente do preço do óleo teve sinal contrário em relação ao que previa o modelo teórico. $O$ coeficiente do preço dos fertilizantes teve os sinais esperados nos dois mercados, mas foi significativo apenas para o mercado de arroz. A variável taxa de juros foi insignificante nos dois mercados.

A análise dinâmica mostrou que a importância e o sentido do impacto das variáveis sobre a margem podem diferir em relação ao enfoque estático. A taxa de juros foi a variável de maior importância na explicação da margem de comercialização dos dois produtos. $\mathrm{O}$ risco de preço mostrou sua grande importância no mercado de feijão e sua reduzida importância no mercado de arroz. A variável preço dos fertilizantes mostrou 
importância significativa e crescente na explicação da margem dos dois produtos. A intensidade dos impactos mostra-se, em geral, com tendência a zero, à medida que o tempo passa; mostra ainda a mudança no sinal do impacto, como é o caso do preço do óleo diesel e da taxa de juros que apresentam impactos negativos nos primeiros meses após os choques seguidos por impactos positivos.

A pesquisa apresentou também implicações de natureza metodológica. $\mathbf{O}$ modelo desenvolvido mostrou-se adequado para a análise dos impactos dinâmicos via multiplicadores de Theil. As combinações de métodos estáticos e dinâmicos, bem como dos diferentes tipos de análise dinâmica, permitiram visualizar diferentes efeitos sobre a margem de comercialização. Sugere-se, assim, o uso desse procedimento na análise de outros mercados. 


\section{COST, RISK AND MARKETING MARGIN OF RICE AND BEANS IN THE STATE OF SÃO PAULO, BRAZIL: DYNAMIC ANALYSIS AND TEST OF ALTERNATIVE MODELS}

Author: DANILO ROLIM DIAS DE AGUIAR

Adviser: PROF. DR. GERALDO SANT'ANA DE CAMARGO BARROS

\section{SUMMARY}

The main objective of this research is to examine the impact of price risk and marketing cost on marketing margin formation of rice and beans in the State of São Paulo, Brazil. It was developed and estimated a theoretical model and compared with other models used in similar studies. This model was also used for dynamic analysis through mean of Theil multipliers and estimation of a vector autoregressive model.

For both products, best fittings of the developed model were observed using monthy data. The static analysis showed that the price risk variable is important on the beans margin explanation, but it is not important on the explanation of the rice margin; in both cases, the positive signals indicated risk aversion of the midlemen. The wage and the oil price variables were important in the beans market, but oil price coefficient had opposite sign in relation to the theoretical framework. The fertilizer price coeficient had the expected signal in both markets, but it was significative only for the rice market. The interest rate variable was insignificant in both markets.

Dynamic analysis showed that the importance and the direction of the impact of cost shocks on marketing margin can be different with respect to the static approach. The interest rate was the most important variable in explaining the marketing margins for both products. The price risk presents its importance on the beans market and 
reduced importance on the rice market. The fertilizer price variable shows a significative and increasing importance on the explanation of the margin for both products. All impacts tend to zero and many of them had signal changes over time; this is the case of oil price and interest rate, that had negative impacts on the earlier months after shocks followed by positive impacts.

The research presented also implications of methodological nature. The developed model was suitable for analysis of dynamic impacts by mean of Theil multipliers. The combination of static and dynamic methods, as well as the different types of dynamic analysis, allow to measure different effects of costs on marketing margins. It is suggested using this procedure in other markets analysis. 


\section{INTRODUÇÃO}

\subsection{O problema}

Neste trabalho propõe-se estudar as margens de comercialização de arroz e.de feijão no Estado de São Paulo. A teoria sugere ${ }^{1}$ que as variações da margem de comercialização produtor-varejo podem estar associadas a choques na oferta agrícola, na demanda ao varejo ou na oferta dos insumos de comercialização. Sendo assim, o objetivo principal deste trabalho é examinar a importância dos choques de oferta dos insumos de comercialização sobre a margem dos dois produtos citados por meio das relações entre: variáveis proxies dos preços de alguns insumos; risco de preço; preços dos produtos ao varejo e ao produtor; e margem de comercialização. Para que o objetivo proposto seja atendido, desenvolver-se-á um modelo de margem que será estimado e analisado estática e dinamicamente. Este modelo será também comparado a especificações empíricạ que vêm sendo utilizadas em estudos similares.

No Brasil, as análises empíricas de margens de comercialização têm enfocado, predominantemente, a transmissão de preços entre diferentes níveis de mercado (principalmente entre varejo, atacado e produtor). As possibilidades de explicar o comportamento das margens em termos de seus componentes internos não têm sido muito exploradas. A proposta de estudar os componentes das margens relaciona-se aos estudos da transmissão de preços: por um lado, o conhecimento da intensidade de transmissão é de grande interesse na implementação de medidas que visem amenizar os efeitos de choques de preços; por outro, o conhecimento dos elementos responsáveis pela grandeza da margem de comercialização fornece valiosas indicações para a elaboração de

1 Ver modelo de GARDNER, no capítulo 2. 
políticas que efetivamente reduzam essas margens, beneficiando produtores e consumidores.

A importância dos custos na formação da margem não requer maiores esclarecimentos. Grosso modo, a margem pode ser vista como a soma dos custos de comercialização com os lucros (ou prejuízos) dos agentes intermediários. O que é relevante definir é se o impacto dos choques de oferta agrícola e demanda no varejo não é mais importante do que o do custo de comercialização, e quais são os componentes do custo que impactam mais intensamente a margem. A ausência de estudos detalhados sobre os elementos do custo de comercialização de cada produto conduz ao uso de variáveis proxies (por exemplo, preço do combustível como proxy do transporte, salário como proxy do custo de mão-de-obra etc.). Neste trabalho também lança-se mão de variáveis proxies do custo de comercialização.

No tocante aos riscos de comercialização, não se sabe de nenhum esforço feito até o momento para quantificar seu impacto sobre as margens no Brasil. Recentemente, foram desenvolvidos modelos sobre comportamento de margens que envolvem risco, os quais têm apresentado bom desempenho em testes realizados em outros países (por exemplo, BRORSEN et al., 1985) e que, aparentemente, são aplicáveis ao caso brasileiro.

Em nível internacional, especificações empíricas na forma reduzida vêm sendo utilizadas no estudo das margens de comercialização (por exemplo, BUSE \& BRANDOW, 1960; WOHLGENANT \& MULLEN, 1987; THOMPSON \& LYON, 1989; FAMINOW \& LAUBSCHER, 1991; e LYON \& THOMPSON, 1993)². Embora alguns resultados empíricos interessantes tenham sido obtidos, esses modelos, na maioria

2 Esses trabalhos reconhecem que um modelo estrutural com equações simultâneas de oferta e demanda, tanto ao nivel de produtor quanto ao nivel de varejo, permitiria um conhecimento mais preciso das relações entre as inúmeras variáveis que afetam os preços agrícolas. Entretanto, existem algumas razões que justificam a estimação de formas reduzidas dos modelos de margem. Uma delas seria a dificuldade de encontrar dados necessários para a estimação dos modelos estruturais com a mesma periodicidade com que se quer estudar as margens. Outra razão, apontada por FAMINOW \& LAUBSCHER, é que a intervenção governamental no mercado pode obscurecer a estimação de um modelo estrutural. 
das vezes, têm se mostrado pouco fundamentados teoricamente ${ }^{3}$. Essa constatação motivou o desenvolvimento do modelo que será estimado neste trabalho.

\subsection{O conceito de margem de comercialização}

\subsubsection{Definição}

A definição mais aplicativa de margem, que permite inclusive se depreénder como ela pode ser calculada, apresenta a margem de comercialização como sendo a diferença entre o preço pelo qual um intermediário (ou um conjunto de intermediários) vende uma unidade de um produto e o pagamento que ele faz pela quantidade-equivalente de produto que precisa comprar para vender essa unidade (JUNQUEIRA \& CANTO, 1971).

Em termos analíticos, considerando-se apenas os níveis de produtor e varejo (que são objetos desse estudo) e admitindo-se mercados competitivos, essa definição equivale a dizer que a margem é a diferença entre os preços, em unidades equivalentes, formados em dois mercados onde interagem diferentes curvas de oferta e demanda: o. mercado varejista e o mercado ao nível de produtor agrícola. O preço recebido, pelo produtor rural é determinado pelo equilíbrio entre a oferta do produto agrícola, denominada oferta primária, e a demanda derivada, que nada mais é do que a demanda dos intermediários pelo produto agrícola. O preço ao varejo é fruto do equilibrio entre a demanda primária, do consumidor, e a oferta derivada, obtida a partir da oferta do produto agrícola.

A Figura 1 apresenta a determinação gráfica da margem de comercialização ${ }^{4}$. Supondo que se esteja representando os mercados de leite (produtor) e queijo (varejo) e que 10 litros de leite sejam necessários para produzir 1 quilograma de queijo, a quantidade de equilíbrio (2), na abcissa, seria a representação de 2 toneladas de queijo e

\section{Item 3.6.}

4 A figura representa o caso em que a margem independe da quantidade comercializada, ou seja, a curva de oferta de serviços de comercialização é perfeitamente elástica (item 1.2.2). 
de 20.000 litros de leite. Para essa quantidade comercializada, ter-se-ia como margem a diferença entre os preços de equilíbrio ao varejo e na fazenda, dados pela ordenada. Assim, a margem de comercialização é igual a $(4-2)=2$.

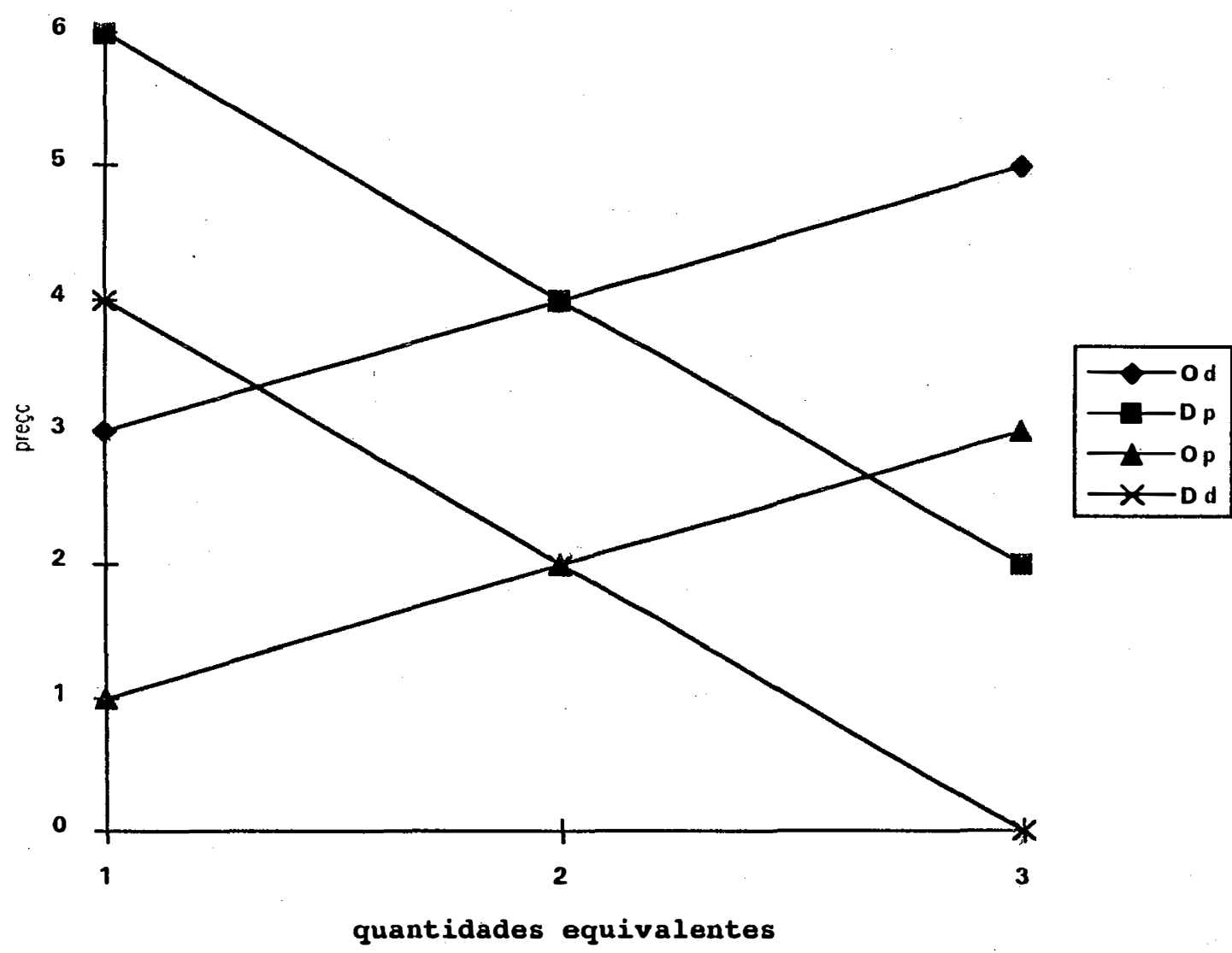

Figura 1 - Exemplo de determinação da margem de comercialização na produção de queijo, sendo Od = oferta derivada; $\mathbf{O p}=$ oferta primária; $\mathbf{D p}=$ demanda primária; e Dd = demanda derivada.

$\mathrm{O}$ uso de quantidades equivalentes é necessário, porque geralmente a quantidade vendida é diferente da quantidade comprada pelo intermediário.]Essa diferença existe como decorrência da geração de subprodutos durante o processamento dos produtos que não são comercializados in natura e das perdas por deterioração fisica ocorridas durante as operações de comercialização (armazenamento, transporte etc.). 
Dada a ocorrência de perdas, os produtos que não sofrem processamento também apresentam diferenças nas quantidades equivalentes nos diversos níveis da cadeia de comercialização. Mesmo que não ocorram perdas e que não se gerem subprodutos, muitas vezes é necessário fazer a conversão em quantidades equivalentes, pelo simples fato de o produto ser medido em unidades diferentes em diferentes níveis de mercado; por exemplo, supondo-se que a goiaba seja integralmente convertida em suco, ainda assim será necessário converter quilogramas de goiaba em litros de suco para se calcular a margem.

A determinação da margem pode ser feita de forma separada para cada categoria de intermediário, bem como pode ser apresentada na forma absoluta ou relativa. A margem total absoluta mostra a quantidade de moeda auferida, por unidade vendida, pelo conjunto dos agentes que intermediam a comercialização do produto desde o nível de produtor agrícola até o nível de consumidor final. As margens absolutas do varejo e do atacado mostram a renda auferida, também por unidade vendida, pelos varejistas e pelos atacadistas, respectivamente. As margens relativas representam as parcelas dos preços de venda cabíveis a cada categoria de intermediário (Tabela 1).

Conceito análogo ao de margem é o de markup. O markup absoluto não difere em nada da margem absoluta, mas o markup relativo (Tabela 1) é diferente e apresenta aplicações distintas da margem relativa. Enquanto a margem relativa representa a fração do preço de venda apreendida pelos intermediários, o markup relativo mostra a parcela do preço de compra que é absorvida pelo setor de intermediação, Por se relacionar ao preço de compra, que é de pleno conhecimento do intermediário, o markup muitas vezes é utilizado como estratégia de determinação de preço por parte dos agentes de comercialização 5 .

5 Por exemplo, se um atacadista tiver como prática de determinação de seu preço a aplicação de um markup percentual de $20 \%$ sobre o preço de compra, ao comprar uma tonelada de produto agrícola ao preço de CR\$1.000.000,00, ele deverá revendê-la a CR\$1.200.000,00 ao varcjista. Notar que um markup de $20 \%$ não corresponde a uma margem relativa de $20 \%$; no exemplo dado, supondo-se uma equivalência de 1 para 1 entre os níveis de produtor e varejo, a margem relativa é de $16,67 \%$ (veja MARQUES, 1993, para uma fórmula de conversão entre markup e margem relativa). 
Tabela 1 - Definições de margens de comercialização para os níveis de produtor, atacado e varejo

\begin{tabular}{ll}
\hline Conceito & Fórmula $^{*}$ \\
\hline Margem total absoluta & $M T=P_{v}-P_{p}$ \\
Margem total relativa & $M T^{\prime}=\frac{P_{v}-P_{p}}{P_{v}}$ \\
Margem absoluta do varejo & $M_{v}=P_{v}-P_{a}$ \\
Margem relativa do varejo & $M_{v}^{\prime}=\frac{P_{v}-P_{a}}{P_{v}}$ \\
Margem absoluta do atacado & $M_{a}=P_{a}-P_{p}$ \\
Margem relativa do atacado & $M_{a}^{\prime}=\frac{P_{a}-P_{p}}{P_{a}}$ \\
Markup relativo do atacado & $M K^{\prime}=\frac{P_{v}-P_{p}}{P_{p}}$ \\
\hline Markup relativo do varejo & $M K_{a}^{\prime}=\frac{P_{a}-P_{p}}{P_{p}}$ \\
\hline
\end{tabular}

${ }^{*} \mathrm{Pv}=$ preço de uma unidade ao varejo;

$\mathrm{Pa}=$ preço ao atacado da quantidade-equivalente;

$\mathrm{Pp}=$ preço recebido pelo produtor da quantidade-equivalente.

\Outra definição de margem de comercialização, com um enfoque um pouco diferente, mostra que a margem representa o pagamento pelas atividades executadas pelos agentes de comercialização. Nas palavras de TOMEK \& ROBINSON 
(1981, p. 120), a margem de comercialização é "o preço de um conjunto de serviços de comercialização, o qual seria o resultado de uma demanda e de uma oferta por tais serviços". Essa definição será importante, no capítulo 3, na especificação de um dos modelos empíricos de margem.

Sob esse último enfoque, a margem pode ser dividida em dois itens: lucro e custo. Os serviços de comercialização prestados pelos agentes de intermediação são aqueles que acrescentam utilidades de forma, tempo e espaço ao produto agrícola bruto. Essas utilidades são acrescentadas mediante diversas operações, tais como classificação, processamento, armazenamento, transporte etc. '́ justamente a dificuldade de mensurar, separadamente, os componentes de custo e lucro das atividades de intermediação que torna atraente o uso da margem de comercialização como indicador de desempenho dos mercados.

\subsubsection{Interpretação: abordagem preliminar}

Um tratamento interpretativo mais rigoroso das margens de comercialização só será possível quando da exposição dos modelos teóricos, a partir do capítulo 2. Por òra, algumas observações são suficientes para que se estabeleçam, exatamente, as inferências que podem ser extraídas da mensuração da margem de comercialização e os cuidados que devem ser tomados, evitando-se, assim, uma interpretação inadequada dessa medida.

Inicialmente, cabe destacar que a margem de comercialização é um indicador imperfeito, mas de mais fácil estimação do real desempenho dos mercados. Daí a necessidade de cuidado na interpretação de seu comportamento. Um crescimento do valor da margem pode tanto estar associado ao aumento da taxa de lucro dos intermediários quanto à melhoria do produto final, via introdução de novos processos ou serviços.

Produtos 6 processados ou perecíveis que demandam maiores cuidados na comercialização tendem a apresentar maiores margens de comercialização; o mesmo

6 Este e os próximos dois parágrafos baseiam-se em BARROS (1987, p.42-45). 
ocorre com produtos de peso ou volume excessivos (devido ao custo de transporte e armazenamento). Espera-se ainda que as margens sejam menores quanto mais concorrenciais forem os mercados.

Cuidado adicional deve ser tomado quanto ao efeito dúbio de algumas variáveis sobre a evolução das margens de comercialização. Mudanças tecnológicas podem reduzir o custo e, conseqüentemente, a margem de comercialização. Podem também, por outro lado, aumentar o custo e a margem, se a nova tecnologia estiver associada à incorporação de novos serviços ao produto agrícola.

As perdas de comercialização também podem ter efeitos distintos sobre a evolução da margem. Por um lado, o combate às perdas (uso de inseticida, fungicida, câmaras frigoríficas etc.) tenderia a encarecer 0 processo de comercialização, aumentando a margem. Por outro lado, no caso de não se combater perdas, dever-se-ia comprar mais produto, o que poderia levar à diminuição da margem devido a dois fatores: (1) pelo aumento da quantidade-equivalente a ser utilizada no cálculo da margem (mais produto seria utilizado para gerar uma unidade de venda); e (2) por um possível aumento do preço a ser pago (em mercado competitivo; aumento da demanda derivada tenderia a elevar o preço, para dada oferta primária).

O efeito da quantidade comercializada sobre o valor da margem também merece uma análise mais acuradà. A chave para a determinação desse efeito está na inclinação da curva de oferta dos serviços de comercialização: Admitindo-se que essa curva seja positivamente inclinada, aumento na quantidade vendida pelo intermediário proporciona maior custo médio e maior margem de comercialização. Uma curva de oferta horizontal (perfeitamente elástica) dos serviços de comercialização traria, como conseqüência, uma margem fixa, independente da quantidade comercializada ${ }^{7}$. A existência de economia de escala no mercado de serviços de comercialização produziria uma curva de oferta de serviços decrescente, à medida que aumentasse a quantidade vendida; sendo este o caso, dever-se-iam esperar margens menores associadas a maior volume de produção (TOMEK \& ROBINSON, 1981).

7 Situação representada na figura 1 (p. 4). 
Outra questão relevante é que, geralmente, existe uma defasagem de tempo entre os ajustamentos dos preços nos diversos níveis de mercado. $\mathrm{O}$ uso de preços ocorridos no mesmo período (mês, semana etc.), para o cálculo da margem entre niveis de mercado, pode fazer com que o efeito do ajustamento não seja captado e as margens sejam super ou subdimensionadas. Embora esse problema seja de amplo conhecimento, é comum a estimação de margens correntes, em função de não se saber, com precisão, o período de tempo que o produto fica sob os cuidados do setor de comercialização agrícola.

\subsection{Os mercados de arroz e de feijão e o custo de comercialização}

O estudo empírico que será desenvolvido engloba dois dos principais produtos de consumo popular do Brasil: feijão e arroz. A opção por estudar estes dois produtos decorre de seu elevado peso na despesa alimentar das famílias de baixa renda e na sua importância estratégica em qualquer política que vise combater a fome e a desnutrição no Brasil. Neste item serão descritas algumas das características desses dois mercados e serão apresentadas algumas figuras com as evoluções das margens e dos preços dos produtos e dos insumos. Essas figuras permitirão uma primeira visualização das inter-relações das variáveis estudadas.

Tanto o arroz quanto o feijão são produtos comercializados in natura, com possibilidade de armazenamento (maior no caso do arroz) e abastecidos quase que integralmente pela produção doméstica. Os dois produtos são comercializados em mercados relativamente competitivos, nos quais os agentes varejistas e os produtores rurais possuem pequenas parcelas individuais do mercado. $O$ mercado de feijão caracteriza-se por comercializar um produto praticamente indiferenciado quanto à marca comercial. No caso do arroz, alguma diferenciação ocorre entre marcas comerciais, embora exista boa possibilidade de substituição entre produtos de marcas distintas, particularmente por parte dos consumidores de menor poder aquisitivo. Mesmo no atacado, onde o número de agentes é menor nos dois mercados, a competição potencial com atacadistas dos mercados de outros produtos tende a limitar o poder de monopólio 
neste nível de mercado ${ }^{8}$. Essas características, aliadas ao fato de que a análise empírica será conduzida, neste trabalho, com dados médios de mercadorias de diversas marcas comerciais, justificam o uso de modelos teóricos concorrenciais na análise da tendência dos preços e das margens de comercialização?

Outra questão relevante, que se deriva das características dos mercados estudados, é que o feijão, em decorrência da perda de qualidade que esse produto sofre durante o armazenamento, da dispersão geográfica e temporal de sua produção e de suas exigências agroclimáticas, é um produto que admite a hipótese de o risco de comercialização ter peso significativo em sua margem. $\mathrm{O}$ arroz, por ser mais facilmente armazenado, ter apenas uma safra anual, ser produzido em regiões mais concentradas geograficamente e possuir um mercado internacional mais expressivo, deve ser menos impactado pelo risco. Quanto ao custo de comercialização, não se levantam a priori hipóteses sobre eventuais diferenças em seu impacto sobre o mercado de cada um dos produtos; os componentes utilizados são os mesmos para os dois mercados, envolvendo combustível, salários e juros.

A Figura 2 mostra que a margem absoluta de comercialização de arroz no Estado de São Paulo não tem apresentado tendência de crescimento. Na verdade, essa variável tem seguido um sentido de queda, particularmente desde o início da década de 1980. Não existem indícios de mudanças estruturais ao longo do tempo que justificassem a adoção de algum procedimento de separação entre períodos.

A evolução dos preços reais do arroz mostra também uma tendência decrescente, tanto ao nível de produtor quanto ao nível de varejo (Figura 3). Já o risco de preço, aqui medido apenas com a utilização de quatro meses consecutivos ${ }^{10}$, mostra picos mais elevados e maior instabilidade entre 1989 e 1992 (Figura 3).

8 Ver AGUIAR et al. (1994) para uma argumentação a respeito dessa possibilidade.

9 Obviamente, esses mercados não são perfeitamente competitivos. Utilizando-se o conceito de workable competition, em que se argumenta que "algum" afastamento da norma de competição perfeita ou pura não é danoso numa perspectiva de longo prazo (ver SCHERER \& ROSS, 1990, p. 52-55), é possivel considerar-se razoável o uso dos modelos teóricos competitivos na análise dos mercados de arroz e de feijão.

10 capitulo 5 mostrará as duas formas como a variável risco é construida. Por ora, é suficiente saber que uma delas envolve a média-móvel de 4 meses e a outra envolve a média-móvel de 12 meses. 


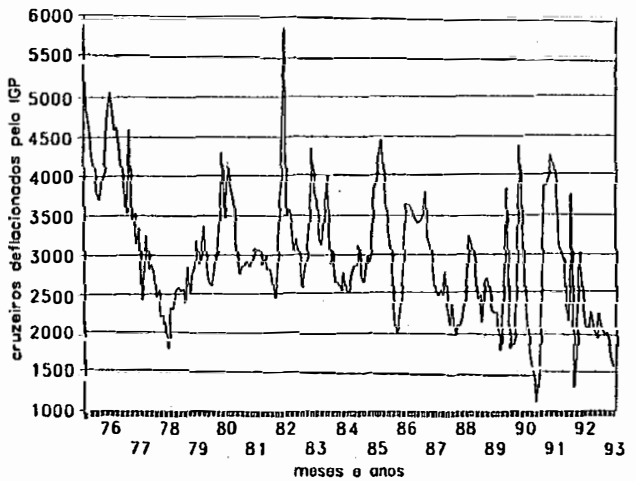

Figura 2 - Margem absoluta de comercialização de arroz em São Paulo, 1975-1993 Fonte: vide capítulo 5 .

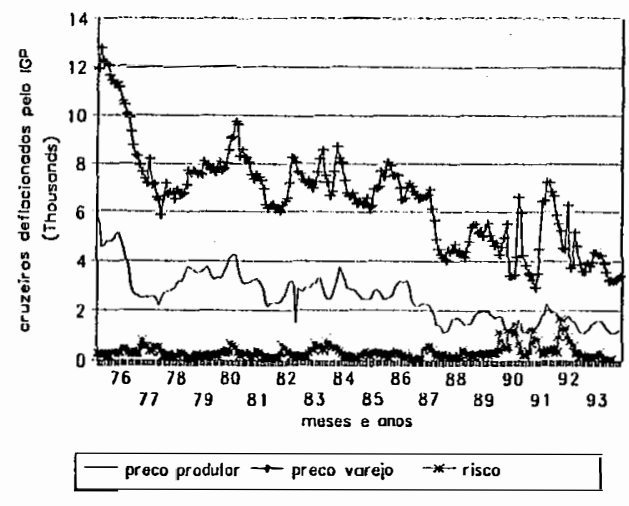

Figura 3 - Evolução dos preços de arroz ao produtor e varejo e do risco de preço em São Paulo, 1975-1993

Fonte: vide capítulo 5. 
No mercado de feijão, verifica-se maior estabilidade da margem absoluta, particularmente ao longo da década de 1980. Flutuações acentuadas acontecem, principalmente entre 1989 e 1992, mas essas flutuações tendem a ocorrer em torno de um valor médio aparentemente estável (Figura 4). Também nesse mercado, os indícios não apontam para mudanças estruturais. Os preços ao varejo e ao produtor flutuam em torno de uma tendência visivelmente decrescente, enquanto o risco de 4 meses mostra-se mais estável do que no mercado de arroz, com picos mais significativos apenas em 1984 e 1989 (Figura 5).

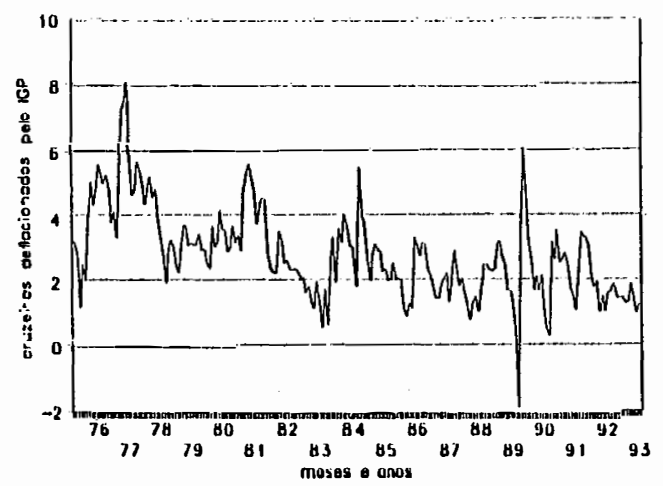

Figura 4 - Margem absoluta de comercialização de feijão em São Paulo, 1975-93 Fonte: vide capítulo 5. 


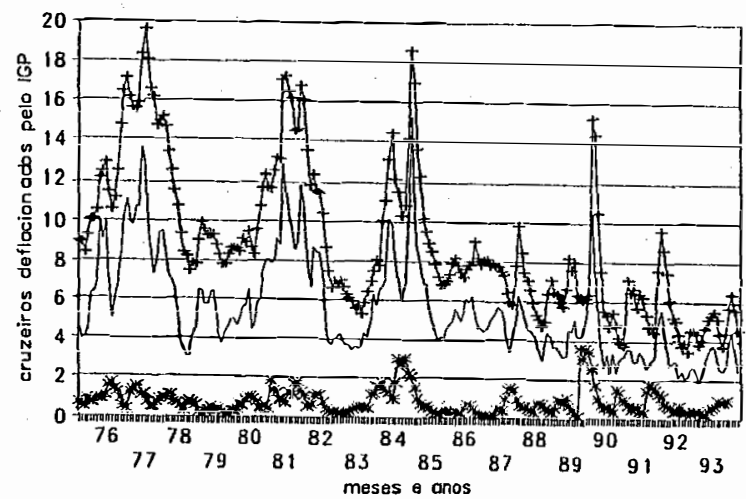

preco produtor $\rightarrow$ preco varejo $\rightarrow-$ risco

Figura 5 - Evolução dos preços ao produtor e varejo e do risco de preço de feijão em São Paulo, 1975-93

Fonte: vide capítulo 5.

A análise da margem relativa dos dois produtos mostra que os intermediários de arroz ficaram com maior parcela do preço do varejo ao longo de quase todo o período, em comparação com os intermediários do mercado de feijão (Figura 6). Verifica-se, também, certo incremento da margem relativa de arroz, principalmente após o ano de 1980, e provável ausência de tendência da margem relativạ de feijão. 


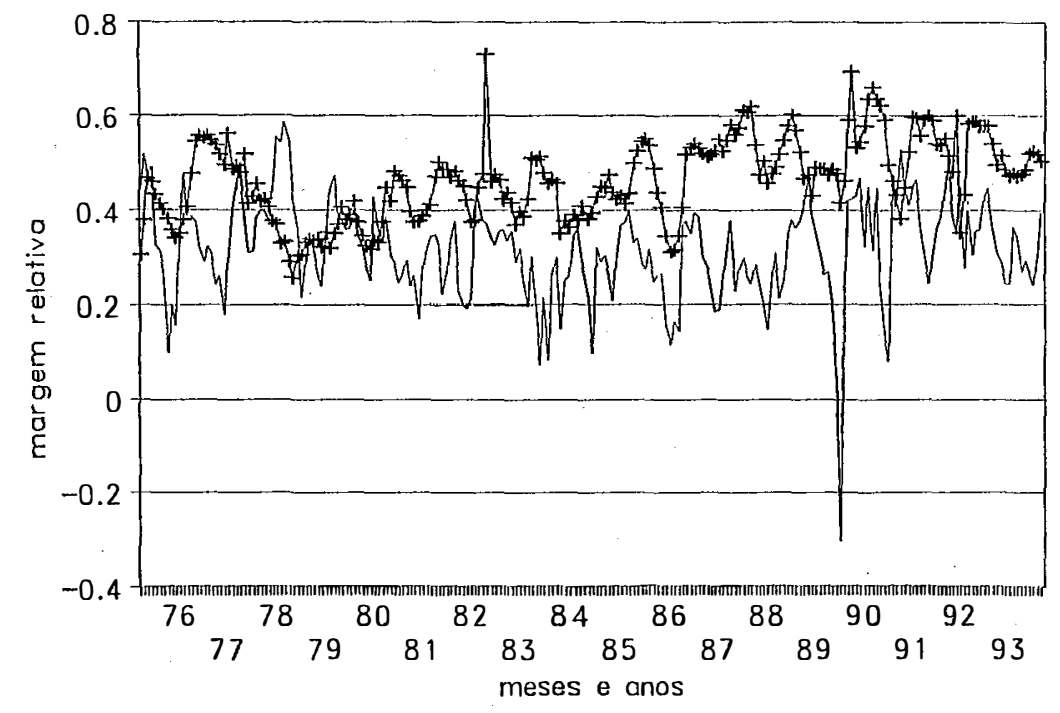

$$
\text { feijoo } \rightarrow \text { arroz }
$$

Figura 6 - Margens relativas de comercialização de arroz e de feijão em São Paulo, 19751993

Fonte: vide capítulo 5.

O comportamento dos preços dos insumos mostra também movimento de decréscimo e/ou estabilização (Figura 7). O preço real do óleo diesel aumenta até 1986, reduz-se, acentuadamente, entre 1986 e 1990 e apresenta leve movimento de acréscimo no início da década de 1990 . Os preços reais dos fertilizantes e o salário-mínimo mostram quedas mais moderadas e persistentes. 


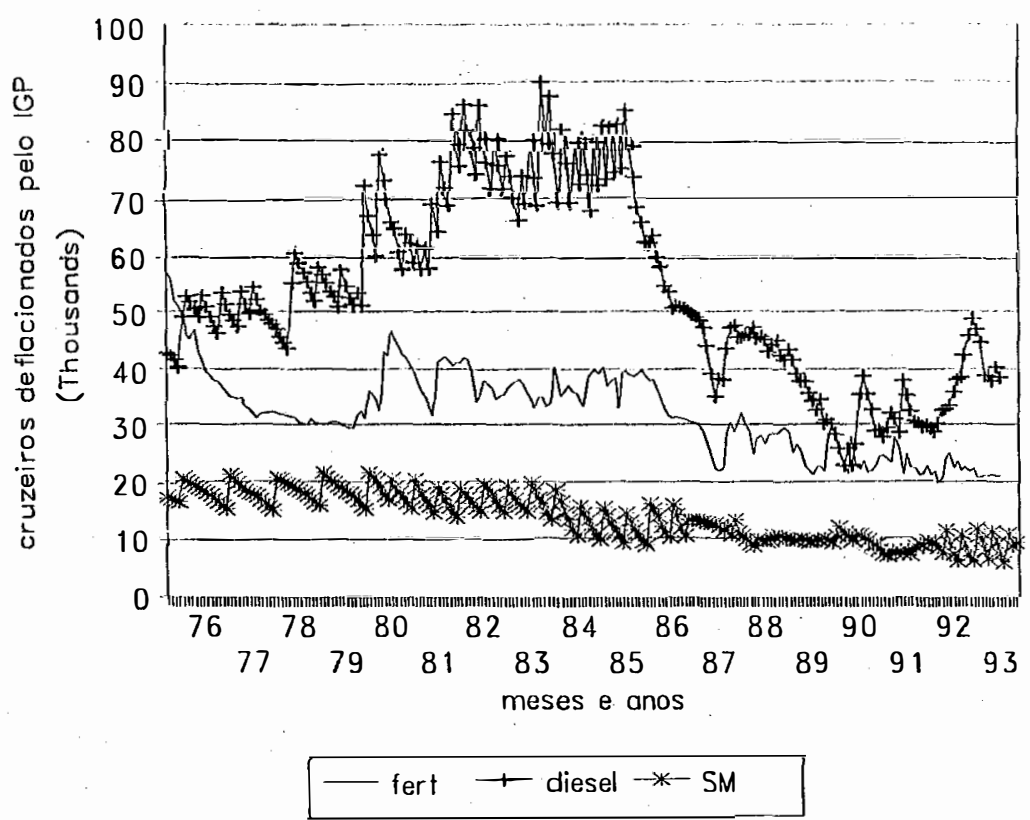

Figura 7 - Evolução dos preços dos fertilizantes (Fert), óleo diesel e salário-mínimo (SM), 1975-1993

Fonte: vide capítulo 5.

A evolução do risco de preço dos dois produtos já foi apresentada nas Figuras 3 e 5. Como os gráficos apresentados envolviam apenas as variáveis de risco formadas a partir de médias-móveis quadrimestrais, torna-se interessante comparar as duas formas como o risco é calculado. A Figura 8 mostra o risco apenas para o mercado de feijão. Verifica-se que a variável formada com 12 dados apresenta evolução mais suave do que a variável construída quadrimestralmente. A significância de cada uma dessas formas de risco será testada na análise empírica. 


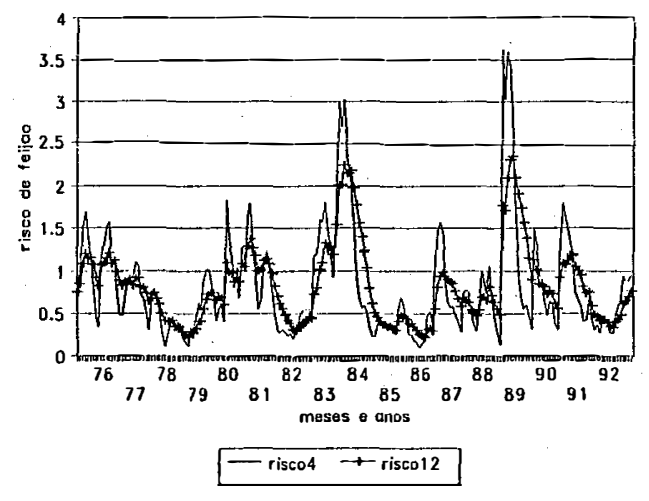

Figura 8 - Evolução do risco de 4 meses (risco4) e de 12 meses (risco12) de feijão no Estado de São Paulo, 1975-1993

Fonte: vide capítulo 5 .

A última das variáveis de custo utilizadas é o juro. A taxa de juros cobrada pela captação de capital de giro, na Figura 9, mostra enorme instabilidade a partir de 1989, depois de um período relativamente estável entre 1975 e 1987. Também os valores médios parecem ser maiores no final do período analisado.

Uma primeira comparação entre as variáveis analisadas mostra que a maioria delas segue um sentido decrescente desde o início da década de 1980. Particularmente no caso das margens absolutas de comercialização, isso sugere que os consumidores não estariam sendo crescentemente explorados pelos intermediários, como muitas vezes informações divulgadas pelos meios de comunicação fazem pensar. A redução dos preços da maioria dos insumos sugere que pressões de custo não têm surgido sobre a margem. Exceção a essa regra é a taxa de juros que, visivelmente, cresceu e aumentou sua instabilidade no final do período. O preço do óleo diesel, que seguiu movimentos distintos em diferentes períodos, tem um impacto sobre a margem 
dificil de ser antecipado. Também o risco não pode ter seu impacto sobre a margem antecipado apenas com base na análise das Figuras.

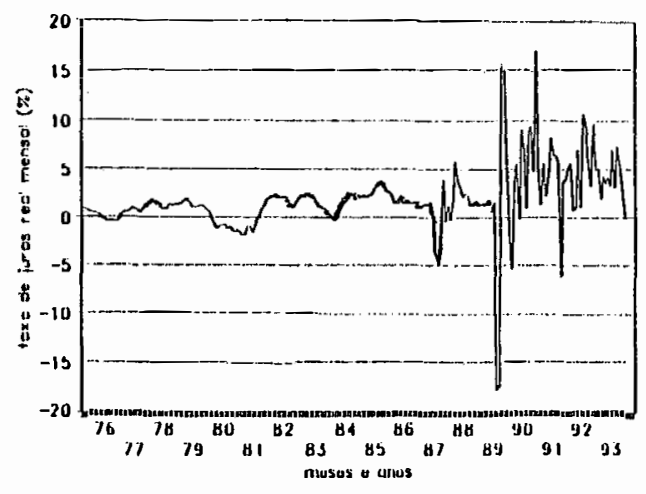

Figura 9 - Evolução do custo efetivo real mensal do financiamento do capital de giro, 1975-1993

Fonte: vide capítulo 5.

\subsection{Delineamento do trabalho}

A revisão da literatura relevante sobre as questões teóricas e empíricas de margens de comercialização prossegue nos próximos capítulos.

As questões a respeito das margens de comercialização serão apresentadas nos capítulos 2 a 4 . 0 capítulo 2 tratará dos modelos e conceitos teóricos relevantes para a análise das margens de comercialização e o capítulo 3 apresentará os modelos empíricos que vêm sendo estimados e testados nos estudos econométricos das margens. $\mathrm{O}$ capítulo 4 apresentará um modelo teórico aplicável para situações dinâmicas. 
A descrição dos métodos e dos dados empregados nessa pesquisa será feita no capítulo 5. Alguns aspectos dos métodos estatísticos utilizados na pesquisa também serão apresentados neste capítulo. A análise dos resultados encontrados será apresentada no capítulo 6 e as conclusões e implicações da pesquisa serão apresentadas no capítulo 7. 


\section{MODELOS TEÓRICOS}

Os modelos teóricos de margens de comercialização procuram explicar a formação dos preços em diferentes níveis de mercado. $O$ principal desses modelos é o desenvolvido por GARDNER (1975). A importância deste modelo pode ser dimensionada ao observar que a maioria dos modelos de margens e formação de preços desenvolvidos desde 1975 parte da estrutura montada por GARDNER e a ela acrescenta algumas particularidades ou exclui alguns pressupostos. Um dos principais modelos desenvolvidos nessa linha é o modelo de HEIEN (1980), que, partindo do modelo de GARDNER, admite a ocorrência de desequilibrio nos mercados no curto prazo.

Esses dois principais modelos serão expostos neste capitulo, sendo extraídas suas principais implicações no que diz respeito ao comportamento das margens de comercialização. Adicionalmente, apresentar-se-á o modelo de BARROS (1990), que fundamenta o modelo dinâmico a ser desenvolvido no capítulo 4 . Como o risco de variação de preços é uma das variáveis explicativas dos modelos a serem testados, apresentar-se-á também neste capítulo o modelo de margem de comercialização com incerteza de preços desenvolvido por BRORSEN et al. (1985).

\subsection{Modelo Competitivo de GARDNER (1975)}

GARDNER apresenta um modelo estático-comparativo, com um produto e dois insumos, e examina as conseqüências do equilíbrio competitivo nos mercados de insumos e produto sobre a relação entre o preço recebido pelo produtor agrícola e o preço do produto final ao varejo. $\mathrm{O}$ modelo pressupõe equilíbrio instantâneo nos mercados de insumos e de produto. 
O modelo básico envolve 6 equações e 6 variáveis endógenas. Sendo $\boldsymbol{x}$ a quantidade do produto vendido ao varejo, obtida pela combinação da matéria-prima agrícola $(a)$ e de um agregado de insumos de comercialização $(b)$, a função de produção da indústria de comercialização, com retorno constante à escala, é:

$$
x=f(a, b) .
$$

A demanda primária (ao varejo) é:

$$
x=D(P x, N)
$$

em que $P x$ é o preço ao varejo e $N$ é uma variável exógena deslocadora da demanda primária (tal como população).

O modelo completa-se com as equações dos mercados de $a$ e $b$. As demandas por insumos são dadas pela igualdade entre seus preços e os valores dos seus produtos fisicos marginais:

$$
P b=P x f_{b}
$$

e

$$
P a=P x f_{a},
$$

em que $f_{a}$ e $f_{b}$ são produtos físicos marginais (derivadas parciais de $\boldsymbol{x}$ em relação aos insumos $\boldsymbol{a}$ e $\boldsymbol{b}$ ) e $\boldsymbol{P} \boldsymbol{a}$ e $\boldsymbol{P b}$ são, respectivamente, os preços de $\boldsymbol{a}$ e $\boldsymbol{b}$.

As ofertas dos insumos são:

$$
P b=g(b, T)
$$

e

$$
P a=h(a, W),
$$

em que $\boldsymbol{T}$ e $\boldsymbol{W}$ são variáveis deslocadoras das ofertas de $\boldsymbol{b}$ e $\boldsymbol{a}$, respectivamente (por exemplo, tributos e clima). 
Em condições normais (demanda decrescente e ofertas não decrescentes), existe um ponto de equilibrio único para cada conjunto de variáveis exógenas.

O sistema de 6 equações e 6 incógnitas pode ser reduzido para 3 equações e 3 incógnitas. Igualando-se as equações (1) com (2), (3) com (5), e (4) com (6), eliminam-se, respectivamente, $\boldsymbol{x}, \boldsymbol{P} \boldsymbol{b}$ e $\boldsymbol{P a}$. $\mathrm{O}$ sistema que envolve $\boldsymbol{a}, \boldsymbol{b}$ e $\boldsymbol{P} \boldsymbol{x}$ fica:

$$
\begin{aligned}
& D(P x, N)=f(a, b) \\
& g(b, T)=P x f_{b} \\
& h(a, W)=P x f_{a}
\end{aligned}
$$

A partir das equações básicas, a análise é conduzida por meio da relação de preços $P \boldsymbol{x} / \boldsymbol{P a}$. Note-se que a margem relativa de comercialização, $(\boldsymbol{P x}-\boldsymbol{P a}) / \boldsymbol{P x}$, é igual a 1-(Pa/Px), de forma que, quanto maior for a relação de preços $P x / P a$, maior será a margem relativa. A seguir, analisam-se os efeitos de variações na demanda primária, na oferta agrícola e na oferta de insumos de comercialização sobre a relação de preços e sobre a margem relativa de comercialização.

\subsubsection{Efeito de uma variação na demanda primária}

A variação da demanda decorre de uma mudança em $N$. Seu efeito sobre os três mercados é obtido pela diferenciação das equações (7) a (9) com relação a $N$, enquanto $W$ e $T$ são mantidos constantes.

O efeito sobre o mercado de a é obtido pela diferenciação da equação (9):

$$
h_{a} \frac{d a}{d N}=P x \frac{d f_{a}}{d N}+f_{a} \frac{d P x}{d N}
$$

Desenvolvendo $\left(d f_{a}\right) /(d N)$ e substituindo em (10), chega-se a:

$$
h_{a} \frac{d a}{d N}=P x f_{a a} \frac{d a}{d N}+P x f_{a b} \frac{d b}{d N}+f_{a} \frac{d P x}{d N},
$$


em que $f_{a a}$ é a derivada parcial de $f_{a}$ em relação a $a$ (derivada segunda de $\boldsymbol{x}$ em relação à matéria-prima $a)$ e $f_{a b}$ é a derivada parcial de $f_{a}$ em relação a $b$.

O efeito da variação de $N$ sobre o mercado de $b$ é obtido por meio da diferenciação da equação (8):

$$
g_{b} \frac{d b}{d N}=P x f_{b b} \frac{d b}{d N}+P x f_{b a} \frac{d a}{d N}+f_{b} \frac{d P x}{d N}
$$

em que $f_{b b}$ é a derivada parcial de $f_{b}$ em relação a $b$ e $f_{b a}$ é a derivada parcial de $f_{b}$ em relação à matéria-prima agrícola $\boldsymbol{a}$.

A equação (12) mostra a relação entre $\boldsymbol{d P x}$ e $\boldsymbol{d P a}$, enquanto o mercado de $\boldsymbol{b}$ permanece em equilíbrio [note-se que (12) é a derivada do equilíbrio no mercado de $\boldsymbol{b}$ representado pela expressão (8)]. $O$ equilíbrio no mercado de $\boldsymbol{x}$ é obtido, similarmente, pela diferenciação da equação (7):

$$
f_{a} \frac{d a}{d N}+f_{b} \frac{d b}{d N}=D_{P x} \frac{d P x}{d N}+D_{N}
$$

em que $D_{N}$ é a derivada parcial de $D$ em relação a $N$ e $D_{P_{x}}$ é a derivada parcial de $D$ em relação a $P \boldsymbol{x}$.

GARDNER transforma as equações (11)-(13) em elasticidades, de maneira a tornar os resultados mais inteligíveis. As equações para os mercados de $\boldsymbol{a}, \boldsymbol{b} \mathrm{e}$ $\boldsymbol{x}$, ficam, respectivamente:

$$
\begin{aligned}
& 0=-\left(\frac{S_{b}}{\sigma}+\frac{1}{e_{a}}\right) E_{a N}+\frac{S_{b}}{\sigma} E_{b N}+E_{P x N}, \\
& 0=\frac{S_{a}}{\sigma} E_{a N}-\left(\frac{S_{a}}{\sigma}+\frac{1}{e_{b}}\right) E_{b N}+E_{P x N} \\
& \eta_{N}=S_{a} E_{a N}+S_{b} E_{b N}-\eta E_{P x N},
\end{aligned}
$$

em que $S_{a}$ e $S_{b}$ são as parcelas dos insumos na despesa do consumidor com o produto $\mathbf{x}$ (por exemplo, $S_{a}=a P(\boldsymbol{x} P x$ ); $\sigma$ é a elasticidade de substituição entre os insumos; $\boldsymbol{\eta}$ é a 
elasticidade-preço da demanda primária; $\boldsymbol{e}_{a}$ e $\boldsymbol{e}_{b}$ são as elasticidades-preço da oferta dos insumos; $\eta_{N}$ é a elasticidade da demanda primária com respeito a $N$; e $E_{a N}, E_{b N}$ e $E_{P x N}$ são derivadas do primeiro subscrito em relação a $N$.

Para se saber o efeito de $\boldsymbol{N}$ sobre a margem relativa, precisa-se ainda derivar a elasticidade de $\boldsymbol{P x} \boldsymbol{X P a}$ com respeito a $\boldsymbol{N}$. O resultado apresentado por GARDNER ${ }^{11}$ é:

$$
E_{\frac{P x}{P a}, N}=\frac{\eta_{N} S_{b}\left(e_{a}-e_{b}\right)}{D}
$$

em que $D=-\eta\left(S_{b} e_{a}+S_{a} e_{b}+\sigma\right)+e_{a} e_{b}+\sigma\left(S_{a} e_{a}+S_{b} e_{b}\right)$

A equação (17) pode também ser aplicada a um agregado de alimentos ao varejo, desde que se pressuponha que os preços relativos de seus itens não se alterem. Da mesma forma, o agregado de insumos de comercialização é suposto com preços relativos constantes. Num caso mais restrito, com, por exemplo, um só produto, o problema da agregação torna-se menos sério (GARDNER exemplifica essa situação com a relação trigo-pão).

Quanto ao sinal da expressão, o denominador, $D$, é positivo para situações normais, ou seja, para $\boldsymbol{\eta}<0$ e $\boldsymbol{e}_{\boldsymbol{a}}$ e $\boldsymbol{e}_{\boldsymbol{b}} \geq \mathbf{0}$. Assim, o sinal do impacto de $\boldsymbol{N}$ sobre $\boldsymbol{P x} / \boldsymbol{P a}$ é dado pelo numerador da equação (17). Como $S_{b}$ e $\eta_{N}$ são positivos $\left(\eta_{N}\right.$ mostra que um aumento da população incrementa a demanda), o sinal da equação (17) depende apenas da relação entre $\boldsymbol{e}_{\boldsymbol{a}}$ e $\boldsymbol{e}_{\boldsymbol{b}}$. Para casos normais, em que a matéria-prima agrícola é mais específica para a produção de $\boldsymbol{x}$, enquanto $\boldsymbol{b}$ (trabalho, transporte, embalagem etc.) possui muitos usos alternativos (havendo uma oferta potencial de $b$ que facilmente pode ser deslocada para a produção de $x$ ), $e_{a}<e_{b}$, do que resulta que $\boldsymbol{P x} / \boldsymbol{P a}$ tende a se reduzir (e a margem também) em decorrência de um aumento de demanda. GARDNER aborda ainda a possibilidade (improvável, segundo o autor) de $e_{a}=e_{b}$; neste caso, a margem ficaria constante diante de variações da demanda, havendo compatibilidade entre a regra de markup percentual fixo e o equilibrio competitivo.

11 Ver o apêndice apresentado por GARDNER (p. 408-409), para os desenvolvimentos aqui omitidos. 
Lembrando que $D$ inclui a elasticidade de substituição entre insumos $(\sigma)$, pode-se examinar o efeito dessa variável sobre a margem. Como em condições normais o aumento da demanda primária aumenta $\mathbf{P a} / \mathbf{P b}$, pois a oferta de $\boldsymbol{a}$ é menos elástica, há tendência de se substituir $a$ por $\boldsymbol{b}$ na produção de $\boldsymbol{x}$. Quanto maior for $\sigma$, maior a possibilidade de substituição, o que eleva a demanda derivada por $b$ e reduz a demanda derivada por $\boldsymbol{a}$. O resultado dessa substituição é uma amenização do crescimento de $\boldsymbol{P a}$, de maneira que a margem de comercialização não diminui tanto diante de um aumento de demanda primária. Numa situação extrema, com $\sigma \rightarrow \infty$, a margem não se alteraria. Porém, o caso mais realista é quando $\boldsymbol{\sigma} \rightarrow \mathbf{0}$, sendo bastante dificil a substituição entre os insumos 12 .

A variação na participação do produtor na despesa do consumidor, decorrente de um choque de demanda, é dada por:

$$
E_{S_{a}, N}=\frac{\eta_{N} S_{b}\left(e_{a}-e_{b}\right)(\sigma-1)}{D}
$$

O sentido da variação da parcela do produtor depende do sinal do numerador, já que o denominador é positivo: se $e_{b}=e_{\mathrm{a}}$ ou $\sigma=1$, a parcela do produtor não se altera diante de choques de demanda; se $e_{b}>e_{a}$ e $\sigma<1$, ou $e_{b}<e_{a}$ e $\sigma>1$, a parcela do produtor aumenta com um aumento da demanda primária; e se $\boldsymbol{e}_{b}>\boldsymbol{e}_{a}$. e $\sigma>1$, ou $\boldsymbol{e}_{b}<\boldsymbol{e}_{a} \mathrm{e}$ $\sigma<1$, um aumento na demanda primária irá reduzir a parcela do produtor. $\mathrm{O}$ caso mais comum, pela argumentação de GARDNER, é $\boldsymbol{e}_{b}>\boldsymbol{e}_{a}$ e $\sigma<1$, resultando num aumento da parcela dos produtores diante de um aumento na demanda primária.

É possível também relacionar a parcela do produtor com a margem de comercialização. Inicialmente, pode-se notar que a diferença entre as equações (17) e (18) é a presença de $\sigma$-1 multiplicando esta última equação. Foi visto também que, para casos normais, a equação (17) é negativa, o que mostra que um aumento na demanda reduz a margem. Sendo assim, se $\sigma>1$, a equação (18) também será negativa, de maneira que uma redução (aumento) na margem se faz acompanhar por uma redução (aumento) na parcela do produtor na despesa do consumidor. No caso mais comum, com $\sigma<1$, a equação (18) será positiva [sinal inverso ao da equação (17)], de forma que um aumento da margem diminuirá a parcela do produtor e vice-versa.

12 Para o caso de $\sigma=0$, BARROS (1987) apresenta um tratamento gráfico do modelo de GARDNER. 


\subsubsection{Efeito de uma mudança na oferta agrícola}

Trata-se de analisar o efeito de $W$ sobre a margem. $O$ procedimento é o mesmo: diferenciam-se as equações com respeito a $W$, mantendo $N$ e $\boldsymbol{T}$ invariáveis, e convertem-se os resultados das derivações em elasticidades, de maneira semelhante às equações (14)-(16). $O$ impacto de $W$ sobre $P x / P \imath$ é dado por:

$$
E_{\frac{P x}{P a}, W}=\frac{e_{W} S_{b} e_{a}\left(\eta-e_{b}\right)}{D},
$$

em que $\boldsymbol{e}_{W}$ é a elasticidade de $\boldsymbol{P a}$ com respeito a $W^{13}$.

Supondo uma redução na oferta agrícola (por exemplo, em razão de uma seca), o efeito esperado (nas condições normais apresentadas no item anterior) seria uma redução em $\boldsymbol{P x} / \boldsymbol{P a}$, ou seja, uma redução na margem de comercialização (sendo oposto o efeito de um aumento da oferta agrícola). Esse efeito pode ser analisado da seguinte forma: dada uma redução na oferta agrícola, $\boldsymbol{P a}$ aumenta, mas $\boldsymbol{P b}$ cai (pois a menor oferta de $\boldsymbol{x}$ reduzirá a demanda derivada por $\boldsymbol{b}$ ), de maneira que $\boldsymbol{P a}$ aumenta mais que $\boldsymbol{P x}$ (que se compõe por $\boldsymbol{P a}$ e $\boldsymbol{P b}$ ). $\mathrm{O}$ efeito de $\boldsymbol{\sigma}$ é novamente de amenização da variação da margem.

Outras hipóteses quanto ao valor de $\boldsymbol{e}_{\boldsymbol{b}}$ levariam a efeitos distintos sobre a margem de comercialização. Sendo $e_{b}$ não-negativo, quanto menor ele for (curto prazo), maior tenderá a ser a variação da margem em virtude da mudança na oferta agrícola, pois maior será a variação em $\boldsymbol{P b}$. Outra situação seria o caso extremo de economia externa de escala na atividade de comercialização, no qual $e_{b}<\boldsymbol{\eta}<0$; assim, um incremento na oferta agrícola reduziria a margem de comercialização (e vice-versa).

O efeito de um choque de oferta agrícola sobre a participação do produtor no valor final do bem pode ser analisado por meio da seguinte fórmula:

$$
E_{S_{a}, W}=\frac{e_{W} S_{b} e_{a}\left(\eta-e_{b}\right)(\sigma-1)}{D}
$$

$13 W$ é visto como uma variável que reduz a oferta agrícola (por exemplo, seca). Logo, $e_{W}$ é sempre positiva e a equação (19) é negativa em condições normais. 
Novamente, a diferença entre a fórmula da parcela do produtor [equação (20)] e a da elasticidade da margem [equação (19)] é a multiplicação pelo fator $\sigma-1$. Em condições normais, a equação (19) será negativa. Sendo assim, caso $\sigma>1$, aumento da oferta agrícola eleva a margem e a parcela do produtor; e caso $\sigma<1$, aumento da oferta agrícola aumenta a margem, mas a parcela do produtor na despesa do consumidor diminui.

\subsubsection{Efeito da mudança na oferta de insumos de comercialização}

O procedimento é similar ao dos dois itens anteriores: diferenciam-se as equações com respeito a $T$, mantendo $N$ e $W$ constantes, e transformam-se as novas equações em elasticidades. $\mathrm{O}$ efeito de $\boldsymbol{T}$ sobre $\boldsymbol{P x} / \boldsymbol{P a}$ é apresentado por GARDNER como sendo:

$$
E_{\frac{P x}{P a} T}=\frac{e_{T} S_{b} e_{b}\left(e_{a}-\eta\right)}{D},
$$

em que $\boldsymbol{e}_{T}$ é a elasticidade de $\boldsymbol{P b}$ com respeito a $T^{14}$.

A equação (21) é positiva nos casos normais; redução na oferta dos insumos de comercialização (por exemplo, devido a um aumento de impostos) eleva a margem de comercialização. A lógica é análoga à do caso anterior: uma redução na oferta de $\boldsymbol{b}$ tende a elevar $\boldsymbol{P b}$ e a reduzir $\boldsymbol{P a}$, já que diminui a demanda derivada por $\boldsymbol{a}$, fazendo com que $\boldsymbol{P} \boldsymbol{x} / \boldsymbol{P} \boldsymbol{a}$ aumente.

GARDNER chama atenção para a maior restrição na aplicação da equação (21) em relação às equações (19) e (17). Argumenta que é dificil imaginar mudanças exógenas na oferta dos insumos de comercialização que afetem todos os preços dos componentes de $\boldsymbol{b}$, proporcionalmente.

14 A variável $T$ é vista como redutora da oferta de $b$ (um tributo, por exemplo), de maneira que $e_{T}$ deve ser positiva. 


\subsubsection{Elasticidade de transmissão de preços e elasticidade-preço da demanda derivada}

GARDNER mostra que a elasticidade de transmissão de preços entre o produtor agrícola e o varejo depende da origem da variação.

Para choques de demanda (variação originada na demanda por $\boldsymbol{x}$ ), a elasticidade de transmissão é dada por:

$$
E_{P x, P a}=\frac{\sigma+S_{a} e_{b}+S_{b} e_{a}}{\sigma+e_{b}}
$$

A equação (22) mostra que, para variações originadas na demanda, a elasticidade de transmissão de preços deve ser menor ou igual à unidadel5; podendo assumir valor maior que 1 apenas se $\boldsymbol{e}_{a}>\boldsymbol{e}_{b}$ (hipótese pouco provável, como já se argumentou, pela maior especificidade da matéria-prima agrícola).

Para variação iniciada na oferta agrícola, a fórmula derivada por GARDNER é:

$$
E_{P x, P a}=\frac{S_{a}\left(e_{b}+\sigma\right)}{e_{b}+S_{a} \sigma-S_{b} \eta}
$$

A ordem de grandeza da elasticidade dada pela equação (23) depende dos valores de $\boldsymbol{e}_{\boldsymbol{b}}$ e $\boldsymbol{\eta}$. Se $\boldsymbol{e}_{\boldsymbol{b}}>\boldsymbol{\eta}$ (o que se espera, pois $\boldsymbol{\eta}$ deve ser negativa), $\boldsymbol{E}_{\boldsymbol{P} \boldsymbol{x}, \boldsymbol{P a}}<\mathbf{1}^{16}$.

Existe ainda a possibilidade de a variação em $\boldsymbol{P x}$ e $\boldsymbol{P a}$ originar-se de uma mudança na oferta dos insumos de comercialização (mudança em $T$ ). Nesse caso, a elasticidade de transmissão de preços é dada por:

15 Como $S_{a}+S_{b}=1$, se $e_{a}=e_{b}$ a elasticidade será exatamente igual a um. Se $e_{a}<e_{b}$, como se espera, a elasticidade de transmissão de preços será menor que um.

16 Elasticidade de transmissão de preços menor que um equivale a:

$$
\begin{aligned}
& S_{a}\left(e_{b}+\sigma\right)<e_{b}+S_{a} \sigma-S_{b} \eta \Rightarrow e_{b}\left(1-S_{a}\right)>S_{b} \eta \\
& \Rightarrow e_{b}>\eta .
\end{aligned}
$$




$$
E_{P x, P a}=\frac{e_{a}+\sigma}{\sigma+\eta}
$$

Enquanto nos dois primeiros casos [equações (22) e (23)] a elasticidade de transmissão de preços mostrou-se, em condições normais, positiva, no caso representado pela equação (24) a elasticidade pode assumir valores tanto positivos quanto negativos. Como o numerador da fração é positivo, se $\boldsymbol{\sigma}>|\boldsymbol{\eta}|, \boldsymbol{P x}$ e $\boldsymbol{P a}$ mover-se-ão no mesmo sentido (denominador positivo) e a elasticidade de transmissão de preços será positiva; se $\sigma<|\eta|$, o denominador será negativo, $\boldsymbol{P x}$ e $\boldsymbol{P a}$ variarão em sentidos opostos e a elasticidade ${ }^{-}$de transmissão de preços será negativa ${ }^{17}$.

GARDNER deriva também a elasticidade-preço da demanda derivada pelo produto agrícola, que é dada por:

$$
E_{a, P a}=\frac{\eta \sigma+e_{b}\left(S_{a} \eta-S_{b} \sigma\right)}{e_{b}+S_{a} \sigma-S_{b} \eta}
$$

A demanda derivada será menos elástica que a demanda primária, se e somente se $\sigma<|\eta|$. Se $\sigma=|\eta|$, a equação (25) resulta em $\boldsymbol{E}_{\boldsymbol{a}, \boldsymbol{P} \boldsymbol{a}}=\boldsymbol{\eta}$, ou seja, as elasticidades das demandas primária e derivada são iguais. Se $\sigma>|\eta|$, a demanda derivada será mais elástica que a primária ${ }^{18}$.

Em resumo, o modelo de GARDNER permite, principalmente, as seguintes generalizações: (1) eventos que aumentam a demanda ao varejo reduzirão a margem relativa de comercialização, se a oferta dos insumos de comercialização for mais elástica que a da matéria-prima agrícola (situação mais provável), mas aumentarão a margem se a oferta agrícola for mais elástica; (2) eventos que aumentam (diminuem) a oferta da matéria-prima agrícola aumentam (diminuem) a margem de comercialização; (3) eventos que aumentam (diminuem) a oferta dos insumos de comercialização diminuem (aumentam) a margem de comercialização; (4) aumento da margem equivale à redução da parcela dos agricultores na despesa do consumidor, se $\sigma<1$, e ao aumento dessa parcela,

17 BRONFENBRENNER, citado por BARROS (1987, p. 79), mostra que, numa situação competitiva, espera-se que $\sigma|\eta|$, de onde se deduz que choques na oferta de insumos de comercialização originam elasticidades de transmissão de preços negativas.

18 A afirmação de BRONFENBRENNER (nota anterior) mostra que o primeiro caso deve prevalecer (demanda derivada mais inelástica). 
se $\sigma>1$; (5) a demanda derivada ao produtor agrícola será menos elástica que a demanda primária, se $\sigma|\dot{\eta}|$ (situação mais provável, pois normalmente é mais fácil haver substituição no consumo do que na produção), e mais elástica se $\sigma>|\eta|$; e (6) a elasticidade de transmissão de preços entre produtor e varejo depende da origem da variação, podendo ser negativa para choques oriundos da oferta de insumos de comercialização (caso $\sigma<|\eta|$ ), e devendo ser positiva e menor ou igual à unidade para variações originadas na oferta agrícola ou na demanda primária.

\subsection{Modelo de Markup de HEIEN (1980)}

A principal diferença entre os modelos de HEIEN (ou de markup) e de GARDNER é, conforme afirmou-se, a suposição feita por HEIEN de desequilíbrio de curto prazo no mercado varejista ${ }^{19}$. HEIEN argumenta que a pressuposição de GARDNER quanto à igualdade entre oferta e demanda em todos os mercados é realista apenas para cenários que envolvem períodos de tempo em que a variação no estoque é pequena em relação à demanda total. Quando o período em consideração é encurtado, o desequilíbrio passa a ser a norma. Assim, o modelo de GARDNER, embora útil para analisar os determinantes dos valores de equilíbrio das variáveis endógenas, tem pouco a dizer a respeito da conduta temporal entre duas situações de equilíbrio.

O modelo apresentado por HEIEN é consistente com o modelo estático de GARDNER, mas vai adiante ao descrever a dinâmica de ajustamento do mercado. Além disso, envolve os níveis de produtor, atacado e varejo 20 .

Considere-se que as letras maiúsculas são quantidades, as minúsculas são preços e os sobrescritos $\boldsymbol{d}$ e $\boldsymbol{s}$ representam, respectivamente, demanda e oferta. As funções de oferta e demanda nos três níveis de mercado são:

19 Ver TEIXEIRA (1982) para uma aplicação do modelo de HEIEN aos preços de feijão, arroz e farinha de mandioca, nos niveis de atacado e varejo.

$20 \mathrm{Na}$ verdade, o modelo de HEIEN considera, inicialmente, os três niveis de mercado, mas acaba expondo o processo dinâmico apenas para os níveis de produtor e varejo (por simplificação, como argumenta 0 autor). 


\section{Varejo:}

$R^{d}=h_{1}(r, y)$, em que $R$ é a quantidade ao varejo, $\boldsymbol{r}$ é o preço ao varejo e $\boldsymbol{y}$ representa fatores exógenos (tal como renda);

$R^{s}=h_{2}(r, w, z)$, em que $z$ representa preços de fatores exógenos, tais como serviços de comercialização e $w$ é o preço ao atacado.

\section{Atacado:}

$W^{d}=h_{3}(r, w, z)$, em que $W$ é a quantidade ao atacado;

$W^{s}=h_{4}(w, f, x)$, em que $f$ é o preço ao produtor rural e $\boldsymbol{x}$ representa os preços de outros itens de custo dos atacadistas.

\section{Produtor:}

$$
\begin{aligned}
& F d=h_{5}(w, f, x) \text {, em que } F \text { é a quantidade ao nível de produtor; } \\
& F^{s}=h_{6}(f) .
\end{aligned}
$$

Em contraste com o modelo de GARDNER, o de HEIEN, além de apresentar as funções de oferta e demanda para os três níveis de mercado, exclui as relações de oferta e demanda dos insumos de comercialização. Adicionalmente, não assume a igualdade entre oferta e demanda nos mercados $\left(R^{d} \neq R^{s}, W^{d} \neq W^{s}\right.$ e $\left.F^{d} \neq F^{s}\right)$. Para igualar o sistema em termos de equações e incógnitas e para determinar a forma de ajustamento dos preços, HEIEN propõe, inicialmente, três equações de excesso de demanda:

$$
\begin{aligned}
& r=h_{7}\left(R^{d}-R^{s}\right) \\
& w=h_{8}\left(W^{d}-W^{s}\right) \\
& f=h_{9}\left(F^{d_{-}} F^{s}\right)
\end{aligned}
$$

Nesse ponto, reconhecendo que o ajustamento por excesso de demanda é improvável no mercado varejista, dada a gama de produtos comercializados nesse nível, o 
que torna inviável aos agentes de comercialização o acompanhamento de todos os mercados, o autor sugere um mecanismo de markup para a determinação do preço ao varejo. Como todos os agentes receberiam os mesmos "sinais", dados pelo preço pago pelos insumos, tenderia a haver resposta similar em todo o mercado.

O comportamento do varejo pode ser explicitado pelas equações que se seguem. Considere-se que, com a pressuposição de retornos constantes à escala, a função de custo das firmas varejistas seja:

$$
\begin{gathered}
C=h_{10}\left(R^{s}, w, z\right)=h_{10}(w, z) R^{s} . \\
\text { O custo marginal é: } \\
\frac{\partial C}{\partial R}=h_{10}(w, z) .
\end{gathered}
$$

Em condições competitivas, esse custo marginal iguala-se ao preço:

$$
r=h_{10}(w, z)
$$

Admitindo-se que a função de produção dos varejistas é do tipo de Leontief (proporções fixas), hipótese bastante plausível no curto prazo $^{21}$, tem-se:

$$
R=\min \left(\frac{W}{a_{1}}, \frac{Z}{a_{2}}\right)
$$

Essa função de produção conduz às demandas por insumos: $W=a_{1} R$ e $Z$ $=a_{2} R ;$ para retornos constantes à escala, a função de custo é:

$$
C=\left(a_{1} w+a_{2} z\right) R
$$

Da equação (26):

$$
r=a_{1} w+a_{2} z
$$

21 Naturalmente, no longo prazo essa pressuposição não se manteria. $\mathrm{O}$ autor sugere, como alternativa, a pressuposição de elasticidade de substituição não nula, mas constante, através da inclusão de uma função CES (constant elasticity of substitution). 
HEIEN mostra, então, que a equação (28) consiste na função de oferta com retornos constantes à escala e proporções fixas, sendo também a política de preços ótima para as firmas, pois relaciona o preço do produto com os preços dos insumos. A introdução da hipótese de desequilíbrio é feita por meio da política de estoques e levando em consideração, para fins de simplificação, apenas os níveis de produtor e varejo.

Com os dois níveis, a equação (27) é transformada em:

$$
R=\min \left(\frac{F}{a_{1}}, \frac{Z}{a_{2}}\right) .
$$

A equação (28) é convertida em:

$$
r_{t}=a_{1} f_{t}+a_{2} z_{t}
$$

A demanda de matéria-prima agrícola fica:

$$
F^{d}=a_{1} R^{s} \quad a_{1}>0
$$

A demanda ao varejo é suposta uma relação linear do preço:

$$
R_{t}^{d}=\alpha_{0}+\alpha_{1} r_{t} \quad \alpha_{1}<0
$$

A oferta do produtor também é uma relação linear do preço corrente:

$$
F^{s}=\gamma_{0}+\gamma_{1} f_{t} \quad \gamma_{1}>0
$$

O preço recebido pelo produtor é determinado por excesso de demanda:

$$
\Delta f_{t}=\beta_{0}\left(F^{d}-F^{s}\right) \quad \quad \beta_{0}>0
$$

Como o preço é dado pela equação (29), resta ao varejista determinar a quantidade oferecida. A regra sugerida por HEIEN consiste em igualar a oferta de um período à demanda do período anterior:

$$
R_{t}=R_{t-1}^{d}
$$

Essa regra permite a dinâmica que se segue. Dado um aumento na demanda ao varejo, os estoques reduzem-se mais do que o esperado, mas o preço 
permanece inalterado. No início do período seguinte, os estoques serão aumentados por meio da equação (34). Esse aumento se transmite ao prọdutor pela equação (30) e os preços nos níveis de produtor e varejo aumentam, respectivamente, pelas equações (33) e (29). O aumento do preço ao varejo tende a restringir a demanda [equação (31)] e a diminuir a oferta no período seguinte [equação (34)]. Esse processo continuará por vários períodos até que um novo ponto de equilíbrio seja atingido, caso a solução seja estável.

Para testar a estabilidade do sistema formado pelas equações (29) a (34), este é reduzido a um sistema simultâneo de equações em diferença de $1^{\text {a }}$ ordem, da forma como segue.

Das equações (31) e (34):

$$
R_{t}=\alpha_{0}+\alpha_{1} r_{t-1}
$$

Da equação (30):

$$
F d_{t}=a_{1}\left(\alpha_{0}+\alpha_{1} r_{t-1}\right)
$$

Utilizando ainda as equações (33) e (32):

$$
f_{t}=\frac{\beta_{0} a_{1} \alpha_{0}-\beta_{0} \gamma_{0}}{1+\beta_{0} \gamma_{1}}+\frac{\beta_{0} a_{1} \alpha_{1}}{1+\beta_{0} \gamma_{1}} r_{t-1}+\frac{1}{1+\beta_{0} \gamma_{1}} f_{t-1} .
$$

Fazendo:

$$
\begin{aligned}
& k_{0}=\left(\beta_{0} a_{1} \alpha_{0}-\beta_{0} \gamma_{0}\right) k_{2} \\
& k_{1}=\left(\beta_{0} a_{1} \alpha_{1}\right) k_{2} \\
& k_{2}=\left(1+\beta_{0} \gamma_{1}\right)^{-1}
\end{aligned}
$$

A equação fica:

$$
f_{t}=k_{0}+k_{1} r_{t-1}+k_{2} f_{t-1}
$$

Substituindo a equação (35) na equação (29), chega-se à outra equação do sistema: 


$$
r_{t}=a_{1} k_{0}+a_{1} k_{1} r_{t-1}+a_{1} k_{2} f_{t-1}+a_{2} z_{t}
$$

A solução é estável se o módulo da equaçã̃o característica de (35) e (36) ficar no círculo unitário. As duas raízes, dadas por $\lambda^{2}+\lambda\left(-k_{1} a_{1}-k_{2}\right)=0$, são $\lambda_{1}=0$ e $\lambda_{2}=$ $\boldsymbol{k}_{1} \boldsymbol{a}_{1}+\boldsymbol{k}_{2}$. Analisando os possíveis sinais de $\lambda_{2}$, HEIEN mostra que o sistema pode dar origem a soluções estáveis.

A regra de decisão sugerida pelo modelo pode também ser analisada com relação à sua consistência teórica. HEIEN mostra, mediante o teorema da dualidade ${ }^{22}$, que toda função de produção com retornos constantes à escala origina relações de preços conforme a equação (29). Dados os retornos constantes à escala, o custo pode ser representado por $C=h_{10}(R, f, z)=h_{10}(f, z) R=\left(b_{1} f+b_{2} z\right) R$, em que os parâmetros são $b_{1}=(\partial C / \partial f)$ e $b_{2}=(\partial C / \partial)$.

Assim:

$$
\frac{\partial C}{\partial R}=C M a=r=b_{1} f+b_{2} z,
$$

ou seja, os coeficientes dos preços dos insumos utilizados na determinação do preço ao varejo são as derivadas parciais da função de custo em relação a esses insumos.

Logo, a determinação de preço por markup fixo produz resultados consistentes, num sentido teórico, para modelos com retornos constantes à escala $\mathrm{e}$ tecnologia fixa ( $b_{1}$ e $b_{2}$ fixos). No caso do modelo de GARDNER, diferentemente, $\boldsymbol{b}_{1} \mathrm{e}$ $b_{2}$ seriam endógenos, tornando esse modelo válido para períodos de tempo em que a tecnologia pudesse mudar. HEIEN sugere que um teste de estabilidade dos parâmetros da equação (29) pode indicar se o período de tempo considerado na estimação é suficiente para que a hipótese de tecnologia fixa seja abandonada, suportando então o modelo de GARDNER.

22 BARBOSA (1985, p. 287-288) apresenta uma descrição desse teorema. 


\subsection{Modelo de BARROS (1990)}

Os dois modelos expostos anteriormente relacionam-se com modelos empíricos que vêm sendo estimados e testados empiricamente, os quais serão apresentados no próximo capítulo. O modelo de BARROS, por sua vez, é aqui apresentado porque serve de base para o modelo teórico dinâmico que vai ser desenvolvido no capítulo 4.

Embora a estrutura básica de seu modelo seja muito próxima da de HEIEN, BARROS vai adiante ao analisar os três níveis de mercado (produtor-atacadovarejo) e ao enfatizar o papel do atacado. BARROS considera que os preços se ajustam instantaneamente ao nível de atacado, em que se teriam maior acesso a informações (decorrente da maior especialização), baixo custo de mudança de preço e elevada freqüência de transações. Os níveis de produtor e varejo, o primeiro por manusear pequena parcela do mercado e o segundo por não ser especializado, ajustar-se-iam defasadamente em relação ao atacado. $O$ varejo utilizaria a prática do markup para definir um "preço-meta" para o qual se dirigiria mediante ajustes parciais. $O$ produtor também se dirigiria mediante ajustes parciais até o preço de equilibrio.

Admitindo-se curto prazo, ter-se-iam funções de produção com coeficientes fixos (tipo Leontief) nos níveis de atacado e varejo:

$$
V=\min \left(\frac{A}{b_{1}}, \frac{Z}{b_{2}}\right) \quad \text { e } \quad A=\min \left(\frac{P}{c_{1}}, \frac{X}{c_{2}}\right),
$$

em que $\boldsymbol{V}, \boldsymbol{A}$ e $\boldsymbol{P}$ são quantidades do produto ao varejo, atacado e produtor, respectivamente; $\boldsymbol{Z}$ e $\boldsymbol{X}$ são quantidades dos insumos de comercialização utilizados, ao varejo e ao atacado, respectivamente; $b_{1}, b_{2}, c_{1}$ e $c_{2}$ são coeficientes técnicos de produção.

A demanda ao varejo é dada como uma função linear do preço ao varejo $\left(v_{t}\right)$ :

$$
V^{u}=\theta_{0}+\theta_{1} v_{t}, \quad \theta_{1}<0 .
$$




$$
\begin{aligned}
& \text { O "preço-meta" ao varejo } 23 \text { é dado por : } \\
& v_{t}^{*}=b_{1} a_{t}+b_{2} z_{t},
\end{aligned}
$$

em que $\boldsymbol{a}$ e $\boldsymbol{z}$ são os preços do produto ao atacado e do insumo de comercialização $\boldsymbol{Z}$.

O ajustamento do preço ao varejo se dá por ajustes parciais:

$$
v_{t}-v_{t-1}=\alpha\left(v_{t}^{*}-v_{t-1}\right), \quad 0<\alpha<1
$$

O preço ao atacado se forma por excesso de demanda:

$$
a_{t}-a_{t-1}=\rho\left(A_{t}^{d}-A_{t}^{s}\right), \quad \rho>0
$$

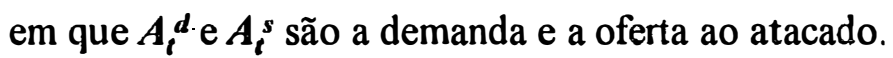

A demanda ao atacado é obtida pela conversão da demanda ao varejo do período anterior:

$$
A_{t}^{d}=b_{1} V_{t-1}^{d}
$$

A oferta ao nível de atacado é obtida pela conversão da oferta ao produtor $\left(P_{t}^{s}\right)$

$$
A_{t}^{s}=\frac{P_{t}^{s}}{c_{1}} .
$$

A oferta ao nível de produtor é uma função linear do preço recebido $(p)$ defasado:

$$
P_{i} s=\gamma_{0}+\gamma_{1} p_{t-1}, \quad \gamma_{1}>0
$$

O "preço-meta" ao produtor é estabelecido por:

$$
p_{t}^{*}=\frac{a_{t}-c_{2} x_{t}}{c_{1}}
$$

23 Notar que o "preço-meta" ao varejo corresponde ao preço de equilíbrio, para função de produção de Leontief e retornos constantes à escala, apresentado por HEIEN. 
O ajustamento do preço ao produtor se dá por ajustes parciais:

$$
p_{t}-p_{t-1}=\beta\left(p_{t}^{*}-p_{t-1}\right), \quad 0<\beta<1 .
$$

Fazendo-se substituições contínuas, o autor chega às equações de transmissão de preços a ser estimadas:

$$
\begin{aligned}
& v_{t}=(1-\alpha) v_{t-1}+\alpha b_{1} a_{t}+\alpha b_{2} z_{t} \\
& p_{t}=(1-\beta) p_{t-1}+\frac{\beta}{c_{1}} a_{t}-\frac{\beta \cdot c_{2}}{c_{1}} x_{t} \\
& a_{t}=\rho\left(\theta_{0} b_{1}-\frac{\gamma_{0}}{c_{1}}\right)+\rho \theta_{1} b_{1} v_{t-1}-\frac{\rho \gamma_{1}}{c_{1}} a_{t-1} .
\end{aligned}
$$

\subsection{Modelo de margem com risco de preço de BRORSEN et al. (1985)}

O risco (ou incerteza) de preço consiste na variabilidade em torno de seu valor esperado. $\mathrm{O}$ comportamento empresarial diante do risco tem merecido inúmeras considerações, tanto teóricas quanto empíricas, com destaque particular ao trabalho de SANDMO (1971). As aplicações em economia agrícola têm privilegiado a área de produção, com pouca ênfase ao setor de comercialização. Apenas na década de 1980, após o trabalho de BRORSEN et al., é que o impacto da incerteza de preço sobre as margens de comercialização passou a ser mais estudado.

O modelo de BRORSEN et al., de natureza estático-comparativa, consiste numa adaptação do modelo de SANDMO para firmas de comercialização agrícola em competição perfeita.

Admitindo-se competição, considera-se uma firma tomadora de preços que produz o produto $y$ a partir da matéria-prima $x$ e de um vetor $z$ de insumos de comercialização (capital, trabalho etc.). A tecnologia da firma é representada por uma função de produção não-estocástica:

$$
y=f(x, z)
$$


em que $f$ é uma função crescente e côncava de $\boldsymbol{x}$ e $\boldsymbol{z}$.

Sendo $\boldsymbol{p}$ o preço do produto $y, \boldsymbol{r}$ o preço da matéria-prima $\boldsymbol{x}$ e $\boldsymbol{q}$ o vetor de preços dos insumos $\boldsymbol{z}$, considera-se que, no momento da decisão de produção, a firma conheça $q$ e $\boldsymbol{r}$, mas não conheça com precisão o valor de $\boldsymbol{p}$ (devido às defasagens de produção).

A demanda é considerada aleatória, com o valor esperado do preço do produto determinado pelo cruzamento da oferta com a demanda esperada de mercado. Admitindo-se a aleatoriedade da demanda como exógena à firma, $\boldsymbol{p}$ é representado por uma variável aleatória com uma distribuição de probabilidade dada, refletindo a expectativa da empresa a respeito do preço do produto.

Supondo que a empresa maximize sua utilidade esperada de riqueza (UE), a decisão de produção é feita de acordo com o modelo:

$$
\operatorname{Max}_{x, z} U E\left[w+p y-q^{\prime} z-r x / y=f(x, z)\right]
$$

A expressão (50) define a riqueza da firma com sendo a riqueza inicial, $w$, mais a receita, $p y$, menos o custo, $q^{\prime} z+r x$, em que $q^{\prime} z$ é o vetor (linha) de preços dos insumos de comercialização multiplicado pelo vetor (coluna) das quantidades desses insumos, e $\boldsymbol{r} \boldsymbol{x}$ é o produto do preço pela quantidade de matéria-prima (note-se que essa soma origina um escalar). A função de utilidade $U E$ é crescente $\left[U E_{w}=\left(\partial U E / \partial_{w}\right)>0\right]$ e côncava $\left[U E_{w w}=\left(\partial^{2} U E / \partial_{w}{ }^{2}<0\right]\right.$ para uma firma avessa a risco.

O problema de maximização representado pela equação (50) é de caráter geral, tendo sido anteriormente apresentado por SANDMO. Para adaptar o modelo para uma firma de comercialização tomadora de preços, BRORSEN et al. fazem duas pressuposições restritivas. Primeiramente, a função de produção $y=f(x, z)$ é suposta ser fracamente separável, podendo ser escrita como $y=g[x, h(z)]$. Essa parece ser uma pressuposição razoável nos casos em que o processo produtivo consiste em tomar dada quantidade de matéria-prima e transformá-la em produto final. A segunda pressuposição é que a função $g$ é do tipo de Leontief (proporções fixas) com respeito à matéria-prima ${ }^{24}$ :

24 Quanto aos insumos de z, admite-se que esses podem ter quaisquer elasticidades de substituição não nulas. 


$$
y=\min \left[\frac{x}{k}, h(z)\right], \quad k>0 .
$$

Para analisar melhor a otimização representada pela equação (50), a maximização, sujeita à tecnologia dada pela equação (51), é decomposta em dois estágios:

$$
\operatorname{Max}_{x, y, z} U E\left(w+p y-q^{\prime} z-r x\right)=\operatorname{Max}_{y}\left\{U E\left[w+p y-\operatorname{Min}_{x, z}\left(q^{\prime} z+r x\right)\right]\right\} .
$$

O primeiro estágio é o problema típico de minimização do custo sem incerteza (pois admite-se que os preços da matéria-prima e dos insumos são conhecidos). Sendo $x^{+}(\boldsymbol{g}, \boldsymbol{r}, \boldsymbol{y})$ e $\boldsymbol{z}^{+}(\boldsymbol{g}, \boldsymbol{r}, \boldsymbol{y})$, respectivamente, funções de demanda de custo mínimo da matéria-prima e dos insumos de comercialização, segue da função de produção (51) que, para preços positivos, a função indireta de custo tem a forma:

$$
C(r, q, y)=q z^{+}+r x^{+}=m(q, y)+r k y,
$$

em que $C$ é uma função linearmente homogênea, crescente e côncava em preços $(\boldsymbol{r}, \boldsymbol{q})$, e crescente e estritamente convexa em produto $y$. Mediante o teorema da curva envolvente (envelope):

$$
\begin{aligned}
& \frac{\partial C}{\partial r}=x^{+}=k y ; \\
& \frac{\partial C}{\partial q}=\frac{\partial n}{\partial q}=z^{+}(q, y) .
\end{aligned}
$$

Essas duas últimas expressões refletem as implicações da tecnologia de produção dada pela equação (51) utilizada na especificação das funções de demanda de custo mínimo da matéria-prima e dos insumos $\left(x^{+}\right.$e $z^{+}$, respectivamente).

Substituindo as equações (53a) e (53b) na equação (52), o segundo estágio de maximização fica:

$$
\operatorname{Max}_{y} U E\left(w+p y-r x^{+}-q^{\prime} z\right)=\operatorname{Max}_{y} U E\left[w+(p-k r) \cdot y-q^{\prime} z^{+}(q, y)\right] .
$$


Observa-se que $\boldsymbol{p}-\boldsymbol{k} \boldsymbol{r}$ é a diferença entre o preço do produto final e o preço da matéria-prima, em quantidades equivalentes, ou seja, é a margem de comercialização $(M)$. Substituindo $M$ na equação (54), tem-se:

$$
\operatorname{Max}_{y} U E\left[w+M y-q^{\prime} z^{+}(q, y)\right]
$$

que é um problema de maximização de utilidade esperada com respeito a $y$ sob incerteza de $M$.

A solução do problema de maximização representado pela expressão (55) é a função de oferta sob risco $\boldsymbol{y}^{*}=\boldsymbol{y}[\boldsymbol{w}, \boldsymbol{q}, \boldsymbol{E}(\boldsymbol{p})-\boldsymbol{K} \boldsymbol{r}, \sigma]$, em que $\boldsymbol{y}^{*}$ é a solução ótima de produção, $\boldsymbol{E}(\boldsymbol{p})$ é o preço esperado e $\sigma$ é o desvio padrão do preço ${ }^{25}$.

A relação entre as funções de demanda minimizadoras de custo da matéria-prima e dos insumos $\left(x^{+}\right.$e $\left.z^{+}\right)$e suas respectivas funções de demanda de resposta ao risco $\left(x^{*}\right.$ e $\left.z^{*}\right)$ são 26 :

$$
x^{*}[w, q, E(p)-K r, \sigma]=x^{+}\left(y^{*}\right)=k y^{*}[w, q, E(p)-K r, \sigma],
$$

e

$$
z^{*}[w, q, E(p)-K r, \sigma]=z^{+}\left[q, y^{*}[w, q, E(p)-K r, \sigma]\right.
$$

Diferenciando-se ambas as expressões:

$$
\begin{aligned}
& \frac{\partial x^{*}}{\partial w, q, E(p)-k r, \sigma]}=k \cdot \frac{\partial y^{*}}{\partial w, q, E(p)-k r, \sigma]} \\
& \frac{\partial z^{*}}{\partial q}=\frac{\partial z^{+}}{\partial q}+\frac{\partial z^{+}}{\partial y} \frac{\partial y^{*}}{\partial q} \\
& \frac{\partial z^{*}}{\sigma w, E(p)-k r, \sigma]}=\frac{\partial z^{+}}{\partial y} \frac{\partial y^{*}}{\sigma w, E(p)-k r, \sigma]} .
\end{aligned}
$$

25 Ver SANDMO (p.67). A diferença entre as funções de oferta de $y$ e de demandas de $x$ e $z$ em resposta ao risco $\left(y^{*}, x^{*}\right.$ e $z^{*}$, respectivamente) de SANDMO e as de BRORSEN et al., é a substituição do preço esperado $[E(p)]$ pela margem esperada $[E(p)-k r]$ no último trabalho.

26 Notar que as expressões (56a) e (56b) correspondem à expressões (53a) e (53b), com a substituição da oferta $(y)$ pela oferta sob risco $\left(y^{*}\right)$. 
As expressões $(57 \mathrm{a}, \mathrm{b}, \mathrm{c})$ permitem importantes conclusões acerca do impacto da incerteza sobre a oferta de produto e as demandas de matéria-prima e insumos de comercialização. A equação (57a) mostra que a influência da mudança na incerteza $(\partial \sigma)$ sobre a demanda de $x^{*}$ é proporcional ao seu efeito sobre a produção $\boldsymbol{y}^{*}$. A influência da incerteza sobre $z^{*}$ pode ser obtida da equação (57c); caso $\partial y^{*} / \partial \sigma<0$, a implicação é que um aumento da incerteza reduzirá tanto a oferta do produto quanto a demanda dos insumos $z$ (pois $\partial^{*} / \partial \sigma<0$ ), isto se os insumos no vetor $z$ forem insumos não inferiores $\left(\partial z^{*} / \partial y>0\right)$.

Voltando à função de oferta sob risco $\left(y^{*}\right)$, BRORSEN et al. assumem o pressuposto de que a firma possui preferência com aversão ao risco absoluto decrescente (ARAD), ou seja, a aversão ao risco tende a diminuir à medida que aumenta a riqueza. Uma dedução que será importante mais adiante é que, em ARAD, a inclinação da oferta de produto com respeito ao preço esperado é positiva $\left(\partial y^{*} / \partial E(p)>0\right)^{27}$.

Definindo a função agregada de oferta como $Y^{*}=Y[w, q, E(M), \sigma]$ e assumindo que a indústria comporta-se semelhantemente à firma representativa, $Y^{*}$ teria as mesmas propriedades que a oferta da firma $\left(y^{*}\right)$. Nesse contexto, $Y^{*}$ poderia ser invertida para uma forma com o preço como dependente:

$$
E(M)=E(p)-k r=M[w, q, \sigma, Y]
$$

É essa equação que permite a análise do comportamento da margem esperada sob condições de aversão ao risco. Algumas implicações da equação (58) podem ser obtidas pela sua diferenciação. Da definição da expressão (58):

$$
\begin{aligned}
& \frac{\partial E(M)}{\partial Y}=\left(\frac{\partial Y^{*}}{\partial E(p)}\right)^{-1}, \\
& \frac{\partial E(M)}{\partial \Theta}=-\left(\frac{\partial Y^{*}}{\partial E(p)}\right)^{-1} \frac{\partial Y^{*}}{\partial \Theta}
\end{aligned}
$$

onde $\Theta=(w, q, \sigma)$.

27 SANDMO (p. 69). 
A pressuposição de que $y^{*}$ e $Y^{*}$ têm as mesmas propriedades permite que se usem os resultados obtidos por SANDMO e por ISHII, citado por BRORSEN et al., na derivação das propriedades de $\boldsymbol{E}(\boldsymbol{M})$.

Admitindo preferência ARAD, SANDMO verificou que $\left[\partial Y^{*} / \partial E(p)\right]>0$, o que implica que a margem esperada é positivamente relacionada com a quantidade de produto $[\partial E(M) / \partial Y>0]$. Já ISHII, também assumindo ARAD, verificou que o produto decresce com aumento da incerteza no preço $\left[\partial \gamma^{*} / \partial \sigma<0\right]$, o que permite concluir [da equação (59b)] que:

$$
\frac{\partial E(M)}{\partial \sigma}>\theta
$$

ou seja, um aumento no risco de preço sempre aumenta a margem de comercialização.

Da equação (59b) também se deduz que, em ARAD: $[\partial E(M) / \partial y] \geq 0$ quando $\left(\partial Y^{*} / \partial q\right) \leq 0$, e $[E(M) / \partial q] \leq 0$ quando $\left(\partial Y^{*} / \partial q\right) \geq 0$, ou seja, o impacto de uma mudança no preço dos insumos de comercialização sobre a margem esperada pode ser positivo ou negativo. Entretanto, BATRA \& ULLAH, citados por BRORSEN et al., mostraram que $\left(\partial Y^{*} / \partial_{l}\right)<0$, sob ARAD e complementaridade dos insumos; nessa situação, em que a oferta sob risco diminui diante de aumentos no preço dos insumos, segue-se que a margem esperada aumenta com o preço dos insumos de comercialização. 


\section{MODELOS EMPÍRICOS DE MARGEM DE COMERCIALIZAÇÃO}

Este capítulo apresentará os quatro principais modelos empíricos de margens de comercialização que vêm sendo estimados e testados. Grande parte da exposição basear-se-á nos trabalhos desenvolvidos por WOHLGENANT \& MULLEN (1987), THOMPSON \& LYON (1989), FAMINOW \& LAUBSCHER (1991) e LYON \& THOMPSON (1993) ${ }^{28}$. Os quatro modelos descritos neste capítulo são estáticos, com a margem sendo explicada por valores correntes (não defasados) do preço ao varejo, do custo de comercialização e de outras variáveis. Um tratamento dinâmico da margem de comercialização será apresentado no próximo capítulo:

Os trabalhos citados diferem entre si principalmente em função do produto estudado e da periodicidade dos dados: WOHLGENANT \& MULLEN trabalharam com o mercado de carne bovina e utilizaram dados anuais; THOMPSON \& LYON estudaram o mercado de laranja in natura através de dados semanais; e FAMINOW \& LAUBSCHER estudaram o mercado de milho através de dados mensais. Os dois primeiros estudos foram sobre os Estados Unidos e o último foi sobre o mercado de milho-farinha da África do Sul. Buscando analisar de mạneira mais detalhada a questão da agregação dos dados, LYON \& THOMPSON trabalharam com o mercado de leite fluido nos Estados Unidos e utilizaram dados agregados mensalmente, trimestralmente e semestralmente, variando também a agregação das regiões produtoras ${ }^{29}$.

: Em decorrência de, em cada pesquisa, terem sido estudados os efeitos de diferentes impactos do mercado ou de políticas sobre a margem de comercialização, outras diferenças existem entre as especificações desses autores. Essas diferenças

28 Merecem destaque ainda o comentário de POWERS (1991) ao trabalho de THOMPSON \& LYON, e a réplica destes autores (THOMPSON \& LYON, 1991).

29 Além dos modelos que serão abordados nesse capítulo, LYON \& THOMPSON estimaram um modelo dinâmico que será explicitado no capitulo 4. 
consistem na inclusão de variáveis relacionadas ao risco e de variáveis binárias de diferenciação de situações políticas.

Segue-se, então, a apresentação dos quatro modelos, enfatizando-se, especialmente, as idéias que fundamentam cada modelo e as principais especificações econométricas que foram empregadas.

\section{3:1. Modelo de BUSE \& BRANDOW (1960)}

BUSE \& BRANDOW apresentaram uma especificação econométrica com base no pressuposto de que a quantidade produzida (comercializada) é predeterminada, cabendo aos ajustes do preço ao varejo a incumbência de levar o mercado ao equilíbrio ${ }^{30}$. O modelo genérico pode ser representado por:

$$
M=f(P v, Q, Z)
$$

em que $M$ é a margem de comercialização produtor-varejo, dada pela diferença entre o preço ao varejo, $\boldsymbol{P} \boldsymbol{v}$, e o preço ao produtor, $\boldsymbol{P} \boldsymbol{p}$, em quantidades equivalentes; $\boldsymbol{Q}$ é a quantidade da mercadoria agrícola comercializada; e $\boldsymbol{Z}$ representa outras variáveis, tal como a tendência.

De forma mais específica, o modelo que foi estimado e testado por BUSE \& BRANDOW foi o seguinte (as letras originais foram alteradas para facilitar a interpretação do modelo):

$$
M_{t}=\beta_{0}+\beta_{1} C M_{t}+\beta_{2} C O_{t}+\beta_{3} P v_{t}+\beta_{4} I P_{t}+\beta_{5} T 1_{t}+\beta_{6} T 2_{t}+\varepsilon_{t}
$$

em que, $M$ é a margem de comercialização para a mercadoria; $C M$, a margem produtorvarejo para:uma cesta de mercado de alimentos agrícolas; $\mathrm{CO}$, o consumo per capita da mercadoria, ajustado pela tendência; $\boldsymbol{P} \boldsymbol{v}$, o preço da mercadoria ao varejo, ajustado pela tendência e nível de preço; $\boldsymbol{I P}$, um indicador de direção de preço para a mercadoria; $\boldsymbol{T}$,

30 Apesar de o modelo de BUSE \& BRANDOW ser aqui apresentado separadamente do modelo relativo (item 3.3), WOHLGENANT \& MULLEN e FAMINOW \& LAUBSCHER trataram o primeiro modelo como sendo uma forma especial do último. THOMPSON \& LYON, por outro lado, estimaram as duas formas como sendo independentes. 
uma medida linear do tempo $(1,2,3, \ldots, t)$, com sua origem em 1920 (excluída da análise feita com dados trimestrais); T2, uma medida linear do tempo para o período pósguerra, com origem em 1946 para dados anuais e no último trimestre de 1946 para dados trimestrais; e $\varepsilon_{p}$ o erro.

BUSE \& BRANDOW reconhecem a dificuldade de se interpretar o coeficiente do volume consumido $(C O)$ na equação (61), visto que esta equação também possui o preço ao varejo entre suas variáveis independentè. A elasticidade volume deveria ser interpretada como o efeito de uma mudança no volume sobre a margem de comercialização quando o preço ao varejo é mantido constante. Entretanto, essa interpretação de elasticidade volume é contrária à usual pressuposição de comportamento do mercado, porque o preço ao varejo deve variar quando o volume varia, mantidas as outras variáveis constantes.

A especificação empirica de THOMPSON \& LYON é um pouco diferente, porque esses autores pretendiam investigar o efeito de uma alteração na política de comercialização de laranjas ocorrida durante o ano de 1985 , no estado da Califórnia. O modelo estimado foi:

$$
M_{t}=\beta_{0}+\beta_{1} P v_{t}+\beta_{2} Q_{t}+\beta_{3} T R_{t}+\beta_{4} D 1985+\beta_{5} D M A Y+\beta_{6} T I M E+\varepsilon_{t}
$$

em que $M_{t}$ é a margem de comercialização produtor-varejo para a semana $t ; P \boldsymbol{v}_{t}$ o preço ao varejo na semana $t ; Q_{b}$ a quantidade comercializada de laranja na semana $t ; T R_{t}$ a tarifa média de transporte de laranja ${ }^{31}$ na semana $t ; D 1985$, uma variável binária, assumindo os valores 1 para o período de suspensão do controle do comércio, de fevereiro a maio de 1985, e 0 para as demais semanas; $D M A Y$, outra variável binária, assumindo 1 para os valores de maio e 0 para os demais; TIME, a variável tendência; e $\varepsilon_{p}$ o erro.

31 Verifica-se que o custo de transporte foi incluido para representar o custo de comercialização, efeito este que no modelo original de BUSE \& BRANDOW era captado pela margem da cesta de mercado. 


\subsection{Modelo de markup: WAUGH (1973) - GEORGE \& KING (1971)}

Essa especificação baseia-se no trabalho de WAUGH $^{32}$, tendo sido também utilizada e difundida por GEORGE \& KNG.

Analisando a transmissão de preços entre níveis de mercado, WAUGH (p.43-44) afirma que:

"Há duas noções conflitantes concernentes às relações entre demandas ao nível do agricultor e ao nível de varejo. Algumas pessoas estão firmemente convencidas de que os preços de alimentos são estabelecidos na empresa agrícola e que os preços ao varejo são estabelecidos sobre o preço do agricultor mais as várias despesas para processamento e distribuição. A curto prazo isto pode, muitas vezes, ser verdadeiro ...

"Mas, a longo prazo, penso que a demanda do consumidor é o fator dominante (...) Sendo isto verdadeiro, a longo prazo, os preços dos alimentos são determinados nos mercados varejistas através do que o consumidor pode ou deseja pagar pelo que é oferecido. $O$ preço do agricultor precisa ser igual ao preço ao varejo menos todas as despesas de transporte, processamento, armazenamento, venda a atacado e venda a varejo".

É justamente a partir da caracterização da formação de preço apresentada por WAUGH que se estabeleceu o modelo denominado pelos diversos autores de modelo de markup. De forma genérica, o modelo poderia ser representado como:

$$
M=f(P v, C)
$$

em que $M$ é a margem de comercialização produtor-varejo; $P \boldsymbol{v}$, o preço ao varejo; e $C$, o custo dos serviços de comercialização.

32 Na verdade, o trabalho de WAUGH foi publicado pela primeira vez em 1964, correspondendo ao Boletim Técnico $n^{\circ} 1316$, do Economic Research Service do United States Department of Agriculture. A versão de 1973 é tradução literal do trabalho original. 
Esse modelo representa margens de comercialização resultantes de markup percentual combinado com markup absoluto ${ }^{33}$. Além disso, conforme argumentam THOMPSON \& LYON, embora o modelo não seja explicitamente dinâmico, ele é consistente com a ênfase de HEIEN (1980) nas regras de markup usadas nas decisões de determinação de preços do varejo no curto prazo.

Uma limitação do modelo do markup, conforme mostra GARDNER (1975, p. 404), é que este método só descreve com precisão a relação entre os preços ao produtor e ao varejo se as mudanças ocorrerem somente na oferta ou na demanda. Caso ocorram alterações simultâneas na oferta e na demanda, esse modelo não se aplica.

Empiricamente, WOHLGENANT \& MULLEN estimaram o modelo de markup para carne bovina da seguinte forma:

$$
M_{t}=\beta_{0}+\beta_{1} P v_{t}+\beta_{2} I C_{t}+\varepsilon_{t}
$$

em que $M_{t}$ é a margem de comercialização da carne bovina; $P \boldsymbol{v}_{b}$ o preço da carne ao varejo; $I C_{t}$ um índice de custo de comercialização para carne (uma simples média do índice de salários nas firmas de embalagem e do índice de preços recebidos pelos produtores de combustíveis e produtos relacionados); e $\varepsilon_{t}$ o erro. Todos os preços $\left(\boldsymbol{M}_{t}\right.$ $P v_{t}$ e $I C_{t}$ ) são deflacionados pelo índice de preços ao consumidor.

O modelo empírico de markup estimado por THOMPSON \& LYON é muito semelhante ao de WOHLGENANT \& MULLEN, tendo como diferença a inclusão do custo de transporte como proxy do custo de comercialização e as variáveis binárias já apresentadas:

$$
M_{t}=\beta_{0}+\beta_{1} P v_{t}+\beta_{2} T R_{t}+\beta_{3} D 1985+\beta_{4} D M A Y+\beta_{5} T I M E+\varepsilon_{t},
$$

em que $M_{\imath}$ é a margem de comercialização produtor-varejo para a semana $t ; \boldsymbol{P} \boldsymbol{\nu}_{\boldsymbol{b}}$ o preço ao varejo na semana $t ; T R_{t}$, a tarifa média de transporte de laranja na semana $t ; D 1985$, uma variável binária, assumindo os valores 1 para fevereiro a maio de 1985 e 0 para as

33 A especificação de GEORGE \& KING (p. 57) é: $\boldsymbol{M}=\alpha+\beta P \nu$. Como $M=P \nu-P p$, a função pode ser recscrita da seguinte maneira: $P \boldsymbol{v}=\alpha /(1-\not)+[1 /(1-\not)] P p$, em que se verifican, explicitamente, os componentes fixo e percentual do markup. 
demais semanas; $D M A Y$, outra variável binária, assumindo 1 para os valores de maio e 0 para os demais; TIME, a variável tendência; e $\varepsilon_{p}$ o erro.

FAMINOW \& LAUBSCHER, interessados em estudar o efeito do risco e de algumas políticas sobre o mercado de milho da África do Sul, estimaram o modelo do markup da seguinte forma:

$$
M_{t}=\beta_{0}+\beta_{1} P v_{t}+\beta_{2} C_{t}+\beta_{3} R I S K+\beta_{4} D 8287+\beta_{5} D 8385+\varepsilon_{t}
$$

em que $\boldsymbol{M}_{\boldsymbol{t}}$ é a margem de comercialização produtor-varejo deflacionada; $\boldsymbol{P} \boldsymbol{\nu}_{\boldsymbol{p}}$ o preço da farinha de milho ao varejo; $C_{b}$ o custo de comercialização; $R I S K$, as várias formas como a variável risco é incorporada ao modelo; $D 8287$, uma variável binária que assume valores 0 para os anos de safra $1982 / 83$ a 1986/87 e 1 para os demais; D8385, uma variável binária que assume valores 1 para 1983/84 e 84/85 e 0 para os demais anos; e $\varepsilon$ ¿o erro.

A equação estimada por LYON \& THOMPSON, para o modelo de markup, foi:

$$
M_{t}=\beta_{0}+\beta_{1} P v_{t}+\beta_{2} W_{t}+\beta_{3} D L O W+\varepsilon_{t}
$$

em que $\boldsymbol{M}_{\boldsymbol{t}}$ é a margem de comercialização produtor-varejo de leite fluido; $\boldsymbol{P} \boldsymbol{v}_{\boldsymbol{p}}$ o preço do leite ao varejo; $W_{b}$ o salário médio por hora pago na indústria de processamento de leite (correspondente aos três períodos de agregação) ${ }^{34} ; D L O W$, uma variável binária que assume valores 1 para o ano de 1988 e 0 para os demais (em 1988 houve uma redução significativa do preço mínimo federal de leite); e $\varepsilon_{t}$ o erro.

\subsection{Modelo relativo: WOHLGENANT \& MULLEN (1987)}

Criando uma alternativa ao modelo de markup, WOHLGENANT \& MULLEN apresentaram um modelo, aqui denominado modelo relativo (originalmente:

34 LYON \& THOMPSON reconhecem que outras variáveis seriam importantes para representar o custo de comercialização, tais como custos de transporte e embalagem, mas justificam a ausência dessas variáveis em todas as equaçð̋es pela indisponibilidade desses dados. 
relative price spread model), que permite mudanças simultâneas nas condições de demanda e oferta.

Um ponto a ser destacado é que o modelo foi desenvolvido voltado para a relação que determina a margem relativa de comercialização entre produtor e varejo, mas no final, através da multiplicação de ambos os lados da equação pelo preço ao varejo, chega-se à forma a ser especificada que é a da margem absoluta de comercialização.

Vistos esses pontos, pode-se agora apresentar, formalmente, o modelo relativo. Pressupondo que a oferta agrícola é predeterminada em relação ao preço ${ }^{35}$, em razão da defasagem que existe no processo produtivo, a demanda derivada tem o preço do produtor como variável dependente:

$$
P p=f(Q, P v, C)
$$

em que $P \boldsymbol{p}$ é o preço do produto agrícola recebido pelo produtor; $\boldsymbol{Q}$, a quantidade de produto agrícola processada; $\boldsymbol{P} \boldsymbol{v}$, o preço ao nível de varejo; e $\mathbf{C}$, um vetor de preços dos insumos de comercialização (salários, custos de transporte etc.).

Como a demanda por um fator de produção não varia em caso de mudanças proporcionais nos preços do produto e de todos os insumos ${ }^{36}$, a equação (68) pode ser reescrita em termos de preços relativos, dividindo-se todos os preços por $\boldsymbol{P v}$ :

$$
\frac{P p}{P v}=f\left(Q, 1, \frac{C}{P v}\right)=g\left(Q, \frac{C}{P v}\right)
$$

em que Pv é o preço ao varejo.

A equação (69) mostra os determinantes teóricos da razão de preços produtor-varejo, de forma que aumentos na produção da mercadoria agrícola ou no custo relativo (ao:preço do varejo) de comercialização devem ocasionar diminuição na razão de

35 Notar que o modelo de BUSE \& BRANDOW partia desta mesma hipótese.

36 As funções de demanda de insumos são homogêneas de grau zero (HENDERSON \& QUANDT, 1988, p. 67-69). 
preços; ou seja, as derivadas parciais de $\boldsymbol{g}$ em relação a $Q$ e em relação a $C / P v$ são nega$\operatorname{tivas}^{37}$.

Para se chegar à especificação da margem, parte-se da margem relativa de comercialização, $\boldsymbol{M} / \boldsymbol{P} \boldsymbol{v}$, que pode ser escrita como $(\boldsymbol{P} \boldsymbol{v}-\boldsymbol{P} \boldsymbol{p}) / \boldsymbol{P} \boldsymbol{v}$, ou, ainda, $\mathbf{1}-(\boldsymbol{P} \boldsymbol{p} / \boldsymbol{P} \boldsymbol{v})$. Portanto, a equação (69) pode ser reescrita como:

$$
\frac{M}{P v}=1-g\left(Q, \frac{C}{P v}\right)=h\left(Q, \frac{C}{P v}\right) \text {. }
$$

Como $\mathbf{g}$ representa relações inversas entre as variáveis independentes e a variável dependente, a função $\boldsymbol{h}$ (que é igual a 1-g) representa relação direta, ou seja, as derivadas parciais de $\boldsymbol{h}$ em relação à quantidade e ao custo relativo são positivas (maior quantidade e maior custo aumentam a margem relativa).

Passando-se Pv para o segundo membro (multiplicando $h$ ), tem-se a margem absoluta de comercialização:

$$
M=P v h\left(Q, \frac{C}{P v}\right)
$$

em que $\boldsymbol{M}=\boldsymbol{P} \boldsymbol{\nu}-\boldsymbol{P p}$ (em preços das quantidades equivalentes).

Comparando esse modelo com o de markup, constata-se que o modelo de WOHLGENANT \& MULLEN não apresenta relação fixa entre a margem e o preço ao varejo. Além disso, esse modelo é consistente com o modelo teórico de GARDNER, pelo fato de a relação entre os preços variar quando mudam a quantidade produzida ou $o$ preço relativo dos insumos de comercialização.

A margem seria função da quantidade produzida (comercializada), do custo de commercialização e do preço ao varejo. As variações nas condições de demanda e oferta se manifestariam, respectivamente, por meio do preço ao varejo e da quantidade produzida. A relação direta entre a margem e as variáveis explicativas mostra que

37 Essa afirmação é mais fácil de ser vista a partir da expressão (68), em que se vê que o preço ao produtor será tão menor quanto maiores forem a quantidade e o custo de comercialização. Como a passagem da expressão (68) para a (69) envolve apenas a divisão por um valor positivo (Pv), verificase 0 mesmo impacto nas duas expressões. 
aumentos na quantidade produzida (maior oferta agrícola) ou no custo relativo de comercialização (redução na oferta de insumos de comercialização e/ou redução da demanda primária) levariam a aumentos na margem de comercialização. Essa conclusão é exatamente o que se prevê por meio do modelo de GARDNER, admitindo-se as condições normais especificadas no capítulo 2 .

Em comparação com o modelo de BUSE \& BRANDOW, verifica-se que tanto esse quanto o modelo relativo consideram a margem como função das mesmas três variáveis: preço ao varejo, quantidade comercializada e custo de comercialização. A diferença está no fato de que, no modelo relativo, a quantidade é multiplicada pelo preço ao varejo. Isso evita a dificuldade encontrada por BUSE \& BRANDOW para explicar as variações apenas em uma dessas variáveis (preço ou quantidade), enquanto a outra permanecesse constante.

O modelo empírico relativo, na forma como WOHLGENANT \& MULLEN estimaram para carne bovina, é o seguinte:

$$
M_{t}=\beta_{1} P v_{t}+\beta_{2}\left(P v_{t} Q_{t}\right)+\beta_{3} I C_{t}+\varepsilon_{t}
$$

em que $M_{t}$ é a margem de comercialização da carne bovina; $P \boldsymbol{v}_{p}$ o preço da carne ao varejo; $I C_{b}$ o índice de custo de comercialização para carne; $Q_{t}$ a quantidade produzida de carne per capita; e $\varepsilon_{b}$ o erro 38 .

A equação estimada por THOMPSON \& LYON, para o modelo relativo, foi:

$$
M_{t}=\beta_{1} P v_{t}+\beta_{2}\left(P v_{t} Q_{t}\right)+\beta_{3} T R_{t}+\beta_{4} D 1985+\beta_{5} D M A Y+\beta_{6} T I M E+\varepsilon_{t}
$$

em que $\boldsymbol{M}_{\boldsymbol{t}}$ é a margem de comercialização produtor-varejo para a semana $\boldsymbol{t} ; \boldsymbol{P} \boldsymbol{v}_{\boldsymbol{b}}$ o preço ao varejo na semana $t ; Q_{t}$ a quantidade comercializada de laranja na semana $t ; T R_{t}$ a tarifa média de transporte de laranja na semana $t ; D 1985$, uma variável binária, assumindo 1 para fevereiro a maio de 1985 e 0 para as demais semanas; $D M A Y$, outra variável binária, assumindo 1 para os valores de maio e 0 para os demais; TIME, a variável tendência; e $\varepsilon_{t}$ o erro.

38 WOHLGENANT \& MULLEN testaram também uma especificação semelhante à apresentada na expressão (72), mas com a inclusão de um intercepto, que não foi significativo. 
O modelo relativo estimado por FAMINOW \& LAUBSCHER foi:

$$
M_{t}=\beta_{1} P v_{t}+\beta_{2} P R Q+\beta_{3} C_{t}+\beta_{4} R I S K+\beta_{5} D 8287+\beta_{6} D 8385+\varepsilon_{t}
$$

em que $\boldsymbol{M}_{\boldsymbol{t}}$ é a margem de comercialização produtor-varejo deflacionada; $\boldsymbol{P} \boldsymbol{v}_{\boldsymbol{p}}$ o preço da farinha de milho ao varejo; $P R Q$, a variável de interação preço-quantidade; $C_{b}$ o custo de comercialização; RISK, as várias formas como a variável risco é incorporada ao modelo; D8287, uma variável binária que assume valores 0 para os anos de safra 1982/83 a 1986/87 e 1 para os demais; D8385, uma variável binária que assume valores 1 para 1983/84 e 1984/85 e 0 para os demais anos; e $\varepsilon_{\mathfrak{p}}$ o erro.

A forma estimada por LYON \& THOMPSON foi:

$$
M_{t}=\beta_{1} P v_{t}+\beta_{2}\left(P v_{t} Q_{t}\right)+\beta_{3} W_{t}+\beta_{4} D L O W+\varepsilon_{t}
$$

em que $\boldsymbol{M}_{\boldsymbol{t}}$ é a margem de comercialização produtor-varejo de leite fluido; $\boldsymbol{P} \boldsymbol{v}_{\boldsymbol{t}}$ o preço do leite ao varejo; $\boldsymbol{Q}_{\boldsymbol{t}}$ a quantidade comercializada de leite (nos três niveis de agregação temporal); $W_{p}$ o salário médio por hora pago na indústria de processamento de leite (correspondente aos três períodos de agregação); DLOW, uma variável binária que assume valores 1 para o ano de 1988 e 0 para os demais (em 1988 houve uma redução significativa do preço mínimo federal de leite); e $\varepsilon_{t}$ o erro.

\subsection{Modelo do custo de comercialização}

Essa especificação corresponde à definição de margem de comercialização como o preço de um conjunto de serviços de comercialização, apresentada por TOMEK \& ROBINSON e já citada no capítulo 1 .

- Conforme mostram WOHLGENANT \& MULLEN, essa especificação pode ser vista como uma forma alternativa de se chegar à equação (71). Com esse enfoque, espera-se que as firmas forneçam serviços de comercialização até o ponto onde a receita marginal (preço, em competição perfeita) desses serviços (que é a própria margem, $\boldsymbol{M}$ ) iguale ao custo marginal. Assim:

$$
M=K(Q, C)
$$


em que $K$ é a função de custo marginal do agregado de serviços de comercialização; $Q$, a quantidade de produto agrícola processada; e $C$, o custo dọs insumos de comercialização. Sendo a função de custo marginal homogênea de grau um em preços dos insumos, $K(Q, C)=(1 / t) K(Q, t C)$, para todo $t>0$. Logo, basta supor que $t=(1 / P v)$, para que a equação (76) seja transformada na equação (71).

Portanto, o modelo do custo de comercialização admite que margem é o conjunto de preços dos serviços de comercialização; em equilíbrio competitivo, a margem é igual ao custo marginal de se oferecer esses serviços. Dessa forma, a margem de comercialização pode ser especificada como função apenas das variáveis do custo marginal: custo e quantidade.

A especificação estatística estimada por WOHLGENANT \& MULLEN, para o modelo do custo de comercialização, foi a seguinte:

$$
M_{t}=\beta_{0}+\beta_{1} Q_{t}+\beta_{2} I C_{t}+\varepsilon_{t}
$$

em que $M_{t}$ é a margem de comercialização da carne bovina; $I C_{t}$ o índice de custo de comercialização para carne; $Q_{t}$ a quantidade produzida de carne per capita; e $\varepsilon_{t}$ o erro.

Incluindo, como nas demais equações, as variáveis binárias específicas para o mercado estudado, a equação estimada por THOMPSON \& LYON, para o modelo de TOMEK \& ROBINSON, é a seguinte:

$$
M_{\mathrm{t}}=\beta_{0}+\beta_{1} Q_{\mathrm{t}}+\beta_{2} T R_{\mathrm{t}}+\beta_{3} D 1985+\beta_{4} D M A Y+\beta_{5} T I M E+\varepsilon_{\mathrm{p}}
$$

em que $M_{t}$ é a margem de comercialização produtor-varejo para a semana $t ; Q_{t}$, a quantidade comercializada de laranja na semana $t ; \boldsymbol{R}_{b}$ a tarifa média de transporte de laranja na semana $t$; D1985, uma variável binária, assumindo 1 para fevereiro a maio de 1985 e 0 para as demais semanas; $D M A Y$, outra variável binária, assumindo 1 para os valores de maio e 0 para os demais; TIME, a variável tendência; e $\varepsilon_{p}$ o erro.

FAMINOW \& LAUBSCHER estimaram o modelo do custo de comercialização da seguinte forma:

$$
M_{t}=\beta_{0}+\beta_{1} Q_{t}+\beta_{2} C_{t}+\beta_{3} R I S K+\beta_{4} D 8287+\beta_{5} D 8385+\varepsilon_{t},
$$


em que $M_{t}$ é a margem de comercialização produtor-varejo deflacionada; $Q_{p}$ a quantidade de milho comercializada; $C_{b}$ o custo de comercialização; $R \boldsymbol{S K K}$, as várias formas como a variável risco é incorporada ao modelo; D8287, uma variável binária que assume valores 0 para os anos de safra 1982/83 a 1986/87 e 1 para os demais; D8385, uma variável binária que assume valores 1 para 1983/84 e 84/85 e 0 para os demais anos; e $\varepsilon_{p}$ o erro.

A especificação utilizada por LYON \& THOMPSON, para o modelo do custo de comercialização, foi:

$$
M_{t}=\beta_{0}+\beta_{1} Q_{t}+\beta_{2} W_{t}+\beta_{3} D L O W+\varepsilon_{t}
$$

em que $M_{l}$ é a margem de comercialização produtor-varejo de leite fluido; $Q_{b}$ a quantidade de leite comercializada (agregada temporalmente das três formas); $W_{b}$ o salário médio por hora pago na indústria de processamento de leite (correspondente aos três períodos de agregação); $D L O W$, uma variável binária que assume valores 1 para 0 ano de 1988 e 0 para os demais (em 1988 houve uma redução significativa do preço mínimo federal de leite); e $\varepsilon_{t}$ o erro.

\subsection{Comparação entre os modelos}

Sistematizando os modelos para facilitar a comparação, estes podem ser divididos em três categorias em decorrência das variáveis que determinam a margem: (1) margem como função do preço ao nível de varejo, da quantidade comercializada (produzida) e do custo de comercialização (modelos de BUSE \& BRANDOW e relativo); (2) margem como função apenas do preço ao varejo e do custo de comercialização (modelo de markup); e (3) margem como função apenas da quantidade comercializada e do custo de comercialização (modelo do custo de comercialização). Desses três, a literatura tem enfatizado a contraposição entre os dois primeiros, o que permitiria, segundo os diversos autores que estimaram esses modelos, um teste indireto da aderência dos modelos de GARDNER e de HEIEN. 
Nessa contraposição entre os modelos, a primeira questão que parece ser crucial é a periodicidade dos dados utilizados nas estimações, ou seja, o nível de agregação temporal (semanal, mensal, semestral, anual etc.) dos dados.

Maior agregação, talvez com dados anuais, pode permitir a captação do ajuste do mercado à condição de equilibrio, nos moldes propostos pelo modelo de GARDNER. Nesse caso, um ajustamento melhor do modelo relativo deveria ser esperado, o que realmente ocorreu no estudo de WOHLGENANT \& MULLEN.

Estimações com dados mais desagregados, tais como semanais, admitiriam a constatação de uma forma de determinação de preços semelhante à proposta por HEIEN, com a aplicação de um markup sobre o custo. Nesse caso, o modelo de markup tenderia a ser o de melhor ajuste, o que foi verificado no estudo com dados semanais de THOMPSON \& LYON.

No caso do modelo do custo de comercialização, seria improvável bom ajustamento com dados mais desagregados, pois seria dificil para as firmas ajustarem seus preços ou a produção rapidamente, diante de mudanças de custos, de forma a igualar a receita marginal ao custo marginal de curto prazo (LYON \& THOMPSON).

Conforme afirmam FAMINOW \& LAUBSCHER, a contraposição do trabalho de WOHLGENANT \& MULLEN com o de THOMPSON \& LYON fornece fraca evidência quanto à relação entre o modelo que melhor se ajusta e a periodicidade dos dados. Isto porque esses dois estudos envolvem diferentes produtos e circunstâncias de mercado, além de cobrirem épocas distintas. Em outras palavras, pesquisas que envolvessem um único produto e dados de diferentes periodicidades, dentro da mesma época, poderiam fornecer evidências mais confiáveis da questão levantada.

O trabalho de LYON \& THOMPSON tentou caminhar no sentido de testar a hipötese levantada por FAMINOW \& LAUBSCHER; porém, o menor nível de agregação utilizado consistiu de dados mensais. Esses autores constataram que o modelo de markup foi válido em todos os níveis de agregação temporal (dados mensais, trimestrais e semestrais), sendo, no entanto, preterido quando os dados foram agregados espacialmente. A agregação espacial levaria a se ter substituição entre os insumos, o que contraria a hipótese de proporções fixas, subjacente ao modelo de markup, no curto prazo. 
Resultado que também pode ser encontrado, apesar das sugestões apresentadas em relação aos modelos que parecem ser mais adequados, é a situação em que não é tão evidente que um modelo possa ser escolhido com a exclusão de outro. Os resultados encontrados por FAMINOW \& LAUBSCHER mostram que existem razões "institucionais e empiricas para se suspeitar que a escolha entre modelos seja, de fato, indeterminada" (p. 62).

FAMINOW \& LAUBSCHER, trabalhando com dados mensais, obtiveram estimativas consistentes para os três tipos de modelos estimados (apenas o de BUSE \& BRANDOW não foi estimado), tendo o relativo apresentado os melhores resultados estatísticos. Mas constataram que os valores defasados do preço ao varejo e da margem são fatores importantes na determinação da margem corrente, o que sugere a existência de regras de markup fixo nas decisões de determinação de preço das firmas de comercialização. Por outro lado, os fatores de oferta e demanda também afetam, claramente, o tamanho da margem (como puderam os autores verificar pela significância de outras variáveis do modelo), o que suporta o modelo relativo. Além disso, o coeficiente negativo dos custos de comercialização encontrado em todas as estimações não fornece suporte para o modelo de markup 39 .

Em suma, o trabalho de FAMINOW \& LAUBSCHER sugere que uma situação de ambigüidade possa caracterizar o sistema no qual a margem de comercialização é observada e que este pode ser especialmente o caso do uso de dados de curta ou média periodicidade. LYON \& THOMPSON generalizaram essa questão, afirmando, a partir dos seus resultados, que a ambigüidade na escolha do modelo tende a aumentar com a agregação dos dados, seja temporal ou espacial; as dificuldades encontradas por FAMINOW \& LAUBSCHER seriam, então, explicadas pelo uso de dados nacionais ${ }^{40}$.

39 Conforme afirmam FAMINOW \& LAUBSCHER, a filosofia que fundamenta o modelo de markup é que aumentos no custo são passados adiante no canal de comercialização quando eles ocorrem (ou talve $z$ com alguma defasagem), o que sugere relação direta (positiva) entre margem e custo.

40 Embora LYON \& THOMPSON tenham encontrado maior ambigüidade para maior agregação temporal, esses autores não chegaram a utilizar dados anuais (que deram bons ajustes no trabalho de WOHLGENANT \& MULLEN). 
As estimações de WOHLGENANT \& MULLEN permitiram também algumas importantes conclusões. Em primeiro lugar, o resultado favorável ao modelo relativo é devido, provavelmente, à existência de variações simultâneas na oferta do produtor e na demanda do consumidor, que se refletiriam na quantidade produzida e no preço do varejo.

WOHLGENANT \& MULLEN concluem também que o baixo efeito da quantidade obtida por BUSE \& BRANDOW e os resultados por eles obtidos sugerem que "a quantidade produzida afeta o comportamento da margem principalmente através do seu efeito no markup percentual - um maior volume leva a um maior markup percentual e vice-versa" (p.124). Embora esses autores utilizem o termo markup percentual, a afirmação diz respeito ao conceito de margem relativa apresentado no capítulo 1. Sendo a margem relativa igual a $M / P v$, se essa fosse positivamente relacionada com a quantidade, ter-se-ia que a margem absoluta seria positivamente relacionada com a quantidade multiplicada por $\boldsymbol{P} \boldsymbol{\nu}$. Relembrando as deduções do modelo de GARDNER (capitulo 2), em condições normais, aumento na quantidade de matériaprima agrícola levaria a aumento na margem relativa de comercialização. Sendo assim, a constatação de WOHLGENANT \& MULLEN, embora não explicitada por esses autores, é coerente com as previsões do modelo de GARDNER.

Finalizando a comparação entre os modelos, WOHLGENANT \& MULLEN verificaram que os modelos de markup (utilizando a fórmula apresentada por GEORGE \& KING) e relativo fornecem estimativas muito próximas da equação de demanda derivada. Dessa forma, se o objetivo da análise for unicamente estimar a função de demanda derivada, é indiferente o uso de qualquer um dos dois modelos. Mas se o objetivo for utilizar o modelo para a análise dos efeitos de políticas que alterem a oferta agrícola e a demanda ao varejo, a especificação de margem relativa deveria ser preferivel.

\subsection{Deficiências dos modelos}

Os modelos empíricos de margem de comercialização apresentados neste capítulo vêm sendo submetidos a intenso processo de estimação e teste. Infelizmente, tem sido bem menor o esforço no sentido de examinar a origem de cada modelo no que diz respeito a seus pressupostos e a sua consistência econômica. Neste item, discutem-se 
alguns aspectos dos modelos de markup, relativo e do custo de comercialização, que são as três formulações mais estimadas nos estudos empíricos e que também serão objeto de estimação neste trabalho.

O modelo de markup baseia-se, segundo os diversos autores que o utilizaram, na forma de determinação do preço no curto prazo apresentada por WAUGH. Segundo WAUGH, no curto prazo, os preços se formariam ao nível de produtor; o preço ao varejo seria obtido pelo acréscimo do custo de comercialização ao preço do produtor $^{41}$. Essa é justamente a forma de determinação do preço assumida por HEIEN, em seu modelo teórico apresentado no capítulo 2, motivo pelo qual melhor ajuste do modelo de markup vem sendo utilizado como argumento favorável ao modelo de HEIEN. Porém, observação cuidadosa da forma empírica utilizada pode levantar dúvidas sobre a relação entre o modelo de HEIEN e o modelo empirico de markup.

Na equação (114) de GEORGE \& KING (p. 57), o preço ao varejo é realmente colocado com variável dependente do preço ao produtor, coerentemente com WAUGH e HEIEN. Entretanto, ao formularem a expressão da margem de comercialização -[equação (115), na p. 57 da publicação original], GEORGE \& KING colocam o preço ao varejo como variável explicativa. Essa formulação, que é utilizada por GEORGE \& KING e por todos os demais trabalhos aqui citados que estimaram o modelo de markup, podę ser consistente com diversas formas de determinação de preço (inclusive com a formação do preço ao nível de consumidor), não servindo como teste do modelo de HEIEN. Mais 'coerente seria a estimação do modelo apresentado por BARROS (1987, p.47), no qual a margem teria o preço ao produtor como variável explicativa.

O modelo relativo também apresenta-se pouco fundamentado teoricamente. Embora permita conclusões bastante próximas das advindas do modelo teórico de GARDNER, o modelo parte da forma implícita da demanda derivada pelo produto agrícola e não apresenta equações estruturais que permitiriam maior segurança quanto aos sinais esperados dos parâmetros da equação reduzida da margem.

41 Ver item 3.2. 
O modelo do custo de comercialização é consistente com a teoria econômica neoclássica; sendo a margem de comercializạ̧ão vista como o preço dos serviços de comercialização, em competição perfeita ela também seria igual ao custo marginal de se oferecer esses serviços. Entretanto, num ambiente de incerteza e onde os intermediários oferecem uma gama enorme de serviços, regras como a aplicação de markups parecem ser mais realistas, ao menos no curto prazo. Além disso, também neste modelo não existe clara definição de como as variáveis se relacionam no processo de formação da margem.

Dos aspectos levantados, pode-se concluir que os modelos utilizados apresentam algumas sérias deficiências que dificultam a interpretação dos resultados e a estruturação das relações entre as variáveis. Uma definição clara das relações contemporâneas entre as variáveis é de extrema importância na estruturação/identificação dos modelos econométricos, como se discutirá no capítulo 5 , além de permitir uma análise mais segura dos sinais esperados dos coeficientes estimados. Como isso não é proporcionado pelos modelos que vêm sendo estimados, desenvolver-se-á um modelo, no próximo capítulo, que se propõe a subsidiar mais claramente a análise empírica que será conduzida. 


\section{MODELO DINÂMICO}

\subsection{Aspectos gerais}

Modelos dinâmicos admitem a importância de valores defasados ou expectativas de valores futuros de uma ou mais variáveis na explicação da variável dependente. Uma forma de se considerar essa relação dinâmica foi utilizada por LYON \& THOMPSON, por meio do modelo de WOHLGENANT (1985), o qual considera que a margem, de comercialização depende da expectativa quanto ao valor do preço do produtor no período seguinte. Nesse item é exposto o modelo utilizado por LYON \& THOMPSON. No próximo item, apresentar-se-á um modelo alternativo.

A forma implícita do modelo utilizado por LYON \& THOMPSON é:

$$
M_{t}=f\left[P p_{b} E_{t}\left(P p_{t+1}\right), C_{i}, g\right]
$$

em que $\boldsymbol{M}_{\boldsymbol{t}}$ é a margem de comercialização produtor-varejo; $\boldsymbol{P} \boldsymbol{p}_{\mathrm{b}}$ o preço corrente ao produtor; $E_{t}\left(P p_{t+1}\right)$, a expectativa em $t$ do preço ao produtor em $t+1 ; C$, o custo de comercialização; $\boldsymbol{r}$, a taxa de juros; e $\boldsymbol{g}$, a razão: estoque desejado / vendas.

A expectativa do preço é incluída no modelo pela equação de previsão do preço. Como essa previsão é feita através de valores defasados do preço do produtor (os autores utilizam dados de outros estudos que mostram que 4 defasagens seriam significativas), a equação estimada por LYON \& THOMPSON é a seguinte:

$$
M_{t}=\beta_{0}+\sum_{k=0}^{4} \beta_{k+1} P p_{t-k}+\beta_{6} W_{t}+\beta_{7} D L O W+\varepsilon_{t}
$$


em que $\boldsymbol{M}_{\boldsymbol{t}}$ é a margem de comercialização produtor-varejo de leite fluido; $\boldsymbol{P} p_{t-k}$, o preço do leite ao produtor no mês $t-k(k=0,1,2,3,4) ; W_{t}$ o șalário médio por hora pago na indústria de processamento de leite (correspondente aos três períodos de agregação); DLOW, uma variável binária que assume valores 1 para o ano de 1988 e 0 para os demais (em 1988, houve redução significativa do preço mínimo federal de leite); e $\varepsilon_{p}$ o erro. No caso das especificações com dados trimestrais e semestrais, LYON \& THOMPSON utilizaram $k=2$ e $k=1$, respectivamente.

\subsection{Modelo.proposto}

O modelo que se propõe aqui é diferente do utilizado por LYON \& THOMPSON; baseia-se, essencialmente, nos modelos de HEIEN e de BARROS (1990). Utilizam-se apenas os niveis de produtor e varejo, enfatizando os ajustamentos parciais, os ajustamentos por excesso de demanda e a utilização do markup como "preço-meta" por parte dos agentes de comercialização. Os ajustamentos parciais e por excesso de demanda são formas de se admitir a existência de desequilíbrio nos mercado no curto prazo. 0 predomínio de situações de desequilíbrio é defendido por ECKSTEIN \& FROMM (1968), que argumentam que uma situação de contínuo equilíbrio (ou equilíbrio instantâneo, como preconizado no modelo de GARDNER), em que a produção iguala a oferta e a oferta iguala a demanda é "... possivelmente uma exceção. Desequilíbrio é a situação mais comum."(p. 1160).

A exposição que se segue inicia-se por um modelo no qual as variações de preços começam ao nível de produtor e são transmitidas ao varejo (item 4.2.1.). No item 4.2.2., apresentar-se-á um modelo no qual se admite que as variações de preços se iniciam ao varejo e são depois transmitidas ao produtor ${ }^{42}$.

42 BARROS \& AGUIAR (1994) discutem, também, algumas alternativas de margem num contexto semelhante. 


\subsubsection{Modelo com causalidade produtor $\rightarrow$ varejo}

A estrutura básica do modelo admite que as variações de preços se originam ao nível de produtor e são depois transmitidas, via ajustes parciais, até o varejo. Esses ajustes parciais levam a um "preço-meta" que corresponde à aplicação de um markup sobre o custo. As equações do modelo, apresentadas a seguir, colocam as quantidades em letras maiúsculas e os preços em letras minúsculas:

\section{Mercado varejista}

A demanda é suposta uma relação linear do preço ao varejo:

$$
V_{i}^{d}=\theta_{0}+\theta_{1} v_{i}, \quad \theta_{1}<0
$$

em que $V_{t}^{d}$ é a quantidade demandada ao varejo e $\boldsymbol{v}_{\boldsymbol{t}}$ é o preço ao varejo, ambos no instante $\boldsymbol{t}$.

Quanto à oferta, parte-se da pressuposição de que, no curto prazo, pouca flexibilidade existe na substituição entre os insumos. Admite-se, então, que o varejo opera com uma função de produção de proporções fixas (tipo Leontief):

$$
V=\min \left(\frac{P}{b_{1}}, \frac{Z}{b_{2}}\right),
$$

em que $V$ é a quantidade do produto final ao varejo, $\boldsymbol{P}$ é a quantidade de matéria-prima agrícola, $\boldsymbol{Z}$ é a quantidade de um agregado de insumos de comercialização (armazenamento, transporte, processamento etc.) e $\boldsymbol{b}_{1}$ e $\boldsymbol{b}_{2}$ são coeficientes técnicos de produção.

Admitindo-se, ainda, retornos constantes à escala, o custo total do mercado varejista no instante $\mathrm{t}$ é: $\boldsymbol{C}=\left(b_{1} p_{t}+b_{2} z_{t}\right) V_{t}^{s}$, em que $p_{t}$ e $z_{t}$ são os preços correntes da matéria-prima agrícola e do agregado de insumos de comercialização, respectivamente, e $V_{i}^{s}$ é a quantidade ofertada ao varejo. $O$ preço dos insumos de comercialização é exógeno. Como o custo marginal ao varejo é igual a $b_{1} p_{t}+b_{2} z_{t} 0$ preço de equilíbrio ao varejo será aquele que iguala o custo marginal: 


$$
v_{t}^{*}=b_{1} \mathrm{p}_{\mathrm{t}}+\mathrm{b}_{2} z_{t}
$$

A idéia de o preço de equilibrio ser um "preço-meta", apresentada por BARROS (1990), decorre da existência de incerteza, para o varejista, a respeito do caráter permanente da mudança ocorrida no preço ao produtor. Caso o varejista tivesse certeza da permanência da mudança no preço do produtor, ele imediatamente cobraria o "preço-meta"; como existe incerteza, o varejista ajusta seu preço, paulatinamente, em direção ao "preço-meta".

Dessa forma, o preço ao varejo ajusta-se por ajustamentos parciais:

$$
v_{t}-v_{t-1}=\alpha\left(v_{t}^{*}-v_{t-1}\right), \quad 0<\alpha<1 .
$$

O modelo supõe, também, que a oferta em dado período busca igualar a demanda verificada no período anterior:

$$
V_{t}^{s}=V_{t-1}{ }^{d}
$$

\section{Mercado ao nivel de produtor}

Admite-se que o mercado da matéria-prima agrícola seja um mercado competitivo, com seu preço se ajustando através de equações de excesso de demanda, ou seja, novamente admite-se a ocorrência de desequilibrio, entre oferta e demanda no curto prazo. A função de oferta é uma relação linear do preço ao produtor no período anterior e do preço (exógeno) corrente de um agregado de insumos agrícolas $\left(c_{t}\right)$ :

$$
P_{i}^{s}=\gamma_{0}+\gamma_{1} p_{t-1}+\gamma_{2} c_{t}, \quad \gamma_{1}>0 \text { e } \gamma_{2}<0
$$

A função de demanda ao produtor é uma demanda derivada, obtida pela multiplicação da oferta ao varejo do mesmo período pelo fator de equivalência:

$$
P_{t}^{d}=b_{1} V_{i}^{s}
$$

O ajustamento do preço ao produtor se dá por excesso de demanda:

$$
p_{t}-p_{t-1}=\rho\left(P_{t}^{d}-P_{t}^{s}\right), \quad \rho>0 .
$$


Trabalhando com essas equações estruturais, pode-se chegar às equações reduzidas do preço ao produtor e ao varejo e, conseqüentemente, à margem de comercialização.

\section{Equações reduzidas dos preços}

Das equações (88) e (86):

$$
P_{t}^{d}=b_{1} V_{t-1}^{d}
$$

Da equação (83):

$$
P_{t}^{d}=b_{1} \theta_{0}+b_{1} \theta_{1} v_{t-1}
$$

Substituindo-se as equações (90) e (87) na equação (89):

$$
p_{t}-p_{t-1}=\rho\left[\left(b_{1} \dot{\theta}_{0}+b_{1} \theta_{1} v_{t-1}\right)-\gamma_{0}-\gamma_{1} p_{t-1}-\gamma_{2} c_{t}\right]
$$

Isolando-se o preço corrente ao produtor:

$$
p_{t}=\rho\left(b_{1} \theta_{0}-\gamma_{0}\right)+\rho b_{1} \theta_{1} v_{t-1}+\left(1-\rho \gamma_{1}\right) p_{t-1}-\rho \gamma_{2} c_{t}
$$

A expressão (91) mostra que o preço ao produtor é positivamente afetado pelo preço do insumo agrícola e negativamente relacionado ao preço ao varejo defasado.

O preço ao varejo pode ser obtido pela substituição da equação (84) na equação (85):

$$
\begin{aligned}
& v_{t}-v_{t-1}=\alpha\left(b_{1} p_{t}+b_{2} z_{t}-v_{t-1}\right), \\
& v_{t}=\alpha b_{1} p_{t}+\alpha b_{2} z_{t}+(1-\alpha) v_{t-1} .
\end{aligned}
$$

Substituindo-se a equação (91) na (92):

$$
\begin{aligned}
v_{t}= & \alpha b_{1} \rho\left(b_{1} \theta_{0}-\gamma_{0}\right)+\left[\alpha b_{1}\left(\rho b_{1} \theta_{1}\right)+(1-\alpha)\right] v_{t-1}+ \\
& \alpha b_{1}\left(1-\rho \gamma_{1}\right) p_{t-1}-\alpha b_{1} \rho \dot{\gamma}_{2} c_{t}+\alpha b_{2} z_{t}
\end{aligned}
$$


A expressão (93) mostra que os sinais dos coeficientes dos preços defasados ao varejo e ao produtor dependem dos valores dos parâmetros, sendo positivos os sinais dos coeficientes do insumo agrícola e do custo de comercialização. Dessa forma, aumento nos preços do insumo agrícola e do insumo de comercialização tende a aumentar o preço ao varejo no mesmo mês.

\section{Margem de comercialização}

No capítulo 1, a margem de comercialização foi definida como a diferença de preços de quantidades equivalentes em diferentes níveis de mercado, ou seja, utilizando-se a notação do modelo dinâmico, a margem pode ser descrita como: $\boldsymbol{M}_{\boldsymbol{t}}=\boldsymbol{v}_{\boldsymbol{t}}$ $b_{1} p_{t}$. Das equações (91) e (93):

$$
\begin{aligned}
M_{t}= & (\alpha-1) b_{1} \rho\left(b_{1} \theta_{0}-\gamma_{0}\right)+\left[(\alpha-1) \rho\left(b_{1}\right)^{2} \theta_{1}+(1-\alpha)\right] v_{l-1}+ \\
& b_{1}(\alpha-1)\left(1-\rho \gamma_{1}\right) p_{t-1}+(1-\alpha) b_{1} \rho \gamma_{2} c_{t}+\alpha b_{2} z_{l} .
\end{aligned}
$$

Fazendo-se:

$k_{0}=b_{1}(\alpha-1) \rho\left(b_{1} \theta_{0}-\gamma_{0}\right)$

$k_{1}=(\alpha-1) \rho\left(b_{1}\right)^{2} \bar{\theta}_{1}+(1-\alpha)$;

$k_{2}=b_{1}(\alpha-1)\left(1-\rho \gamma_{1}\right)$

$k_{3}=(1-\alpha) b_{1} \rho \gamma_{2}$

tem-se:

$$
M_{t}=k_{0}+k_{1} v_{t-1}+k_{2} p_{t-1}+k_{3} c_{t}+\alpha b_{2} z_{t}
$$

A equação (94') é a forma a ser estimada para representar a margem de comercialização, estando em negrito as variáveis envolvidas na estimação. Dados os sinais de seus componentes, $\boldsymbol{k}_{\boldsymbol{1}}$ tende a ser positivo, mostrando que, quanto maior $o$ preço ao varejo, maior deve ser a margem de comercialização no período seguinte. $\mathbf{O}$ coeficiente do preço ao produtor defasado, $k_{2}$, será negativo se $\left(\rho \gamma_{1}\right)<1$ e positivo em caso contrário. $\mathrm{O}$ insumo de comercialização deve ter coeficiente positivo, dados os si- 
nais pressupostos dos componentes de seu coeficiente nas equações básicas. 0 coeficiente do insumo agrícola, $\boldsymbol{k}_{3}$, deve ser negativo, de forma que, quanto maior for 0 preço deste insumo, menor tende a ser a margem de comercialização.

\section{Impacto dinâmico}

Embora não permitam verificar a estrutura de funcionamento do mercado, as formas reduzidas do modelo são mais convenientes para se mensurar o impacto de mudanças nas variáveis exógenas sobre as endógenas. THEIL (1971, p. 463-468) apresenta ainda uma terceira forma, além da estrutural e da reduzida, denominada forma final, que seria mais adequada para mensurar o efeito dos choques nas variáveis exógenas, por ter as variáveis endógenas como função apenas das variáveis exógenas correntes e defasadas.

Para se chegar à forma final, parte-se das equações reduzidas dos preços ao produtor e ao varejo e da margem de comercialização, apresentadas anteriormente como equações (91), (93) e (94):

$$
\begin{aligned}
p_{t}= & \rho\left(b_{1} \theta_{0}-\gamma_{0}\right)+\rho b_{1} \theta_{1} v_{t-1}+\left(1-\rho \gamma_{1}\right) p_{t-1}-\rho \gamma_{2} c_{t} \\
v_{t}= & \alpha b_{1} \rho\left(b_{1} \theta_{0}-\gamma_{0}\right)+\left[\alpha b_{1}\left(\rho b_{1} \theta_{1}\right)+(1-\alpha)\right] v_{t-1}+ \\
& \alpha b_{1}\left(1-\rho \gamma_{1}\right) p_{t-1}-\alpha b_{1} \rho \gamma_{2} c_{t}+\alpha b_{2} z_{t} \\
M_{t}= & (\alpha-1) b_{1} \rho\left(b_{1} \theta_{0}-\gamma_{0}\right)+\left[(\alpha-1) \rho\left(b_{1}\right)^{2} \theta_{1}+(1-\alpha)\right] v_{t-1}+ \\
& b_{1}(\alpha-1)\left(1-\rho \gamma_{1}\right) p_{t-1}+(1-\alpha) b_{1} \rho \gamma_{2} c_{t}+\alpha b_{2} z_{t} .
\end{aligned}
$$

As variáveis e os coeficientes desse sistema de equações reduzidas podem ser agrupados em vetores e matrizes da seguinte forma: 
$w_{t}=\left[\begin{array}{c}p_{t} \\ v_{t} \\ M_{t}\end{array}\right] \quad x_{t}=\left[\begin{array}{l}c_{t} \\ z_{t}\end{array}\right] \quad d_{0}=\left[\begin{array}{c}\rho\left(b_{1} \theta_{0}-\gamma_{0}\right) \\ \alpha b_{1} \rho\left(b_{1} \theta_{0}-\gamma_{0}\right) \\ (\alpha-1) b_{1} \rho\left(b_{1} \theta_{0}-\gamma_{0}\right)\end{array}\right]$

$D_{1}=\left[\begin{array}{ccc}\left(1-\rho \gamma_{1}\right) & \rho b_{1} \theta_{1} & 0 \\ \alpha b_{1}\left(1-\rho \gamma_{1}\right) & {\left[\alpha b_{1}\left(\rho b_{1} \theta_{1}\right)+(1-\alpha)\right]} & 0 \\ b_{1}(\alpha-1)\left(1-\rho \gamma_{1}\right) & {\left[(\alpha-1) \rho b_{1}^{2} \theta_{1}+(1-\alpha)\right]} & 0\end{array}\right] \quad D_{2}=\left[\begin{array}{cc}-\rho \gamma_{2} & 0 \\ -\alpha b_{1} \rho \gamma_{2} & \alpha b_{2} \\ (1-\alpha) b_{1} \rho \gamma_{2} & \alpha b_{2}\end{array}\right]$

Sendo essas as matrizes e os vetores, o sistema formado pelas três equações reduzidas pode ser representado pela equação:

$$
w_{t}=d_{0}+D_{1} w_{t-1}+D_{2} x_{t}+\varepsilon_{p}
$$

em que $\varepsilon_{t}$ é o vetor de desvios das equações reduzidas, incluído na forma a ser estimada.

Partindo da equação anterior, pode-se defasar $w_{t}$ e substituir o resultado no lado direito dessa equação:

$$
\begin{aligned}
w_{t} & =d_{0}+D_{1}\left(d_{0}+D_{1} w_{t-2}+D_{2} x_{t-1}+\varepsilon_{t-1}\right)+D_{2} x_{t}+\varepsilon_{t} \\
& =\left(I+D_{1}\right) d_{0}+D_{1}^{2} w_{t-2}+D_{2} x_{t}+D_{1} D_{2} x_{t-1}+\varepsilon_{t}+D_{1} \varepsilon_{t-1}
\end{aligned}
$$

A condição necessária e suficiente para convergência do modelo, ou seja, para que $D_{1}{ }^{s}$ se aproxime de uma matriz nula à medida que $s$ aumenta, é que todas as raízes características da matriz $\mathrm{D}_{1}$ estejam dentro do círculo unitário (THEIL, p. 464). As estimativas dos parâmetros de $D_{1}$ podem ser utilizadas na verificação da convergência ${ }^{43}$.

- Substituindo, continuamente, os valores defasados de $w$, chega-se à forma final, que relaciona o vetor de variáveis endógenas apenas às variações nas variáveis exógenas:

43 CHIANG (1982, p. 297) mostra como calcular as raizes características de uma matriz. 


$$
w_{t}=\left(I-D_{1}\right)^{-1} d_{0}+D_{2} x_{t}+\sum_{j=1}^{\infty} D_{1}^{j-1} D_{1} D_{2} x_{t-j}+\sum_{j=0}^{\infty} D_{1}^{j} \varepsilon_{t-j} .
$$

Os multiplicadores de impacto, que mostram em quantos cruzeiros reais variam as variáveis endógenas em decorrência de uma variação de um cruzeiro real nas variáveis exógenas, são dados pelas matrizes de coeficientes da forma final. Assim, o efeito imediato é dado pela primeira matriz de coeficientes: $\boldsymbol{D}_{\mathbf{2}}$; o efeito com defasagem de um período é dado por $D_{1} D_{2}$; o efeito com defasagem de 2 períodos é dado por $\mathbf{D}_{1}{ }^{2} \mathbf{D}_{2}$; o efeito com defasagem $k$ é igual a $\mathbf{D}_{1}{ }^{k} \mathbf{D}_{2} ;$ e o efeito total é dado por $\left(I-D_{1}\right)^{-1} D_{2}$.

\subsubsection{Modelo com causalidade varejo $\rightarrow$ produtor}

Agora, admite-se que o preço varia inicialmente no varejo, mediante equação de excesso de demanda, e que essa variação é transmitida ao produtor via ajustes parciais, até atingir um "preço-meta" que seria o preço de equilíbrio em competição perfeita. Também admite-se que o varejo opera com uma função de produção de proporções fixas (tipo Leontief): $V=\min \left\{\left(P / b_{1}\right),\left(Z / b_{2}\right)\right\}$. Mantendo sempre que possível as notações do modelo apresentado anteriormente, as demais equações do modelo são:

\section{Mercado varejista}

A demanda é suposta uma relação linear do preço ao varejo:

$$
V_{t}^{d}=\theta_{0}+\theta_{1} v_{t} \quad \theta_{1}<0
$$

A oferta no varejo relaciona-se à oferta agrícola através do coeficiente técnico de produção:

$$
V_{l}^{s}=\frac{P_{1}^{s}}{b_{1}}
$$

O ajustamento do preço ao varejo se dá por excesso de demanda: 


$$
v_{t}-v_{t-1}=\rho\left(V_{t}^{d}-V_{t}^{s}\right), \quad \rho>0 .
$$

\section{Mercado ao nivel de produtor}

A oferta ao nível de produtor é suposta a mesma do modelo anterior: uma relação linear do preço ao produtor no período anterior e do preço (exógeno) corrente de um agregado de insumos agrícolas $\left(c_{t}\right)$ :

$$
P_{t}^{s}=\gamma_{0}+\gamma_{1} p_{t-1}+\gamma_{2} c_{t}, \quad \gamma_{1}>0 \text { e } \gamma_{2}<0 .
$$

O "preço-meta" ao produtor é suposto aquele que leva o mercado varejista ao equilibrio em competição perfeita, ou seja, é aquele que ocorre quando o varejo iguala seu custo marginal ao preço. Essa igualdade seria:

$$
C M a=b_{1} p_{t}^{*}+b_{2} z_{t}=v_{t}
$$

em que $p_{t}^{*}$ é o "preço-meta" do produtor e $C M a$ é o custo marginal do varejista. Rearranjando os termos, tem-se:

$$
p_{t}^{*}=\frac{v_{t}-b_{2} z_{t}}{b_{1}}
$$

O ajuste do preço ao produtor se dá por ajustamentos parciais:

$$
p_{t}-p_{t-1}=\alpha\left(p_{t}^{*}-p_{t-1}\right), \quad 0<\alpha<1 .
$$

\section{Equações reduzidas dos preços}

Substituindo a equação (99) na (100):

$$
p_{\imath}=\frac{\alpha}{b_{1}} v_{\imath}+(1-\alpha) p_{t-1}-\frac{\alpha b_{2}}{b_{1}} z_{\imath} \text {. }
$$

A expressão (101) mostra que o preço ao produtor se encontra positivamente relacionado com seu valor defasado e com o preço ao varejo, e negativamente relacionado com o preço dos insumos de comercialização. Como o preço 
se forma ao varejo, aumento do preço dos insumos de comercialização tende a deprimir o preço ao produtor.

Substituindo a equação (98) na equação (96), chega-se à equação da oferta ao varejo. Substituindo essa equação e a equação da demanda (95) em (97), temse:

$$
v_{t}=\frac{\rho\left(\theta_{0} b_{1}-\gamma_{0}\right)}{b_{1}\left(1-\rho \theta_{1}\right)}+\frac{1}{1-\rho \theta_{1}} v_{t-1}-\frac{\rho \gamma_{1}}{b_{1}\left(1-\rho \theta_{1}\right)} p_{t-1}-\frac{\rho \gamma_{2}}{b_{1}\left(1-\rho \theta_{1}\right)} c_{t}
$$

A expressão (102) mostra que aumento no preço do insumo agrícola aumenta o preço ao varejo, em decorrência de menor oferta (agrícola e no varejo). Embora o preço do insumo agrícola afete, inicialmente, a oferta agrícola, o preço agrícola só se altera após a mudança no preço ao varejo.

Substituindo a equação (102), que já é a equação reduzida do preço ao varejo, na equação (101), chega-se à equação reduzida do preço ao produtor:

$$
\begin{aligned}
p_{t}= & \frac{\alpha \rho\left(\theta_{0} b_{1}-\gamma_{0}\right)}{b_{1}^{2}\left(1-\rho \theta_{1}\right)}+\frac{\alpha}{b_{1}\left(1-\rho \theta_{1}\right)} v_{t-1}+\left[(1-\alpha)-\frac{\alpha \rho \gamma_{1}}{b_{1}^{2}\left(1-\rho \theta_{1}\right)}\right] p_{t-1}- \\
& \frac{\alpha \rho \gamma_{2}}{b_{1}^{2}\left(1-\rho \theta_{1}\right)} c_{t}-\frac{\alpha b_{2}}{b_{1}} z_{t} .
\end{aligned}
$$

\section{Margem de comercialização}

A margem é dada por $M_{t}=v_{t}-b_{1} p_{t}$. Dessa forma, substituindo as equações (102) e (10̣) nesta última, obtém-se a equação reduzida da margem de comercialização:

$$
\begin{aligned}
M_{t}= & \frac{\rho(1-\alpha)\left(\theta_{0} b_{1}-\gamma_{0}\right)}{b_{1}\left(1-\rho \theta_{1}\right)}+\frac{1-\alpha}{1-\rho \theta_{1}} v_{t-1}+\frac{(\alpha-1)\left[b_{1} \rho \gamma_{1}+b_{1}^{3}\left(1-\rho \theta_{1}\right)\right]}{b_{1}^{2}\left(1-\rho \theta_{1}\right)} p_{t-1}+ \\
& \frac{(\alpha-1) \rho \gamma_{2}}{b_{1}\left(1-\rho \theta_{1}\right)} c_{t}+\alpha b_{2} z_{t} .
\end{aligned}
$$

Para simplificar, pode-se definir: 
$N_{0}=N_{1} \frac{\rho\left(\theta_{0} b_{1}-\gamma_{0}\right)}{b_{1}}$

$N_{1}=\frac{1-\alpha}{1-\rho \theta_{1}}$

$N_{2}=-N_{1} \frac{b_{1} \rho \gamma_{1}+b_{1}^{3}\left(1-\rho \theta_{1}\right)}{b_{1}^{2}}$

$N_{3}=-N_{1} \frac{-1}{\rho \hat{y_{2}}}$

A equação a ser estimada para representar a margem de comercialização utiliza as mesmas variáveis que foram utilizadas na equação (94'):

$$
\boldsymbol{M}_{t}=N_{0}+N_{1} \boldsymbol{v}_{t-1}+N_{2} \boldsymbol{p}_{t-1}+N_{3} \boldsymbol{c}_{t}+\alpha b_{2} z_{t}
$$

O sinal esperado para o impacto do custo de comercialização sobre a margem de comercialização é o mesmo do modelo com causalidade produtor $\rightarrow$ varejo: positivo. No entanto, o sinal do coeficiente do preço do insumo agrícola é inverso; aumẹnto no preço do insumo agrícola agora aumenta a margem de comercialização (já que, num primeiro momento, esse efeito repercute na oferta agrícola e na oferta e preço ao varejo). Os sinais dos coeficientes dos preços defasados não podem ser antecipados; podem ser positivos ou negativos, dependendo dos sinais dos parâmetros que os compõem.

\section{Impacto dinâmico}

A análise dos multiplicadores de impacto no modelo de causalidade varejo $\rightarrow$ produtor pode ser feita de maneira análoga à apresentada para o modelo anterior. Utilizam-se, agora, as equações (102), (103) e (104), para compor a forma final do sistema. Os vetores e matrizes que compõem o sistema são: 


$$
\begin{aligned}
& w_{t}=\left[\begin{array}{c}
p_{t} \\
v_{t} \\
M_{t}
\end{array}\right] \quad x_{t}=\left[\begin{array}{c}
c_{t} \\
z_{t}
\end{array}\right] \quad d_{0}=\left[\begin{array}{c}
\alpha \rho\left(\theta_{0} b_{1}-\gamma_{0}\right) / b_{1}^{2}\left(1-\rho \theta_{1}\right) \\
\rho\left(\theta_{0} b_{1}-\gamma_{0}\right) / b_{1}\left(1-\rho \theta_{1}\right) \\
\rho(1-\alpha)\left(\theta_{0} b_{1}-\gamma_{0}\right) / b_{1}\left(1-\rho \theta_{1}\right)
\end{array}\right] \\
& D_{1}=\left[\begin{array}{ccc}
(1-\alpha)-\left(\alpha \rho \gamma_{1} / b_{1}^{2}\left(1-\rho \theta_{1}\right)\right. & \left(\alpha / b_{1}\left(1-\rho \theta_{1}\right)\right. & 0 \\
-\left(\rho \gamma_{1} / b_{1}\left(1-\rho \theta_{1}\right)\right) & \left(1 /\left(1-\rho \theta_{1}\right)\right) & 0 \\
\left([\alpha-1]\left[b_{1} \rho \gamma_{1}+b_{1}^{3}\left(1-\rho \theta_{1}\right)\right] / b_{1}^{2}\left(1-\rho \theta_{1}\right)\right. & \left((1-\alpha) /\left(1-\rho \theta_{1}\right)\right) & 0
\end{array}\right] \\
& D_{2}=\left[\begin{array}{cc}
-\left(\alpha \rho \gamma_{2} / b_{1}^{2}\left(1-\rho \theta_{1}\right)\right. & -\left(\alpha b_{2} / b_{1}\right) \\
-\left(\rho \gamma_{2} / b_{1}\left(1-\rho \theta_{1}\right)\right. & 0 \\
\left((\alpha-1) \rho \gamma_{2} / b_{1}\left(1-\rho \theta_{1}\right)\right. & \alpha b_{2}
\end{array}\right]
\end{aligned}
$$

Sendo essas as matrizes e vetores, o sistema formado pelas três equações reduzidas pode ser representado pela equação:

$$
w_{t}=d_{0}+D_{1} w_{t-1}+D_{2} x_{t}+\varepsilon_{t}
$$

em que $\varepsilon_{t}$ é o vetor de desvios das equações reduzidas, incluído na forma a ser estimada.

As raízes características de $\mathbf{D}_{1}$ precisam também estar dentro do círculo unitário para que haja convergência dinâmica do sistema, o que pode ser testado a partir dos parâmetros de $\mathbf{D}_{1}$ estimados.

O procedimento para se chegar à forma final, já apresentado no modelo de causalidade produtor $\rightarrow$ varejo, consiste na substituição sucessiva da variável endógena defasada no lado direito da equação. Da mesma maneira, os impactos são os seguintes: o efeito imediato é dado pela primeira matriz de coeficientes, $D_{2}$; o efeito com defasagem 
de um período é dado por $D_{1} D_{2}$; o efeito com defasagem de 2 períodos é dado por $\mathbf{D}_{1}{ }^{2} \mathbf{D}_{2}$; o efeito com defasagem $k$ é igual a $\mathbf{D}_{1}{ }^{k} \mathbf{D}_{2}$; e o ofeito total é dado por ( $\boldsymbol{I}-$ $\left.D_{1}\right)^{-1} D_{2}$.

\subsection{O modelo dinâmico e os mercados de arroz e de feijão}

O objetivo do desenvolvimento do modelo dinâmico, com suas possibilidades de sentido de causalidade entre os preços, é buscar instrumentos para melhor compreensão dos mercados estudados. Sendo assim, é importante levantar alguns aspectos que permitam enquadrar os mercado de arroz e de feijão no arcabouço do modelo.

O mercado de feijão tem pelo menos três safras anuais dispersas geograficamente e com grande importância da produção de pequena escala. Esse fato, na linha de raciocínio de ECKSTEIN \& FROMM, permite deduzir que os varejistas de feijão teriam dificuldade para conhecer com precisão a oferta do produto nos locais de produção. Soma-se ainda o fato de que o produto é de mais dificil estocagem e não possui um mercado internacional dinâmico, com produtos de qualidade comparável à do consumido domesticamente. Assim, os intermediários de feijão tenderiam a acompanhar o desenvolvimento do mercado em nível de produção (onde, muitas vezes, têm seus representantes). Sob o ponto de vista de formação de preços, esses argumentos levam a assumir que o mercado de feijão comporta-se como o modelo dinâmico com causalidade produtor $\rightarrow$ varejo, ou seja, o nível de produtor teria um papel mais ativo na formação do preço.

Numa situação oposta encontra-se o mercado de arroz. Sendo produzido em áreas mais definidas, por produtores de maior porte do que os de feijão (em geral) e sendo mais facilmente armazenável, o arroz permitiria aos intermediários desse mercado maior segurança quanto à disponibilidade do produto. Também ter-se-ia um mercado internacional de acesso mais fácil e com produto de maior semelhança ao consumido internamente do que se verifica no mercado de feijão. Esses argumentos permitem supor que o setor de intermediação poderia iniciar as variações de preço no mercado de arroz que funcionaria de forma semelhante ao modelo dinâmico com causalidade varejo $\rightarrow$ produtor. 


\section{DADOS E PROCEDIMENTOS}

A exposição dos modelos teóricos e das especificações empíricas utilizadas em diversos trabalhos de pesquisa, bem como do modelo dinâmico proposto, permite que se relacionem agora as principais questões que se pretende analisar no estudo empírico dos mercados de feijão e de arroz. Essas questões são:

a) Qual é a teoria que explica a formação da margem de comercialização em cada um dos mercados? Para responder a essa questão, são estimadas equações dos principais modelos empíricos para os dois mercados e são feitos testes de qualidade de ajustamento, para verificar se existe um (ou mais) modelo(s) que se ajusta(m) melhor a cada mercado. Como se mostrou nos capítulos anteriores, as especificações empíricas são desenvolvidas a partir de algumas pressuposições quanto à maneira de funcionamento do mercado. Essas pressuposições são, em maior ou menor grau, embasadas na teoria econômica. Definido o modelo empírico, se estará aceitando que o mercado funciona da forma preconizada por este modelo e se estará compreendendo melhor a formação da margem de comercialização no mercado de cada produto.

b) Qual é a importância do risco de preço na formação da margem e como o setor de comercialização se comporta diante desse risco? Existem elementos, já apresentados no capítulo 1, que permitem supor que o mercado de feijão é mais afetado que o de arroz pelo risco de variação de preço; as especificações empíricas permitirão o teste dessa hipótese. Além do mais, o sinal do coeficiente da variável risco, caso não nulo, permitirá que se confirme ou não a hipótese teórica de que os intermediários são avessos ao risco. Caso o risco esteja positivamente relacionado com a margem de comercialização, medidas que diminuam a variabilidade dos preços seriam desejáveis sob o ponto de vista de redução do custo de comercialização. 
c) Como os demais componentes do custo de comercialização afetam a margem? Os coeficientes dos demais elementos do custo de comercialização (óleo diesel, saláriomínimo e taxa real de juros) permitirão verificar se esses elementos são importantes na explicação da margem de comercialização. Como as variáveis utilizadas são proxies do custo de determinadas atividades de comercialização, a significância dessas variáveis mostrará quais atividades são mais importantes em cada um dos mercados. Isto permitirá inferir quais medidas poderiam ser adotadas em relação a esses insumos, para que a grandeza da margem de comercialização seja reduzida.

d) Como a margem, o risco e os preços dos insumos se relacionam ao longo do tempo? A análise dinâmica, através dos multiplicadores de THEIL e dos modelos de auto-regressão vetorial, revelará o comportamento e a inter-relação das variáveis no decorrer do período de tempo. Permitirá que se verifique se o ajustamento do mercado não modifica o efeito de uma variável sobre as demais. Mais particularmente, permitirá que se certifique se os elementos de custo de comercialização impactam da mesma forma a margem durante todo o período em que o mercado se ajusta.

e) Dados os impactos dos preços dos elementos do custo de comercialização e dos preços ao varejo e ao produtor, as variações da margem de comercialização estariam mais relacionadas com choques nos preços dos insumos de comercialização ou com choques de oferta agrícola e demanda primária?

Levantadas essas questões, cabe agora detalhar os dados utilizados e os procedimentos de estimação das equações e de teste das hipóteses levantadas.

\subsection{Dados}

\section{Feijão}

O mercado varejista de feijão considerado foi a cidade de São Paulo, maior centro consumidor do Brasil. $O$ produto consumido em São Paulo é predominantemente da variedade "carioca". A série de dados de preços ao varejo foi obtida junto ao Instituto de Economia Agrícola (IEA) da Secretaria de Agricultura do Governo do 
Estado de São Paulo, para os anos de 1989 a 1993, e a SANTIAGO (1990), para os anos de 1975 a 1988. A série utilizada envolve dados mensais de janeiro de 1975 a julho de 1993. Esses dados foram deflacionados pelo Índice Geral de Preços - Disponibilidade Interna (IGP-DI) da Fundação Getúlio Vargas (FGV).

Os preços ao nível de produtor utilizados foram os preços médios mensais do Estado de São Paulo, também coletados e divulgados pelo IEA e por SANTIAGO. A série envolve o mesmo período e também foi deflacionada pelo IGP-DI. A série de quantidade produzida anualmente no Brasil é composta por dados apresentados por SILVA (1990), para o período 1975-1988, e por dados da Companhia Nacional de Abastecimento (CONAB) do Ministério da Agricultura e Reforma Agrária, para o período 1989-92. Na composição dos dados anuais de margens e preços, calculou-se a média aritmética dos doze meses de cada ano; para 1993, a média envolveu apenas os meses para os quais havia dados disponíveis.

Em razão da indisponibilidade de estudos sobre perdas de comercialização de feijão, atribuiu-se arbitrariamente o seguinte coeficiente de quantidade-equivalente: 1,1 $\mathrm{kg}$ de feijão ao nível de produtor originando $1 \mathrm{~kg}$ de feijão ao varejo.

\section{Arroz}

Também utilizaram-se a cidade de São Paulo como centro varejista e os preços médios do estado como representativos dos preços ao nível de produtor. $\mathrm{O}$ período coberto foi janeiro de 1975 a agosto de 1993. A fonte de dados foi o IEA e SANTIAGO, não havendo distinção entre arroz irrigado e "de sequeiro". Os dados foram deflacionados pelo IGP-DI da FGV.

- Também no caso do arroz, a série de quantidade produzida anualmente para o Brasil foi composta por dados apresentados por SILVA, para o período 19751988, e por dados da CONAB, para o período 1989-92. Os dados anuais de preços e margem foram compostos pelas média aritmética dos meses de cada ano.

A quantidade-equivalente utilizada na composição da margem de comercialização do arroz foi a calculada por CANTO (1986): 1,428 kg de arroz em casca 
para $1 \mathrm{~kg}$ de arroz beneficiado; resulta ainda, como subproduto, a casca do arroz, que é excluída dos cálculos pela indisponibilidade de dados menșais de preços desse subproduto e por sua pequena importância em relação ao valor do arroz.

\section{Insumos de comercialização}

Os insumos utilizados são: óleo diesel, representando o custo de transporte; taxa de juros real, representando o custo de armazenamento; e saláriomínimo, como uma proxy do custo de mão-de-obra incorrido durante as diversas atividades de comercialização. As fontes de dados foram: FGV, para salário-mínimo; IEA, para preço do óleo diesel; e TAXA DE JUROS DO BRASIL (1992), para a taxa de juros real. A taxa de juros utilizada é o custo real efetivo do financiamento do capital de giro (pagamento em 6 meses) cobrado pelas instituições financeiras. O período de todas as séries foi de janeiro de 1975 a agosto de 1993, com exceção da taxa de juros que cobre o período de janeiro de 1975 a março de 1993.

\section{Insumos de produção agrícolă}

Formulou-se um índice que incluía apenas fertilizantes; embora este item não represente a maior parte do custo de comercialização dos produtores de feijão e de arroz, ele é importante indicador levado em conta pelos agricultores no acompanhamento da evolução do custo de produção agrícola. Na construção do índice, levaram-se em conta três fertilizantes que equivalem à maior parte dos produtos utilizados isoladamente ou em misturas: superfosfato simples ( $18 \%$ de $\left.\mathrm{P}_{2} \mathrm{O}_{5}\right)$, sulfato de amônia $(20 \%$ de $\mathrm{N})$ e cloreto de potássio $\left(60 \%\right.$ de $\left.\mathrm{K}_{2} \mathrm{O}\right) \mathrm{O}$ consumo de nutrientes no Brasil, em 1990 (ANDA, 1991), foi convertido em consumo desses fertilizantes, do que resultou: $3.896 .575 \mathrm{t}$ de sulfato de amônia, $6.587 .739 \mathrm{t}$ de superfosfato simples e $1.976 .322 \mathrm{t}$ de cloreto de potássio. $\mathrm{O}$ índice foi ponderado da seguinte forma: 0,3127 x $\mathbf{P}_{\mathbf{S A}}+\mathbf{0 , 5 2 8 7} \times \mathbf{P}_{\mathrm{SS}}+$ $\mathbf{0 , 1 5 8 6} \times \mathbf{P}_{\mathbf{C P}}$, em que $\mathbf{P}_{\mathbf{S A}}$ é o preço mensal da tonelada de sulfato de amônia; $\mathbf{P}_{\mathbf{S S}}, \mathrm{o}$ preço mensal da tonelada de superfosfato simples; e $\mathbf{P}_{\mathbf{C P}}$, o preço mensal da tonelada de cloreto de potássio. $O$ fator de ponderação de cada fertilizante é a razão entre a 
quantidade que teria sido utilizada desse produto e o total que teria sido utilizado dos três fertilizantes no ano de 1990.

Os preços utilizados na formação da série do índice são os preços médios pagos pelos agricultores do Estado de São Paulo, obtidos em SANTIAGO e IEA; a série foi deflacionada pelo IGP-DI da FGV.

\section{Risco}

Diversas formas de se mensurar o risco são encontradas na literatura. Grosso modo, elas consistem em alguma medida de defasagem distribuída ou médiamóvel da variabilidade dos preços passados. Neste trabalho utilizam-se duas formas alternativas, uma que envolve 12 meses e outra que envolve 4 meses, conforme foi feito por FAMINOW \& LAUBSCHER.

$\mathrm{Na}$ construção da variável risco com 12 meses, FAMINOW \& LAUBSCHER utilizaram o procedimento de BRORSEN et al.. Pressupõe-se que a percepção do risco se dá através de uma média-móvel ponderada do valor absoluto das variações do preço, da seguinte forma:

$$
R=\frac{12 \Delta p_{t}+11 \Delta p_{t-1}+10 \Delta p_{t-2}+\ldots+1 \Delta p_{t-11}}{78}
$$

em que $R$ é a variável risco, $p$ é o preço e $\Delta \Delta_{i}=\left|p_{i}-p_{i-1}\right|$, ou seja, é o valor absolutó da diferença consecutiva dos preços. A soma é dividida por 78 , para se ter a média ponderada, já que $1+2+\ldots+12=78$.

Outra forma, mais adequada para produtos que permanecem pouco tempo armazenado (como o feijão), envolve a média-móvel ponderada de quatro meses (FAMINOW \& LAUBSCHER):

$$
R=0,4 \Delta p_{t}+0,3 \Delta p_{t-1}+0,2 \Delta p_{t-2}+0,1 \Delta p_{t-3},
$$

em que as variáveis são as mesmas definidas na equação anterior. 
Os preços utilizados na construção da variável risco foram os preços ao varejo (da cidade de São Paulo, publicados por IEA e SANTIAGO), conforme preconizado no modelo de BRORSEN et al.

\subsection{Procedimentos}

Partindo-se dos modelos apresentados, a diferença que existe entre as formulações teóricas e as equações a ser estimadas neste trabalho é a segmentação da variável custo de comercialização. Enquanto o custo de comercialização era representado por uma única variável na maioria dos modelos (por exemplo, $\boldsymbol{z}$, no modelo dinâmico), nas formas estimadas com dados mensais o custo é segmentado em, salário-mínimo, preço do óleo diesel, taxa real de juros e risco de preço. O risco é visto nos modelos como um "insumo" a ser "comprado" pelos varejistas 44.

A análise empírica ${ }^{45}$ divide-se em três fases: (1) comparação entre especificações alternativas de modelos de margem de comercialização; (2) análise da importância estática do risco e das variáveis de custo sobre a margem de comercialização; e (3) análise dinâmica da margem de comercialização. Nos itens seguintes, expõem-se, separadamente, as três fases citadas.

\subsubsection{Comparaç̃o entre modelos alternativos}

Os principais modelos empíricos de margem que vêm sendo testados são aqueles expostos no capítulo 3 . Os modelos que serão estimados nessa pesquisa são o de markup, o relativo, o de custo de comercialização e o dinâmico; o modelo de BUSE \& BRANDOW não será estimado, por se considerar que ele representa um caso especial do modelo relativo. As variáveis exógenas envolvidas (a variável endógena é a margem de

44 Essencialmente, BRORSEN et al. também incorporaram o risco como custo por meio da inclusão do preço esperado e de scu desvio-padrăo na equaçĩo de oferta sob risco. Maior risco (assim como maior custo) implicava menor oferta e maior prę̧o ao varejo (para dada demanda). Assim como em BRORSEN et al., aqui se assume que os agentes de comercialização são avessos ao risco.

45 A análise econométrica é desenvolvida pelo software RATS (Regression Analysis of Time Series). 
comercialização produtor-varejo) são: o preço ao varejo, o preço ao produtor (utilizado apenas no modelo dinâmico), o custo de comercialização (preço dos insumos de comercialização, incluindo o risco de preço), o custo agrícola (índice de preços de fertilizantes) e a quantidade (produzida ou comercializada). Essa última variável impõe restrição ao procedimento aqui adotado: não existe disponibilidade de dados mensais de quantidades comercializadas de feijão e arroz (tanto para São Paulo como para o Brasil); existern apcenas dados anuais de produção para o Brasil. Dessa forma, parte da análise é feita com dados agregados anualmente. O modelo de markuı e o modelo dinâmico, por não possuírem a quantidade entre suas variáveis explicativas, são os únicos que admitem comparação com dados mensais.

As variáveis utilizadas nas estimações com dados anuais são as seguintes: $\boldsymbol{M}_{\boldsymbol{r}}$ a margem de comercialização produtor-varejo do produto (feijão e arroz); $\boldsymbol{P}_{\boldsymbol{p}} \mathbf{o}$ preço ao varejo no ano $t ; \boldsymbol{P} p_{p}$ o preço ao produtor no ano $t ; Q_{b}$ a quantidade produzida de feijão ou arroz no ano $t ; S M_{b}$ o salário-mínimo médio do ano $t ; c_{t}$ o índice de preços de fertilizantes no ano $t$; e $\varepsilon_{p}$ o erro. As equações a serem estimadas são as seguintes:

- Modelo de Markup:

$M_{t}=\beta_{0}+\beta_{1} P v_{t}+\beta_{2} M_{t}+\varepsilon_{t}$

- Modelo Relativo:

$M_{t}=\beta_{1} P v_{t}+\beta_{2}\left(P v_{t} Q_{t}\right)+\beta_{3} S M_{t}+\varepsilon_{t}$

- Modelo do Custo de Comercialização:

$M_{t}=\beta_{0}+\beta_{1} Q_{t}+\beta_{2} S M_{t}+\varepsilon_{r}$

J - Modelo Dinâmico:

$$
M_{t}=\beta_{0}+\beta_{1} P v_{t-1}+\beta_{2} P p_{t-1}+\beta_{3^{2}} S M_{t}+\beta_{4} c_{t}+\varepsilon_{t}
$$

O uso do salário isoladamente, como representante do custo de comercializą̧ão, da mesma forma que foi feito por LYON \& THOMPSON, decorre da necessidade de se evitar perdas de graus de liberdade; com dados anuais, apenas 18 observações estão disponíveis. 
Será feita, também, a comparação entre os modelos de markup e dinâmico com dados mensais, visto que ambos não utilizam a variável quantidade. Nessa parte da análise, outras variáveis de custo e a variável risco de preço serão incluídas nos modelos, já que o maior número de observações relaxa a restrição às perdas de graus de liberdade. As especificações ficam:

- Modelo dinâmico com dados mensais:

$$
M_{t}=\beta_{0}+\beta_{1} P v_{t-1}+\beta_{2} P p_{t-1}+\beta_{3} D_{t}+\beta_{4} c_{t}+\beta_{5} J_{t}+\beta_{6} S M_{t}+\beta_{7} r_{t}+\varepsilon_{t}
$$

- Modelo de markup com dados mensais:

$$
M_{t}=\beta_{0}+\beta_{1} P v_{t}+\beta_{2} D_{t}+\beta_{3} J_{t}+\beta_{4} S M_{t}+\beta_{s} r_{t}+\varepsilon_{t}
$$

em que $D_{t}$ é o preço do óleo diesel no mês $t ; J_{t}$ a taxa real de juros no mês t; $\boldsymbol{r}_{\boldsymbol{t}}$ o risco de preço; e as demais variáveis são as definidas anteriormente, só que agora representando dados mensais.

As estimações das equações serão feitas por mínimos quadrados ordinários (MQO), conforme feito por WOHLGENANT \& MULLEN e por FAMINOW \& LAUBSCHER. O procedimento de Cochrane-Orcutt (KMENTA, 1988) será utilizado quando da constatação de autocorrelação entre os resíduos; a verificação da autocorrelação será feita pelo teste $\mathbf{Q}$ de Ljung-Box.

A comparação entre os modelos estimados será feita pelos indicadores de qualidade de ajustamento tradicionais, tais como o coeficiente de determinação, a significância e a coerência dos sinais dos parâmetros, e por um teste mon-nested. $\mathrm{O}$ fato de nenhum dos modelos estimados ser um caso especial dos demais faz com que testes non-nested sejam adequados para comparar os modelos. O teste a ser empregado é o teste J, proposto por DAVIDSON \& MACKINNON (1981), o qual também foi utilizado por WOHLGENANT \& MULLEN, e FAMINOW \& LAUBSCHER, entre outros.

Como exemplo do teste $\mathbb{J}$, suponha-se que a hipótese nula seja o modelo de markup: $M_{t}=a_{0}+a_{1} v_{t}+a_{2} C_{t}+\varepsilon_{1 b}$; e que a hipótese alternativa seja o modelo relativo: $M_{t}=b_{1} v_{t}+b_{2}\left(v_{t} Q_{t}\right)+b_{3} C_{t}+E_{2 j} ;$ em que $M_{t}$ é a margem de comercialização, $v_{t}$ é o preço ao varejo, $Q_{t}$ é a quantidade e $C_{t}$ é o custo de comercialização. Forma-se, então, o modelo composto: 


$$
M_{1}=(1-\lambda)\left(a_{0}+a_{1} v_{t}+a_{2} C_{t}\right)+\lambda M_{2 t}^{*}+\varepsilon_{1}=a_{0}^{\prime}+a_{1}^{\prime} v_{1}+\alpha_{2}^{\prime} C_{t}+\lambda M_{2 t}^{*}+\varepsilon_{1},
$$

em que $\mathbf{M}^{*}{ }_{2 t}$ é o valor previsto da margem pelo modelo relativo.

Sob a hipótese de nulidade dada pelo modelo de markup, o valor de $\lambda$ é zero, ou seja, o modelo relativo não explica nada da margem que já não tenha sido explicado pelo modelo de markup. DAVIDSON \& MACKINNON mostram que pode-se testar a nulidade de $\lambda$, estimando a equação (111) e utilizando o teste $\mathbf{t}$, de Student. Esse procedimento será adotado na comparação entre as expressões (109) e (110), para os dois mercados estudados.

Caso haja mais de uma hipótese alternativa, pode-se estimar uma equação semelhante à (111) contra as variáveis que fazem parte da hipótese nula (o modelo de markup, no exemplo anterior) e contra os valores previstos pelas várias hipóteses alternativas, fazendo-se o teste por meio do teste $\mathbf{F}$ convencional. Esse procedimento será adotado na comparação entre os quatro modelos estimados com dados anuais [expressões (105) a (108)].

\subsubsection{Efeito estático do risco de preço e do custo de comercialização}

Esse efeito será verificado por meio dos coeficientes estimados para a equação que melhor representar os mercados a partir de dados mensais, ou seja, pelo modelo que melhor se ajustar a cada mercado. A análise possibilitará a inferência sobre quais medidas poderiam ser adotadas com o intuito de reduzir a margem de comercialização dos produtos. Como o óleo diesel é uma proxy do custo de transporte, o salário-mínimo é uma proxy de todo o custo de mão-de-obra do processo de comercialização e a taxa de juros é uma proxy do custo (de oportunidade) de armazenamento, a significância dos coeficientes dessas variáveis dimensiona a importância direta de cada uma dessas atividades sobre a margem de comercialização de cada um dos mercados estudados.

A análise da importância do risco, por sua vez, mostra como é o comportamento do setor de intermediação de arroz e de feijão com respeito a essa variável. Constatando suporte para a hipótese de aversão ao risco, se estará inferindo que 
políticas que reduzam o risco de preços (divulgação de informações de mercado, incentivo à comercialização em mercados futuros, políticas de preços bem executadas etc.) podem levar à redução da margem e à melhoria de bem-estar social.

\subsubsection{Efeito dinâmico do risco de preço e do custo de comercialização}

Essa parte está dissociada da anterior (que se preocupa com o efeito instantâneo), tanto porque muitas vezes o efeito de longo prazo difere do de curto prazo como também pelo fato de os métodos de análise serem distintos. A análise dinâmica será conduzida com dados mensais e seguirá dois procedimentos analíticos: a análise dos multiplicadores de THIEIL e o método de auto-regressão vetorial (VAR). O método de THEIL leva em conta a formulação do modelo dinâmico, consistindo no cálculo da forma final do modelo, apresentada no capítulo 4 , e dos multiplicadores de impacto. A análise de auto-regressão vetorial, como se verá, segue um procedimento mais empírico, em que o modelo teórico é utilizado como mera referência na ordenação das variáveis; apresenta a vantagem de também possibilitar a mensuração de choques nas variáveis endógenas, enquanto o método de THIEIL permite a mensuração apenas dos impactos sobre as variáveis exógenas. A análise VAR será dividida em duas partes: numa primeira fase serão estimados modelos VAR convencionais (não-identificados), com todas as variáveis que aparecem nas formas reduzidas da margem no modelo dinẩmico, inclusive os preços dos produtos; depois, proceder-se-á à maior estruturação dos itens de custo por meio de um modelo VAR identificável, quando o modelo será restringido com a exclusão dos preços dos produtos. Segue-se a descrição desses métodos.

\section{Multiplicadores de THEIL}

O procedimento a ser seguido aqui já foi apresentado no capítulo anterior, sob o título de "impacto dinâmico". Consiste na estimação dos coeficientes das equações reduzidas dos preços ao produtor e ao varejo e da margem de comercialização [equações (91), (93) e (94), para feijão, e (102), (103) e (104), para arroz], na definição das matrizes de relações entre as variáveis endógenas $\left(D_{1}\right)$ e de choque das variáveis 
exógenas $\left(D_{2}\right)$, e na multiplicação contínua dessas matrizes para se calcular o efeito de choques nas variáveis exógenas sobre as endógenas, mês a mês.

Considerando que as equações reduzidas são oriundas do mesmo sistema estrutural, o que sugere que seus erros são naturalmente correlacionados, a estimação será processada pelo método de Zellner para modelos aparentemente não-relacionados (encontrado na literatura como SUR ou SURE). PINDYCK \& RUBINFELD (1991) apresentam uma descrição detalhada desse método ${ }^{46}$.

Uma mudança que se processará em relação à descrição do capítulo 4 é a ampliação do vetor de variáveis exógenas $\left(x_{t}\right)$, para a inclusão de todos os insumos considerados neste trabalho. Este vetor passa a ser:

$$
x_{t}=\left[\begin{array}{c}
\text { Fert } \\
\text { Risco } \\
\text { Juros } \\
\text { SM } \\
\text { Diesel }
\end{array}\right],
$$

em que Fert é o índice de preços de fertilizantes, Risco é o risco de preço, Juros é a taxa de juros, $S M$ é o salário-mínimo e Diesel é o preço do óleo diesel. Com essa alteração, a matriz $D_{2}$ passa a tẹ dimensão $3 \times 5$, permanecendo $D_{1}$ com dimensão $3 \times 3$.

\section{Modelos VAR}

Os modelos VAR foram introduzidos por SIMS (1980); como uma alternativa aos modelos estruturais multi-equacionais. Esses modelos permitem análises dinâmicas, sem a necessidade de especificação de modelos teóricos que mostrem o relacionamento intertemporal das variáveis. Segundo PINDYCK \& RUBINFELD (1991), os modelos VAR aplicam-se, principalmente, a situações como: quando a teoria é muito complicada para permitir uma derivação precisa da especificação, de forma que

46 Grosso modo, o método de estimação de Zellner consiste em combinar as equações do sistema e aplicar o método de mínimos quadrados generalizados. Ocorre ganho de eficiência devido ao aumento do número de graus de liberdade oriundo da combinação das equaçòes. 
especificações aproximadas ou ad hoc precisam ser feitas; quando a teoria pode ser consistente com diversas formas de estrutura de defasagem, mas essas estruturas de defasagem podem resultar em modelos com comportamento dinâmico muito distintos; $\mathrm{e}$ quando existe dúvida sobre qual é a teoria correta. Nessas circunstâncias, os dados podem indicar a estrutura dinâmica do modelo por meio dos modelos VAR.

Para estruturar modelos VAR, é necessário definir, basicamente, duas coisas: (1) o conjunto de variáveis (endógenas e exógenas) que, acredita-se, interage entre $\mathrm{si}^{47}$; e (2) o maior número de defasagens necessário para captar a maior parte dos efeitos que as variáveis têm umas sobre as outras. Além disso, restringe-se as equações do modelo à forma linear.

Supondo que o sistema só contenha variáveis endógenas (como se faz neste trabalho), representadas por $\boldsymbol{x}_{1}, \boldsymbol{x}_{2}, \ldots, \boldsymbol{x}_{w}$, um VAR é representado por um conjunto de $\mathbf{n}$ equações lineares:

$$
\begin{aligned}
& x_{1, t}=\sum_{j=1}^{p} \theta_{11,} x_{1, t-j}+\sum_{j=1}^{p} \theta_{12 j} x_{2, t-j}+\ldots+\sum_{j=1}^{p} \theta_{1 n j} x_{n, t-j}+\varepsilon_{1 t} \\
& x_{n, t}=\sum_{j=1}^{p} \theta_{n 1 j} x_{1, t-j}+\sum_{j=1}^{p} \theta_{n 2 j} x_{2, t-j}+\ldots+\sum_{j=1}^{p} \theta_{n n j} x_{n, t-j}+\varepsilon_{n t}
\end{aligned}
$$

em que $\boldsymbol{p}$ é o número de defasagens das variáveis, $\theta$ são os parâmetros e $\varepsilon$ são os erros..

Em notação matricial, o mesmo VAR, que também é chamado de VAR(p), pode ser representado por:

$$
x_{t}=\Theta_{1} x_{t-1}+\ldots+\Theta_{\cdot p} x_{t-p}+\varepsilon_{t}=\sum_{s=1}^{p} \Theta_{s} x_{t-s}+\varepsilon_{t},
$$

47 Conforme salientam PINDYCK \& RUBINFELD, os modelos VAR, como foram formulados por SIMS, pressupoem todas as variáveis cono endógenas. A definiçâo de algumas variáveis como exógenas introduz. restrições ao modelo, porque essas viariáveis estarão em condições de afetar as variáveis endógenas apenàs diretamente, e não indiretamente mediante o feéchack entre variáveis endógenas. Ainda segundo PINDYCK \& RUBINFELD, um purista poderia argunentar que restriçðes desse tipo são uma imposição arbitrária da tendenciosidade teórica do modelador, o que impediria que os dados "falassem" livremente. 
em que $\boldsymbol{x}_{\boldsymbol{t}}$ é o vetor das variáveis incluídạs no modelo; $\Theta_{1}, \ldots, \Theta_{p}$ são matrizes $\mathbf{n x n}$ que relacionam os valores defasados das variáveis aos valores correntes das mesmas; e $\varepsilon_{t}$ é um vetor nx1 dos erros. A mesma equação pode ser representada, com o uso do operador de defasagem $\boldsymbol{B}$, da seguinte forma:

$$
\left(I-\Theta_{1} B-\ldots-\Theta_{p} B^{p}\right) \boldsymbol{x}_{\boldsymbol{t}}=\varepsilon_{p}
$$

em que $\mathbb{B}^{n} x_{t}=x_{t-n}$, para qualquer $1 \leq n \leq p$.

A situação apresentada nas equações (113) e (113') é a forma definitiva do modelo, quando já se definiu o número de defasagens a ser incluído. É importante, porém, olhar o modelo de forma mais geral, para se compreender os tipos de análise que podem ser feitos a partir do VAR.

Em termos gerais, admite-se que $\boldsymbol{x}_{\boldsymbol{t}}$ representa um processo estocástico estacionário com representação de médias-móveis ${ }^{48}$.

$$
x_{t}=A_{0} \varepsilon_{t}+A_{1} \varepsilon_{t-1}+A_{2} \varepsilon_{t-2}+\ldots
$$

em que $A_{j}$ são matrizes nxn, para todo $j ; A_{0}$ é a matriz identidade; e $\varepsilon_{t \cdot i}$ é o vetọr nx1 de erros com defasagem $i$, para $i \geq 0$.

A equação (114) pode ser representada, de forma mais concisa, pelo operador de defasagem $\mathbf{B}$ :

$$
\boldsymbol{x}_{\mathbf{t}}=A(B) \boldsymbol{\varepsilon}_{\mathbf{t}},
$$

em que $A(B)=A_{0}+A_{1} B+A_{2} B^{2}+\ldots$.

É importante notar que, na expressão (115), $\varepsilon_{t}$ é o erro de previsão de um período ${ }^{49}$, dado por (BRANDÃO):

$$
\varepsilon_{t}=x_{t}-\mathrm{E}\left(x_{t} \mid x_{t-1}, x_{t-2}, \ldots\right)
$$

48 Pelo teorema de Wold (citado por BRANDÃO, 1985), todo processo estocástico estacionário possui uma representação de médias-nióveis.

49 Erro da previsão um periodo à frente feita com as informações disponíveis até t-1. 
O erro de previsão de K-períodos é definido por $\boldsymbol{x}_{t+k}-\mathbf{E}\left(\boldsymbol{x}_{t+k} \mid \boldsymbol{x}_{t}, \boldsymbol{x}_{t-1}, \ldots\right)$. Esses erros de previsão serão utilizados mais adiante na derivação das fórmulas da variância desses erros e na sua decomposição.

A equação (115) pode também ser escrita na forma auto-regressiva, desde que as raizes do polinômio $A(B)$ sejam todas maiores que um. Pré-multiplicando os dois lados de (115) por $A(B)^{-1}$, tem-se:

$$
A(B)^{-1} x_{t}=\varepsilon_{t} .
$$

O processo auto-regressivo vetorial, representado pela expressão (116), é, na verdade, uma representação mais ampla da expressão (113'). Para partir de (116) e chegar a (113'), é necessário definir o número de defasagens do modelo. Essa definição pode ser feita experimentalmente, como fez BRANDÃO, através do teste de razão de verossimilhança $^{5 \bullet}$, ou ad hoc. Mesmo o método experimental nem sempre é conclusivo; BRANDÃO não encontrou diferença entre utilizar 6 ou 13 defasagens, optando pelo último númer "em se tratando da atividade agrícola, que tem um ciclo anual..." (p. 40). BARROS (1991 e 1992) optou por 12 defasagens em decorrência de resultados obtidos em diversos trabalhos macroeconômicos; testou também o modelo com 6 defasagens, que foi rejeitado pela razão de verossimilhança a $1 \%$. Nesse trabalho, lança-se mão dos resultados encontrados pelos diversos autores e utiliza-se uma estrutura com 12 defasagens, ou seja, o modelo estimado é um VAR(12).

A estimação do sistema apresentado em (112) pode ser feita por MQO. Visto que não existe nenhuma variável endógena, do lado direito das equações, que não seja defasada, e desde que as variáveis do lado direito das equações são as mesmas em quaisquer equações, o mẹtodo de MQO gera eștimadores consistentes e eficientes (PINDYCK \& RUBINFELD).

Dispondo-se das estimativas dos parâmetros do modelo (112), podem ser feitos três tipos de análise: (1) obtenção de elasticidades de impulso, a partir do modelo de médias-móveis [tipo equações (114) e (115), na notação mais geral]; (2) decomposição da variância dos erros de previsão k-períodos à frente; e (3) teste de causalidade tipo Granger-Sims.

50 PINDYCK \& RUBINFELD (p. 240). 
A análise dos impulsos é mais facilmente visualizável a partir da equação (114). Por exemplo, o coeficiente da $\mathbf{k}$-ésima linha e da i-ésima coluna de $A_{4}$ mostra o efeito de um choque unitário no i-ésimo componente (que poderia ser, por exemplo, salário-mínimo), no período $t-4$, sobre $\boldsymbol{x}_{\boldsymbol{k}}$ (que poderia ser, por exemplo, preço ao varejo), no período $t$. Assim, estimando-se todos os coeficientes da equação (114), tornase possível conhecer a resposta dinâmica de qualquer das variáveis a choques em qualquer das demais.

Um problema que surge nessa operação decorre da matriz de variânciacovariância de $\varepsilon_{t}$ (matriz aqui denominada $\sigma$ ) geralmente não ser diagonal, o que significa que tendem a ocorrer choques contemporâneos em mais de uma das variáveis. Para verificar o efeito de um choque em apenas uma das variáveis sobre o sistema, lança-se mão de um procedimento que diagonaliza a matriz de variância-covariância: o método de decomposição de Cholesky.

O método de Cholesky é aqui descrito com base em BRANDÃO (p. 4042). Admitindo-se que $\sigma$ seja não-singular, existe uma matriz $C$, triangular inferior e nãosingular, tal que $\sigma=C C^{\prime}$, em que $C^{\prime}$ é a transposta de $C^{\prime}$. Segue que $C^{-1} \sigma\left(C^{\prime}\right)^{-1}=I$, em que $I$ é a matriz identidade. Definindo-se $\eta_{t}=C^{-1} \varepsilon_{t}$, tem-se que $\mathbf{E}\left[\eta_{t} \eta_{t}\right]=I$.

O passo seguinte é multiplicar a equação (116) por $C^{-1}$, do que resulta:

$$
H(B) x_{t}=\eta_{t}
$$

em que $\left.H(B)=C^{-1} A(B)\right)^{-1}$. Na representação de médias-móveis, ter-se-ia:

$$
\boldsymbol{x}_{\mathbf{t}}=G(B) \boldsymbol{\eta}_{\boldsymbol{t}}
$$

em que $G(B)=A(B) C$. Note-se que a expressão (118) é uma representação de médiasmóveis, visto que $\eta_{i}$ é um ruído branco.

' $A$ ' equação (118) permite que se mensure o efeito de um choque unitário (também conhecido como "inovação"), de um desvio-padrão, em apenas uma variável, sobre todas as variáveis do sistema, período a período. Os coeficientes da i-ésima coluna de $\boldsymbol{G}_{\boldsymbol{j}}$ mostram o efeito de um choque de um desvio-padrão na variável $\boldsymbol{i}$, en $\boldsymbol{t} \boldsymbol{j} \boldsymbol{j}$, sobre o vetor $\boldsymbol{x}$, no período $\boldsymbol{t}$. 
O procedimento que será aqui seguido para analisar esses impulsos é o mesmo adotado por BARROS (1991 e 1992). Os dados serão transformados em logaritmos neperianos, de maneira que, dividindo-se o efeito sobre cada variável, em cada mês, pelo valor do desvio-padrão da variável que sofre o choque, ter-se-á uma medida de elasticidade. Cada valor, de cada mês, mostrará a variação percentual sofrida pela variável considerada em resposta a uma variação de um por cento na variável que sofre o choque. A única variável que não será transformada em logaritmo é a taxa de juros.

Um segundo tipo de análise que pode ser feito com os modelos VAR é a decomposição da variância dos erros de previsão de k-períodos. A exposição que se śegue parte da decomposição da variância do erro de previsão de um período para depois se generalizar para $\mathbf{k}$-períodos.

Lembrando que o erro de previsão de um período é $\varepsilon_{t}=x_{t}-\mathbf{E}\left(x_{t} \mid x_{t-1}\right.$, $\left.\boldsymbol{x}_{t-2}, \ldots\right)$, a matriz de variância-covariância de um período será $\mathbf{E}\left(\varepsilon_{t} \varepsilon_{i}^{\prime}\right)=\boldsymbol{\sigma}=C C^{\prime}$.

No caso do erro de previsão k-períodos à frente, este é dado por $\varepsilon_{t+k}=$ $x_{t+k}-\mathbb{E}\left(x_{t+k} \mid x_{t}, x_{t-1}, x_{t-2}, \ldots\right), \operatorname{mas} x_{t+k}=G_{0} \eta_{t+k}+G_{1} \eta_{t+k-1}+\ldots+G_{k-1} \eta_{t+1}+G_{k} \eta_{t}$ $+G_{k+1} \eta_{t-1}+\ldots$. Logo, o erro de previsão k-períodos à frente é:

$$
\varepsilon_{l+k}=\sum_{j=0}^{k-1} G_{j} \eta_{t+k-j}
$$

A matriz de variância-covariância k-períodos à frente é dada por:

$$
\sum_{j=0}^{\mathrm{k}-1} A_{j} \sigma A_{j}^{\prime}=\sum_{j=0}^{\mathrm{k}-1}\left(\mathrm{~A}_{j} C\right)\left(A_{j} C\right)^{\prime} .
$$

A diagonal principal de cada matriz dessa soma é uma soma de quadrados, o que permite se atribuir à variância de cada uma das inovações a parcela que se deve à própria inovação e as parcelas devidas às demais.

Desse procedimento depreende-se certa arbitrariedade: a matriz $C$ depende da seqüência em que as variáveis são incluídas no sistema. Note-se que, na decomposição, inovações na primeira variável da seqüência afetam as demais variáveis contemporaneamente, mas não são afetadas pelas demais; a segunda variável irá impactar contemporaneamente a terceira, a quarta e as seguintes, não sendo afetada por estas; e 
assim por diante. Essa questão coloca grande responsabilidade no ordenamento das variáveis no sistema. Deve-se definir quais variáveis são.contemporaneamente afetadas pelas demais e quais não são. Um instrumento de grande valia neste ordenamento é levarse em conta predições de modelos econômicos relevantes. Muito embora os modelos VAR tenham sido propostos no sentido de os dados mostrarem livremente as relações que existem, um modelo econômico torna-se útil na definição da contemporaneidade das relações entre as variáveis.

A terceira análise passivel de ser feita, a partir da estimação do modelo VAR, é o teste de causalidade tipo Granger-Sims. Segundo GRANGER (1969), uma variável $\boldsymbol{x}$ causa uma variável $\boldsymbol{y}$, quando valores correntes e passados de $\mathrm{x}$ ajudam a melhorar a previsão de $\boldsymbol{y}$. Considerando uma das equações apresentadas no sistema (112):

$$
x_{i, t}=\sum_{j=1}^{p} \theta_{i 1 j} x_{1, t-j}+\sum_{j=1}^{p} \theta_{i 2 j} x_{2, t-j}+\ldots+\sum_{j=1}^{p} \theta_{i i j} x_{i, t-j}+\varepsilon_{i t},
$$

o teste para se verificar se $\boldsymbol{x}_{\boldsymbol{i}}$ é causada por $\boldsymbol{x}_{\boldsymbol{k}}$ consiste em testar se os coeficientes de $\boldsymbol{x}_{\boldsymbol{k}}$ são nulos; ou seja, se $\theta_{i k 1}=\ldots=\theta_{i k p}=0$. Essa verificação pode ser feita pelo tradicional teste F. É importante notar que o conceito de causalidade de Granger não implica relação de causa-efeito, sendo baseada apenas em "previsibilidade" (GRIFFITHS et al., 1993). Por esse motivo, o teste de causalidade tem sido olhado com bastante reserva por parte dos estudiosos.

\section{Estrutura do modelo}

O modelo teórico apresentado no capítulo 4 fornece os elementos necessários para definir as equações estruturais do modelo VAR. Em ambas as formulações adotadas, uma com causalidade produtor $\rightarrow$ varejo e outra com causalidade varejo $\rightarrow$ produtor, as variáveis de custo são vistas como independentes das demais. A variável que depende de todas as demais é a margem de comercialização. Por isso, a margem será a última variável colocada no modelo e as variáveis de custo serão as primeiras. 
Em ambos os modelos (de causalidade produtor $\rightarrow$ varejo e de causalidade varejo $\rightarrow$ produtor), a primeira variável colocada será o preço do óleo diesel, seguida pelo índice de preços de fertilizantes, pelo salário-mínimo, pela taxa de juros e pelo risco de preços, seqüencialmente ${ }^{51}$.

No modelo com causalidade produtor $\rightarrow$ varejo, as equações-chave para 0 ordenamento são (91), (92), (93) e (94). Verifica-se que o preço se forma ao nível de produtor (equação 91), que afeta o preço ao varejo (équação 92) e, depois, forma-se a margem. Nesse modelo, após as variáveis de custo, coloca-se o preço ao produtor, seguido pelo preço ao varejo e pela margem. Em função dos argumentos apresentados no item 4.3, esse modelo será adotado para o mercado de feijão.

O modelo com causalidade varejo $\rightarrow$ produtor tem como equações principais: (101), (102), (103) e (104). O preço forma-se ao varejo [equação (102)], afetạ o preço ao produtor [equação (101)], e essas duas variáveis formam a margem de comercialização. Assim, o ordenamento, após os itens de custo, é: preço ao varejo, preço ao produtor e margem de comercialização. Da mesma forma, em razão dos argumentos do capítulo 4, essa versão será utilizada para representar o mercado de arroz.

\section{Modelo VAR identificável}

A simples ordenação das variáveis já representa uma' forma de identificação das variáveis do modelo, conforme mostrado no item anterior. Entretanto, os modelos VAR convencionais assumem uma estrutura recursiva bastante restritiva que, muitas vezes, afasta a forma empírica daquilo que é esperado do ponto de vista teórico. Por exemplo, dada a ordenação dos itens de custo definida anteriormente, assume-se que. o preço do fertilizante é afetado, contemporaneamente, pelo preço do óleo diesel; o salário-mínimo é afetado, contemporaneamente, pelo preço do ólẹo diesel e pelo preço do fertilizante; o juro é afetado pelo salário-mínimo e pelo preço das outras duas variáveis; e o risco é afetado por todos os demais elementos de custo. Embora o modelo

51 Uma tentativa de aumentar a identificação dos itens de custo agricola e de custo de comercialização será apresentada no próxinıo item. 
teórico utilizado não preveja as interações dessas variáveis, é uma pressuposição bastante forte a existência de uma estrutura recursiva entre todas elas. Nesse item será apresentada uma forma de estruturar melhor a relação entre esses insumos; busca-se, assim, maior conhecimento sobre o impacto das variáveis de custo na margem de comercialização.

Diversos procedimentos vêm sendo propostos para permitir maior identificação das variáveis envolvidas num modelo VAR. O método que será implementado neste trabalho é o proposto por ORDEN \& FACKLER (1989), o qual também føi utilizado por BARROS (1991 e 1992). A proposta é concentrar as restrições nas interações contemporâneas das variáveis, não se impondo restri̧̧ões às variáveis defasadas.

A lógica de se restringir, exclusivamente, as interações contemporâneas está no fato de que a teoria econômica geralmente define com maior rigor essas relações do que as relações de defasagem. Além disso, realizações passadas de todas as variáveis são geralmente do conhecimento dos agentes econômicos, vindo a ser utilizadas na formulação de expectativas. Essas expectativas fornecem uma ligação entre realizações passadas e correntes de todas as variáveis do modelo, para o que a teoria econômica tem pouco a dizer (ORDEN \& FACKLER).

Um modelo VAR, com restrições na matriz de interações contemporâneas, pode ser representado por:

$$
A_{0} x_{t}=\sum_{s=1}^{p} A_{s} x_{t-s}+\varepsilon_{t}
$$

em que $x_{\boldsymbol{t}}$ é o vetor das variáveis incluídas no modelo; $A_{0}$ é a matriz $n \times n$ de coeficientes de relações contemporâneas e $A_{s}$ são matrizes nxn de coeficientes de relações com defasagem $s$, para $s=1, \ldots, p$; e $\varepsilon_{t}$ é um vetor $n x 1$ dos erros aleatórios.

A expressão ,estrutural (119) pode ser reescrita na forma reduzida, multiplicando-se ambos os lados da expressão pela inversa da matriz de coeficientes de interações contemporâneas $\left(A_{0}^{-1}\right)$. Para o cálculo dos parâmetros de $A_{0}$, estima-se, num primeiro estágio, por MQO, os parâmetros da equação reduzida:

$$
x_{\imath}=\sum_{s=1}^{p} A_{0}^{-1} A_{s} x_{t-s}+A_{0}^{-1} \varepsilon_{1}
$$


Sendo $\mu_{t}=A_{0}{ }^{-1} \varepsilon_{t}$ os resíduos da estimação por MQO da equação (120), tem-se que a matriz de variância-covariância de $\mu_{t}$ é $\Omega$. Essa matriz será utilizada na estimação de $A_{0}{ }^{-1}$. Como ela possui $\mathbf{n}(\mathbf{n}+1) / 2$ parâmetros livres, este é o número máximo de parâmetros que podem ser estimados em $A_{0}$, sendo n(n-1)/2 o número mínimo de restrições que precisam ser impostas para identificação. O modelo VAR convencional recursivo é exatamente identificado, pois sua matriz $A_{0}$ é uma triangular inferior, com $\mathbf{n}(\mathbf{n}+1) / 2$ parâmetros ${ }^{52}$. Caso haja um número menor de restrições, tem-se um modelo subidentificado e, no caso de um número maior, tem-se superidentificação.

Para se estimar o modelo dado pela expressão (119), utiliza-se o procedimento de Bernanke incorporado ao sofiware RATS. O segundo estágio da estimação é feito com a maximização da função logarítmica de verossimilhança:

$$
\ln L=-T(0,5 n) \ln (2 \pi)+T\left(\left|\ln A_{0}\right|-0,5 \ln |D|\right)-0,5 T \operatorname{tr}\left(D^{-1} A_{0} \Omega A_{0}{ }^{\prime}\right),
$$

sendo $\mu_{t}$ distribuído multinormalmente, com matriz diagonal de variância-covariância dos erros do modelo igual a $D=\operatorname{Cov}\left[\mu_{t}\right]$ e $\boldsymbol{T}$ igual ao número de observações. No método de Bernanke, a matriz de variância-covariância da forma reduzida, $\Omega$, é substituída por $T$ multiplicado pela matriz de produtos residuais cruzados. A maximização da função de verossimilhança apresentada é conduzida pelo método de Newton, pois as condições de primeira ordem são quadráticas.

Após estimar os coeficientes das matrizes $A$ e $D$, podem-se analisar as respostas de cada variável a choques em quaisquer das variáveis do modelo e a decomposição da variância dos erros de previsão, similarmente aos modelos VAR convencionais. $\mathrm{O}$ modelo auto-regressivo pode ser expresso em sua forma de médiasmóveis:

$$
x_{t}=\sum_{s=1}^{\infty} C_{s} \mu_{t-s}
$$

em que $C_{s}$ representa as matrizes que medem os impactos do vetor de erros. Lembrando que $\mu_{t}=A_{0}^{-1} \varepsilon_{t}$ a expressão anterior fica:

52 A fatoraçĩo, agora feita com a matriz $A_{0}$, era feita pela matriz triangular inferior $C$ no método de Cholesky. 


$$
x_{t}=\sum_{s=1}^{\infty} C_{s} A_{0}^{-1} D^{\frac{1}{2}} \varepsilon_{t}
$$

Os choques unitários em $\varepsilon_{\mathfrak{p}}$ multiplicados pela raiz quadrada de $D$, são equivalentes a choques de um desvio-padrão. Como serão utilizados valores em logaritmos, os valores obtidos, divididos pelo logaritmo do desvio-padrão da variável que sofre 'o choque, darão uma medida de elasticidade. A decomposição da variância dos erros de previsão também será obtida a partir da expressão (121).

Exposto o método, cabe agora definir as restrições contemporâneas da matriz $\boldsymbol{A}_{\mathbf{0}}$. Um primeiro procedimento a ser adotado é a redução da matriz inicial que possuía 8 variáveis. Esse procedimento foi adotado porque a matriz anterior era excessivamente grande, o que dificultaria até mesmo a consecução da convergência no processo de maximização de Bernanke. Como o objetivo do trabalho é a análise do impacto dos itens de custo na margem, e não nos preços dos produtos, optou-se por excluir os preços ao varejo e ao produtor da nova matriz de interações. A matriz passa agora a ter dimensão 6x6, com as seguintes variáveis: preço do óleo diesel, índice de preço de fertilizantes, salário-mínimo, taxa de juros, risco de preço e margem de comercialização produtor-varejo.

$\mathrm{Na}$ definição da matriz de interações contemporâneas $\left(A_{0}\right)$, as equações relevantes, para mostrar as variáveis que afetam a margem de comercialização, são as equações reduzidas: (94), para feijão, e (104), para arroz. A relação entre as variáveis de custo não pode ser derivada do modelo teórico, pois estas só foram segmentadas para a implementação da análise empírica; porém, a lógica econômica permite que se formulem algumas hipóteses sobre essas relações.

O preço do óleo diesel não deve ser, contemporaneamente, afetado pelo valor de nenhuma das demais variáveis, o mesmo ocorrendo com o salário-mínimo, que é definido por lei e normalmente leva em conta apenas a evolução passada dos preços. $\mathrm{O}$ preço dos fertilizantes deve ser impactado, contemporaneamente, pelo preço do óleo diesel de forma direta, visto que o petróleo é insumo de produção dos fertilizantes e também porque variações dos preços dos derivados de petróleo (como o óleo diesel) são rapidamente divulgadas e difundidas no País. A taxa de juros pode ser afetada positivamente pelo salário-mínimo, já que seu valor tende a ser sensível aos rendimentos da economia como um todo. $\mathrm{O}$ risco de preço pode ser, contemporaneamente, afetado 
pela taxa de juros, visto que esta impacta a formação e a desova de estoques, os quais têm impacto sobre os preços e sobre sua variabilidade; o. sentido deste impacto, no entanto, não pode ser antecipado.

A equação (94) mostra que a margem de comercialização de feijão é afetada, contemporaneamente, pelos preços dos insumos agrícola e de comercialização. O que se espera é que aumento no preço dos insumos de comercialização provoque aumento na margem de comercialização, enquanto aumento no preço dos insumos agrícolas leve à queda na margem. Como os coeficientes da matriz $A_{0}$ são invertidos [estão do lado esquerdo da equação (119)], os sinais devem ser negativos para os itens de comercialização e positivo para o insumo agrícola.

No modelo do mercado de arroz [equação (104)], a margem também é afetada, contemporaneamente, apenas pelos preços dos insumos de comercialização e agrícola. Entretanto, espera-se que aumento do preço do insumo agrícola também leve a aumento da margem. Dessa forma, os efeitos contemporâneos de todos os itens sobre a margem de comercialização devem ser negativos na matriz $\boldsymbol{A}_{\mathbf{0}}$.

\section{Operacionalização da análise de auto-regressão vetorial}

$\mathrm{Na}$ discussão das questões teóricas relacionadas com os métodos de análise VAR, alguma ênfase já foi dada aos procedimentos empiricos, no sentido de justificá-los. Para facilitar a interpretação dos resultados que serão apresentados no próximo capítulo, esse item apresenta uma descrição mais prática dos procedimentos seguidos.

A análise do modelo VAR convencional para o mercado de feijão consistirá na estimação do modelo de defasagem de 12 meses com 8 variáveis, seqüencialmente arranjadas na seguinte ordem: preço do óleo diesel, índice de preços de fertilizantes, salário-mínimo, taxa de juros, risco de preço, preço ao produtor, preço ao varejo e margem absoluta de comercialização. Todas as variáveis serão transformadas em logaritmos, com exceção da taxa de juros que, por ter muitos valores negativos e bastante próximos de zero, será utilizada em nível. No caso do mercado de arroz, haverá a troca de ordem entre os preços ao produtor e ao varejo, para se fazer jus ao sentido de 
causalidade suposto para esse mercado. Essas estimações permitirão a execução do teste F de causalidade entre as variáveis, o exame das elasticidades de impacto de cada uma das variáveis sobre todas as variáveis do modelo é também a decomposição da variância dos erros de previsão das 8 variáveis. Como a intenção da pesquisa é estudar o impacto das variáveis sobre a margem, apenas os impulsos sobre essa variável serão apresentados no próximo capítulo; será apresentada, também, a decomposição da variância dos erros de previsão da margem e dos preços ao varejo e ao produtor, nesse últimó caso para examinar possíveis relações causais entre os preços.

$\mathrm{Na}$ análise do modelo VAR identificável, a estimação, também com 12 defasagens, envolverá apenas seis variáveis, com a exclusão dos preços ao produtor e ao varejo. Também serão transformadas em logaritmos todas as variáveis, com exceção da taxa de juros. A estimação dos coeficientes da matriz de interações contemporâneas, $\boldsymbol{A}_{0}$, permitirá verificar se essas relações são como se espera, ou seja, se: o preço do óleo diesel e o salário-mínimo não são afetados por nenhuma das demais variáveis; o preço dos fertilizantes é afetado (com sinal negativo) pelo preço do óleo diesel; a taxa de juros é afetada (com sinal negativo) pelo salário-mínimo; o risco é afetado pela taxa de juros (com sinal indefinivel a priori); e a margem de comercialização é afetada por todas as demais variáveis (sinal negativo para todas as variáveis no mercado de arroz; sinal negativo para os insumos de comercialização e positivo para insumos agrícolas no mercado de feijão). Além da matriz $A_{0}$, serão apresentadas as elasticidades de impacto das 6 variáveis sobre a margem e a decomposição da variância dos erros de previsão dessa última. 


\section{ANÁLISE DOS RESULTADOS}

Nesse capítulo serão apresentados e discutidos os resultados das análises empíricas desenvolvidas. As variáveis e estatísticas apresentadas são as apresentadas na Tabela 2.

Tabela 2. Descrição das variáveis e estatísticas utilizadas na análise

Variáveis e

Descrição

Estatísticas

\begin{tabular}{ll}
$P v_{t-1}, P v_{t}$ & preço real ao varejo no período anterior e no período corrente \\
$P p_{t-1}, P p_{t}$ & preço real ao produtor no período anterior e no período corrente \\
$S M_{t}$ & salário-mínimo corrente real \\
Diesel & preço real do óleo diesel \\
$J u r o s_{t}$ & taxa de juros real do capital de giro \\
$Q_{t}$ & quantidade produzida no ano corrente \\
$P V Q_{t}$ & preço médio do varejo multiplicado pela quantidade \\
Fert & valor deflacionado do índice de preços de fertilizante \\
$R^{2}$ & coeficiente de determinação \\
G.L. & número de graus de liberdade da estimação \\
teste $Q$ & teste Q, de Ljung-Box \\
Risco & variável risco construída com dados de 4 meses consecutivos \\
Riscol2 & variável risco construída com dados de 12 meses consecutivos \\
Marg & margem de comercialização produtor-varejo \\
\hline
\end{tabular}




\subsection{Comparação entre os modelos empíricos}

Inicia-se pela comparação entre os modelos, em que estimações com dados anuais dos modelos de markup (equação 105), dinâmico (equação 108), relativo (equação 106) e do custo de comercialização (equação 107), e com dados mensais dos modelos de markup (equação 110) e dinâmico (equação 109), são submetidas a exame e teste, para verificar qual dos modelos melhor explica cada um dos mercados. O teste empregado, além das estatísticas tradicionais, é o teste $\mathbf{J}^{53}$.

\section{Dados anuais}

\section{Feijão:}

Os resultados estatísticos das estimações dos modelos de margem de comercialização de feijão com dados anuais [correspondentes às equações (105) a (108), do capítulo 5], apresentados na Tabela 3, mostram que os modelos do custo de comercialização e dinâmico apresentaram os piores ajustamentos. No modelo do custo de comercialização, a quantidade produzida mostrou-se não-significativa (apenas o custo de comercialização, representado pelo salário-mínimo, foi significativo a 1\%) e o coeficiente de determinação foi relativamente baixo $(51,9 \%)$. No modelo dinâmico, nenhum coeficiente foi significativo e o $\boldsymbol{R}^{2}$ foi de $57,2 \%$.

$\mathrm{O}$ modelo relativo apresentou coeficiente de determinação com valor relativamente elevado $(79,8 \%)$, provavelmente em decorrência das significâncias do preço ao varejo e da variável de interação do preço com a quantidade; o salário-mínimo foi não-significativo.

O modelo de markup teve um $\boldsymbol{R}^{2}$ de $76 \%$, o que se deve particularmente à significância do preço ao varejo; o salário-mínimo não foi significativo.

53 Para uma recapitulação, ver item 5.2.1. 
Tabela 3 - Estimações dos modelos alternativos de margem de comercialização de feijão no Estado de São Paulo, dados anuais de 1975 a $1992^{1}$

\begin{tabular}{|c|c|c|c|c|}
\hline $\begin{array}{l}\text { Variáveis e } \\
\text { Estatísticas }\end{array}$ & $\begin{array}{l}\text { Modelo de } \\
\text { Markup }\end{array}$ & $\begin{array}{l}\text { Modelo } \\
\text { Relativo }\end{array}$ & $\begin{array}{l}\text { Modelo Custo } \\
\text { de Comercial. }\end{array}$ & $\begin{array}{c}\text { Modelo } \\
\text { Dinâmico }\end{array}$ \\
\hline Constante & $\begin{array}{r}-1,5417 \\
(-0,21)\end{array}$ & - & $\begin{array}{l}8,7235 \\
(0,29)\end{array}$ & $\begin{array}{c}-8,7649 \\
(-0,56)\end{array}$ \\
\hline$P v_{t-1}$ & - & - & - & $\begin{array}{l}0,1415 \\
(0,32)\end{array}$ \\
\hline$P v_{t}$ & $\begin{array}{c}0,2472 \\
(5,00)^{* * *}\end{array}$ & $\begin{array}{l}.0,1229 \\
(1,94) *\end{array}$ & - & - \\
\hline$P p_{t-1}$ & - & - & - & $\begin{array}{c}-0,0897 \\
(-0,14)\end{array}$ \\
\hline$S M_{t}$ & $\begin{array}{l}9 \times 10^{-4} \\
(1,06)\end{array}$ & $\begin{array}{c}4,6 \times 10^{-4} \\
(0,92)\end{array}$ & $\begin{array}{c}0,0032 \\
(3,49) * * *\end{array}$ & $\begin{array}{l}0,0018 \\
(0,94)\end{array}$ \\
\hline$Q_{t}$ & - & - & $\begin{array}{c}-2,2 \times 10^{-5} \\
(-0,23)\end{array}$ & - \\
\hline$P V Q_{t}$ & - & $\begin{array}{l}6,7 \times 10^{-7} \\
(2,42)^{* *}\end{array}$ & - & - \\
\hline Fert, & - & - & - & $\begin{array}{l}5 \times 10^{-4} \\
(0,73)\end{array}$ \\
\hline$R^{2}$ & 0,760 & 0,798 & 0,519 & 0,572 \\
\hline G.L. & 14 & 14 & 15 & 12 \\
\hline teste $Q$ & $6,69(8)$ & $4,08(8)$ & $11,97(8)$ & $12,13(8)$ \\
\hline
\end{tabular}

1 Observações: entre parênteses, após os coeficientes, estão os valores do teste t; após os valores do teste $\mathrm{Q}$, estão os números de graus de liberdade do teste;

* significativo, a $10 \%$;

** significativo, a $5 \%$;

*** significativo, a $1 \%$;

Fonte: dados da pesquisa. 
Vale destacar que a quantidade, isoladamente, não foi significativa, mas sua interação com o preço (no modelo relativo) foi significativa e positiva. Esse resultado é idêntico ao encontrado por WOHLGENANT \& MULLEN, o que leva a admitir a suposição de que a margem relativa de comercialização é positivamente relacionada com quantidade, coerentemente com as deduções do modelo de GARDNER. Além disso, a insignificância da variável quantidade pode estar associada à deficiência dos dados; utilizou-se a quantidade produzida de feijão no Brasil (e não só a comercializada em São Paulo), de todos os tipos de feijão (e não apenas o "carioca", que é consumido em São Paulo).

Os resultados dos testes $\mathbf{J}$ para o mercado de feijão, apresentados na Tabela 4, não permitem a escolha de um modelo único, embora permitam a exclusão dos modelos dinâmico e do custo de comercializaçã்.

Tabela 4 - Valores dos testes $\mathbf{J}$ das estimações anuais dos modelos de margem de comercialização de feijão

\begin{tabular}{|c|c|c|c|c|}
\hline \multirow[t]{2}{*}{ Hipótese Nula } & \multicolumn{4}{|c|}{ Alternativa } \\
\hline & Markup & Relativo & Custo de Com. & Dinâmico \\
\hline Markup & - & $0,8052_{1}$ & 0,8052 & 0,8052 \\
\hline Relativo & 0,5745 & - & 0,5745 & 0,5745 \\
\hline Custo de Com. & $7,5495^{*}$ & $7,5495^{*}$ & - & $7,5495^{*}$ \\
\hline Dinâmico & $8,9578^{*}$ & $8,9578^{*}$ & $8,9578^{*}$ & - \\
\hline
\end{tabular}

* Significativo, a $1 \%$;

Fonte: dados da pesquisa.

Cada modelo foi incluído como hipótese nula e também como hipótese alternativa aos demais, porque o resultado do teste pode ser sensível à colocação de um modelo como hipótese nula ou alternativa (WOHLGENANT \& MULLEN). A primeira e 
a segunda linha da Tabela 4 mostram que não se rejeitam os modelos relativo e de markup em função de suas respectivas hipóteses alternativas. A terceira e a quarta linha mostram que se rejeitam os modelos do custo de comercialização e dinâmico a $1 \%$ de significância ${ }^{54}$.

\section{Arroz:}

As estimações para arroz (Tabela 5), também referentes aos modelos (105) a (108), do capítulo 5, mostram fracas performances de todos os modelos, tanto sob a ótica dos coeficientes de determinação quanto pela significância e sinal das principais variáveis.

O modelo dinâmico, nesse mercado, apresenta o índice de preços de fertilizantes significativo. $\mathrm{O}$ sinal do coeficiente desse índice (positivo) é compativel com a segunda versão do modelo, com causalidade varejo $\rightarrow$ produtor. 0 coeficiente de determinação foi um pouco superior $(62,6 \%)$ em relação ao ajustamento para o feijão, mas os preços defasados continuaram não-significativos.

O modelo de markup teve o preço ao varejo significativo e com o sinal esperado, mas o coeficiente de determinação foi baixo $(45,2 \%)$ em relação ao do modelo dinâmico.

O modelo relativo voltou a ter a variável de interação preço-quantidade significativa e positiva, similarmente ao verificado para o feijão e coerentemente com o modelo de GARDNER e com os resultados de WOHLGENANT \& MULLEN; o preço do arroz ao varejo (significativo a $10 \%$ ) teve o sinal oposto ao esperado; o $\boldsymbol{R}^{2}$ foi ainda inferior ao do modelo de markup $(35,5 \%)$.

O modelo do custo de comercialização para arroz teve também performance sofrível: embora o coeficiente do custo de comercialização (salário-mínimo) fosse significativo e tivesse o sinal esperado, a quantidade não foi significativa e o $\mathbb{R}^{2}$ não alcançou $30 \%$.

54 Notar que os valores dos testes são os mesmos ao longo de cada linha; isto porque são frutos de um mesmo teste $\mathbf{F}$. 
Tabela 5 - Estimações dos modelos alternativos de margem de comercialização de arroz no Estado de São Paulo, dados anuais de 1975 a $1992^{1}$

\begin{tabular}{|c|c|c|c|c|}
\hline $\begin{array}{c}\text { Variáveis e } \\
\text { Testes }\end{array}$ & $\begin{array}{l}\text { Modelo de } \\
\text { Markup }\end{array}$ & $\begin{array}{l}\text { Modelo } \\
\text { Relativo } \\
\end{array}$ & $\begin{array}{l}\text { Modelo Custo } \\
\text { de Comercial. }\end{array}$ & $\begin{array}{c}\text { Modelo } \\
\text { Dinâmico }\end{array}$ \\
\hline Constante & $\begin{array}{l}32878,6 \\
(3,16) * * *\end{array}$ & - & $\begin{array}{c}19825,21 \\
(0,77)\end{array}$ & $\begin{array}{l}47523,4 \\
(3,39)^{* * *}\end{array}$ \\
\hline$P v_{t-1}$ & - & - & - & $\begin{array}{l}0,8427 \\
(1,64)\end{array}$ \\
\hline$P v_{t}$ & $\begin{array}{l}0,4982 \\
(2,14)^{* *}\end{array}$ & $\begin{array}{l}-0,6524 \\
(-1,76) *\end{array}$ & - & - \\
\hline$P p_{t-1}$ & - & - & - & $\begin{array}{c}-0,3877 \\
(-1,32)\end{array}$ \\
\hline$S M_{t}$ & $\begin{array}{c}-0,2443 \\
(-0,26)\end{array}$ & $\begin{array}{l}0,6531 \\
(0,71)\end{array}$ & $\begin{array}{l}1,6081 \\
(2,34) * *\end{array}$ & $\begin{array}{l}-0,8560 \\
(-1,30)\end{array}$ \\
\hline$Q_{t}$ & - & - & $\begin{array}{c}9,6 \times 10^{-4} \\
(0,46)\end{array}$ & - \\
\hline$P V Q_{t}$ & - & $\begin{array}{l}1,8 \times 10^{-7} \\
(3,8)^{* * * *}\end{array}$ & - & - \\
\hline Fert, & - & - & - & $\begin{array}{l}0,9557 \\
(2,54)^{* *}\end{array}$ \\
\hline$R^{2}$ & 0,452 & 0,355 & 0,295 & 0,626 \\
\hline G.L. & 15 & 15 & 15 & 10 \\
\hline teste $Q$ & $9,39(9)$ & $3,13(9)$ & $7,53(9)$ & $7,49(7)$ \\
\hline
\end{tabular}

1 Observações: entre parênteses, após os coeficientes, estão os valores do teste t; após os valores do teste $\mathrm{Q}$, estão os números de graus de liberdade do teste;

* significativo, a $10 \%$;

** significativo, a $5 \%$;

*** significativo, a $1 \%$;

Fonte: dados da pesquisa. 
A Tabela 6 é similar à Tabela 4. Os resultados confirmam os fracos ajustamentos de todos os modelos. Todos eles são rejeitados a $1 \%$ de significância.

Compatibilizando os resultados encontrados nas estimações anuais para feijão e arroz, verifica-se que os modelos relativo e de markup foram os melhores para explicar a margem de feijão, enquanto o dinâmico foi o que melhor se ajustou ao mercado de arroz (inclusive sugerindo, através do sinal do coeficiente do índice de fertilizantes, que sentido causal predomina entre os preços desse mercado). Entretanto, diversas variáveis importantes tiveram seus coeficientes não-significativos, como foi o caso dos preços defasados no modelo dinâmico do arroz e do custo de comercialização (salário-mínimo) no modelo relativo de feijão. De maneira geral, pode-se dizer que os ajustes não foram bons, o que decorre de diversos fatores, tais como variáveis utilizadas e pequeno número de observações disponível. Devido ao maior número de observações disponível, os resultados das estimações com dados mensais, que se seguem, têm condições de trazer mais luzes para o problema estudado.

Tabela 6 - Valores dos testes $\mathbf{J}$ das estimações anuais dos modelos de margem de comercialização de arroz

\begin{tabular}{|c|c|c|c|c|}
\hline \multirow[t]{2}{*}{ Hipótese Nula } & \multicolumn{4}{|c|}{ Hipótese Alternativa } \\
\hline & Markup & Relativo & Custo de Com. & Dinâmico \\
\hline Markup & - & $263,1639^{*}$ & $263,1639^{*}$ & $263,1639^{*}$ \\
\hline Relativo & $693,7546^{*}$ & - & $693,7546^{*}$ & $693,7546^{*}$ \\
\hline Custo de Com. & $18,9597^{*}$ & $18,9597^{*}$ & - & $18,9597^{*}$ \\
\hline Dinâmico & $8,7510^{*}$ & $8,7510^{*}$ & $8,7510^{*}$ & - \\
\hline
\end{tabular}

* Significativo, a $1 \%$;

Fonte: dados da pesquisa. 


\section{Dados Mensais}

As estimações com dados mensais permitem comparar apenas os modelos de markup e dinâmico, provenientes das expressões (109) e (110), do capítulo 5 (Tabelas 7 e 8, respectivamente para feijão e arroz). As estimações dos dois modelos foram feitas apenas com o risco quadrimestral, já que o objetivo dessa seção é comparar os modelos e não analisar, de forma mais detalhada, o efeito do risco (que será objeto do próximo item).

Os resultados para o feijão (tabela 7) mostram uma performance superior por parte do modelo dinâmico. É interessante notar que o uso de dados mensais e a inclusão de novos itens de custo de comercialização melhoraram, expressivamente, a qualidade do ajustamento do modelo dinâmico e pioraram o ajustamento do modelo de markup, em comparação com a estimação feita a partir de dałos anuais. $\mathrm{O}$ coeficiente de determinação foi bastante superior no modelo dinâmico $(70,9 \%)$, em relação ao de markup (49,4\%). Os coeficientes do preço do óleo diesel (significativo) e da taxa de juros (não-significativo) tiveram sinais negativos no modelo dinâmico, enquanto o modelo previa sinais positivos para essas variáveis. phá o sinal negativo do coeficiente do índice de fertilizantes é compatível com a versão do modelo dinâmico de causalidade produtor $\rightarrow$ varejo, embora esse coeficiente não tenha se mostrado estatisticamente diferente de zero." Também no modelo de markup, em que o coeficiente da variável taxa de juros foi positivo e não-significativo, o preço do óleo diesel teve coeficiente significativo e com sinal negativo. $O$ salário-mínimo teve coeficientes significativos e positivos nos dois modelos. $\mathrm{O}$ risco de preço teve coeficientes com sinal positivo, como se esperava, mas significativo apenas no modelo dinâmico.

No caso do mercado de arroz (Tabela 8), os dois modelos apresentaram performances muito semelhantes. Os coeficientes de determinação foram $65,3 \%$ e $59,7 \%$, para os modelos dinâmico e de markup, rẹspectivamente. $\mathrm{O}$ modelo dinâmico teve os preços defasados significativos a $1 \%$ e o coeficiente do índice de preços de fertilizantes significativo a 10\%; os coeficientes do preço do óleo diesel, do salário-mínimo e do juro foram não-significativos. No modelo de markup, os coeficientes dos insumos de comercialização, com exceção dos juros (e do risco), e o preço corrente no varejo foram significativos a $1 \%$; entretanto, os sinais dos coeficientes desses insumos foram o oposto do que era esperado. Novamente, o sinal do coeficiente do índice de preços de 
fertilizantes mostra-se compativel com o modelo dinâmico com causalidade varejo $\rightarrow$ produtor. $\mathrm{O}$ risco de preço teve coeficientes positivos. e não-significativos nos dois modelos.

Os testes $\mathbf{J}$ (Tabela 9) levam à rejeição dos dois modelos, cada um deles em favor do outro. Assim como na estimação anual para arroz, os resultados mostraramse inconclusivos. Resultado semelhante foi encontrado por FAMINOW \& LAUBSCHER e pode ser, como afirmaram esses autores, uma característica das estimações com dados de média periodicidade, tais como os mensais. Os demais indicadores de qualidade de ajustamento sugerem uma vantagem para o modelo dinâmico (maior no mercado de feijão), de forma que esse modelo será utilizado, na seção seguinte, na análise dos itens de custo de comercialização. Embora a vantagem do modelo dinâmico não seja tão definitiva no mercado de arroz, sua estimação é preferível, porque as equações do capítulo 4 permitem um análise mais segura dos resultados encontrados. 
Tabela 7 - Estimações dos modelos dinâmico e de markup para feijão, dados mensais de 1975 a 19931

\begin{tabular}{|c|c|c|}
\hline Variáveis e Estatísticas & Modelo Dinâmico & Modelo de Markup \\
\hline Constante & $\begin{array}{c}0,1962 \\
(0,81)\end{array}$ & $\begin{array}{l}0,2013 \\
(1,12)\end{array}$ \\
\hline$P p_{t-1}$ & $\begin{array}{c}-0,3732 \\
(-6,40) * * *\end{array}$ & - \\
\hline$P v_{t-1}$ & $\begin{array}{c}0,4973 \\
(11,35) * * *\end{array}$ & - \\
\hline$P v_{t}$ & - & $\begin{array}{c}0,2499 \\
(8,57) * * *\end{array}$ \\
\hline Diesel $_{t}$ & $\begin{array}{c}-1,27 \times 10^{-5} \\
(-2,54)^{* *}\end{array}$ & $\begin{array}{c}-1,80 \times 10^{-5} \\
(-3,57)^{* * *}\end{array}$ \\
\hline$S M_{t}$ & $\begin{array}{c}6,55 \times 10^{-5} \\
(3,52)^{* * * *}\end{array}$ & $\begin{array}{l}7,85 \times 10^{-5} \\
(3,90)^{* * * *}\end{array}$ \\
\hline Fert, & $\begin{array}{c}-7,86 \times 10^{-6} \\
(-0,55)\end{array}$ & - \\
\hline Juros, & $\begin{array}{r}\Theta 1,3297 \\
(-0,94)\end{array}$ & $\begin{array}{l}0,5387 \\
(0,39)\end{array}$ \\
\hline Risco4 $_{t}$ & $\begin{array}{c}0,3283 \\
(3,28) * * *\end{array}$ & $\begin{array}{l}0,1309 \\
(0,98)\end{array}$ \\
\hline$R^{2}$ & 0,709 & 0,494 \\
\hline G.L. da estimação & 203 & 202 \\
\hline teste $Q$ & $48,20(42)$ & $49,37(42)$ \\
\hline
\end{tabular}


Tabela 8 - Estimações dos modelos dinâmico e de markup para arroz, dados mensais de 1975 a 19931

\begin{tabular}{|c|c|c|}
\hline Variáveis e Estatísticas & Modelo Dinâmico & Modelo de Markup \\
\hline Constante & $\begin{array}{l}317,72 \\
(1,66)^{*}\end{array}$ & $\begin{array}{l}-21,60 \\
(-0,30)\end{array}$ \\
\hline$P p_{t-1}$ & $\begin{array}{c}-0,8838 \\
(-9,36) * * *\end{array}$ & - \\
\hline$P v_{t-1}$ & $\begin{array}{c}0,6630 \\
(12,61)^{* * *}\end{array}$ & - \\
\hline$P v_{t}$ & - & $\begin{array}{c}0,6226 \\
(16,62)^{* * *}\end{array}$ \\
\hline Diesel $_{t}$ & $\begin{array}{c}-0,0018 \\
(-0,65)\end{array}$ & $\begin{array}{c}-0,0096 \\
(-2,62)^{* * *}\end{array}$ \\
\hline$S M$ & $\begin{array}{l}0,0023 \\
(0,19)\end{array}$ & $\begin{array}{c}-0,0313 \\
(-2,70)^{* * *}\end{array}$ \\
\hline Fert, & $\begin{array}{l}0,0167 \\
(1,89) *\end{array}$ & - \\
\hline Juros, & $\begin{array}{c}-798,83 \\
(-0,76)\end{array}$ & $\begin{array}{l}-78,78 \\
(-0,12)\end{array}$ \\
\hline Risco4, & $\begin{array}{l}0,1822 \\
(1,26)\end{array}$ & $\begin{array}{l}0,0421 \\
(0,32)\end{array}$ \\
\hline$R^{2}$ & 0,653 & 0,597 \\
\hline G.L. da estimação & 206 & 197 \\
\hline teste $Q$ & $32,12(42)$ & $51,59(42)$ \\
\hline \multicolumn{3}{|c|}{$\begin{array}{l}1 \text { Entre parênteses, após os coeficientes, estão os valores do teste t; após os valores do } \\
\text { teste } Q \text {, estão os números de graus de liberdade do teste; } \\
\text { * significativo, a } 10 \% \text {; } \\
\text { "* significativo, a } 5 \% \text {; } \\
\text { *** significativo, a } 1 \% \text {; } \\
\text { Fonte: dados da pesquisa. }\end{array}$} \\
\hline
\end{tabular}


Tabela 9 - Valores dos testes $\mathbf{J}$ das estimações mensais dos modelos de markup e dinâmico para arroz e para feijão

\begin{tabular}{|c|c|c|c|c|}
\hline \multirow[t]{3}{*}{ Hipótese Nula } & \multicolumn{2}{|r|}{ Hipótese } & \multicolumn{2}{|l|}{ Alternativa } \\
\hline & \multicolumn{2}{|c|}{ Mercado de Arroz } & \multicolumn{2}{|c|}{ Mercado de Feijão } \\
\hline & Markup & Dinâmico & Markup & Dinâmico \\
\hline Markup & - & $9,1261^{*}$ & - & $10,0808 *$ \\
\hline Dinâmico & $18,7857^{*}$ & - & $3,0483^{*}$ & - \\
\hline
\end{tabular}

* Significativo, a 1\%;

Fonte: dados da pesquisa.

\subsection{Efeito estático do risco e do custo de comercialização}

Dada a melhor performance do modelo dinâmico nas estimações que utilizaram dados mensais, a equação (109) é utilizada para se analisar o impacto do custo e do risco sobre a margem de comercialização. Conforme descrito no capítulo anterior, o risco foi incorporado às equações de duas formas distintas, combinando 4 ou 12 meses.

\section{Feijão:}

A Tabela 10 mostra que $o$ risco afeta positivamente a margem de comercialização de feijão, quando a variável é construída com dados de 4 meses $^{55}$; o resultado é consistente com as características do mercado do produto, que é armazenado por período inferior a um ano. No caso da variável construída com dados de 12 meses, o coeficiente não foi estatisticamente diferente de zero, pelo teste $t$, de Student. $\mathbf{O}$ sinal

${ }^{55}$ A $2^{\mathrm{a}}$ coluna da Tabela 10 já havia sido apresentada, anteriormente, na Tabela 7 . A $2^{\mathrm{a}}$ coluna da Tabela 11 também repetirá as estimativas apresentadas na Tabela 8. 
positivo do risco sugere que o setor de intermediação do mercado de feijão comporta-se com aversão ao risco, o que é condizente com o esperado.

O modelo teórico (capítulo 4) sugere que o coeficiente do custo de comercialização seja positivo, o que se mostra verdadeiro para o salário-mínimo (positivo e estatisticamente diferente de zero) nas duas estimações (Tabela 10). Isso significa que, quanto maior for o salário-mínimo, maior tenderá a ser o custo e a margem de comercialização.

O sinal negativo do coeficiente do preço do óleo diesel (significativo a $10 \%$, na estimação 1, e não-significativo, na estimação 2) é contrário ao que se esperaria teoricamente. Isso significa que aumento do preço do óleo diesel leva à redução da margem de comercialização. $O$ coeficiente do preço do insumo agrícola (índice de preços de fertilizantes) também foi negativo, embora não-significativo em nenhuma das estimações. $\mathrm{O}$ sinal negativo do coeficiente do preço do óleo diesel pode encontrar sua explicação no fato de este insumo ser utilizado também na produção agrícola; o modelo de causalidade produtor $\rightarrow$ varejo prevê sinal negativo para o coeficiente do insumo agrícola (como se verificou para o índice de preços de fertilizantes), de forma que o sinal negativo do coeficiente do preço do óleo diesel poderia ser negativo caso predominasse seu efeito como insumo agrícola em relação ao seu efeito como insumo de comercialização.

A variável taxa de juros mostra-se negativa $e$ não-significativa estatisticamente. $\mathrm{O}$ modelo teórico incorpora o juro como um elemento de custo, de maneira que seu sinal deveria ser positivo. $O$ sinal negativo pode ser interpretado a partir do reconhecimento de que o mercado financeiro é uma alternativa à estocagem de produtos agrícolas. Dessa forma, quando a taxa de juros aumentasse, os indivíduos que detivessem feijão estocado optariam por vender parte do estoque. Esse aumento da oferta provocaria redução do preço no varejo e a margem também cairia no curto prazo. 
Tabela 10 - Estimações do modelo dinâmico de margem de comercialização para feijão, dados mensais de 1975 a 19931

\begin{tabular}{|c|c|c|}
\hline Variáveis e Estatísticas & $\begin{array}{c}\text { Coeficientes e Estatísticas } \\
\text { Estimação } 1 \\
\end{array}$ & $\begin{array}{c}\text { Coeficientes e Estatísticas } \\
\text { Estimação } 2 \\
\end{array}$ \\
\hline Constante & $\begin{array}{c}0,1962 \\
(0,81)\end{array}$ & $\begin{array}{c}0,4212 \\
(1,51)\end{array}$ \\
\hline$P p_{t-1}$ & $\begin{array}{c}-0,3732 \\
(-6,40)^{* * *}\end{array}$ & $\begin{array}{c}-0,3438 \\
(-5,54)^{* * *}\end{array}$ \\
\hline$P v_{t-1}$ & $\begin{array}{c}0,4973 \\
(11,35) * * *\end{array}$ & $\begin{array}{c}0,5069 \\
(11,05) * * *\end{array}$ \\
\hline Diesel $_{t}$ & $\begin{array}{l}-1,27 \times 10^{-5} \\
(-2,54) * *\end{array}$ & $\begin{array}{l}-1,01 \times 10^{-5} \\
(-1,91)^{* *}\end{array}$ \\
\hline$S M_{t}$ & $\begin{array}{l}6,55 \times 10^{-5} \\
(3,52)^{* * *}\end{array}$ & $\begin{array}{l}6,19 \times 10^{-5} \\
(3,51)^{* * *}\end{array}$ \\
\hline Fert $t_{t}$ & $\begin{array}{l}-7,86 \times 10^{-6} \\
(-0,55)\end{array}$ & $\begin{array}{c}-2,13 \times 10^{-5} \\
(-1,34)\end{array}$ \\
\hline Juros, & $\begin{array}{r}-1,3297 \\
(-0,94)\end{array}$ & $\begin{array}{r}-0,8103 \\
(-0,55)\end{array}$ \\
\hline Risco $_{t}$ & $\begin{array}{l}0,3283 \cdots \cdots \\
(3,28)^{* *}\end{array}$ & - \\
\hline Riscol2, & - & $\begin{array}{r}0,1729 \\
(1,30)\end{array}$ \\
\hline$R^{2}$ & 0,709 & 0,747 \\
\hline G.L. da estimação & 203 & 193 \\
\hline teste $Q$ & $48,20(42)$ & $51,72(42)$ \\
\hline \multicolumn{3}{|c|}{$\begin{array}{l}\text { TEntre parênteses, após os coeficientes, estão os valores do teste t; após os valores do } \\
\text { teste } Q \text {, estão os números de graus de liberdade do teste; } \\
\text { * significativo, a } 10 \% \text {; } \\
\text { ** significativo, a } 5 \% \text {; } \\
\text { *** significativo, a } 1 \% \text {; } \\
\text { Fonte: dados da pesquisa. }\end{array}$} \\
\hline
\end{tabular}




\section{Arroz:}

Os resultados para o arroz, na Tabela 11, mostram que o mercado desse produto não se ajustou tão bem quanto o de feijão ao modelo adotado. Os coeficientes relativos ao custo de comercialização não foram significativos em nenhuma das estimações $^{56}$. Entretanto, o coeficiente do insumo agrícola apresentou-se significativo e com o sinal esperado (para modelo com causalidade varejo $\rightarrow$ produtor), nas duas estimações.

O risco mostrou-se não-significativo, quer na forma anual quer na forma quadrimestral. Isso confirma hipótese de que essa variável seria importante no mercado de feijão e não no mercado de arroz.

A taxa de juros não foi significativa em nenhuma das estimações; o sinal dos coeficientes dessa variável foi negativo como no mercado de feijão.

56 A estimação do modelo de markup (Tabela 8) apresentou os coeficientes do óleo diesel e do salário mínimo significativos e negativos. Esse resultado, com coeficientes dos custos de comercialização negativos, embora inconsistentes teoricamente, já havia sido encontrado por FAMINOW \& LAUBSCHER, nos três modelos por eles estimados. 
Tabela 11 - Estimações do modelo dinâmico de margem de comercialização para arroz, dados mensais de 1975 a $1993^{1}$

\begin{tabular}{|c|c|c|}
\hline Variáveis e Estatísticas & $\begin{array}{c}\text { Coeficientes e Estatísticas } \\
\text { Estimação } 1\end{array}$ & $\begin{array}{c}\text { Coeficientes e Estatísticas } \\
\text { Estimação } 2\end{array}$ \\
\hline Consiante & $\begin{array}{l}317,72 \\
(1,66)^{*}\end{array}$ & $\begin{array}{l}276,13 \\
(1,22)\end{array}$ \\
\hline$P p_{t-1}$ & $\begin{array}{c}-0,8838 \\
(-9,36)^{* * *}\end{array}$ & $\begin{array}{c}-0,8663 \\
(-8,56)^{* * *}\end{array}$ \\
\hline$P v_{t-1}$ & $\begin{array}{c}0,6630 \\
(12,61) * * *\end{array}$ & $\begin{array}{c}0,6827 \\
(13,06) * * *\end{array}$ \\
\hline Diesel $_{t}$ & $\begin{array}{l}-0,0018 \\
(-0,65)\end{array}$ & $\begin{array}{c}-0,0052 \\
(-1,45)\end{array}$ \\
\hline$S M_{t}$ & $\begin{array}{l}0,0023 \\
(0,19)\end{array}$ & $\begin{array}{l}-0,0041 \\
(-0,32)\end{array}$ \\
\hline Fert, & $\begin{array}{l}0,0167 \\
(1,89)^{*}\end{array}$ & $\begin{array}{l}0,0229 \\
(2,19) * *\end{array}$ \\
\hline Juros, & $\begin{array}{l}-798,83 \\
(-0,76)\end{array}$ & $\begin{array}{c}-336,40 \\
(-0,31)\end{array}$ \\
\hline Risco4t $_{t}$ & $\begin{array}{l}0,1822 \\
(1,26)\end{array}$ & - \\
\hline Riscol2 ${ }_{t}$ & - & $\begin{array}{l}0,0347 \\
(0,16)\end{array}$ \\
\hline$R^{2}$ & 0,653 & 0,619 \\
\hline G.L. das estimações & 206 & 198 \\
\hline teste $Q$ & $32,12(42)$ & $32,42(42)$ \\
\hline \multicolumn{3}{|c|}{$\begin{array}{l}1 \text { Entre parênteses, após os coeficientes, estão os valores do teste t; após os valores do } \\
\text { teste Q, estão os números de graus de liberdade do teste; } \\
\text { * significativo, a } 10 \% ; \\
* * \text { significativo, a } 5 \% ; \\
* * * \text { significativo, a } 1 \% ; \\
\text { Fonte: dados da pesquisa. }\end{array}$} \\
\hline
\end{tabular}




\subsection{Efeito dinâmico do risco e do custo de comercialização}

Essa seção apresenta e analisa os resultados das estimações dos multiplicadores de THEIL, do modelo VAR convencional (não-identificável) e do modelo VAR identificável, conforme explicitado no capítulo 5. Embora se procure manter as representações das variáveis apresentadas na Tabela 2, deve-se lembrar que, na análise dos modelos VAR, utilizaram-se os logaritmos das variáveis e não as variáveis em nível como nas seções anteriores; a única exceção foi a taxa de juros, que foi incluída em nível. Na estimação das equações reduzidas do modelo dinâmico, as quais permitiram o cálculo dos multiplicadores de THEIL, todas as variáveis foram utilizadas em nível.

\subsubsection{Multiplicadores de THEIL}

\section{Arroz:}

Os coeficientes das estimações das equações reduzidas dos preços e da margem de arroz permitiram a composição das matrizes $\mathbf{D}_{\mathbf{1}}$ e $\mathbf{D}_{\mathbf{2}}$ :

$$
\begin{aligned}
& D_{1}=\left[\begin{array}{cccc}
0,91933 & -0,01662 & 0 \\
0,44601 & 0,65853 & 0 \\
-0,86715 & 0,68187 & 0
\end{array}\right] \wedge \\
& D_{2}=\left[\begin{array}{ccccc}
0,42212 \times 10^{-2} & -0,04952 & 298,007 & 0,97341 \times 10^{-2} & 0,12271 \times 10^{-2} \\
0,02363 & 0 & 0 & 0 & 0 \\
0,01761 & 0,07300 & -432,730 & -0,01357 & -0,17645 \times 10^{-2}
\end{array}\right]
\end{aligned}
$$

Relembrando, a primeira linha em cada matriz diz respeito ao preço do produtor; a segunda diz respeito, ao preço no varejo; e a terceira diz respeito à margem de 
comercialização. Na matriz $\mathbf{D}_{1}$, a primeira coluna refere-se aos valores defasados do preço ao produtor; a segunda, aos valores defasados do preço ao varejo; e a terceira, aos valores defasados da margem de comercialização (que são nulos, pois as equações reduzidas não têm a variável margem defasada). Na matriz $\mathbf{D}_{\mathbf{2}}$, a primeira coluna mostra os impactos imediatos do preço de fertilizantes; a segunda, do risco; a terceira, dos juros; a quarta, do salário-mínimo; e a quinta, do preço do óleo diesel.

$\mathrm{O}$ cálculo das raízes características da matriz $\mathbf{D}_{1}$, estimada para arroz, apresenta os valores: $0 ; 0,966$; e 0,616 . Como todas essas raizes são menores que 1 , não se rejeita a hipótese de convergência dinâmica do modelo no mercado de arroz.

A multiplicação consecutiva da matriz $\mathbf{D}_{\mathbf{1}}$ por ela mesma e por $\mathbf{D}_{\mathbf{2}}$, conforme explicitado no capítulo 4, permitiu que se determinassem os multiplicadores apresentados na Tabela 12 .

Verifica-se, na Tabela 12, que aumento de CR\$ 1,00 no preço de fertilizantes leva a aumentos na margem de comercialização de arroz durante todos os 24 meses da análise; o aumento imediato na margem é de $\mathrm{CR} \$ 0,01761$ e o efeito total é de um aumento de $\mathrm{CR} \$ 0,06550$.

As demais variáveis têm mudança no sentido de seus efeitos 5 meses após o choque. $\mathrm{O}$ risco de preço tem efeito positivo nos primeiros 4 meses que se seguem ao choque, o que corresponde a intermediários avessos ao risco, mas apresenta impacto negativo sobre a margem a partir da defasagem 5; o efeito total do risco, no entanto, é positivo.

A taxa de juros apresenta efeito negativo imediato e nas 4 primeiras defasagens, sendo também negativo o efeito total. Esses multiplicadores podem ser interpretados como variação da margem, em CR\$, para aumento de $100 \%$ na taxa de juros. $\mathrm{O}$ efeito inicial negativo pode ser explicado como o efeito da desova de estoques sobre os preços ao produtor e ao varejo. $\mathrm{O}$ efeito positivo seria resultado do impacto do juro no custo de comercialização.

O salário-mínimo apresenta impacto inicial negativo, contrário ao esperado, mas que se torna positivo a partir do $6^{\circ}$ mês. $O$ efeito total é negativo. 
Resultado muito semelhante é encontrado para o preço do óleo diesel, embora, neste caso, todos os multiplicadores sejam muito próximos a zero.

\section{Feijão:}

As matrizes $\mathbf{D}_{1}$ e $\mathbf{D}_{2}$, formadas a partir dos coeficientes estimados para feijão, são:

$$
\begin{aligned}
& D_{1}=\left[\begin{array}{cccc}
0,89248 & -0,03002 & 0 \\
0,48478 & 0,55640 & 0 \\
-0,47231 & 0,57642 & 0
\end{array}\right] \\
& D_{2}=\left[\begin{array}{ccccc}
0,31999 \times 10^{-4} & 0 & 0 & 0 & 0 \\
0,14273 & 0,31251 & -2,38305 & 0,53684 \times 10^{-4} & -0,59772 \times 10^{-5} \\
-0,23065 \times 10^{-4} & 0,28540 & -2,63354 & 0,52914 & -0,64786 \times 10^{-5}
\end{array}\right]
\end{aligned}
$$

As linhas e as colunas têm os mesmos significados que no mercado de arroz e a multiplicação consecutiva das matrizes levou aos multiplicadores de THEIL. As raizes características, calculadas a partir das estimativas dos elementos da matriz $\mathbf{D}_{\mathbf{1}}$, para feijão, são: $0 ; 0,752$; e 0,697 . Estão todas elas dentro do círculo unitário, o que permite não se rejeitar a hipótese de convergência do modelo.

Os multiplicadores, apresentados na Tabela 13, mostram que todos os efeitos alteraram o sentido após 9 meses. $O$ preço de fertilizantes tem efeito imediato negativo, efeito positivo entre o segundo e o nono mês e, novamente, efeito negativo daí em diante. $\mathrm{O}$ risco mostra-se com efeito positivo e bastante acentuado entre o mês corrente e a defasagem 8 , tornando-se esse efeito negativo e irrisório a partir da nona defasagem. A taxa de juros tem efeitos inicial e total negativos, como no mercado de arroz. O salário-mínimo apresenta efeitos inicial e total positivos, conforme pressupõe o modelo; entre a $9^{\mathrm{a}}$ e a $24^{\mathrm{a}}$ defasagem o efeito é negativo, mas muito próximo de zero. $\mathrm{O}$ preço do óleo diesel tem efeitos total e mensal muito próximos de zero, porém negativos. 
Tabela 12 - Efeito de choques nas variáveis exógenas sobre a margem de comercialização de arroz - multiplicadores de THEIL

\begin{tabular}{cccccc}
\hline Meses & Fert $_{f}$ & Risco, $_{\text {f }}$ & Juros $_{\text {, }}$ & SM & Diesel $_{\text {f }}$ \\
\hline 0 & 0,01761 & 0,07300 & $-432,730$ & $-0,01357$ & $-0,00176$ \\
1 & 0,01245 & 0,04294 & $-258,417$ & $-0,00844$ & $-0,00106$ \\
2 & 0,00887 & 0,02442 & $-146,940$ & $-0,00480$ & $-0,00061$ \\
3 & 0,00636 & 0,01221 & $-73,488$ & $-0,00240$ & $-0,0003$ \\
4 & 0,00461 & 0,00431 & $-25,907$ & $-0,00085$ & $-0,00011$ \\
5 & 0,00337 & $-0,00069$ & 4,158 & 0,00014 & $1,71 \times 10^{-5}$ \\
6 & 0,00249 & $-0,00373$ & 22,437 & 0,00073 & $9,24 \times 10^{-5}$ \\
7 & 0,00187 & $-0,00546$ & 32,854 & 0,00107 & 0,00014 \\
8 & 0,00142 & $-0,00633$ & 38,090 & 0,00124 & 0,00016 \\
9 & 0,00110 & $-0,00664$ & 39,966 & 0,00131 & 0,00017 \\
10 & 0,00086 & $-0,00660$ & 39,719 & 0,00130 & 0,00016 \\
11 & 0,00068 & $-0,00634$ & 38,179 & 0,00125 & 0,00016 \\
12 & 0,00055 & $-0,00597$ & 35,901 & 0,00117 & 0,00015 \\
13 & 0,00045 & $-0,00552$ & 33,250 & 0,00109 & 0,00014 \\
14 & 0,00038 & $-0,00506$ & 30,462 & 0,00100 & 0,00013 \\
15 & 0,00032 & $-0,00460$ & 27,689 & 0,00090 & 0,00011 \\
16 & 0,00027 & $-0,00416$ & 25,022 & 0,00082 & 0,00010 \\
17 & 0,00023 & $-0,00374$ & 22,513 & 0,00074 & $9,27 \times 10^{-5}$ \\
18 & 0,00020 & $-0,00335$ & 20,188 & 0,00066 & $8,31 \times 10^{-5}$ \\
19 & 0,00017 & $--0,00300$ & $-18,058$ & 0,00059 & $7,44 \times 10^{-5}$ \\
20 & 0,00015 & $-0,00268$ & 16,121 & 0,00053 & $6,64 \times 10^{-5}$ \\
21 & 0,00013 & $-0,00239$ & 14,370 & 0,00047 & $5,92 \times 10^{-5}$ \\
22 & 0,00011 & $-0,00213$ & 12,795 & 0,00042 & $5,27 \times 10^{-5}$ \\
23 & $9,98 \times 10^{-5}$ & $-0,00189$ & 11,383 & 0,00037 & $4,69 \times 10^{-5}$ \\
24 & $8,77 \times 10^{-5}$ & $-0,00168$ & 10,119 & 0,00033 & $4,17 \times 10^{-5}$
\end{tabular}


Tabela 13 - Efeito de choques nas variáveis exógenas sobre a margem de comercialização de feijão - multiplicadores de THEIL

\begin{tabular}{|c|c|c|c|c|c|}
\hline Meses & Fert, & Risco, $_{\text {, }}$ & Juros $_{\text {, }}$ & $S M_{b_{-}}$ & Diesel, \\
\hline 0 & $-2,3 \times 10^{-5}$ & 0,28540 & $-2,63354$ & 0,52914 & $-6,5 \times 10^{-6}$ \\
\hline 1 & 0,08226 & 0,17869 & $-1,37364$ & $3,09 \times 10^{-5}$ & $-3,4 \times 10^{-6}$ \\
\hline 2 & 0,04780 & 0,10382 & $-0,79808$ & $1,8 \times 10^{-5}$ & $-2,0 \times 10^{-6}$ \\
\hline 3 & 0,02721 & 0,05909 & $-0,45422$ & $1,02 \times 10^{-5}$ & $-1,1 \times 10^{-6}$ \\
\hline 4 & 0,01499 & 0,03255 & $-0,25018$ & $5,64 \times 10^{-6}$ & $-6,3 \times 10^{-7}$ \\
\hline 5 & 0,00781 & 0,01695 & $-0,13032$ & $2,94 \times 10^{-6}$ & $-3,3 \times 10^{-7}$ \\
\hline 6 & 0,00366 & 0,00793 & $-0,06095$ & $1,37 \times 10^{-6}$ & $-1,5 \times 10^{-7}$ \\
\hline 7 & 0,00130 & 0,00282 & $-0,02169$ & $4,89 \times 10^{-7}$ & $-5,4 \times 10^{-8}$ \\
\hline 8 & $2,15 \times 10^{-5}$ & $3,61 \times 10^{-5}$ & $-0,00028$ & $6,25 \times 10^{-9}$ & $-7,0 \times 10^{-10}$ \\
\hline 9 & $-0,00064$ & $-0,00139$ & 0,01068 & $-2,4 \times 10^{-7}$ & $2,68 \times 10^{-8}$ \\
\hline 10 & $-0,00093$ & $-0,00203$ & 0,01562 & $-3,5 \times 10^{-7}$ & $3,92 \times 10^{-8}$ \\
\hline 11 & $-0,00103$ & $-0,00223$ & 0,01718 & $-3,9 \times 10^{-7}$ & $4,31 \times 10^{-8}$ \\
\hline 12 & $-0,00101$ & $-0,00220$ & 0,01690 & $-3,8 \times 10^{-7}$ & $4,24 \times 10^{-8}$ \\
\hline 13 & $-0,00094$ & $-0,00204$ & 0,01571 & $-3,5 \times 10^{-7}$ & $3,94 \times 10^{-8}$ \\
\hline 14 & $-0,00084$ & $-0,00184$ & 0,01412 & $-3,2 \times 10^{-7}$ & $3,54 \times 10^{-8}$ \\
\hline 15 & $-0,00074$ & $-0,00162$ & 0,01243 & $-2,8 \times 10^{-7}$ & $3,12 \times 10^{-8}$ \\
\hline 16 & $-0,00064$ & $-0,00140$ & 0,01079 & $-2,4 \times 10^{-7}$ & $2,72 \times 10^{-8}$ \\
\hline 17 & $-0,00055$ & $-0,00121$ & 0,00928 & $-2,1 \times 10^{-7}$ & $2,33 \times 10^{-8}$ \\
\hline 18 & $-0,00047$ & $-0,00103$ & 0,00793 & $-1,8 \times 10^{-7}$ & $1,99 \times 10^{-8}$ \\
\hline 19 & $-0,00040$ & $-0,00088$ & 0,00675 & $-1,5 \times 10^{-7}$ & $1,69 \times 10^{-8}$ \\
\hline 20 & $-0,00034$ & $-0,00074$ & 0,00573 & $-1,3 \times 10^{-7}$ & $1,44 \times 10^{-8}$ \\
\hline 21 & $-0,00029$ & $-0,00063$ & 0,00484 & $-1,1 \times 10^{-7}$ & $1,22 \times 10^{-8}$ \\
\hline 22 & $-0,00024$ & $-0,00053$ & 0,00409 & $-9,2 \times 10^{-8}$ & $1,03 \times 10^{-8}$ \\
\hline 23 & $-0,00021$ & $-0,00045$ & 0,00345 & $-7,8 \times 10^{-8}$ & $8,66 \times 10^{-9}$ \\
\hline 24 & $-0,00017$ & $-0,00038$ & 0,00291 & $-6,6 \times 10^{-8}$ & $7,31 \times 10^{-9}$ \\
\hline Total & 0,17463 & 0,66465 & $-5,54896$ & 0,52921 & $-1,4 \times 10^{-5}$ \\
\hline
\end{tabular}

Fonte: dados da pesquisa. 


\subsubsection{Modelo VAR não-identificável}

Esse item apresenta os resultados da estimação do modelo VAR realizada com o uso da fatoração de Cholesky, ou seja, admitindo-se uma relação recursiva entre as variáveis. Recapitulando, o produto dessa análise são os testes $\mathbf{F}$ de exogeneidade, a parcela de cada variável na decomposição da variância dos erros de previsão da margem de comercialização e dos preços ao produtor e ao varejo, e as elasticidades de impulso das variáveis sobre a margem de comercialização. Note-se que as variáveis agora são transformadas em logaritmos (com exceção da taxa de juros), de maneira que se dispõem de elasticidades e não de variações como na análise dos multiplicadores de THEIL.

\section{Arroz:}

As relações de exogeneidade tipo Granger-Sims entre as variáveis do mercado de arroz estão sumariadas nos testes $\mathbf{F}$, apresentados na Tabela 14. No tocante aos insumos, considerando-se níveis de significância de até $10 \%$, os resultados mostram que: o preço do óleo diesel é exógeno em relação às demais variáveis; o índice de preço de fertilizantes é afetado pelos valores defasados do preço do óleo diesel e da taxa de juros, além de depender de seu próprio valor defasado; o salário-mínimo tem seu valor antecipado pelos valores passados de todas as demais variáveis, exceção feita ao índice de preços dos fertilizantes e ao risco de preço57; a taxa de juros tem suas variações antecipadas pelo índice de preços dos fertilizantes e por seu valor defasado; e o risco de preço comporta-se como exógeno às demais variáveis.

De maior interesse para os objetivos deste trabalho é a relação entre os preços aos diferentes níveis de mercado. A Tabela 14 mostra que o preço do varejo é explicado por valores passados da taxa de juros e do preço de fertilizantes; o modelo realmente previa que o preço ao varejo seria função do preço do insumo agrícola. $\mathbf{O}$ preço ao produtor é afetado apenas pela taxa de juros, o mesmo ocorrendo com a margem de comercialização.

57 Isso em parte se justifica pelo fato de o salário-mínimo ter sido, na maior parte do período analisado, reajustado com base na inflação passada, que, por sua vez, é influenciạda por diversos dos preços aqui utilizados. 
Tabela 14 - Valores dos testes F para o mercado de arroz, dạdos de 1975 a 1993

\begin{tabular}{l|ccccccccc}
\hline Equacão & \multicolumn{7}{c}{ Variável } \\
& Diesel & Fert & SM & Juros & Risco4 & Pv & Pp & Marg \\
\hline Diesel & $24,96^{* * *}$ & 1,07 & 1,06 & 1,11 & 0,67 & 1,01 & 1,02 & 0,89 \\
Fert & $2,82^{* * *}$ & $14,15 * * *$ & 0,67 & $2,33 * * *$ & 1,02 & 0,29 & 0,39 & 0,28 \\
SM & $2,05 * *$ & 1,15 & $25,72 * * *$ & $1,77^{*}$ & 1,57 & $3,09 * * *$ & $2,47 * *$ & $2,89 * * *$ \\
Juros & 1,57 & $2,07 * *$ & 0,87 & $6,43 * * *$ & 1,12 & 0,72 & 0,80 & 0,67 \\
Risco4 & 0,60 & 0,73 & 1,00 & 0,84 & $12,12 * * *$ & 0,73 & 0,68 & 0,86 \\
Pv & 0,80 & $1,67 *$ & 1,49 & $4,79 * *$ & 1,26 & 0,73 & 0,92 & 0,62 \\
Pp & 0,62 & 0,86 & 1,15 & $2,01 * *$ & 1,17 & 1,24 & 0,60 & 1,39 \\
Marg & 0,74 & 1,05 & 1,24 & $2,96 * * *$ & 1,38 & 0,64 & 0,91 & $1,59 *$ \\
\hline
\end{tabular}

* significativo, a 10\%;

** significativo, a 5\%;

*** significativo, a $1 \%$;

Fonte: dados da pesquisa.

As elasticidades de impulso das diversas variáveis sobre a margem de comercialização de arroz são apresentadas na Tabela 15 e nas Figuras 1.1 a 1.8 (Apêndice 1). Esses resultados devem ser analisados conjuntamente com a decomposição da variância dos erros de previsão da margem, apresentada na Tabela 16.

Verifica-se que o preço do óleo diesel explica uma parcela muito pequena da variância dos erros de previsão da margem de comercialização de arroz, particularmente nos primeiros meses (Tabela 16). 0 efeito inicial de aumento de $1 \%$ no preço do óleo diesel é redução inexpressiva na margem de comercialização $(0,051 \%)$; apenas a partir do $6^{\circ}$ mês verificam-se aumentos na margem (Tabela 15 e Figura 1.1). No decorrer do período, as elasticidades convergem aproximando-se de zero.

$O$ indice de preços dos fertilizantes tem ganho de importância na explicação da variância dos erros de previsão da margem de comercialização de arroz à medida que os meses passam, atingindo $10 \%$ no $7^{\circ}$ mês e permanecendo nesse patamar 
até o $24^{\circ}$ mês. As elasticidades de impulso dessa variável (Tabela 15 e Figura 1.2) foram quase todas positivas, conforme supõe o modelo de causalidade varejo $\rightarrow$ produtor (para valores correntes do insumo agrícola), aparentemente convergindo após cerca de 12 meses.

$O$ efeito de choques no salário-mínimo sobre a margem de comercialização de arroz é de pequena importância na explicação da variância dos erros de previsão dessa última, principalmente no primeiro mês (Tabela 16). 0 impacto inicial, em termos de elasticidade de impulso (Tabela 15 e Figura 1.3) é positivo, conforme prevê o modelo teórico, havendo um movimento que converge em torno do $6^{\circ}$ mês.

A elasticidade de impulso da taxa de juros sobre a margem foi negativa nos 5 primeiros meses e assumiu dois picos de valores positivos até o $12^{\circ}$ mês, convergindo a seguir (Tabela 15 e Figura 1.4). O valor negativo inicial é o oposto do esperado por meio do modelo teórico. As justificativas para esse sinal são as mesmas apresentadas para a análise estática: o aumento dos juros provoca inicialmente uma desova de estoques que proporciona queda nos preços ao varejo e, conseqüentemente, na margem de comercialização; os valores positivos ocorridos após o $6^{\circ}$ mês decorrem da queda dos preços ao produtor ${ }^{58}$. A importância do juro na explicação da variância dos erros de previsão da margem de arroz acentua-se, significativamente, no decorrer do período, chegando a valores de, aproximadamente, $16 \%$ no segundo ano (Tabela 16).

O risco de preço, de pequena importância na explicação da variância dos erros de previsão da margem de comercialização de arroz, apresenta elasticidades de impulso positivas durante os 9 primeiros meses, oscilando no restante do período (Tabela 15 e Figura 1.5). 0 impacto positivo no início do período é consistente com aversão ao risco por parte dos agentes de comercialização de arroz, muito embora o efeito dessa variável seja, conforme se disse, de menor importância.

A Tabela 16 mostra, também, que o preço ao varejo é o principal fator na explịcação da variância dos erros de previsão da margem de comercialização do arroz.

58 As elasticidades de impulso da taxa de juros sobre os preços ao varejo e ao produtor (não apresentadas aqui) mostram que aumento na taxa de juros reduz o preço ao varejo durante praticamente os 9 primeiros meses que se seguem ao choque (com exceção do $6^{\circ}$ e $7^{\circ}$ mês) e reduz o preço ao produtor (depois de provocar um acréscimo inicial) entre o $6^{\circ}$ e $09^{\circ}$ mês. 
No primeiro mês, quase dois terços da variância dos erros de previsão da margem se devem ao preço no varejo, fração essa que se reduz para cerca de $32 \%$ à medida que cresce a importância da taxa de juros. As elasticidades de impulso (Tabela 15 e Figura 1.6) mostram que aumento de $10 \%$ no preço ao varejo proporciona aumento imediato de $15,8 \%$ na margem de comercialização, seguido de aumentos de $11,1 \%, 8,8 \%, 7,5 \%$ e $3,8 \%$, respectivamente entre o $2^{\circ}$ e o $5^{\circ}$ mês. Entre o $6^{\circ}$ e o $10^{\circ}$ mês, a margem sofre reduções, vindo a convergir a partir de então (admitindo ainda algumas flutuações em torno de zero). Uma explicação plausível para a queda da margem, alguns meses após o aumento do preço no varejo, pode ser encontrada no modelo teórico apresentado: o aumento do preço no varejo provocaria redução das vendas, excesso de demanda negativo e, num segundo momento, menor preço no varejo [equação (97)], com redução da margem. Mais tarde, o menor preço no varejo diminuiria o preço ao produtor [equações (99) e (100)], e a margem se estabilizaria ${ }^{59}$.

O preço ao produtor mostra-se importante na explicação da variância dos erros de previsão da margem principalmente no início do período (Tabela 16); responde por $25 \%$ da variância no primeiro mês. As elasticidades de impulso são negativas no início do período, tornando-se positivas no $5^{\circ}$ mês e convergindo a partir do $10^{\circ}$ mês (Tabela 15 e Figura 1.7). No entanto, os valores dessa elasticidade, com exceção do primeiro mês (em que um aumento de $10 \%$ no preço ao produtor reduz a margem em $9 \%$ ), estão bastante próximos de zero.

O impacto de choques na margem sobre ela mesma é bastante insignificante em termos de explicação da variância dos erros de previsão no primeiro mês, aumentando para algo em torno de $10 \%$ nos meses seguintes (Tabela 16). Os valores iniciais das elasticidades de impulso são positivos (o valor inicial é igual a 1 , obviamente porque aumento de $10 \%$ da margem equivale a aumento de $10 \%$ nela mesma, no mesmo mệs), invertendo-se o seu sinal a partir do $12^{\circ}$ mês (Tabela 15 e Figura 1.8 ). Após os primeiros 23 meses, a elasticidade, aparentemente, converge a zero.

59 As elasticidades de impulso para choques no preço ao varejo (não apresentadas aqui) mostram valores negativos sobre o preço ao varejo entre o $6^{\circ}$ e o $10^{\circ}$ mês (após valores positivos até o $5^{\circ}$ mês) e valores negativos sobre o preço ao produtor entre o $14^{\circ}$ e o $19^{\circ}$ mês; ou seja, um choque positivo (aumento) no preço ao varejo provoca reduções tanto no preço ao varejo quanto no preço ao produtor, dali a alguns meses. 
Tabela 15 - Elasticidades de impulso sobre a margem de comercialização de arroz no modelo VAR não-identificável, dados de 1975 a 1993

\begin{tabular}{ccccccccc}
\hline Meses & Diesel & Fert & $S M$ & Juros & Risco4 & $P v$ & $P p$ & Marg \\
\hline 1 & $-0,0511$ & 0,1267 & 0,2270 & $-1,2737$ & 0,0744 & 1,5773 & $-0,9043$ & 1,0000 \\
2 & $-0,0326$ & 0,3150 & 0,5714 & $-0,6015$ & 0,0709 & 1,1112 & $-0,2931$ & 1,6905 \\
3 & $-0,1034$ & 0,1277 & 0,1399 & $-0,5804$ & 0,0820 & 0,8851 & $-0,3723$ & 1,3410 \\
4 & $-0,1617$ & 0,4900 & 0,2778 & $-0,3838$ & 0,0774 & 0,7485 & $-0,2246$ & 0,7692 \\
5 & $-0,1384$ & 0,6017 & 0,3279 & $-0,0431$ & 0,0008 & 0,3832 & 0,0687 & 0,7575 \\
6 & 0,1663 & 0,7170 & $-0,0361$ & 1,0230 & 0,0066 & $-0,0748$ & 0,2665 & 0,5107 \\
7 & 0,2031 & 0,5768 & 0,0009 & 0,6186 & 0,0032 & $-0,1251$ & 0,3671 & 0,4086 \\
8 & 0,2059 & 0,6581 & $-0,1704$ & $-0,2083$ & 0,0247 & $-0,4141$ & 0,3699 & 0,5733 \\
9 & 0,2999 & 0,3030 & $-0,1130$ & $-0,0750$ & 0,0312 & $-0,3693$ & 0,2814 & $-0,0415$ \\
10 & 0,0680 & 0,3862 & 0,0570 & 1,8798 & $-0,0166$ & $-0,2997$ & 0,4730 & 0,2834 \\
11 & 0,1616 & 0,4693 & 0,0076 & 2,1763 & $-0,0712$ & 0,0048 & 0,1757 & 0,1761 \\
12 & 0,3738 & 0,0498 & $-0,0169$ & 1,7781 & $-0,0491$ & 0,3500 & $-0,0080$ & $-0,5882$ \\
13 & 0,0763 & 0,1953 & $-0,0021$ & 0,4459 & $-0,0190$ & 0,0744 & 0,0538 & $-0,3917$ \\
14 & 0,1411 & 0,0143 & $-0,0020$ & $-0,9234$ & 0,0346 & 0,0330 & $-0,0057$ & $-0,4876$ \\
15 & 0,2699 & 0,0605 & $-0,0621$ & $-0,4996$ & 0,0445 & $-0,1715$ & $-0,0709$ & $-1,0891$ \\
16 & 0,2410 & $-0,0313$ & 0,0219 & $-0,3262$ & 0,0260 & $-0,0903$ & $-0,0965$ & $-0,9226$ \\
17 & 0,1076 & 0,0195 & $-0,1309$ & $-0,3016$ & 0,0192 & $-0,2464$ & 0,0838 & $-0,7779$ \\
18 & 0,0460 & 0,1124 & $-0,1323$ & $-0,0776$ & 0,0401 & $-0,3781$ & 0,0382 & $-0,4916$ \\
19 & 0,1243 & 0,2746 & $-0,1737$ & 0,1099 & $-0,0099$ & $-0,4281$ & 0,0409 & $-0,4097$ \\
20 & 0,1157 & 0,1583 & $-0,1452$ & 0,4547 & 0,0023 & $-0,1578$ & 0,0062 & $-0,5788$ \\
21 & $-0,0292$ & 0,0390 & $-0,0102$ & 1,0870 & 0,0222 & 0,0539 & 0,0924 & $-0,4771$ \\
22 & 0,0404 & 0,1780 & 0,0444 & 1,3158 & 0,0070 & 0,1176 & 0,1975 & $-0,4186$ \\
23 & 0,1125 & 0,0771 & $-0,0162$ & 0,3648 & 0,0033 & 0,1283 & 0,1949 & $-0,1091$ \\
24 & 0,0911 & 0,1038 & 0,0460 & 0,3555 & $-0,0075$ & 0,0546 & 0,0930 & 0,0327 \\
\hline & & & & & & & &
\end{tabular}

Fonte: Dados da pesquisa. 
Tabela 16 - Decomposição da variância dos erros de previsão da margem de comercialização de arroz no modelo VAR não-identificável, dados de 1975 a 1993, em porcentagem

\begin{tabular}{crrrrrrrrr}
\hline Meses & Diesel & Fert & \multicolumn{1}{c}{ SM } & Juros & Risco4 & \multicolumn{1}{c}{ Pv } & \multicolumn{1}{c}{ Pp } & Marg \\
\hline 1 & 0,09 & 0,29 & 2,04 & 5,89 & 3,48 & 59,31 & 25,07 & 3,84 \\
2 & 0,08 & 1,28 & 9,21 & 4,44 & 4,09 & 54,71 & 17,08 & 9,12 \\
3 & 0,25 & 1,19 & 7,90 & 4,24 & 5,46 & 54,00 & 16,06 & 10,90 \\
4 & 0,62 & 2,92 & 8,21 & 3,92 & 6,39 & 52,81 & 14,65 & 10,48 \\
5 & 0,85 & 5,36 & 9,36 & 3,65 & 5,94 & 50,53 & 13,68 & 10,64 \\
6 & 1,17 & 8,51 & 8,76 & 4,85 & 5,56 & 47,24 & 13,60 & 10,31 \\
7 & 1,63 & 10,24 & 8,32 & 5,10 & 5,28 & 45,00 & 14,40 & 10,03 \\
8 & 2,02 & 12,14 & 8,13 & 4,81 & 5,05 & 43,27 & 14,82 & 9,76 \\
9 & 2,96 & 12,22 & 7,99 & 4,63 & 5,06 & 42,70 & 15,05 & 9,39 \\
10 & 2,79 & 12,10 & 7,42 & 8,12 & 4,73 & 40,11 & 15,96 & 8,78 \\
11 & 2,84 & 12,31 & 6,88 & 12,30 & 5,26 & 37,18 & 15,06 & 8,17 \\
12 & 3,96 & 11,61 & 6,48 & 14,58 & 5,35 & 35,79 & 14,18 & 8,04 \\
13 & 3,98 & 11,71 & 6,44 & 14,66 & 5,37 & 35,58 & 14,11 & 8,14 \\
14 & 4,10 & 11,54 & 6,35 & 15,25 & 5,49 & 35,09 & 13,91 & 8,26 \\
15 & 4,64 & 11,26 & 6,23 & 15,08 & 5,66 & 34,36 & 13,59 & 9,18 \\
16 & 5,06 & 11,08 & 6,13 & 14,93 & 5,67 & 33,85 & 13,44 & 9,83 \\
17 & 5,09 & 10,93 & 6,21 & 14,81 & 5,65 & 33,74 & 13,31 & 10,26 \\
18 & 5,03 & 10,82 & 6,28 & 14,59 & 5,80 & 34,04 & 13,12 & 10,32 \\
19 & 5,06 & 10,93 & 6,44 & 14,32 & 5,71 & 34,40 & 12,88 & 10,27 \\
20 & 5,12 & 10,92 & 6,57 & 14,35 & 5,65 & 34,19 & 12,75 & 10,46 \\
21 & 5,06 & 10,78 & 6,48 & 15,13 & 5,65 & 33,75 & 12,64 & 10,52 \\
22 & 4,96 & 10,69 & 6,36 & 16,22 & 5,53 & 33,13 & 12,65 & 10,46 \\
23 & 5,03 & 10,65 & 6,33 & 16,23 & 5,50 & 33,02 & 12,83 & 10,40 \\
24 & 5,08 & 10,66 & 6,33 & 16,29 & 5,49 & 32,93 & 12,85 & 10,37 \\
\hline & & & & & & & &
\end{tabular}

Fonte: Dados da pesquisa. 
A maior importância dos preços do produto do que dos preços dos itens de custo, na explicação da margem de arroz, sugere que a margem de comercialização desse produto tem variado mais em decorrência de choques na oferta agrícola e na demanda primária do que na oferta de insumos. Esse resultado tem importante implicação política, como será discutido mais adiante.

É interessante comparar os resultados obtidos pelos modelos VAR (Tabela 15) com aqueles advindos dos multiplicadores de THEIL (Tabela 12). O preço do óleo diesel, a taxa de juros e o índice de preços de fertilizantes apresentam resultados muito semelhantes, nas duas formas analíticas, no que diz respeito ao sinal do impacto; os preços de fertilizantes têm efeito positivo sobre a margem durante quase todo o período de análise (exceção ao $16^{\circ}$ mês dos modelos VAR), enquanto o preço do óleo diesel e a taxa de juros mostram efeitos negativos até o $5^{\circ}$ mês (que corresponde à defasagem 4 dos multiplicadores de THEIL, já que nos resultados da análise de auto-regressão vetorial denomina-se de mês 1 o efeito imediato denominado de mês zero na análise dos multiplicadores), seguidos de efeitos positivos (havendo ainda algumas oscilações de sinal no impacto da taxa de juros pelos modelos VAR). $O$ risco de preço mostra efeito inicial positivo nos dois métodos, ficando esse efeito negativo a partir da $5^{\mathrm{a}}$ defasagem na análise por multiplicadores e a partir do $10^{\circ}$ mês na análise de auto-regressão vetorial. 0 salário-mínimo é a maior exceção, apresentando efeitos opostos nos dois métodos de análise.

As Tabelas 17 e 18 mostram, ainda, a decomposição da variância dos erros de previsão dos preços ao varejo e ao produtor. Verifica-se que a taxa de juros é o mais importante fator na explicação da variância dos erros de previsão do preço ao produtor (Tabela 18) a partir do $11^{\circ}$ mês. É interessante observar, também, a importância crescente do salário-mínimo sobre o preço ao produtor. A importância do preço dos fertilizantes também não é pequena, girando ao redor de $10 \%$ a partir do $7^{\circ}$ mês.

A Tabela 17 mostra que a variância dos erros de previsão do preço ao varejo depende, nos primeiros meses, quase que tão somente do próprio preço ao varejo; a importância do preço ao produtor e da taxa de juros (principalmente) cresce ao longo do período. Merece destaque, também, a participação do índice de preços de fertilizantes; o modelo teórico previa que o preço do insumo agrícola afetaria, expressivamente, o - preço ao varejo, o que é suportado por esses resūltados. 
Tabela 17 - Decomposição da variância dos erros de previsão do preço de arroz ao varejo no modelo VAR não-identificável, dados de 1975 a 1993, em porcentagem

\begin{tabular}{crrrrrrrr}
\hline Meses & Diesel & Fert & \multicolumn{1}{c}{$S M$} & Juros & Risco4 & \multicolumn{1}{c}{$P v$} & $P p$ & Marg \\
\hline 1 & 0,36 & 1,37 & 3,30 & 3,94 & 2,96 & 88,07 & 0,00 & 0,00 \\
2 & 0,22 & 2,88 & 11,24 & 3,05 & 3,58 & 75,26 & 3,58 & 0,20 \\
3 & 0,28 & 3,94 & 10,89 & 2,76 & 3,32 & 72,83 & 5,68 & 0,30 \\
4 & 0,26 & 9,06 & 10,92 & 2,42 & 2,87 & 65,66 & 8,00 & 0,81 \\
5 & 0,22 & 15,17 & 12,34 & 2,16 & 2,79 & 55,59 & 11,04 & 0,69 \\
6 & 0,69 & 21,35 & 10,77 & 2,02 & 2,59 & 47,80 & 14,16 & 0,60 \\
7 & 1,09 & 25,03 & 9,89 & 1,84 & 2,44 & 42,44 & 16,71 & 0,56 \\
8 & 1,22 & 27,16 & 9,04 & 1,68 & 2,23 & 39,65 & 18,17 & 0,84 \\
9 & 1,62 & 26,47 & 8,54 & 1,68 & 2,40 & 38,26 & 20,22 & 0,80 \\
10 & 1,66 & 24,31 & 7,85 & 7,32 & 2,15 & 34,30 & 21,56 & 0,84 \\
11 & 1,97 & 22,29 & 6,91 & 15,82 & 2,04 & 29,96 & 20,26 & 0,75 \\
12 & 3,25 & 19,69 & 6,24 & 22,53 & 1,87 & 26,99 & 18,48 & 0,97 \\
13 & 3,37 & 18,84 & 6,07 & 24,42 & 1,81 & 25,77 & 18,44 & 1,29 \\
14 & 3,49 & 18,50 & 6,00 & 23,98 & 2,09 & 25,31 & 18,73 & 1,90 \\
15 & 3,74 & 18,01 & 5,86 & 23,45 & 2,23 & 25,21 & 18,38 & 3,11 \\
16 & 3,85 & 17,69 & 5,99 & 23,59 & 2,26 & 24,85 & 17,89 & 3,88 \\
17 & 3,79 & 17,44 & 6,01 & 23,80 & 2,26 & 24,96 & 17,60 & 4,14 \\
18 & 3,72 & 17,11 & 6,14 & 24,06 & 2,37 & 25,20 & 17,26 & 4,14 \\
19 & 3,67 & 16,86 & 6,18 & 24,42 & 2,34 & 25,39 & 17,05 & 4,09 \\
20 & 3,62 & 16,63 & 6,33 & 25,23 & 2,30 & 24,98 & 16,85 & 4,06 \\
21 & 3,55 & 16,15 & 6,67 & 27,04 & 2,28 & 24,16 & 16,20 & 3,95 \\
22 & 3,40 & 15,47 & 6,91 & 29,34 & 2,20 & 23,36 & 15,52 & 3,81 \\
23 & 3,35 & 15,26 & 6,97 & 29,98 & 2,16 & 23,15 & 15,39 & 3,74 \\
24 & 3,33 & 15,03 & 7,26 & 30,41 & 2,13 & 22,84 & 15,30 & 3,71 \\
\hline
\end{tabular}

Fonte: Dados da Pesquisa. 
Tabela 18 - Decomposição da variância dos erros de previsão do preço de arroz ao produtor no modelo VAR não-identificável, dados de 1975 a 1993, em porcentagem

\begin{tabular}{crrrrrrrr}
\hline Meses & Diesel & Fert & \multicolumn{1}{c}{ SM } & Juros & Risco4 & \multicolumn{1}{c}{$P v$} & Pp & Marg \\
\hline 1 & 0,45 & 1,85 & 1,97 & 0,04 & 0,05 & 12,65 & 82,98 & 0,00 \\
2 & 0,30 & 1,53 & 2,65 & 0,27 & 0,42 & 12,50 & 77,51 & 4,81 \\
3 & 1,79 & 2,93 & 2,96 & 0,33 & 1,81 & 8,74 & 72,38 & 9,05 \\
4 & 3,26 & 5,26 & 2,88 & 0,26 & 3,50 & 6,92 & 66,95 & 10,96 \\
5 & 3,71 & 8,24 & 3,15 & 0,70 & 3,46 & 6,12 & 64,23 & 10,39 \\
6 & 3,75 & 11,33 & 3,51 & 1,95 & 3,63 & 5,63 & 60,58 & 9,62 \\
7 & 4,04 & 14,75 & 4,10 & 2,60 & 3,63 & 5,12 & 57,00 & 8,75 \\
8 & 4,01 & 16,23 & 4,83 & 2,53 & 3,50 & 4,95 & 55,59 & 8,37 \\
9 & 3,81 & 15,88 & 5,13 & 3,23 & 3,65 & 4,89 & 55,48 & 7,93 \\
10 & 4,15 & 15,28 & 5,06 & 5,29 & 3,80 & 4,60 & 54,37 & 7,47 \\
11 & 4,50 & 14,64 & 4,66 & 9,94 & 3,81 & 4,22 & 51,34 & 6,88 \\
12 & 4,46 & 13,18 & 4,53 & 16,78 & 3,62 & 3,82 & 47,33 & 6,28 \\
13 & 4,48 & 11,97 & 4,37 & 21,43 & 3,82 & 3,47 & 44,41 & 6,06 \\
14 & 4,34 & 11,36 & 4,27 & 22,65 & 3,87 & 3,40 & 43,64 & 6,47 \\
15 & 4,21 & 10,97 & 4,35 & 23,48 & 3,73 & 3,78 & 42,79 & 6,69 \\
16 & 3,99 & 10,60 & 4,78 & 25,86 & 3,54 & 3,92 & 40,75 & 6,56 \\
17 & 3,82 & 10,40 & 5,50 & 27,58 & 3,40 & 4,03 & 38,97 & 6,30 \\
18 & 3,67 & 10,17 & 6,65 & 28,64 & 3,28 & 4,04 & 37,50 & 6,05 \\
19 & 3,67 & 10,24 & 7,57 & 29,01 & 3,21 & 3,92 & 36,48 & 5,91 \\
20 & 3,73 & 10,46 & 8,75 & 29,31 & 3,07 & 3,79 & 35,15 & 5,73 \\
21 & 3,60 & 10,57 & 9,83 & 30,03 & 2,94 & 3,80 & 33,72 & 5,49 \\
22 & 3,49 & 10,59 & 10,39 & 31,24 & 2,82 & 3,85 & 32,36 & 5,28 \\
23 & 3,42 & 10,64 & 10,48 & 32,01 & 2,76 & 3,88 & 31,64 & 5,17 \\
24 & 3,35 & 10,52 & 10,88 & 32,53 & 2,70 & 3,81 & 31,12 & 5,08 \\
\hline
\end{tabular}

Fonte: Dados da Pesquisa. 


\section{Feijão:}

A Tabela 19 mostra os resultados dos testes $\mathbf{F}$ de exogeneidade tipo Granger-Sims entre as variáveis no mercado de feijão. Considerando-se um nível de significância de até $10 \%$, a relação de causalidade entre preço do óleo diesel e fertilizantes permanece a mesma constatada para o mercado de arroz. Entretanto, a previsão do preço do óleo diesel é melhorada com o uso dos valores passados dos preços ao varejo e ao produtor e da margem de comercialização. Verifica-se também, no que diz respeito aos insumos agrícola e de comercialização, o papel bastante ativo das diversas variáveis sobre a taxa de juros e sobre o salário-mínimo, e da taxa de juros sobre as demais. Os resultados mostram relação bi-causal entre a taxa de juros e o preço de fertilizantes, o risco e o preço ao produtor, e causalidade do preço ao varejo para a taxa de juros. Verifica-se, também, causalidade do preço ao produtor, do preço ao varejo, da taxa de juros e da margem para o salário-mínimo ${ }^{60}$. A variável risco é influenciada por seus valores passados e pelos valores passados da taxa de juros.

Os resultados dos testes $\mathbf{F}$, para os preços e para a margem, não mostram diretamente causalidade produtor $\rightarrow$ varejo. $O$ preço ao produtor de feijão não é influenciado pelo preço ao varejo, mas sim pelo preço do fertilizante e do óleo diesel ${ }^{61}$, pela taxa de juros, pelo salário-mínimo e pelo risco de preço. $\mathrm{O}$ preço ao varejo é influenciado apenas por seus valores passados e pelo preço do óleo diesel. A margem é causada tão somente pela taxa de juros.

60 Da mesma forma que no mercado de arroz, as variáveis do mercado de feijão ajudam na explicação do salário-mínimo. A justificativa é a mesma: o salário-mínimo geralmente é corrigido pela inflação passada, que é influenciada por diversos preços.

61 Embora o preço do óleo diesel tenha sido aqui utilizado como insumo de comercialização, ele também é importante insumo agricola. Admitindo-se causalidade produtor $\rightarrow$ varejo, o preço do produtor só deveria ser influenciado por insumos agrícolas, o que é coerente com os resultados encontrados. 
Tabela 19 - Valores dos testes F para o mercado de feijão, dados de 1975 a 1993

\begin{tabular}{l|llllllll}
\multirow{2}{*}{ Equação } & \multicolumn{7}{c}{ Variável } \\
\cline { 2 - 9 } & Diesel & Fert & $S M$ & Juros & Risco4 & $P_{p}$ & $P v$ & Mar $_{g}$ \\
\hline Diesel & $37,61 * *$ & 0,57 & 1,19 & 1,45 & 1,44 & $2,14 * *$ & $1,99 * *$ & $2,14 * *$ \\
Fert & $2,29 * *$ & $18,19 * *$ & 0,93 & $1,87 * *$ & 1,27 & 0,63 & 0,54 & 0,93 \\
SM & 1,00 & 1,20 & $14,30 * *$ & $2,37 * *$ & 1,44 & $2,03 * *$ & $2,15 * *$ & $1,74 *$ \\
Juros & 0,82 & $2,85 * * *$ & 0,57 & $6,46 * *$ & $1,70 *$ & $1,90 * *$ & $2,05 * *$ & 1,09 \\
Risco4 & 0,27 & 0,72 & 0,50 & $1,68 *$ & $9,43 * * *$ & 0,62 & 0,98 & 0,92 \\
Pp & $2,10 * *$ & $2,06 * *$ & $2,07 * *$ & $1,79 *$ & $1,83 * *$ & 1,03 & 0,96 & 0,84 \\
Pv & $1,63 *$ & 1,07 & 1,22 & 1,30 & 1,49 & 1,35 & $3,95 * *$ & 1,57 \\
Marg & 0,71 & 0,44 & 0,82 & $4,21 * *$ & 1,08 & 1,07 & 1,55 & 1,48 \\
\hline
\end{tabular}

* significativo, a $10 \%$;

** significativo, a 5\%;

*** significativo, a $1 \%$;

Fonte: dados da pesquisa.

As Tabelas 20 a 23 e as Figuras 1.9 a 1.16 (no Apêndice 1) são análogas às apresentadas para o mercado de arroz. Como no item anterior, procede-se à análise com os resultados das elasticidades de impulso e da decomposiçầo da variância dos erros de previsão da margem de comercialização, simultaneamente.

O preço do óleo diesel tem pequena importância, embora crescente, na variância dos erros de previsão da margem de comercialização de feijão (Tabela 21). 0 impacto mostrado pelas elasticidades de impulsos (Tabela 20 e Figura 1.9) é negativo no mês corrente e no $1^{\circ}$ mês (contrário ao esperado), tornando-se positivo entre o $2^{\circ}$ e o $8^{\circ}$ mês (com pico de 0,80 no $7^{\circ}$ mês, ou seja, um aumento de $8 \%$ na margem em decorrência de um aumento de $10 \%$ no preço do óleo diesel) e negativo a partir do $9^{\circ}$ mês. Aparentemente, o efeito não se anula mesmo após 24 meses. Os resultados dos prịmeiros meses (com exceção do mês corrente e do mês seguinte) mostram-se consistentes com o que se esperava teoricamente; esse efeito não havia sido captado pela análise estática. Verifica-se, também, similaridade entre os resultados encontrados para os dois produtos. 
$\mathrm{O}$ índice de preços dos fertilizantes apresenta pequeno poder explicativo da variância do erro de previsão da margem no primeiro ano após o choque, aumentando, expressivamente, sua importância no segundo ano (Tabela 21). $\mathrm{O}$ sinal das elasticidades de impulso do preço de fertilizantes sobre a margem é positivo nos primeiros meses, embora o modelo dinâmico tenha previsto impacto inicial negativo. Existem ainda valores bastante elevados entre $o 11^{\circ}$ e o $20^{\circ}$ mês, fato esse de dificil interpretação econômica (Tabela 20 e Figura 1.10).

O salário-mínimo apresenta efeito irrisório na explicação da variância dos erros de previsão da margem de comercialização de feijão (Tabela 21). A elasticidade de impacto que inicialmente é positiva, conforme previsão do modelo teórico, apresenta oscilações acentuadas ao longo de todo o período (Tabela 20 e Figura 1.11).

A importância da taxa de juros sobre a margem de comercialização de feijão foi tão grande quanto no mercado de arroz. A parcela da variância dos erros de previsão da margem cabível à taxa de juros situa-se entre $12 \%$ e $16 \%$ durante os 24 meses de análise, com exceção da pequena importância nos primeiros 4 meses (Tabela 21). O sinal das elasticidades de impulso da taxa de juros sobre a margem oscilou, sendo negativo no $2^{\circ}$ e $3^{\circ}$ no mês e positivo entre o $4^{\circ}$ e o $6^{\circ}$ mês; nos demais meses, continuaram ocorrendo oscilações expressivas (Figura 1.12 e Tabela 20). 0 relacionamento da margem com o juro é bastante semelhante nos dois mercados aqui estudados, de maneira que cabe ao mercado de feijão a análise que foi feita para o arroz; ter-se-ia, inicialmente, o impacto da venda de estoques e, depois, o efeito do aumento do custo de comercialização.

A variável risco mostra-se de grande importância na explicação da variância dos erros de previsão da margem de feijão durante os 24 meses (Tabela 21). A análise estática já havia mostrado a importância dessa variável para o mercado do feijão, agora confirmada pela análise de auto-regressão vetorial. As elasticidades de impulso do risco sobre a margem são inicialmente positivas, comprovando a aversão ao risco por parte dos comerciantes de feijão (Tabela 20 e Figura 1.13), e oscilam a seguir dentro de uma faixa entre 0,2 e $-0,2$.

O preço ao produtor explica, em média, cerca de $8 \%$ da variância dos erros de previsão da margem de feijão (Tabela 21). $O$ efeito, inicialmente negativo, torna- 
se positivo no $2^{\circ}$ mês, vindo a convergir dali a uns 12 meses após algumas oscilações (Tabela 20 e Figura 1.14).

A variável mais importante na explicação da variância dos erros de previsão da margem de feijão é o preço ao varejo, com parcela que variava de quase $50 \%$, no $1^{\circ}$ mês, a $28 \%$, no $24^{\circ}$ mês (Tabela 21 ). A elasticidade de impulso do preço ao varejo sobre a margem é extremamente elevada nos primeiros meses; no $1^{\circ}$ mês, aumento de $10 \%$ no preço ao varejo proporciona aumento de $37 \%$ na margem de comercialização (Tabela 20 e Figura 1.15). Após o $7^{\circ}$ mês, a elasticidade de impulso oscila em torno do valor zero, apresentando ainda alguns picos elevados (próximos de +1 e -1 ) até o $18^{\circ}$ mês. Esse resultado realça, também, a importância que choques na demanda primária podem ter sobre a margem de comercialização de feijão.

O impacto da margem sobre si mesma mostra-se geralmente negativo (após o valor inicial de 1) e convergente (Tabela 20 e Figura 1.16). A parcela da margem na variância de seus erros de previsão fica entre $19 \%$, no $1^{\circ}$ mês, e $11 \%$, no $24^{\circ}$ (Tabela 21).

Comparando os resultados obtidos com os modelos VAR (Tabela 20) e aqueles procedentes dos multiplicadores de THEIL (Tabela 13), para o mercado de feijão, não se verificam tantas semelhanças como havia ocorrido no mercado de arroz. Entretanto, o salário-mínimo, que havia apresentado os efeitos mais contrastantes no mercado de arroz, agora mostra impactos muito semelhantes nos dois tipos de análise. 0 risco de preço também apresenta, nos dois métodos, impacto positivo nos primeiros meses, seguido por impactos negativos à medida que aumentam as defasagens. Mas em geral, os modelos VAR mostram contínuas oscilações de sinal ao longo dos meses, enquanto os multiplicadores de THEIL apresentam uma única mudança de sinal para cada variável. 
Tabela 20 - Elasticidades de impulso sobre a margem de comercialização de feijão no modelo VAR não-identificável, dados de 1975 a 1993

\begin{tabular}{ccccccccc}
\hline Meses & Diesel & Fert & SM & Juros & Risco4 & $P p$ & $P v$ & Marg \\
\hline 1 & $-0,3875$ & 0,5280 & 0,3924 & 0,2664 & 0,3221 & $-0,7530$ & 3,7301 & 1,0000 \\
2 & $-0,1732$ & 0,1327 & 0,0046 & $-2,1996$ & 0,2077 & 0,2957 & 2,3771 & $-0,1325$ \\
3 & 0,2360 & 0,5036 & 0,0591 & $-2,2107$ & 0,1117 & 0,4403 & 2,0022 & $-0,2716$ \\
4 & 0,0165 & $-0,0915$ & 0,3334 & 1,2899 & 0,0833 & 0,2961 & 1,6093 & $-0,0054$ \\
5 & 0,4614 & 0,2732 & 0,1206 & 5,7472 & $-0,0380$ & 0,3008 & 1,3990 & $-0,2608$ \\
6 & 0,7107 & 0,5972 & $-0,2473$ & 5,1985 & $-0,1933$ & 0,0159 & 0,6435 & $-0,2901$ \\
7 & 0,8029 & $-0,0333$ & 0,1809 & $-1,6236$ & $-0,2275$ & 0,1309 & 0,6933 & $-0,3807$ \\
8 & 0,3237 & 0,6435 & 0,3557 & $-3,5535$ & $-0,2029$ & 0,2062 & $-1,5176$ & $-0,1913$ \\
9 & $-0,0721$ & $-0,1704$ & 0,1907 & $-1,2432$ & 0,0196 & 0,5643 & $-0,0586$ & $-0,0298$ \\
10 & $-0,2505$ & $-0,4181$ & 0,1399 & $-1,4372$ & 0,1113 & 0,6079 & $-0,1951$ & $-0,0072$ \\
11 & $-0,5935$ & 0,9140 & $-0,1501$ & $-0,5253$ & 0,1917 & $-0,0222$ & $-0,8890$ & 0,0113 \\
12 & $-0,1749$ & 1,5899 & $-0,4256$ & $-1,1166$ & 0,1701 & $-0,2088$ & 0,6733 & $-0,3065$ \\
13 & $-0,4684$ & 1,4470 & $-0,1083$ & 0,5625 & 0,1215 & $-0,0708$ & 0,4127 & 0,2209 \\
14 & $-0,0869$ & 1,1498 & 0,2061 & $-0,4989$ & 0,0552 & 0,0571 & 0,7532 & $-0,0268$ \\
15 & $-0,5921$ & 0,7208 & 0,0233 & $-1,4861$ & 0,0475 & 0,0750 & 0,5772 & 0,0472 \\
16 & $-0,8006$ & 0,7213 & 0,0195 & $-1,9478$ & 0,1533 & $-0,0452$ & 0,5455 & 0,0516 \\
17 & $-0,2895$ & 0,9611 & $-0,1928$ & 1,8279 & 0,0384 & 0,1201 & 0,5875 & $-0,2166$ \\
18 & 0,0111 & 1,0067 & 0,0168 & 0,3959 & $-0,0489$ & $-0,2253$ & 0,0238 & $-0,3830$ \\
19 & $-0,1437$ & 0,7404 & 0,7001 & $-1,7014$ & $-0,1076$ & $-0,0600$ & $-0,1222$ & $-0,2937$ \\
20 & $-0,2272$ & 0,6207 & 0,3838 & $-1,4298$ & $-0,1292$ & $-0,1651$ & $-0,8253$ & $-0,2671$ \\
21 & $-0,4391$ & $-0,2683$ & 0,4043 & $-1,8609$ & $-0,0720$ & $-0,0659$ & $-0,5794$ & $-0,2210$ \\
22 & $-0,3491$ & 0,2835 & 0,2720 & $-0,6421$ & $-0,0152$ & $-0,1266$ & $-0,1265$ & $-0,3219$ \\
23 & $-0,4677$ & 0,3405 & 0,1511 & $-0,5799$ & 0,0072 & $-0,0948$ & $-0,1939$ & $-0,1817$ \\
24 & $-0,4940$ & 0,3944 & 0,1089 & $-1,6982$ & 0,0802 & $-0,0254$ & 0,0264 & $-0,2448$ \\
\hline
\end{tabular}

Fonte: Dados da pesquisa. 
Tabela 21 - Decomposição da variância dos erros de previsão da margem de comercialização de feijão no modelo VAR não-identificável, dados de 1975 a 1993 , em porcentagem

\begin{tabular}{ccccccccc}
\hline Meses & Diesel & Fert & SM & Juros & Risco4 & $P p$ & $P v$ & Marg \\
\hline 1 & 0,97 & 1,24 & 1,43 & 0,04 & 17,94 & 9,42 & 49,24 & 19,72 \\
2 & 0,88 & 0,99 & 1,08 & 2,18 & 19,18 & 8,22 & 52,31 & 15,16 \\
3 & 0,96 & 1,54 & 0,93 & 3,64 & 17,46 & 8,94 & 52,88 & 13,64 \\
4 & 0,89 & 1,44 & 1,46 & 3,92 & 16,75 & 9,06 & 53,94 & 12,54 \\
5 & 1,43 & 1,38 & 1,30 & 12,87 & 14,29 & 8,41 & 49,05 & 11,27 \\
6 & 2,63 & 1,88 & 1,37 & 17,96 & 15,17 & 7,30 & 43,20 & 10,49 \\
7 & 4,06 & 1,73 & 1,38 & 17,17 & 17,51 & 6,84 & 40,50 & 10,80 \\
8 & 3,90 & 2,21 & 1,67 & 18,11 & 18,31 & 6,42 & 39,40 & 9,99 \\
9 & 3,77 & 2,18 & 1,72 & 17,75 & 17,66 & 7,99 & 39,30 & 9,63 \\
10 & 3,76 & 2,35 & 1,72 & 17,51 & 17,73 & 9,73 & 37,92 & 9,28 \\
11 & 4,29 & 3,40 & 1,70 & 16,70 & 18,86 & 9,26 & 36,96 & 8,83 \\
12 & 4,06 & 6,45 & 2,08 & 15,79 & 19,05 & 8,85 & 34,94 & 8,78 \\
13 & 4,28 & 8,78 & 2,02 & 15,17 & 18,96 & 8,49 & 33,62 & 8,67 \\
14 & 4,19 & 10,16 & 2,08 & 14,84 & 18,63 & 8,30 & 33,36 & 8,46 \\
15 & 4,71 & 10,57 & 2,04 & 14,88 & 18,36 & 8,16 & 32,98 & 8,30 \\
16 & 5,61 & 10,79 & 1,97 & 14,93 & 18,75 & 7,87 & 32,07 & 8,02 \\
17 & 5,61 & 11,56 & 2,01 & 15,06 & 18,36 & 7,74 & 31,60 & 8,06 \\
18 & 5,49 & 12,42 & 1,96 & 14,76 & 18,07 & 7,78 & 30,92 & 8,60 \\
19 & 5,40 & 12,74 & 2,12 & 14,85 & 18,16 & 7,63 & 30,27 & 8,82 \\
20 & 5,33 & 12,78 & 2,39 & 14,72 & 18,34 & 7,53 & 30,00 & 8,91 \\
21 & 5,51 & 12,62 & 2,69 & 14,91 & 18,20 & 7,40 & 29,70 & 8,96 \\
22 & 5,64 & 12,57 & 2,82 & 14,82 & 18,02 & 7,39 & 29,41 & 9,34 \\
23 & 5,92 & 12,59 & 2,85 & 14,75 & 17,89 & 7,36 & 29,23 & 9,42 \\
24 & 6,18 & 12,57 & 2,83 & 14,92 & 17,88 & 7,26 & 28,81 & 9,55 \\
\hline & & & & & & & &
\end{tabular}

Fonte: Dados da pesquisa. 
As Tabelas 22 e 23 mostram diferenças importantes entre 0 comportamento do mercado de feijão e o de arroz, analisaḑo no item anterior. $\mathrm{O}$ preço ao varejo apresenta pequena importância na explicação da variância dos erros de previsão do preço ao produtor (Tabela 22). Grosso modo, essa variância se explica pelo próprio preço ao produtor, nos primeiros meses, e pelo preço ao produtor mais o preço dos fertilizantes, a partir do $12^{\circ}$ mês. Por outro lado, o preço ao produtor e o risco (principalmente nos primeiros meses) e o preço de fertilizantes (principalmente nos últimos meses) são os principais fatores que explicam a variância dos erros de previsão do preço ao varejo (Tabela 23). Esses resultados estão de acordo com o modelo dinâmico de causalidade produtor $\rightarrow$ varejo. 
Tabela 22 - Decomposição da variância dos erros de previsão do preço de feijão ao produtor no modelo VAR não-identificável, dados de 1975 a 1993, em porcentagem

\begin{tabular}{crrrrrrrr}
\hline Meses & Diesel & Fert & SM & Juros & Risco4 & Pp & Pv & Marg \\
\hline 1 & 0,07 & 0,13 & 0,36 & 0,35 & 4,75 & 94,35 & 0,00 & 0,00 \\
2 & 1,40 & 0,17 & 0,93 & 1,20 & 4,35 & 91,11 & 0,64 & 0,19 \\
3 & 2,32 & 0,37 & 1,00 & 1,54 & 4,21 & 87,74 & 0,90 & 1,92 \\
4 & 5,80 & 0,35 & 0,98 & 1,90 & 3,94 & 81,44 & 1,06 & 4,53 \\
5 & 12,78 & 0,52 & 0,88 & 1,85 & 3,45 & 71,37 & 1,15 & 8,00 \\
6 & 15,43 & 0,81 & 0,84 & 2,22 & 3,83 & 66,36 & 1,09 & 9,42 \\
7 & 15,18 & 1,81 & 1,83 & 7,86 & 4,47 & 58,74 & 1,19 & 8,92 \\
8 & 12,94 & 3,93 & 3,54 & 11,93 & 6,53 & 50,11 & 3,62 & 7,39 \\
9 & 11,28 & 5,43 & 4,01 & 15,65 & 6,48 & 43,23 & 7,59 & 6,33 \\
10 & 9,78 & 11,62 & 3,99 & 15,07 & 6,22 & 37,68 & 10,14 & 5,51 \\
11 & 8,73 & 18,09 & 3,63 & 14,79 & 5,56 & 33,75 & 10,52 & 4,92 \\
12 & 8,55 & 22,33 & 3,36 & 14,04 & 5,58 & 31,23 & 10,30 & 4,62 \\
13 & 8,33 & 24,91 & 3,23 & 13,64 & 5,68 & 29,91 & 9,86 & 4,44 \\
14 & 8,29 & 25,31 & 3,16 & 13,53 & 6,42 & 29,14 & 9,64 & 4,51 \\
15 & 8,10 & 26,12 & 3,19 & 13,24 & 6,42 & 28,70 & 9,76 & 4,46 \\
16 & 7,91 & 26,52 & 3,37 & 13,01 & 6,31 & 28,41 & 10,08 & 4,38 \\
17 & 7,61 & 26,68 & 3,61 & 12,77 & 6,19 & 28,52 & 10,38 & 4,24 \\
18 & 7,35 & 26,37 & 4,23 & 12,68 & 6,28 & 28,36 & 10,61 & 4,12 \\
19 & 7,21 & 25,98 & 4,48 & 12,47 & 6,46 & 28,59 & 10,74 & 4,06 \\
20 & 7,15 & 25,68 & 4,61 & 12,33 & 6,41 & 29,10 & 10,71 & 4,02 \\
21 & 7,07 & 25,45 & 4,74 & 12,19 & 6,33 & 29,62 & 10,62 & 3,98 \\
22 & 6,96 & 25,22 & 5,00 & 12,00 & 6,25 & 30,16 & 10,47 & 3,93 \\
23 & 6,84 & 24,79 & 5,69 & 11,94 & 6,21 & 30,36 & 10,29 & 3,87 \\
24 & 6,73 & 24,39 & 6,40 & 11,77 & 6,11 & 30,59 & 10,17 & 3,83 \\
\hline
\end{tabular}

Fonte: Dados da pesquisa. 
Tabela 23 - Decomposição da variância dos erros de previsão do preço de feijão ao varejo no modelo VAR não-identificável, dados de 1975 a 1993, em porcentagem

\begin{tabular}{crrrrrrrrr}
\hline Meses & Diesel & Fert & SM & Juros & Risco4 & $P p$ & $P v$ & Marg \\
\hline 1 & 0,45 & 1,48 & 0,04 & 0,02 & 28,02 & 38,08 & 31,92 & 0,00 \\
2 & 0,42 & 1,09 & 0,75 & 0,02 & 20,71 & 49,13 & 25,51 & 2,36 \\
3 & 1,32 & 1,31 & 0,67 & 0,07 & 16,62 & 48,72 & 24,64 & 6,65 \\
4 & 2,97 & 1,18 & 0,86 & 0,10 & 15,12 & 46,57 & 23,62 & 9,58 \\
5 & 7,00 & 1,36 & 0,76 & 1,63 & 13,20 & 40,74 & 21,91 & 13,40 \\
6 & 10,03 & 2,28 & 0,76 & 1,61 & 12,28 & 37,63 & 20,25 & 15,15 \\
7 & 11,42 & 2,47 & 0,96 & 6,22 & 11,00 & 34,31 & 18,55 & 15,07 \\
8 & 10,36 & 4,45 & 1,31 & 12,30 & 10,10 & 31,74 & 16,49 & 13,24 \\
9 & 9,43 & 5,40 & 1,59 & 15,30 & 9,87 & 30,09 & 16,35 & 11,98 \\
10 & 8,73 & 8,46 & 1,72 & 15,92 & 9,89 & 27,50 & 16,87 & 10,91 \\
11 & 8,03 & 15,10 & 1,70 & 14,96 & 8,98 & 24,27 & 17,33 & 9,63 \\
12 & 7,74 & 21,56 & 1,56 & 13,90 & 8,02 & 21,76 & 16,84 & 8,62 \\
13 & 7,66 & 25,88 & 1,45 & 13,09 & 7,49 & 20,33 & 16,02 & 8,07 \\
14 & 7,58 & 27,53 & 1,42 & 13,02 & 7,40 & 19,66 & 15,58 & 7,81 \\
15 & 7,65 & 28,67 & 1,46 & 12,97 & 7,22 & 19,24 & 15,17 & 7,62 \\
16 & 7,69 & 29,47 & 1,60 & 12,98 & 7,03 & 19,02 & 14,82 & 7,38 \\
17 & 7,50 & 30,48 & 1,71 & 12,61 & 6,89 & 19,03 & 14,61 & 7,17 \\
18 & 7,23 & 30,52 & 2,25 & 12,40 & 6,95 & 19,22 & 14,46 & 6,97 \\
19 & 7,05 & 30,07 & 2,67 & 12,32 & 7,37 & 19,24 & 14,43 & 6,85 \\
20 & 6,99 & 29,52 & 3,01 & 12,16 & 7,46 & 19,48 & 14,56 & 6,82 \\
21 & 7,08 & 29,06 & 3,37 & 12,08 & 7,39 & 19,71 & 14,51 & 6,80 \\
22 & 7,13 & 28,77 & 3,70 & 11,88 & 7,26 & 20,15 & 14,28 & 6,82 \\
23 & 7,16 & 28,43 & 4,19 & 11,83 & 7,20 & 20,40 & 14,07 & 6,72 \\
24 & 7,17 & 28,06 & 4,74 & 11,81 & 7,15 & 20,60 & 13,84 & 6,62 \\
\hline
\end{tabular}

Fonte: Dados da pesquisa. 


\subsubsection{Modelo VAR identificável}

Nesse item apresentam-se os resultados referentes à estimação do modelo VAR com a fatoração de Bernanke. Além das elasticidades de impacto sobre a margem de comercialização e da decomposição da variância dos erros de previsão dessa variável, apresentam-se as estimativas dos coeficientes da matriz de interações contemporâneas $\left(A_{0}\right)$ que mostram até que ponto as restrições de identificação adotadas são adequadas.

\section{Arroz:}

A Tabela 24 mostra as estimativas dos coeficientes da matriz $\mathbf{A}_{\mathbf{0}}$ para 0 arroz com as interações definidas no capítulo 5 . Verifica-se que os sinais da matriz devem ser invertidos para se ver o impacto de cada uma das variáveis sobre as demais, e todos os coeficientes que relacionam os preços dos insumos à margem (última linha da Tabela 24) tiveram o sinal esperado, ou seja, a margem aumenta em decorrência de aumentos contemporâneos no preço do óleo diesel, no preço de fertilizantes, no salário-mínimo ou no risco de preço. Aumento no preço do óleo diesel aumenta o preço de fertilizantes ( $1^{\mathrm{a}}$ coluna da $2^{\mathrm{a}}$ linha), como se esperava, e aumento na taxa de juros incrementa o risco de preço ( $4^{\mathrm{a}}$ coluna da $5^{\mathrm{a}}$ linha). $\mathrm{O}$ único sinal contrário ao esperado é o do coeficiente que relaciona o salário-mínimo com a taxa de juros ( $3^{\mathrm{a}}$ coluna da $4^{\mathrm{a}}$ linha), que é negativo.

A matriz não apresenta o impacto contemporâneo da taxa de juros sobre a margem, porque o modelo não convergiu de maneira alguma até que essa restrição fosse imposta. As outras análises já haviam mostrado que o impacto imediato da taxa de juros sobre a margem de comercialização de arroz é não-significativo.

Muito embora as estimativas do desvio-padrão sejam elevadas para a maioria das variáveis, levando-se à consideração de que muitas delas sejam nãosignificativas, o fato de que quase todos os sinais foram de acordo com o esperado sugere que as restrições foram adequadas. 
Tabela 24 - Matriz de interações contemporâneas $\left(\mathrm{A}_{0}\right)$ para arroz*

\begin{tabular}{l|cccccc}
\hline \multirow{2}{*}{ Equações } & \multicolumn{5}{|c}{ Variáveis Explicativas } \\
\cline { 2 - 7 } & Diesel & Fert & SM & Juros & Risco4 & Marg \\
\hline Diesel & 1 & & & & &
\end{tabular}

Fert

$\begin{array}{ll}-0,0048 & 1 \\ (0,0478) & \end{array}$

$S M$

Juros

0,0033

1

$(0,0185)$

Risco4

$-0,5230$

1

$(0,9354)$

Marg

$-0,0365$

$-0,1189$

$-0,2245$

$-0,0483$

$(0,1160) \quad(0,1688)$

$(0,0954)$

$(0,0274)$

* Entre parênteses estão as estimativas do desvio-padrão de cada coeficiente;

Fonte: Dados da pesquisa.

As elasticidades de impulso para os choques das variáveis sobre a margem de comercialização de arroz (Tabela 25 e Figuras 2.1 a 2.6, no Apêndice 2) e a decomposição da variância dos erros de previsão (Tabela 26) mostram algumas diferenças entre o modelo identificável e o modelo VAR convencional, porém, não muito expressivas.

Na Tabela 26, verifica-se significativo aumento na participação da margem na explicação da variância dos erros de sua previsão, o que, em grande parte, se deve à exclusão dos preços (especialmente o preço ao varejo, que é muito importante na explicação da margem). Esse resultado sugere maior importância para choques de oferta agrícola e de demanda primária em relação a choques na oferta de insumos de comercialização, confirmando constatação anterior. Outra diferença que se verifica é redução da participação de todos os insumos na decomposição da variância dos erros de previsão da margem nos primeiros meses (particularmente durante o primeiro mês), quando a participação da margem se situa acima de $80 \%$. Verifica-se, também, aumento 
da importância do salário-mínimo em relação aos resultados do modelo convencional (comparar as Tabelas 16 e 26).

Embora a importância do preço do óleo diesel e do risco de preço na explicaçầo da margem seja bastante pequena, os resultados das elasticidades de impulso (Tabela 25 e Figuras 2.1 a 2.6) mostram-se positivos nos primeiros meses, coerentemente com o esperado e não permitindo se rejeitar a hipótese de que os intermediários do mercado de arroz são avessos ao risco. As elasticidades do salário-mínimo mostram sinais positivos nos primeiros meses, assim como as do índice de preços de fertilizantes. As elasticidades do juro sobre a margem também são positivas, mostrando o impacto dessa variável sobre o custo de comercialização. Em suma, a análise pelo modelo VAR identificável no mercado de arroz mostra reduzidos impactos das variáveis de custo sobre a margem nos primeiros meses, mas os sinais de todas as elasticidades iniciais, tanto dos insumos de comercialização quanto do agrícola, foram os esperados.

Numa comparação com os outros dois tipos de análise dinâmica (os multiplicadores de THEIL e o VAR convencional), o VAR identificável difere por apresentar sinais iniciais das elasticidades da taxa de juros e do preço do óleo diesel positivos. Já o sinal positivo para o salário-mínimo é o mesmo que havia sido constatado pelo modelo VAR convencional e oposto à constatação feita pelos multiplicadores. 
Tabela 25 - Elasticidades de impulso sobre a margem de comercialização de arroz no modelo VAR identificável, dados de 1975 a 1993

\begin{tabular}{ccccccc}
\hline Meses & Diesel & Fert & SM & Juros & Risco4 & Marg \\
\hline 1 & 0,0371 & 0,1189 & 0,2244 & 0,0253 & 0,0483 & 1,0000 \\
2 & 0,1282 & 0,3300 & 0,5238 & 0,2377 & 0,0548 & 0,6565 \\
3 & 0,0176 & 0,2347 & 0,1844 & 0,0123 & 0,0752 & 0,5317 \\
4 & $-0,0414$ & 0,6506 & 0,3240 & $-0,2540$ & 0,0751 & 0,4217 \\
5 & $-0,0919$ & 0,7276 & 0,3544 & $-0,2817$ & 0,0049 & 0,2170 \\
6 & 0,0565 & 0,7852 & $-0,0215$ & 0,3503 & 0,0089 & $-0,0051$ \\
7 & 0,0727 & 0,6665 & 0,0235 & 0,0312 & 0,0074 & $-0,0404$ \\
8 & 0,1118 & 0,6153 & $-0,1782$ & $-0,8820$ & 0,0250 & $-0,1943$ \\
9 & 0,2249 & 0,2387 & $-0,1001$ & $-0,7318$ & 0,0313 & $-0,1649$ \\
10 & $-0,0730$ & 0,2810 & $-0,0311$ & 1,4234 & $-0,0133$ & $-0,1639$ \\
11 & $-0,0050$ & 0,4002 & $-0,2074$ & 2,2850 & $-0,0864$ & 0,0023 \\
12 & 0,3068 & 0,0075 & $-0,1482$ & $-2,1545$ & $-0,0693$ & 0,1675 \\
13 & 0,0849 & 0,1516 & $-0,0976$ & 0,9729 & $-0,0379$ & 0,0345 \\
14 & 0,1620 & $-0,0404$ & $-0,0135$ & $-0,3424$ & 0,0103 & $-0,0335$ \\
15 & 0,2228 & $-0,0125$ & 0,0359 & $-0,1816$ & 0,0253 & $-0,1207$ \\
16 & 0,1332 & $-0,1664$ & 0,0496 & $-0,2154$ & 0,0193 & $-0,0654$ \\
17 & 0,0251 & $-0,1940$ & $-0,0473$ & $-0,4527$ & 0,0276 & $-0,1606$ \\
18 & 0,1035 & $-0,0174$ & $-0,0086$ & $-0,5323$ & 0,0425 & $-0,2327$ \\
19 & 0,1456 & 0,1757 & $-0,0679$ & $-0,6417$ & 0,0060 & $-0,2941$ \\
20 & 0,1224 & 0,0099 & $-0,0218$ & $-0,4299$ & 0,0078 & $-0,1676$ \\
21 & 0,0782 & $-0,0655$ & 0,0557 & 0,0135 & 0,0253 & $-0,0700$ \\
22 & 0,1457 & 0,1350 & 0,0588 & 0,3384 & 0,0017 & $-0,0231$ \\
23 & 0,1698 & 0,0749 & 0,0009 & $-0,1817$ & $-0,0071$ & 0,0298 \\
24 & 0,1466 & 0,1842 & 0,0013 & 0,0408 & $-0,0263$ & 0,0631 \\
\hline
\end{tabular}

Fonte: Dados da pesquisa. 
Tabela 26 - Decomposição da variância dos erros de previsão da margem de comercialização de arroz no modelo VAR identificável, dados de 1975 a 1993, em porcentagem

\begin{tabular}{rrrrrrr}
\hline Meses & Diesel & Fert & SM & Juros & Risco4 & Marg \\
\hline 1 & 0,05 & 0,24 & 2,66 & 0,00 & 1,50 & 95,54 \\
2 & 0,40 & 1,28 & 10,71 & 0,13 & 2,15 & 85,32 \\
3 & 0,34 & 1,54 & 9,80 & 0,11 & 3,66 & 84,56 \\
4 & 0,32 & 4,42 & 10,79 & 0,20 & 4,72 & 79,55 \\
5 & 0,41 & 7,62 & 12,58 & 0,30 & 4,34 & 74,76 \\
6 & 0,44 & 11,28 & 12,05 & 0,46 & 4,17 & 71,60 \\
7 & 0,50 & 13,73 & 11,71 & 0,44 & 4,06 & 69,55 \\
8 & 0,63 & 15,23 & 11,67 & 1,43 & 3,99 & 67,06 \\
9 & 1,24 & 15,11 & 11,51 & 2,06 & 4,09 & 65,99 \\
10 & 1,26 & 14,96 & 11,08 & 4,43 & 3,97 & 64,30 \\
11 & 1,15 & 14,47 & 10,81 & 9,80 & 5,07 & 58,70 \\
12 & 2,01 & 13,37 & 10,31 & 13,78 & 5,55 & 54,98 \\
13 & 2,05 & 13,27 & 10,29 & 14,52 & 5,72 & 54,15 \\
14 & 2,30 & 13,22 & 10,24 & 14,57 & 5,72 & 53,95 \\
15 & 2,77 & 13,08 & 10,16 & 14,46 & 5,77 & 53,77 \\
16 & 2,92 & 13,13 & 10,14 & 14,42 & 5,80 & 53,58 \\
17 & 2,90 & 13,14 & 10,05 & 14,45 & 5,86 & 53,60 \\
18 & 2,94 & 12,88 & 9,84 & 14,43 & 6,05 & 53,87 \\
19 & 3,05 & 12,64 & 9,62 & 14,39 & 5,88 & 54,42 \\
20 & 3,15 & 12,51 & 9,53 & 14,42 & 5,83 & 54,55 \\
21 & 3,20 & 12,49 & 9,54 & 14,37 & 5,91 & 54,48 \\
22 & 3,38 & 12,51 & 9,55 & 14,41 & 5,89 & 54,26 \\
23 & 3,62 & 12,49 & 9,51 & 14,39 & 5,88 & 54,10 \\
24 & 3,80 & 12,57 & 9,46 & 14,32 & 5,94 & 53,90 \\
\hline
\end{tabular}

Fonte: Dados da pesquisa. 


\section{Feijão:}

A Tabela 27 é similar à 24 , mas apresenta, adicionalmente, o impacto contemporâneo da taxa de juros sobre a margem de comercialização de feijão. Os sinais das interações dos insumos foram todos contrários ao esperado (com exceção da relação do juro com o risco, para a qual não se pressupôs qualquer sinal) e tiveram estimativas de desvio-padrão bastante elevadas. Já o impacto dos insumos sobre a margem mostrou-se mais significativo, exceção feita ao impacto da taxa de juros.

Tabela 27 - Matriz de interações contemporâneas $\left(\mathrm{A}_{0}\right)$ para feijão*

\begin{tabular}{|c|c|c|c|c|c|c|}
\hline \multirow[t]{2}{*}{ Equações } & \multicolumn{6}{|c|}{ Variáveis Explicativas } \\
\hline & Diesel & Fert & $S M$ & Juros & Risco 4 & Marg \\
\hline Diesel & 1 & & & & & \\
\hline Fert & $\begin{array}{c}0,0584 \\
(0,0495)\end{array}$ & 1 & & & & \\
\hline$S M$ & & & 1 & & & \\
\hline Juros & & & $\begin{array}{c}0,0104 \\
(0,0177)\end{array}$ & 1 & & \\
\hline Risco4 & & & & $\begin{array}{c}-0,7816 \\
(1,2040)\end{array}$ & 1 & \\
\hline Marg & $\begin{array}{c}0,6488 \\
(0,2538)\end{array}$ & $\begin{array}{c}-0,5321 \\
(0,3549)\end{array}$ & $\begin{array}{c}-0,3235 \\
(0,2105)\end{array}$ & $\begin{array}{c}0,4212 \\
(0,8344)\end{array}$ & $\begin{array}{c}-0,3794 \\
(0,0481)\end{array}$ & 1 \\
\hline
\end{tabular}

* Entre parênteses estão as estimativas do desvio-padrão de cada coeficiente;

Fonte: Dados da pesquisa.

Sumariando os resultados da Tabela 27: aumento no preço dos fertilizantes causa aumento da margem, contrariamente ao que sugere o modelo teórico de causalidade produtor $\rightarrow$ varejo (e ao que havia sido constatado na análise estática); 
aumento no preço do óleo diesel reduz, contemporaneamente, a margem, contrariamente ao esperado, mas de acordo com resultados anteriores (possivelmente por seu impacto como insumo agrícola); aumento no salário-mínimo leva a aumento instantâneo da margem de comercialização de feijão; aumento do risco de preço eleva a margem (efeito bastante significativo), sugerindo que os intermediários são avessos ao risco; e aumento no juro reduz a margem, novamente por seu provável impacto na formação e desova de estoques.

As elasticidades de impulso das diversas variáveis sobre a margem de comercialização de feijão (Tabela 28 e Figuras 2.7 a 2.12, no Apêndice 2) e a decomposição da variância dos erros de previsão da margem (Tabela 29) mostram algumas diferenças em relação ao modelo VAR convencional (comparar Tabelas 29 e 21). Grosso modo, reduziu a importância do preço dos fertilizantes e aumentou bastante a importância do risco (principalmente) e da taxa de juros na explicação da margem. Alguns sinais das elasticidades também se alteraram.

O preço do óleo diesel mostra importância semelhante à constatada no modelo convencional, porém com impacto negativo inicial bastante mais acentuado (compare-se as Figuras 1.9 e 2.7). Mostra também maior tendência das elasticidades de impulso a convergirem a zero, no final dos 24 meses, do que no VAR convencional.

O preço dos fertilizantes teve seu impacto sobre a margem reduzido (compare-se Tabelas 21 e 29), não apresentando grande diferença no que concerne às suas elasticidades.

O salário-mínimo mostra-se de importância bastante pequena na explicação da variância dos erros de previsão da margem de feijão, mas seu efeito em termos de elasticidade mostra-se positivo durante todos os primeiros 5 meses (Tabela 28 e Figura 2.9), conforme mostrou, também, a análise pelo VAR convencional..

A taxa de juros mostra-se de extrema importância na explicação da margem de comercialização a partir do quinto mês (Tabela 29), com efeito inicial negativo (Tabela 28 e Figura 2.10), semelhante aos demais resultados encontrados para essa variável. 
O risco de preço foi a variável que teve maior aumento de importância na explicação da variância dos erros de previsão da margem, quando se comparam os modelos VAR convencional (Tabela 21) e identificável (Tabela 29). As elasticidades de impulso dessa variável sobre a margem também aumentaram bastante de valor nos primeiros 4 meses (comparar Tabelas 20 e 28), mostrando tendência convergente a partir de então. $\mathrm{O}$ predomínio continua sendo de elasticidades positivas, coerentemente com agentes de comercialização avessos ao risco.

Mesmo com a exclusão dos preços do produto, a importância da margem e do risco de preço apresenta novos indícios no sentido de que os choques oriundos do mercado do produto têm impacto de maior importância sobre a margem de comercialização de feijão do que os choques no mercado de insumos de comercialização.

Os resultados das elasticidades do modelo VAR identificável no mercado de feijão mostram-se semelhantes aos dos multiplicadores de THEIL, especialmente nos primeiros meses. Com exceção do efeito imediato do preço de fertilizantes constatado na análise de multiplicadores, que foi negativo (mas extremamente próximo de zero), poderse-ia dizer que os sentidos dos impactos foram os mesmos nas duas análises durante os 4 primeiros meses. 
Tabela 28 - Elasticidades de impulso sobre a margem de comercialização de feijão no modelo VAR identificável, dados de 1975 a 1993

\begin{tabular}{ccccccc}
\hline Meses & Diesel & Fert & SM & Juros & Risco4 & Marg \\
\hline 1 & $-0,6799$ & 0,5321 & 0,3248 & $-0,1247$ & 0,3794 & 1,0000 \\
2 & $-0,8116$ & 0,2278 & 0,1507 & $-2,3051$ & 0,3443 & 0,4442 \\
3 & $-0,2596$ & 0,4841 & 0,0776 & $-2,0805$ & 0,2681 & 0,3253 \\
4 & $-0,2068$ & $-0,0772$ & 0,2336 & $-2,4369$ & 0,2413 & 0,3022 \\
5 & 0,1559 & $-0,4229$ & 0,2219 & 5,5459 & 0,1004 & 0,2075 \\
6 & 0,3328 & 0,0229 & $-0,0915$ & 4,2128 & $-0,0212$ & 0,2358 \\
7 & 0,7341 & 0,2902 & 0,2516 & $-1,8557$ & $-0,0855$ & 0,1258 \\
8 & 0,3481 & 1,2657 & 0,3882 & $-3,5884$ & $-0,1066$ & $-0,1586$ \\
9 & 0,2128 & 0,0812 & 0,1373 & $-1,4896$ & $-0,0094$ & $-0,1870$ \\
10 & 0,1300 & $-0,2711$ & 0,1570 & $-1,3877$ & 0,0550 & $-0,1578$ \\
11 & $-0,6512$ & 0,8661 & $-0,1569$ & $-0,5932$ & 0,1022 & 0,0890 \\
12 & $-0,2434$ & 1,4563 & $-0,2585$ & $-0,8958$ & 0,0799 & 0,0703 \\
13 & $-0,3352$ & 1,3117 & 0,1905 & 0,8116 & 0,1190 & 0,1053 \\
14 & $-0,0691$ & 1,3852 & 0,2983 & $-1,1743$ & 0,0379 & 0,1154 \\
15 & $-0,5570$ & 0,8900 & 0,1095 & $-1,4236$ & 0,0636 & 0,1367 \\
16 & $-0,6587$ & 0,7521 & 0,0947 & $-1,2809$ & 0,1582 & 0,1621 \\
17 & $-0,3869$ & 0,3791 & $-0,0487$ & 1,6653 & 0,0728 & 0,1059 \\
18 & 0,1882 & 0,4813 & $-0,0025$ & 0,0184 & 0,0139 & 0,0499 \\
19 & 0,1802 & 0,3803 & 0,2018 & $-1,3992$ & $-0,0590$ & 0,0355 \\
20 & 0,1282 & 0,4198 & 0,1812 & $-1,6574$ & $-0,0840$ & $-0,0109$ \\
21 & $-0,0759$ & $-0,1402$ & 0,1405 & $-2,3865$ & $-0,0739$ & 0,0270 \\
22 & 0,0039 & 0,4083 & 0,0576 & $-1,5034$ & $-0,0515$ & 0,0509 \\
23 & $-0,1848$ & 0,3398 & $-0,0607$ & $-0,7582$ & $-0,0249$ & 0,0568 \\
24 & $-0,0925$ & 0,4342 & $-0,1025$ & $-1,3421$ & $-0,0289$ & 0,0417 \\
\hline
\end{tabular}

Fonte: Dados da pesquisa. 
Tabela 29 - Decomposição da variância dos erros de previsão da margem de comercialização de feijão no modelo VAR identificável, dados de 1975 a 1993, em porcentagem

\begin{tabular}{|c|c|c|c|c|c|c|}
\hline Meses & Diesel & Fert & $S M$ & Juros & Risco4 & Marg \\
\hline 1 & 2,75 & 0,83 & 0,89 & 0,01 & 22,65 & 72,87 \\
\hline 2 & 4,75 & 0,70 & 0,77 & 2,04 & 29,48 & 62,25 \\
\hline 3 & 4,34 & 1,03 & 0,70 & 3,19 & 32,36 & 58,39 \\
\hline 4 & 4,01 & 0,93 & 0,87 & 4,59 & 33,88 & 55,72 \\
\hline 5 & 3,64 & 1,09 & 0,98 & 12,15 & 30,96 & 51,18 \\
\hline 6 & 3,71 & 1,02 & 0,95 & 15,70 & 28,96 & 49,67 \\
\hline 7 & 4,98 & 1,09 & 1,15 & 15,95 & 28,43 & 48,40 \\
\hline 8 & 4,92 & 2,94 & 1,59 & 17,65 & 27,16 & 45,73 \\
\hline 9 & 4,95 & 2,90 & 1,63 & 17,83 & 26,70 & 45,99 \\
\hline 10 & 4,91 & 2,94 & 1,69 & 17,97 & 26,49 & 46,00 \\
\hline 11 & 5,74 & 3,71 & 1,72 & 17,54 & 26,37 & 44,92 \\
\hline 12 & 5,68 & 5,91 & 1,87 & 17,11 & 25,86 & 43,56 \\
\hline 13 & 5,73 & 7,53 & 1,92 & 16,66 & 25,79 & 42,37 \\
\hline 14 & 5,57 & 9,28 & 2,12 & 16,43 & 25,11 & 41,48 \\
\hline 15 & 6,06 & 9,85 & 2,10 & 16,39 & 24,70 & 40,90 \\
\hline 16 & 6,69 & 10,03 & 2,05 & 16,08 & 25,10 & 40,05 \\
\hline 17 & 6,88 & 10,03 & 2,03 & 16,33 & 25,00 & 39,73 \\
\hline 18 & 6,92 & 10,21 & 2,02 & 16,27 & 24,92 & 39,65 \\
\hline 19 & 6,92 & 10,26 & 2,12 & 16,47 & 24,89 & 39,34 \\
\hline 20 & 6,88 & 10,31 & 2,18 & 16,75 & 24,97 & 38,91 \\
\hline 21 & 6,80 & 10,19 & 2,20 & 17,49 & 24,90 & 38,42 \\
\hline 22 & 6,75 & 10,27 & 2,20 & 17,73 & 24,85 & 38,20 \\
\hline 23 & 6,79 & 10,34 & 2,20 & 17,76 & 24,79 & 38,13 \\
\hline 24 & 6,76 & 10,45 & 2,21 & 17,95 & 24,68 & 37,94 \\
\hline
\end{tabular}

Fonte: Dados da pesquisa. 


\section{RESUMO E CONCLUSÕES}

As estimações dos modelos empíricos com dados anuais mostraram a superioridade dos modelos relativo e de markup no mercado de feijão, provavelmente pela importância da variável preço corrente ao varejo. A quantidade, quando incluída isoladamente, foi não-significativa. A significância e o sinal positivo da variável de interação preço-quantidade, nos dois mercados, foi consistente com o modelo de GARDNER e de acordo com os resultados de WOHLGENANT \& MULLEN. No mercado de arroz, todos os modelos tiveram má performance na estimação com dados anuais; esses resultados foram confirmados pelo teste $\mathbf{J}$. Novamente, o preço corrente ao varejo foi importante, embora os coeficientes de determinação tenham ficado baixos para todos os modelos.

Nas estimações com dados mensais, o modelo dinâmico foi bastante superior ao modelo de markup no mercado de feijão, sendo ligeiramente superior a este no mercado de arroz. Os testes $\mathbf{J}$ foram inconclusivos, conforme já havia sido constatado por FAMINOW \& LAUBSCHER, também para dados mensais. $O$ coeficiente do indice de preços de fertilizantes foi positivo no mercado de arroz e negativo no de feijão, fornecendo suporte para a hipótese de que o primeiro comporta-se como o modelo de causalidade varejo $\rightarrow$ produtor e o segundo como o modelo de causalidade produtor $\rightarrow$ varejo.

Os bons ajustes do modelo dinâmico nos mercados dos dois produtos levaram à escolha desse modelo para a análise estática dos componentes da margem. Os resultados mostraram que o risco de variação de preço foi significativo apenas no mercado de feijão, confirmando hipótese levantada. A formulação do risco que mostrouse mais apropriada foi a de 4 meses, o que é coerente com o sistema de comercialização desse produto. $\mathrm{O}$ sinal positivo do coeficiente do risco mostra que os comerciantes de feijão comportam-se com aversão ao risco. O salário-mínimo, o preço do óleo diesel e o 
índice de preços de fertilizantes também se mostraram estatisticamente importantes na explicação da margem de comercialização de feijão. Aumento da salário aumenta a margem, o que é consistente com o modelo teórico. $\mathrm{O}$ sinal negativo do preço do óleo diesel no mercado de feijão poderia ser explicado pela predominância do efeito desse insumo na produção agrícola, em detrimento da comercialização; nesse caso, o modelo teórico levaria a esperar um sinal negativo (tanto para o preço do óleo diesel como para o índice de fertilizantes). 0 índice de fertilizantes teve os sinais esperados nos dois mercados. $\mathrm{O}$ sinal negativo da taxa de juros parece mostrar que o impacto dessa variável sobre a venda de estoques (e queda de preço e margem) tende a superar, ao menos inicialmente, seu impacto sobre o custo de comercialização. No mercado de arroz, os insumos de comercialização mostraram-se não-significativos.

A análise dinâmica pelos multiplicadores de THEIL para arroz mostroụ que a margem de comercialização tende a aumentar, nos primeiros 5 meses, em decorrência de aumentos no preço de fertilizantes (este efeito persiste por, pelo menos, 24 meses) e no risco de preço, e em decorrência de quedas na taxa de juros, no saláriomínimo e no preço do óleo diesel; o impacto total do preço dos fertilizantes e do risco é positivo, sendo negativo o efeito total das demais variáveis. No mercado de feijão, o efeito inicial do preço dos fertilizantes (exceção ao efeito imediato), do risco e do saláriomínimo é positivo, sendo negativos os efeitos do preço do óleo diesel e da taxa de juros; os efeitos totais são no mesmo sentido que os iniciais. Verifica-se, assim, que os efeitos de choques nas variáveis exógenas sobre a margem geralmente mudam de sinal ao longo do tempo.

A análise dinâmica de auto-regressão vetorial convencional do mercado de arroz apresenta, por meio dos testes $\mathbf{F}$, algum suporte indireto à hipótese de que esse mercado possui causalidade varejo $\rightarrow$ produtor. A margem de comercialização é explicada, num primeiro momento, quase que tão somente pelos preços ao varejo (principalmente) e ao produtor. No entanto, a importância das variáveis de custo cresce ao longo do tempo (particularmente no caso da taxa de juros), mostrando um efeito que não era captado pela estimação estática. As elasticidades de impulso mostram que o efeito do preço do óleo diesel passa a ser positivo a partir do $6^{\circ}$ mês, justamente quando aumenta sua parcela na variância dos erros de previsão da margem de comercialização. A elasticidade de impulso dos fertilizantes sobre a margem mantém, pela maioria dos 24 meses, o sinal positivo esperado. A taxa de juros mostra contínua alternância de sinal, 
provavelmente refletindo os impactos sobre a venda de estoques e sobre o custo de comercialização; prevalece, no entanto, sinal positivo durante o período de maior poder explicativo dessa variável. $\mathrm{O}$ salário-mínimo mostra-se pouco importante e com sinais alternantes ao longo dos meses. A análise do modelo identificável não alterou profundamente esse quadro, apenas ressaltou a pequena importância dos insumos sobre a margem no curto prazo e apresentou ganho de importância do salário-mínimo; no que diz respeito às elasticidades, mostrou impacto inicial positivo (e muito próximo de zero) para todos os itens de custo, inclusive preço de óleo diesel e taxa de juros.

$\mathrm{Na}$ análise dinâmica de auto-regressão vetorial convencional do mercado de feijão, o teste $\mathbf{F}$ não permite conclusões acerca do sentido de causalidade entre os preços, mas os demais resultados encontrados não permitem que se rejeite a hipótese do modelo de causalidade produtor $\rightarrow$ varejo. A taxa de juros mostra-se bastante importante, como também se verificou pela análise estática, tendo relação bi-causal com diversas variáveis. A variância dos erros de previsão da margem se deve, inicialmente, ao preço ao varejo, ao risco e a seu próprio valor. $\mathrm{O}$ efeito de todas as variáveis sobre a margem ocorre, no $1^{\circ}$ mês, com o sentido esperado, exceção feita pelo preço do óleo diesel e ao índice de fertilizantes. A taxa de juros, o salário-mínimo, o risco de preço e o preço de fertilizantes apresentam sinais alternados durante os 24 meses; porém, com forte predominância de efeitos positivos. A análise com o modelo identificável não alterou demasiadamente esse panorama, apenas reforçou a importância do risco na margem deste produto.

Uma generalização que pode ser feita sobre os dois mercados é que a importância dos insumos de comercialização analisados, exceção feita à taxa de juros, é pequena em relação à importância dos preços do produto ao varejo e ao produtor. $\mathbf{O}$ risco de preço, que foi importante no mercado de feijão, é uma variável originada no mercado de produto e não no mercado de insumos. Assim, os resultados sugerem que os choques oriundos da oferta de insumos de comercialização são de pequena importância na explicação das variações da margem de comercialização dos dois produtos. Essas variações teriam como agentes causais de maior importância a oferta agrícola e a demanda primária.

Algumas implicações políticas emergem dos resultados encontrados. Em geral, como as margens são fortemente afetadas por choques de oferta agrícola e de 
demanda primária, medidas que promovam a estabilização dos mercados aos níveis de produtor e varejo, amenizando eventuais choques, parecem ter maior impacto sobre a margem dos dois produtos do que medidas que aumentem a oferta de insumos de comercialização. A estabilização dos preços, com conseqüente redução do risco, tende a ser de maior importância no mercado de feijão, em que esta variável se mostrou importante tanto no curto quanto no longo prazo.

O trabalho também apresenta implicações de natureza metodológica, decorrentes tanto do modelo teórico desenvolvido quanto dos procedimentos empíricos utilizados.

Foi proposto um modelo com flexibilidade para servir à análise tanto de mercados com causalidade produtor $\rightarrow$ varejo quanto de causalidade varejo $\rightarrow$ produtor. Esse modelo apresentou bons ajustes aos dados mensais dos mercados analisados e mostrou-se mais consistentemente embasado do que os demais modelos que vêm sendo estimados. Com o uso da forma final de THEIL, foi possivel quantificar o impacto das variáveis exógenas sobre as endógenas ao longo do tempo, tendo-se chegado a resultados próximos dos encontrados na análise de auto-regressão vetorial.

A mudança na importância de algumas variáveis de custo na explicação da margem, à medida que se passa de um enfoque estático para um dinâmico, e a alternância que existe no efeito dessas variáveis ao longo do tempo mostraram que a compatibilização dos métodos de análise estático e dinâmico (seja pelos multiplicadores de THEIL ou pelos modelos VAR) é um instrumento poderoso para se compreender o comportamento da margem de comercialização de produtos agrícolas. $O$ principal exemplo foi a taxa de juros, que só mostrou sua importância quando se realizou a análise dinâmica.

O método de auto-regressão vetorial mostrou-se adequado para captar as inter-relações dinâmicas das variáveis que haviam ficado obscurecidas na análise estática; sua vantagem em relação ao método de THEIL é a possibilidade de quantificar choques também das variáveis endógenas, que foram de importância no presente estudo, e a possibilidade de calcular a importância de cada variável na explicação dos erros de previsão da margem de comercialização. A vantagem do uso dos multiplicadores é uma maior consistência teórica dos resultados, visto que esse método requer maior 
identificação do modelo para ser implementado. O modelo VAR identificável não alterou, qualitativamente, os resultados do modelo VAR convencional, servindo mais para confirmar as conclusões do primeiro modelo.

Dessa forma, o método seguido neste trabalho, bem como o modelo teórico desenvolvido no capítulo 4, podem ser de utilidade em futuros estudos, norteando pesquisas sobre as margens de comercialização dos mercados de outros produtos agrícolas. 


\section{REFERÊNCIAS BIBLIOGRÁFICAS}

AGUIAR, D. R. D.; BARROS, G. 'S. A. C.; BURNQUIST, H. L.; FERREIRA, L. R. Análise da eficiência e competitividade no sistema de comercialização de feijão. Revista de Economia e Sociologia Rural, 1994 (no prelo).

ANDA. Anuário estatístico do setor de fertilizantes: 1990. São Paulo, Associação Nacional para Difusão de Adubos e Corretivos Agrícolas, 1991.

BARBOSA, F. H. Microeconбmia: teoria, modelos econométricos e aplicações à economia brasileira. Rio de Janeiro, IPEA/INPES, 556 p., 1985.

BARROS, G. S. A. C. Effects of international shocks and domestic macroeconomic policies upon Brazilian agriculture. Agricultural Economics, 7: 317-329, 1992.

BARROS, G. S. A. C. Impacts of monetary and real factors on the US dollar in identifiable VAR models. Revista Brasileira de Economia, 45(4):519-41, out./dez. 1991.

BARROS, G. S. A. C. Transmissão de preços pela central de abastecimento de São Paulo, Brasil. Revista Brasileira de Economia, 44(1): 5-20, jan./mar. 1990.

BARROS, G. S. A. C. Economia da comercialização agrícola. Piracicaba', FEALQ, 306 p., 1987.

BARROS, G. S. A. C. \& AGUIAR, D. R. D. Análise dos efeitos da liberação comercial sobre a competitividade da agricultura. (sub-projeto da pesquisa "O custo dos recursos domésticos e a competitividade da agricultura brasileira"). Instituto de Pesquisa Econômica Aplicada (IPEA) - Programa das Nações Unidas para o Desenvolvimento (PNUD). Brasilia, 41 p., 1994 (Relatório de Pesquisa). 
BRANDÃO, A. S. P. Moeda e preços relativos: evidência empírica. Revista de Econometria, 5(2): 33-80, 1985.

BRORSEN, B. W.; CHAVAS, J. P.; GRANT, W. R.; SCHNAKE, L. D. Marketing margins and price uncertainty: the case of the U.S. wheat market. American Journal of Agricultural Economics, 67: 521-528, 1985.

BUSE, R. C. \& BRANDOW, G. E. The relationship of volume, prices, and costs to marketing margins for farm foods. Journal of Farm Economics, 42: 362-70, 1960.

CANTO, W. L. Sistema ponderal de conversões e determinação de margens de comercialização. Estudos Econômicos - Alimentos Processados, Campinas, ITAL, 22, 1986.

CHIANG, A. Matemática para economistas. São paulo, EDUSP/McGraw-Hill, 684 p., 1982.

CONAB. Previsão e Acompanhamento de Safras. Ministério de Agricultura e Reforma Agrária, Companhia Nacional de Abastecimento, ano 16, no 5, junho de 1992.

DAVIDSON, R. \& MACKINNON, J. G. Several tests for model specification in the presence of alternative hypotheses. Econometrica, 49: 781-93, 1981.

ECKSTEIN, O. \& FROMM, G. The price equation. American Economic Review, 58(5): 1159-83,1968.

FAMINOW, M. D. \& LAUBSCHER, J. M. Empirical testing of alternative price spread models in the South African maize market. Agricultural Economics, 6: 49-66, 1991.

FGV. Conjuntura Econômica. Fundação Getúlio Vargas, Rio de Janeiro, diversos.

GARDNER, B. L. The farm-retail price spread in a competitive food industry. American Journal of Agricultural Economics, 57: 399-409, 1975.

GEORGE, P. S. \& KING, G. A. Consumer demand for food commodities in the United States with projections for 1980. Giannini Foundation Monograph $\mathrm{N}^{\circ} 26$, University of California, Berkeley, 1971. 
GRANGER, C. W. J. Investigating causal relations by econometric models and cross spectral methods. Econometrica, 37(3): 424-38, 1969.

GRIFFITHS, W. E.; HILL, R. C. \& JUDGE, G. G. Learning and practicing econometrics. Singapore, John Willey \& Sons, Inc., 866 p., 1993.

HEIEN, D. M. Markup pricing in a dynamic model of food industry. American Journal of Agricultural Economics, 62: 10-18, 1980. '

HENDERSON, J. M. \& QUANDT, R. E. Teoria microeconômica - uma abordagem matemática. $2^{\mathrm{a}}$ ed. São Paulo, Livraria Pioneira Editora, 417 p., 1988.

IEA. Informações Econômicas. Sécretaria de Agricultura e Abastecimento, Instituto de Economia Agrícola, São Paulo, diversos.

JUNQUERA, P. C. \& CANTO, W. L. Cesta de mercado - margens totais de comercialização. Agricultura em São Paulo, São Paulo, 18(9/10): 1-46, set./out., 1971.

KMENTA, J. Elementos de econometria. $2^{a}$ ed. São Paulo, Atlas. 2 v., 694 p., 1988.

LYON, C. C. \& THOMPSON, G. D. Temporal and spacial aggregation: alternative marketing margin models. American Journal of Agricultural Economics, 75: 523536, August 1993.

MARQUES, P. V. Margens de comercialização de produtos agrícolas. $2^{\mathrm{a}}$ ed. Piracicaba, USP/ESALQ/DESR, 1993 (Série Didática, 81).

ORDEN, D. \& FACKLER, P. L. Identifying monetary impacts on agricultural prices in VAR models. American Journal of Agricultural Economics, 71: 495-502, 1989.

PINDYCK, R. S. \& RUBINFELD, D. L. Econometric models and economic forecasts. $3^{\text {a }}$ ed. Singapore, McGraw-Hill, 596 p., 1991.

POWERS, N. J. Marketing order impacts on farm-retail price spreads: comment. American Journal of Agricultural Economics, 73: 507-510, 1991. 
SANDMO, A. On the theory of the competitive firm under price uncertainty. American Economic Review, 61: 65-73, 1971.

SANTIAGO, M. M. D. (coord.). Estatística de preços agrícolas no Estado de São Paulo. São Paulo, Secretaria de Agricultura e Abastecimento, Instituto de Economia Agrícola, 1990. 3V.

SCHERER, F. M. \& ROSS, D. Industrial market structure and economic performance. $3^{\text {a }}$ ed.. Boston, Houghton Mifflin Company, 713 p., 1990.

SILVA, G. L. S. P (coord.). Estatísticas da agricultura brasileira. São Paulo, Secretaria de Agricultura e Abastecimento, Instituto de Economia Agrícola, 1990, $1 \mathrm{~V}$.

SIMS, C. A. Macroeconomics and reality. Econometrica, 48: 1-48, 1980.

TAXA DE JUROS NO BRASIL. São Paulo, Nova Análise Editora, 1992.

TEIXEIRA, H. H. L. Modelo de desequilíbrio de margens de comercialização agrícola. Viçosa, 1982. 69 p. (M.S. - Universidade Federal de Viçosa).

TOMEK, W. G. \& ROBINSON, K. L. Agricultural product prices. Ithaca, N.Y., Cornell University Press, $2^{\mathrm{a}}$ ed., 367 p., 1981.

THEIL, H. Principles of econometrics. New York, John Wiley \& Sons, Inc., 736 p., 1971.

THOMPSON, G. D. \& LYON, C. C. Marketing order impacts on farm-retail price spreads: the suspension of prorates on California-Arizona navel oranges. American Journal of Agricultural Economics, 71: 647-660, 1989.

THOMPSON, G. D. \& LYON, C. C. Marketing order impacts on farm-retail price spreads: reply. American Journal of Agricultural Economics, 73: 51 1-514, 1991.

WAUGH, F. V. Análise de demanda e preços na agricultura. Piracicaba, USP/ESALQ, Departamento de Ciências Sociais Aplicadas (tradução: O. Serrano, D. W. Larson e J. J. C. Engler), 1973. 
WOHLGENANT, M. K. Competitive storage, rational expectations, and short-run food price determination. American Journal of Agricultural Economics, 67(4): 739-48, 1985.

WOHLGENANT, M. K. \& MULLEN, J. D. Modeling the farm-retail price spread for beef. Western Journal of Agricultural Economics, 12(2): 119-125, 1987. 


\section{APEN DICE 1}

Figuras da análise de auto-regressão vetorial com modelo não-identificável 


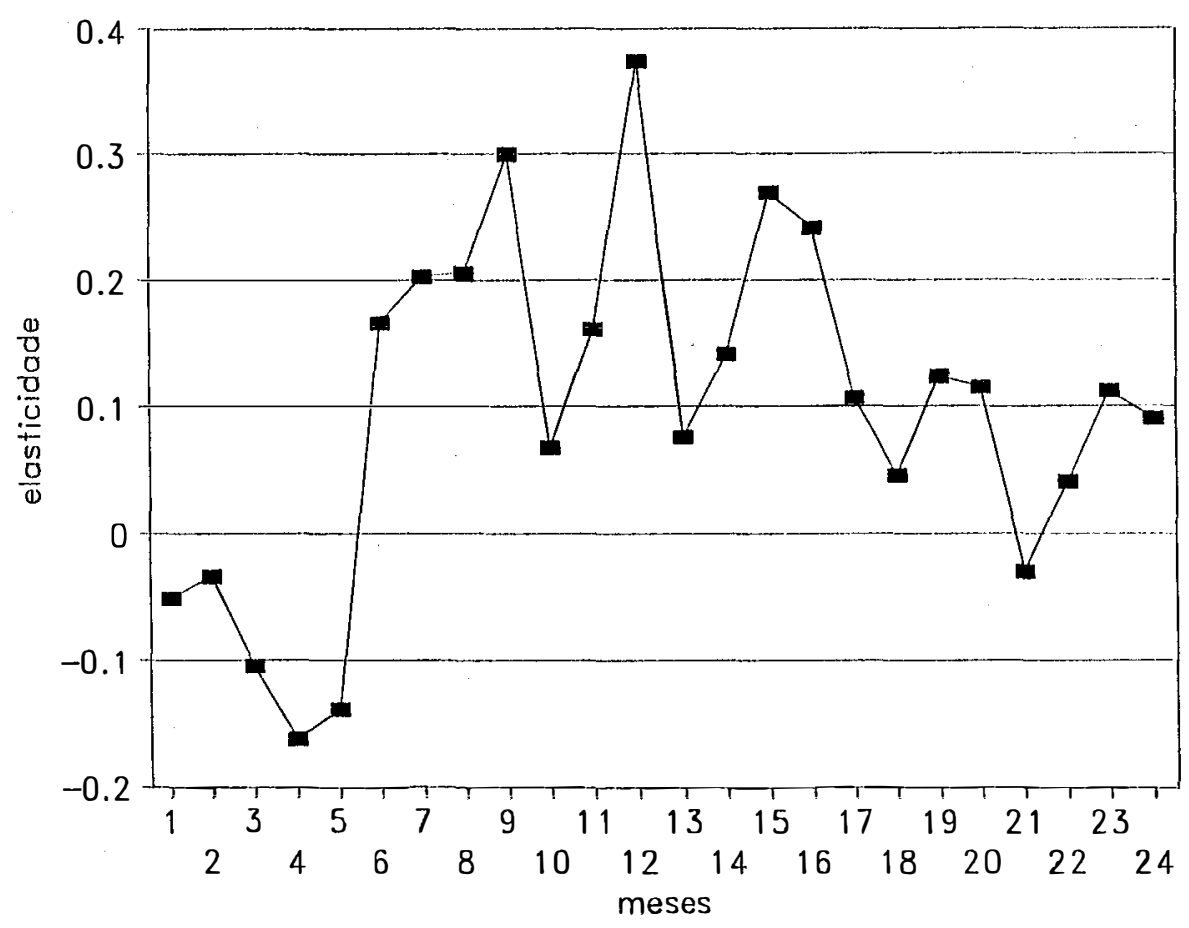

Figura 1.1 - Elasticidades de impulso do preço do óleo diesel sobre a margem de comercialização de arroz - modelo VAR não-identificável. 


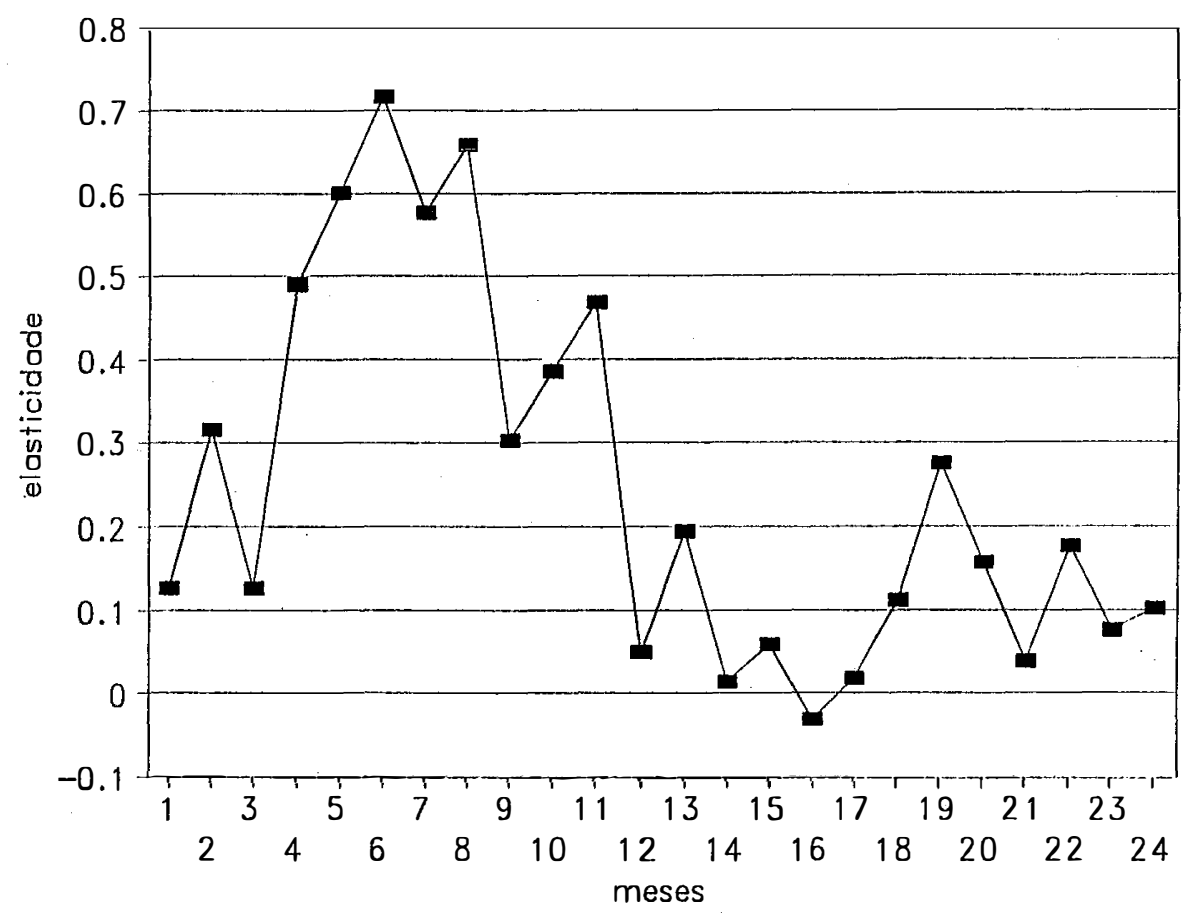

Figura 1.2 - Elasticidades de impulso do preço dos fertilizantes sobre a margem de comercialização de arroz - modelo VAR não-identificável. 


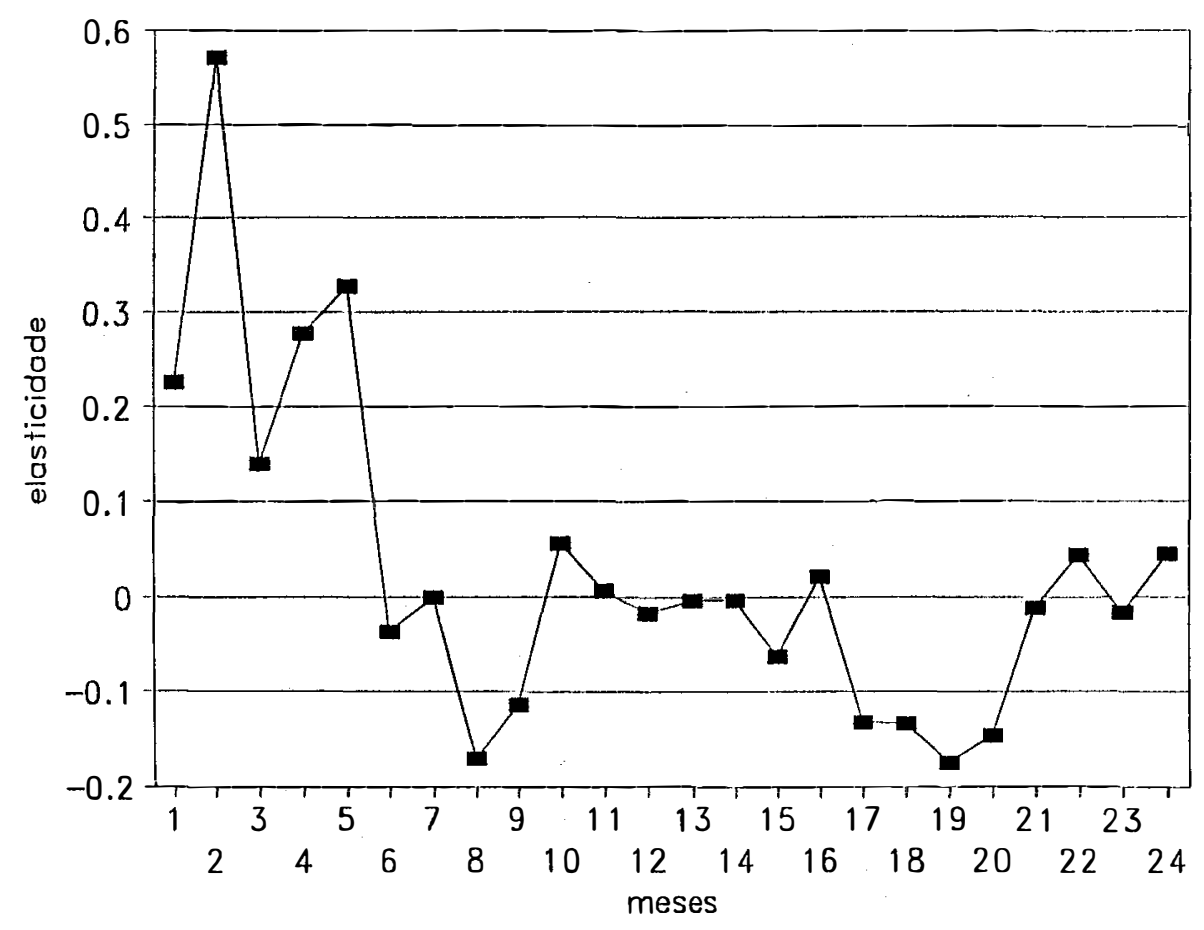

Figura 1.3 - Elasticidades de impulso do salário-mínimo sobre a margem de comercialização de arroz - modelo VAR não-identificável. 


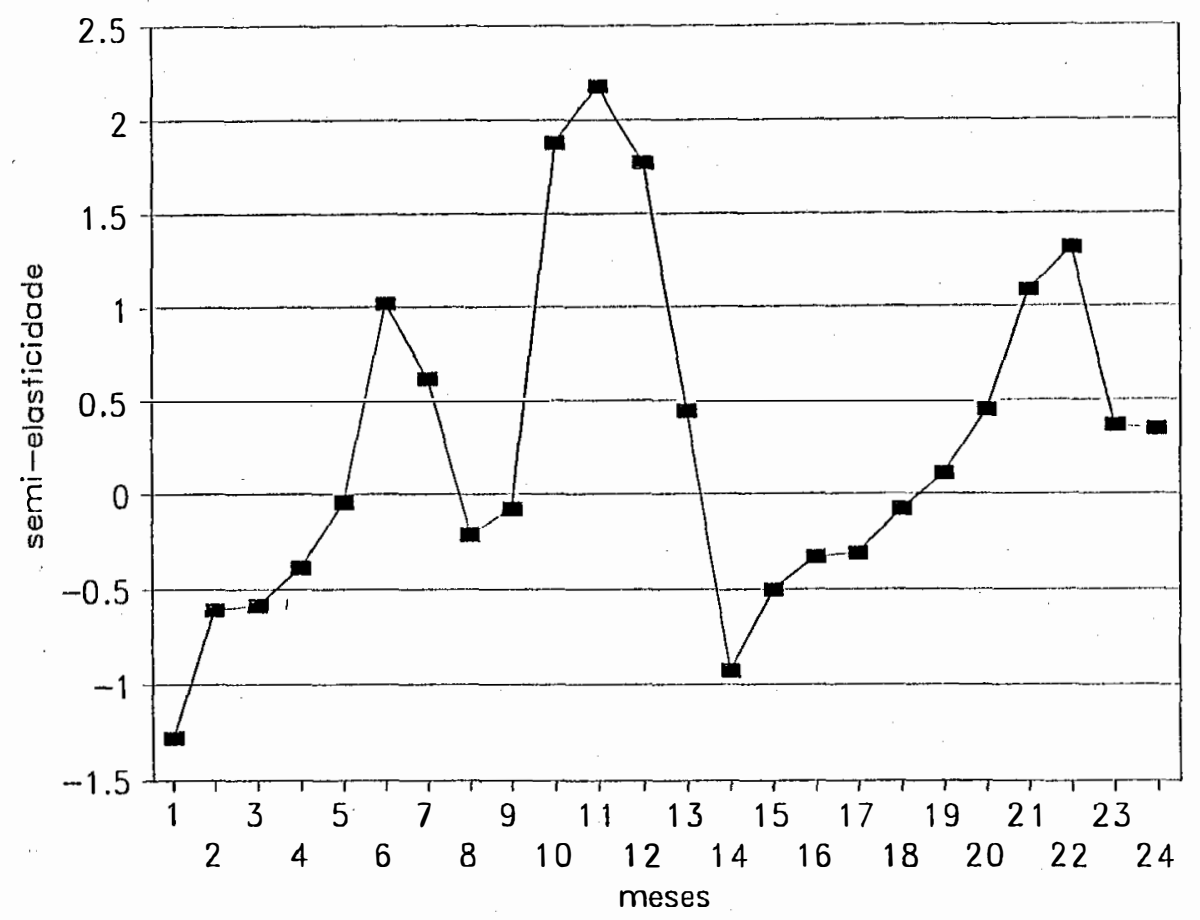

Figura 1.4 - Semi-elasticidades de impulso da taxa de juros sobre a margem de comercialização de arroz - modelo VAR não-identificável. 


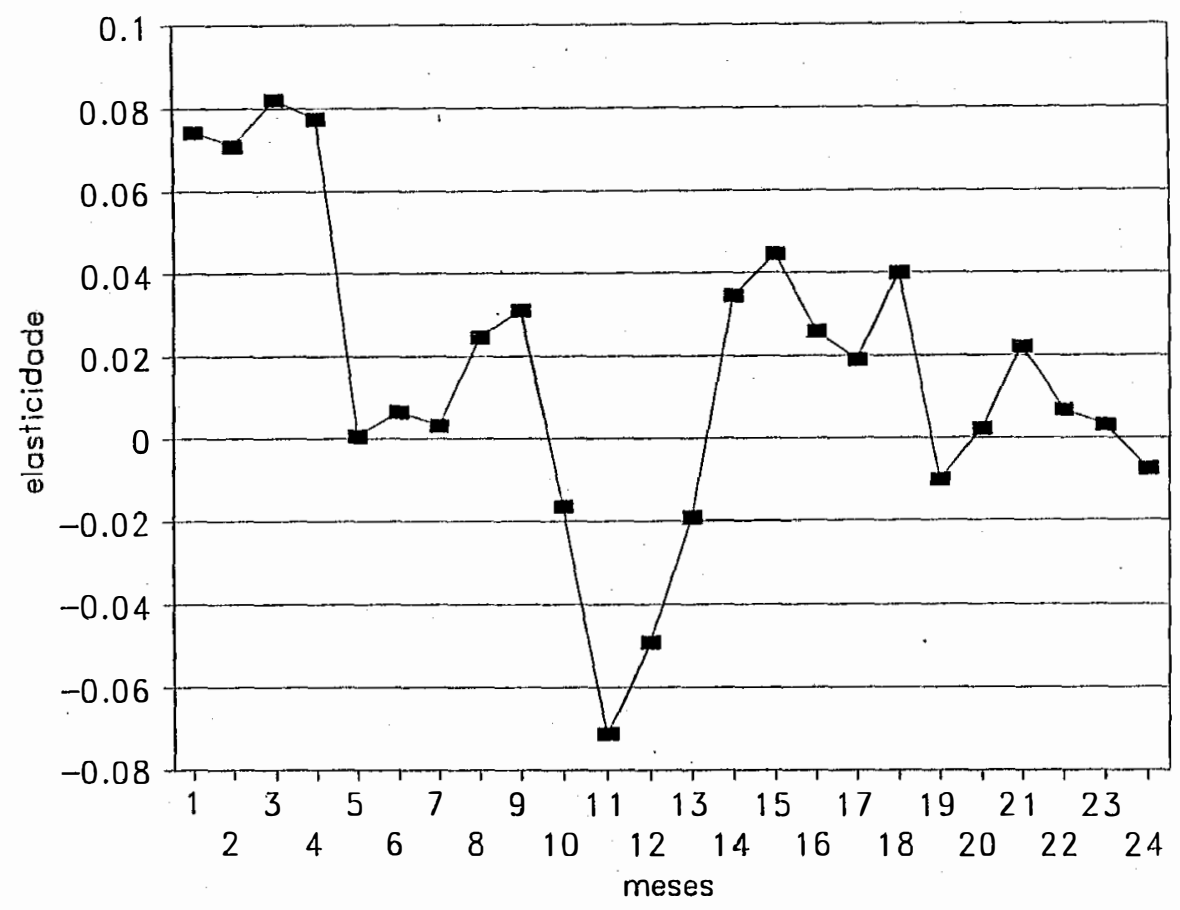

Figura 1.5 - Elasticidades de impulso do risco de preço sobre a margem de comercialização de arroz - modelo VAR não-identificável. 


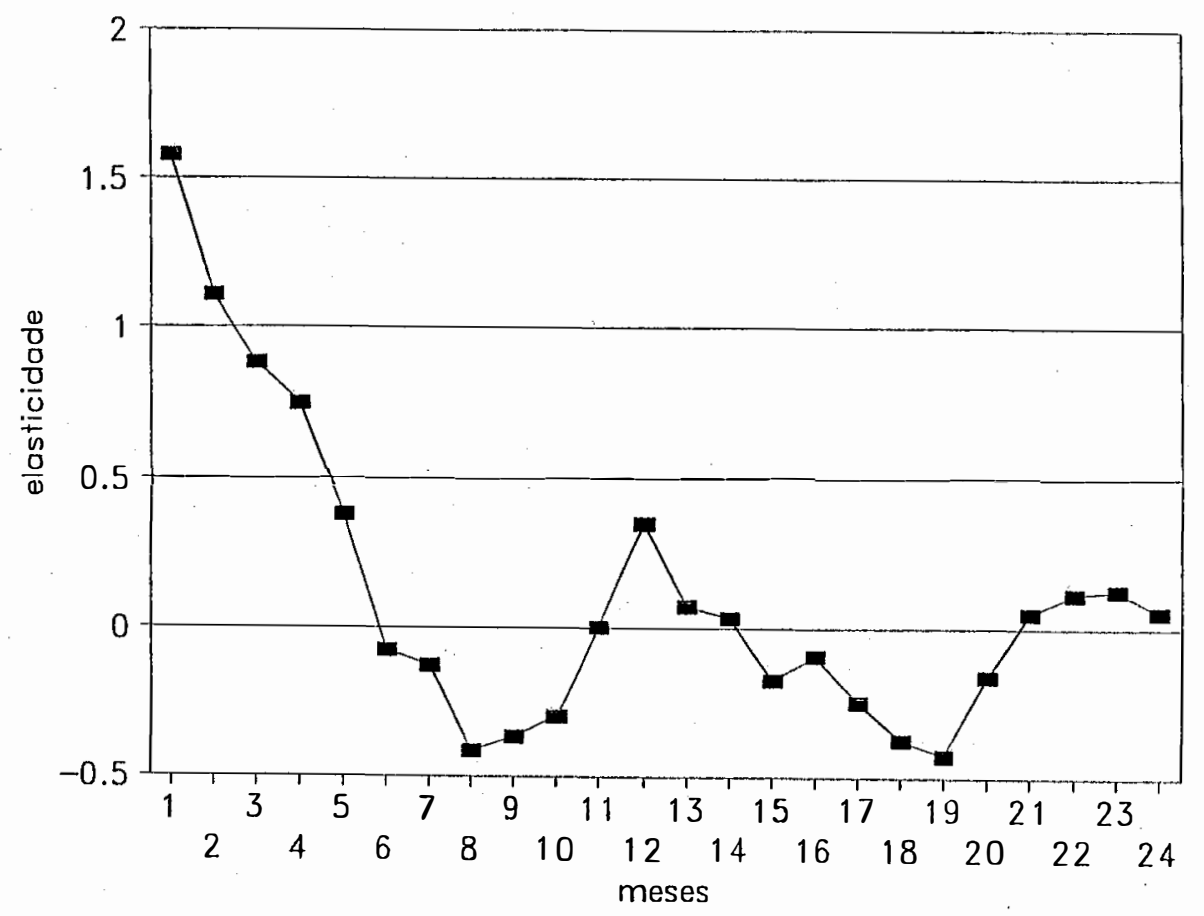

Figura 1.6 - Elasticidades de impulso do preço ao varejo sobre a margem de comercialização de arroz - modelo VAR não-identificável. 


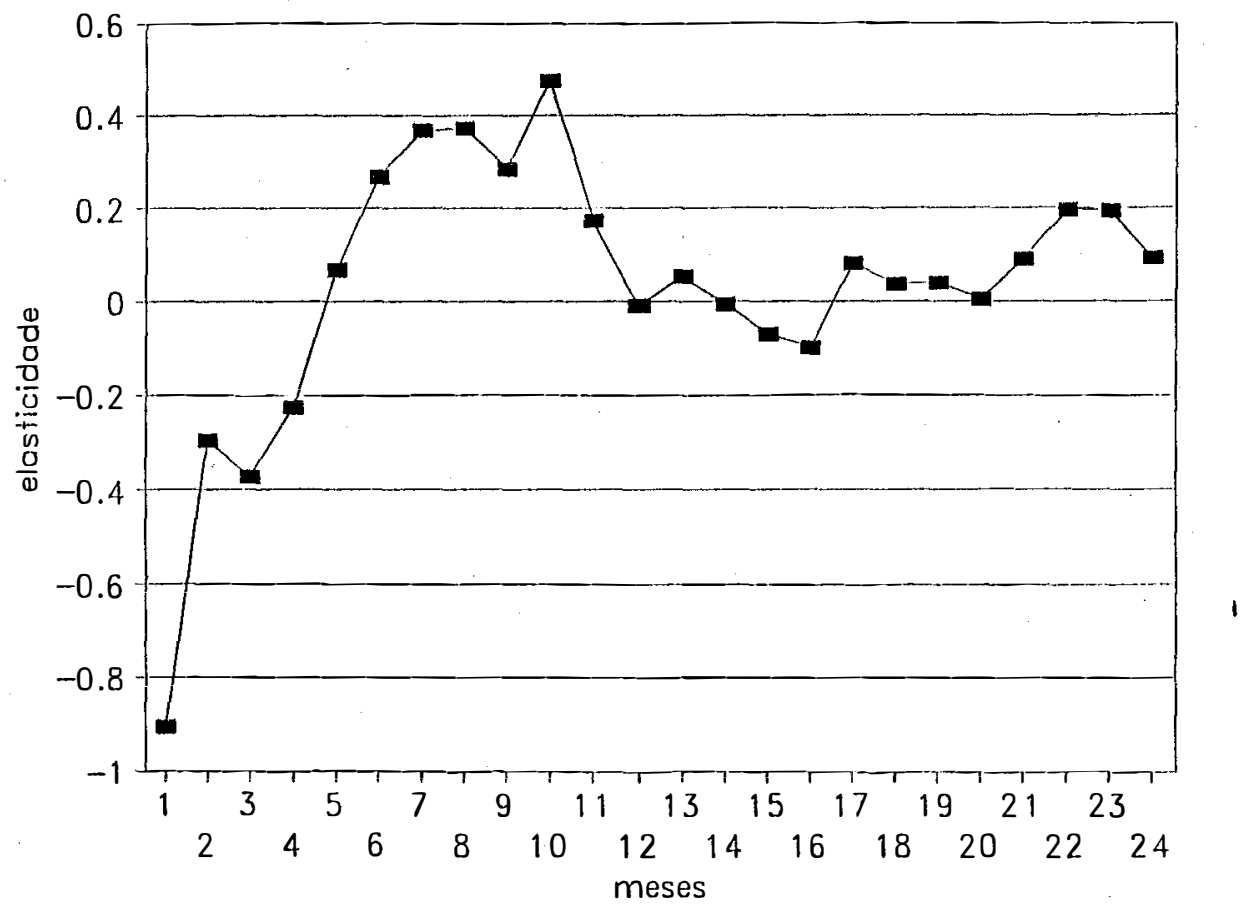

Figura 1.7 - Elasticidades de impulso do preço ao produtor sobre a margem de comercialização de arroz - modelo VAR não-identificável. 


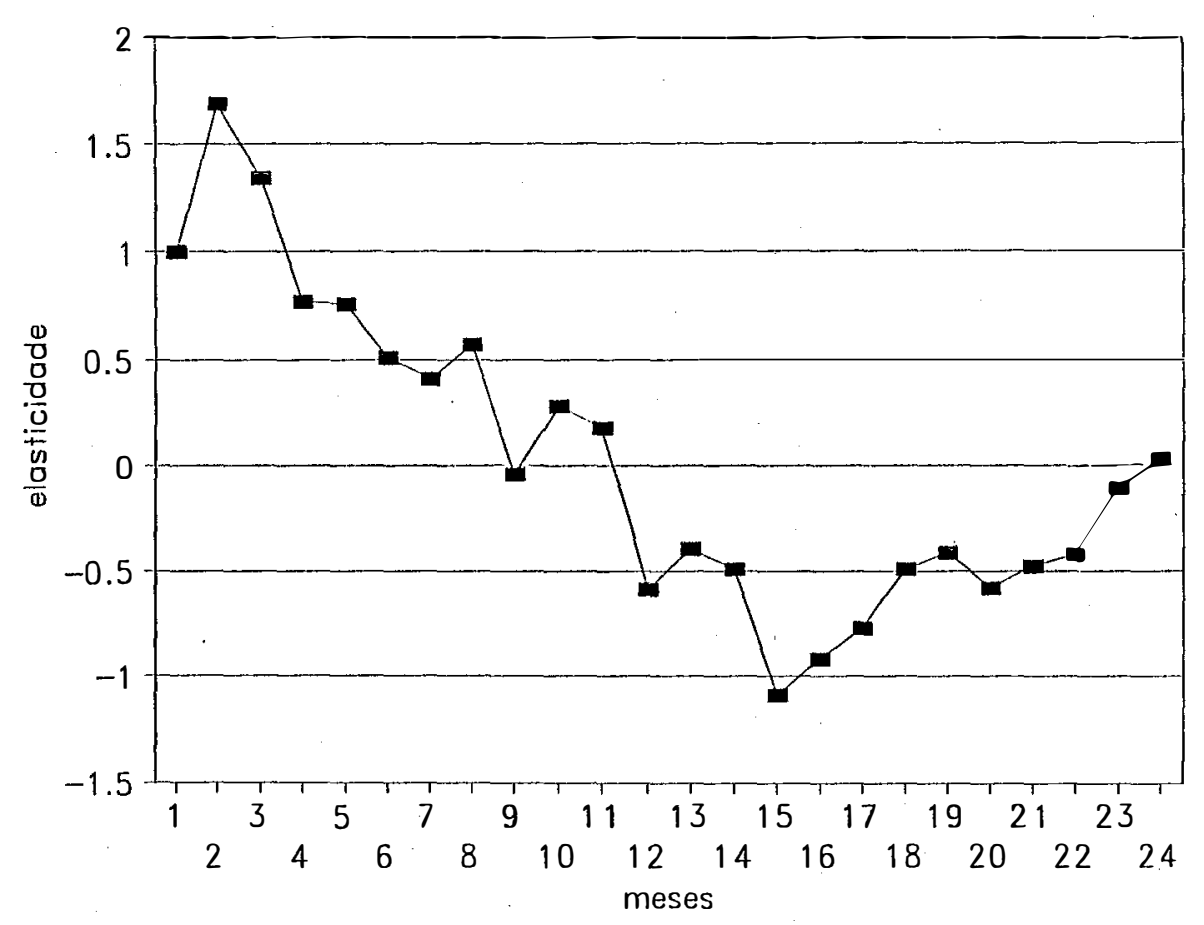

Figura 1.8 - Elasticidades de impulso da margem de comercialização de arroz sobre ela mesma - modelo VAR não-identificável 


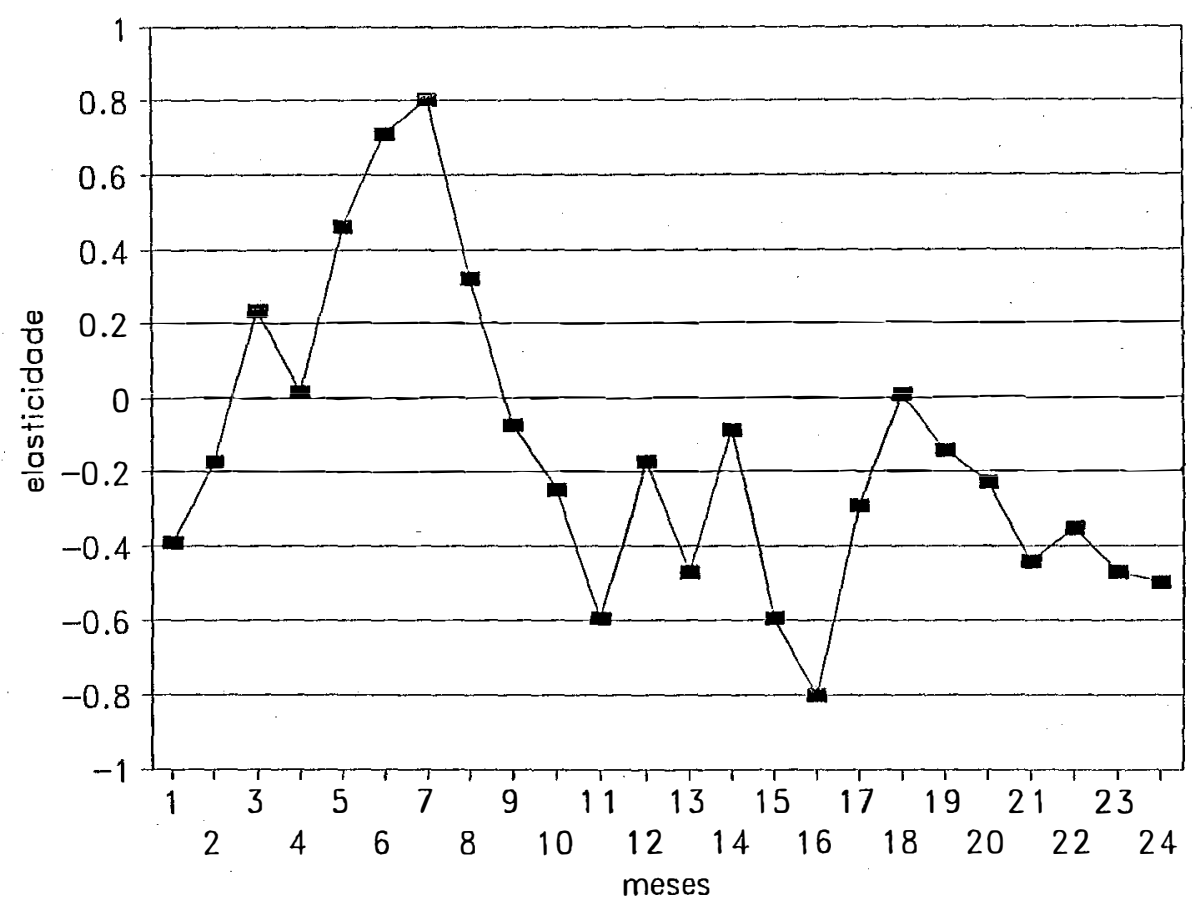

Figura 1.9 - Elasticidades de impulso do preço do óleo diesel sobre a margem de comercialização de feijão - modelo VAR não-identificável. 


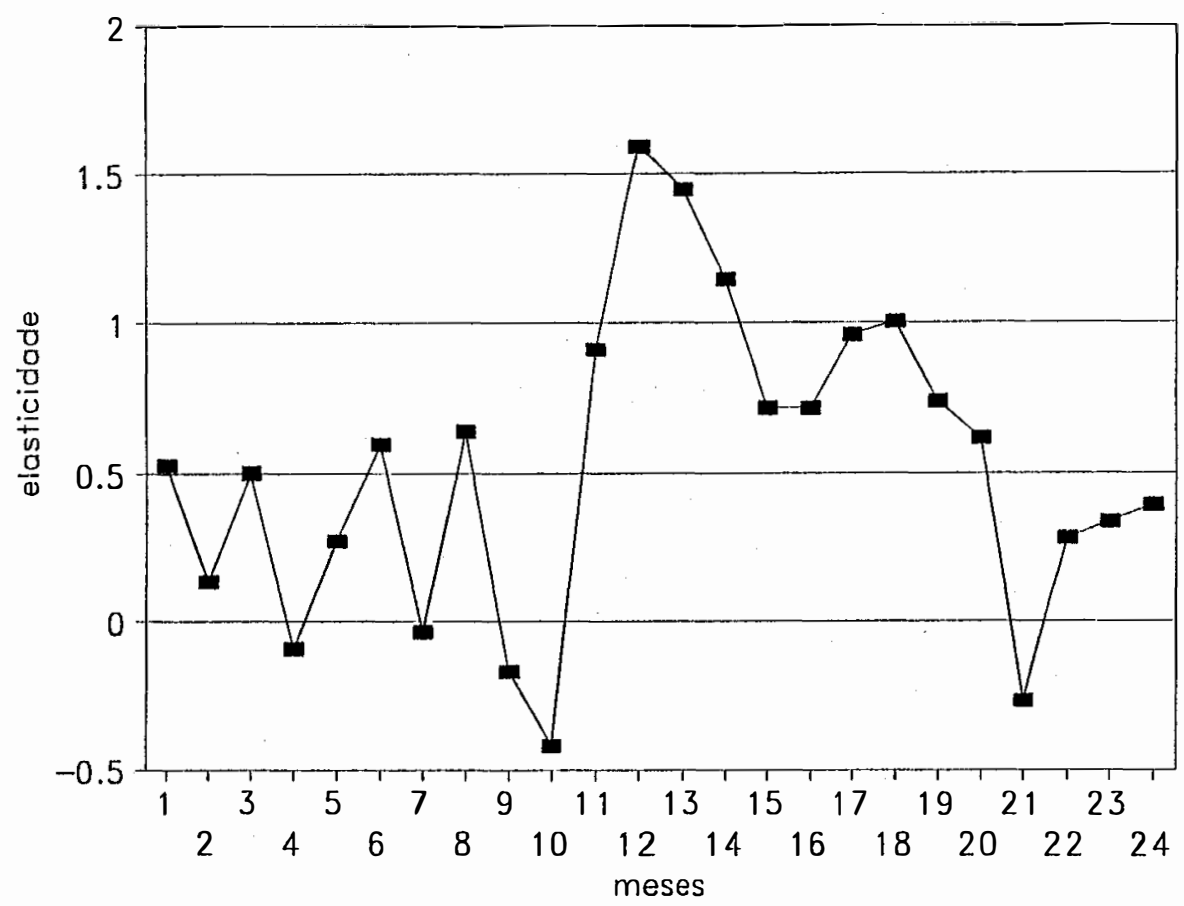

Figura 1.10 - Elasticidades de impulso do preço de fertilizantes sobre a margem de comercialização de feijão - modelo VAR não-identificável. 


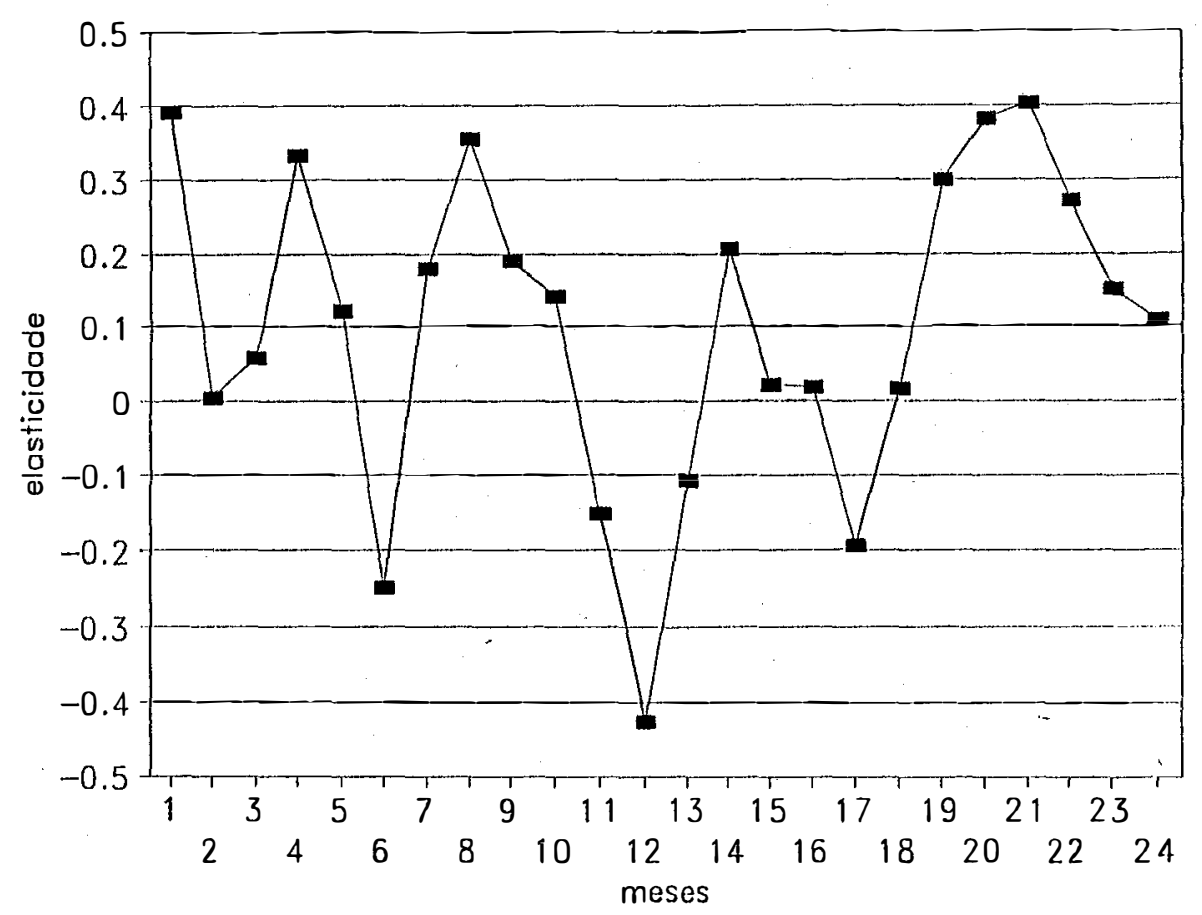

Figura 1.11 - Elasticidades de impulso do salário-mínimo sobre a margem de comercialização de feijão - modelo VAR não-identificável. 


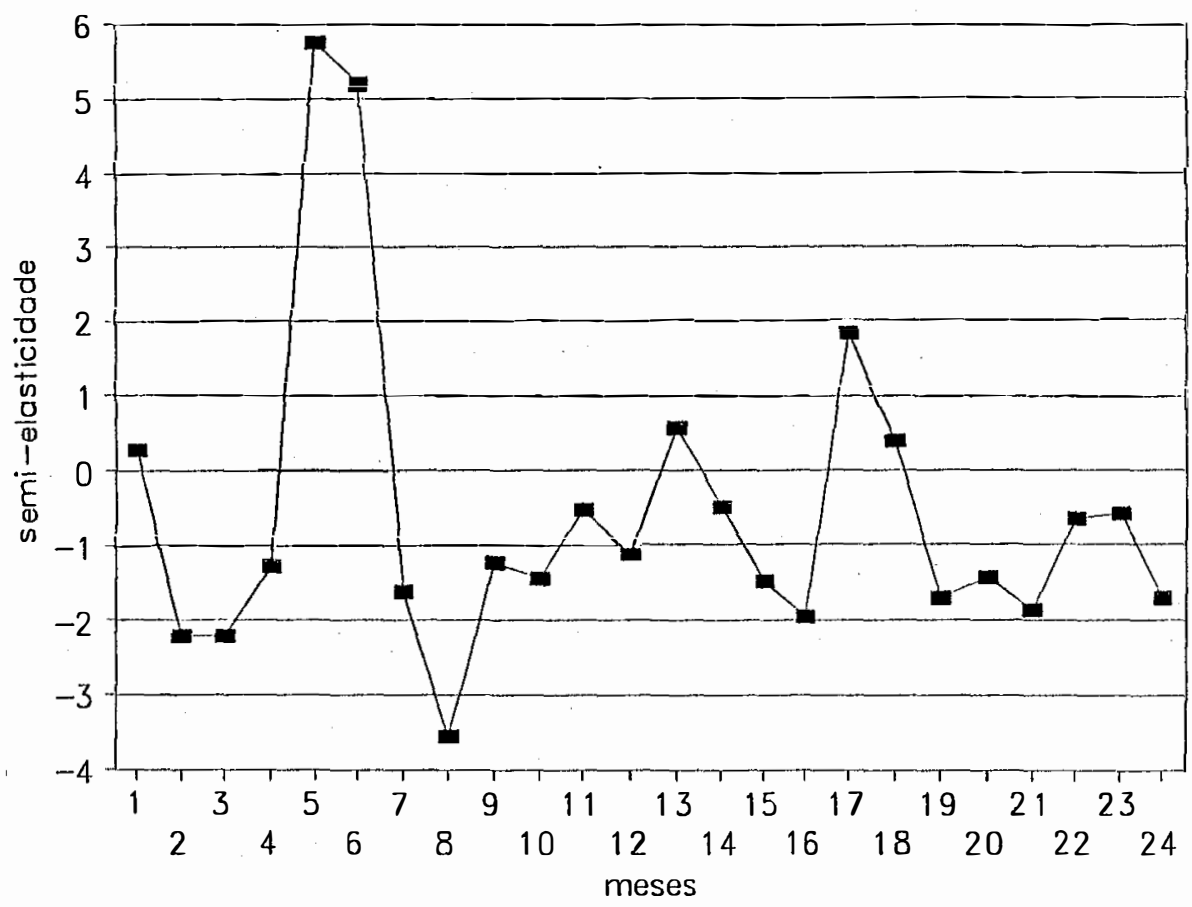

Figura 1.12 - Semi-elasticidades de impulso da taxa de juros sobre a margem de comercialização de feijão - modelo VAR não-identificável. 


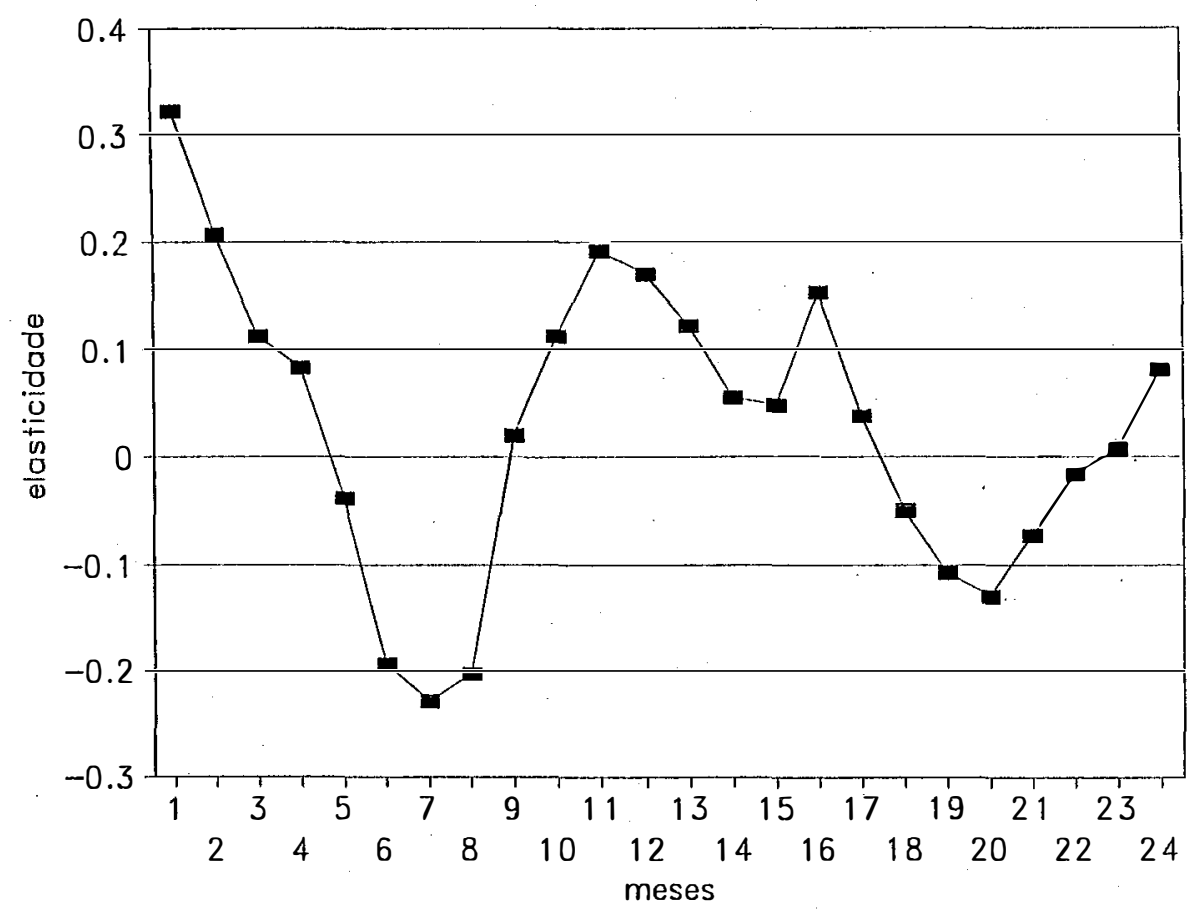

Figura 1.13 - Elasticidades de impulso do risco de preço sobre a margem de comercialização de feijão - modelo VAR não-identificável. 


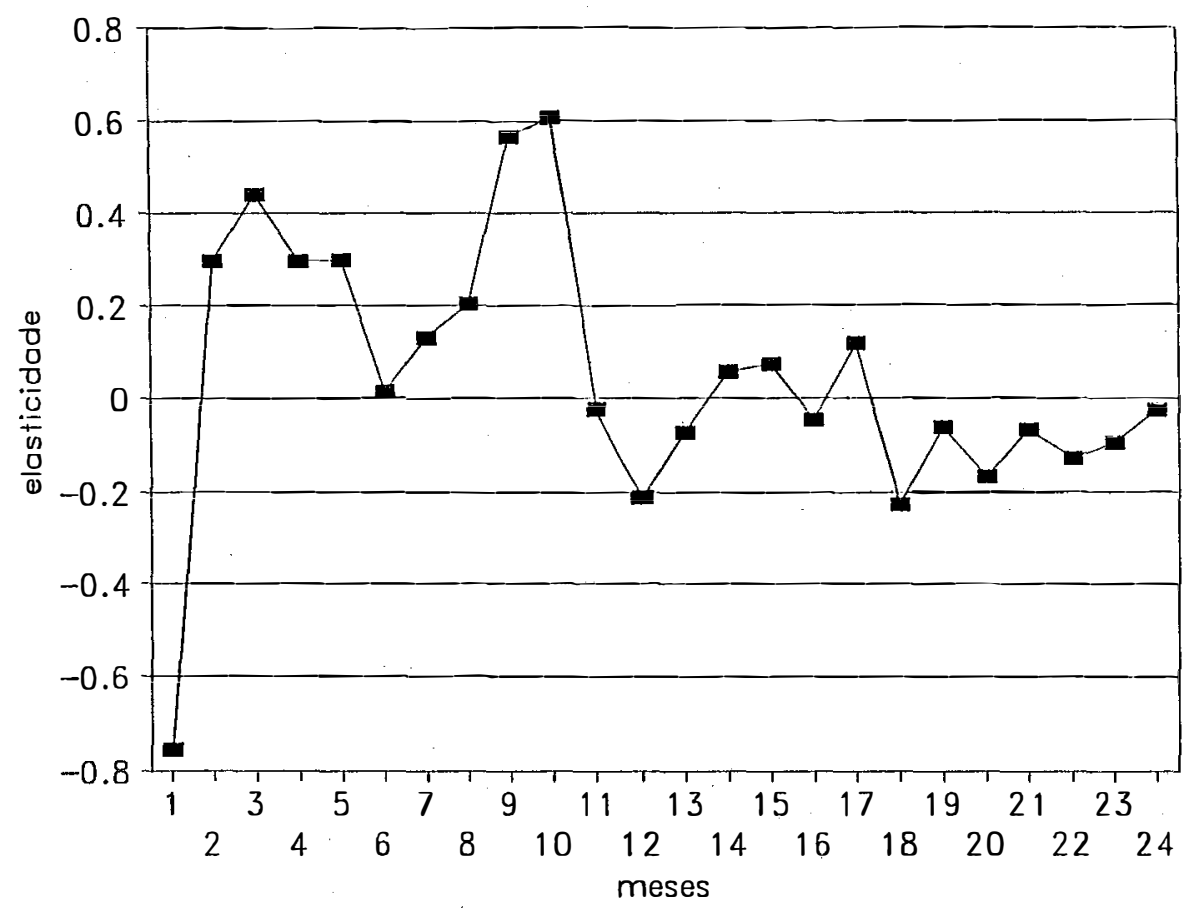

Figura 1.14 - Elasticidades de impulso do preço ao produtor sobre a margem de comercialização de feijão - modelo VAR não-identificável. 


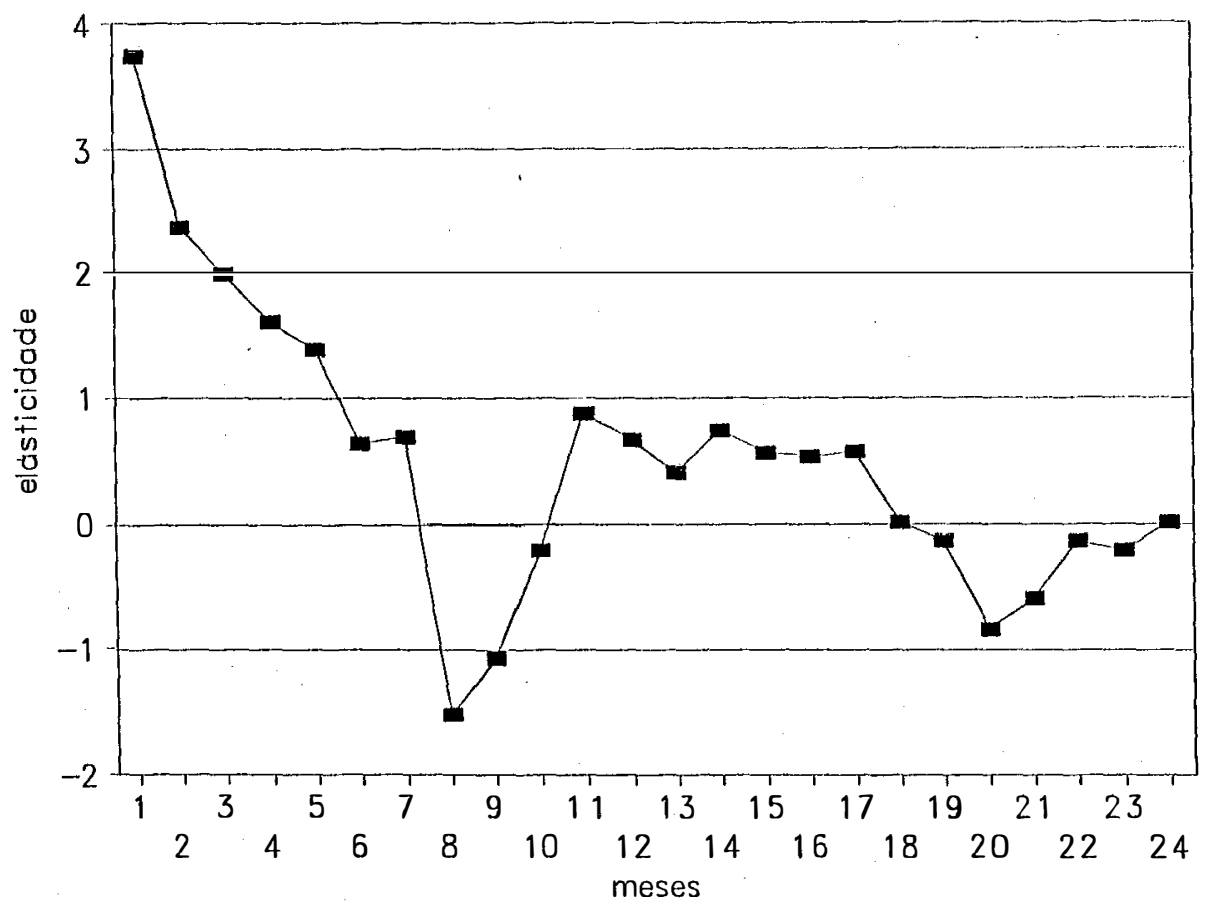

Figura 1.15 - Elasticidades de impulso do preço ao varejo sobre a margem de comercialização de feijão - modelo VAR não-identificável. 


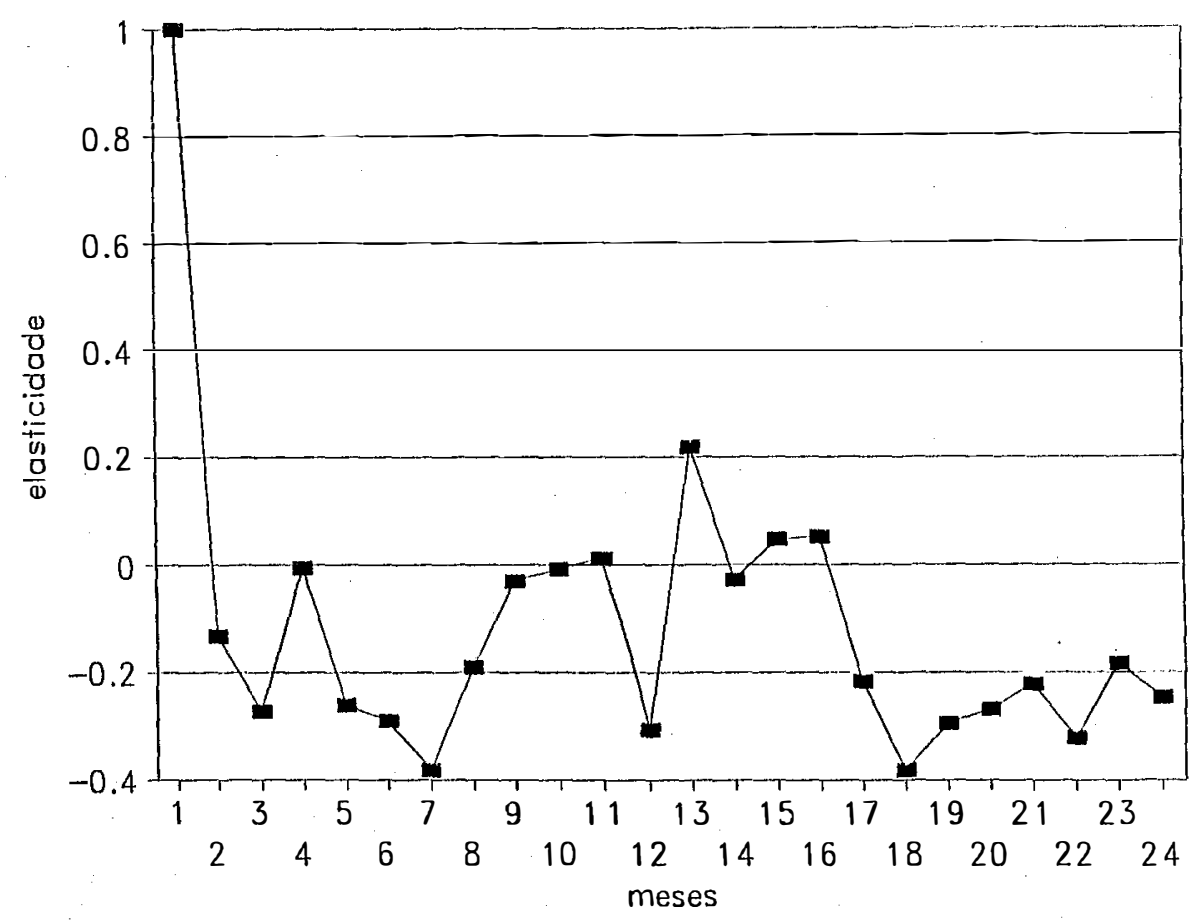

Figura 1.16 - Elasticidades de impulso da margem de comercialização de feijão sobre ela mesma - modelo VAR não-identificável. 


\section{APÊNDICE 2}

Figuras da análise de auto-regressão vetorial com modelo identificável 


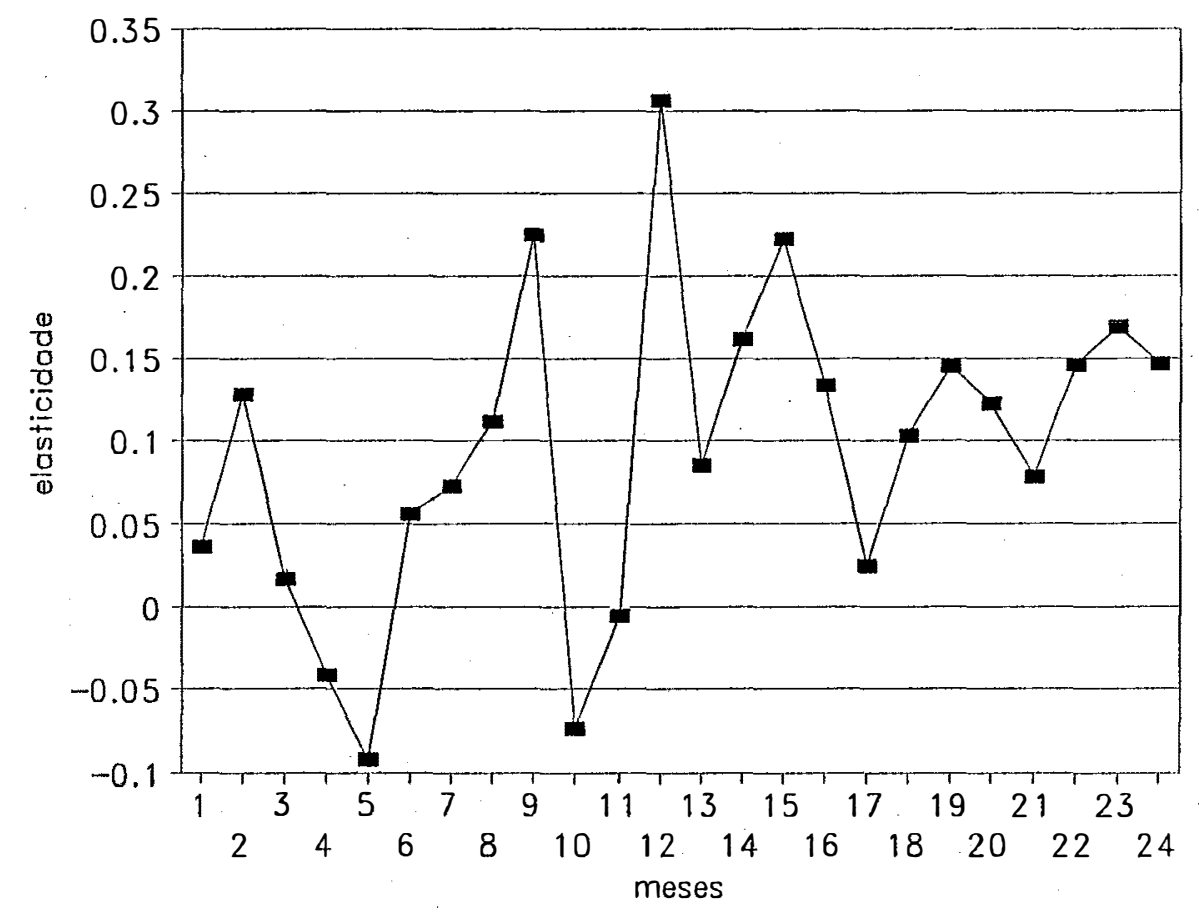

Figura 2.1 - Elasticidades de impulso do preço do óleo diesel sobre a margem de comercialização de arroz - modelo VAR identificável. 


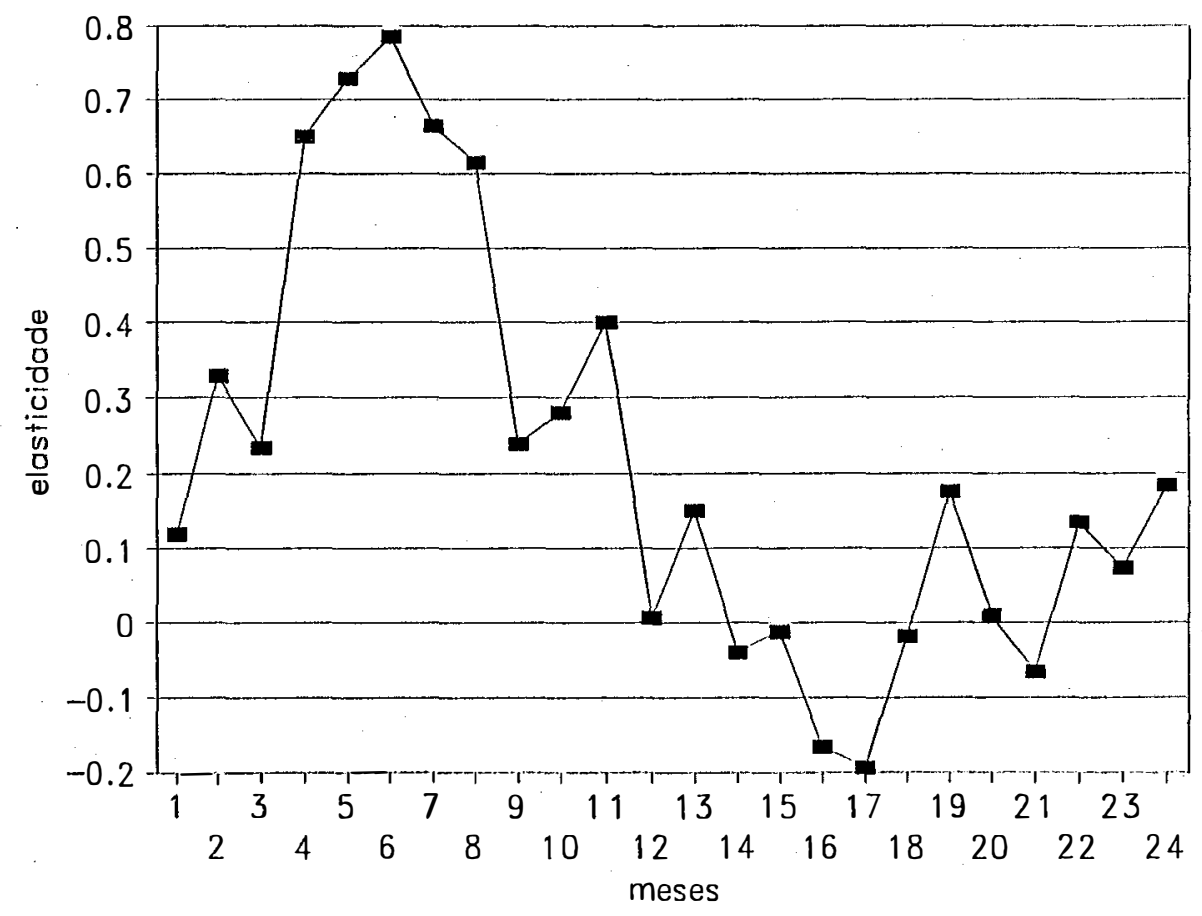

Figura 2.2 - Elasticidades de impulso do preço de fertilizantes sobre a margem de comercialização de arroz - modelo VAR identificável. 


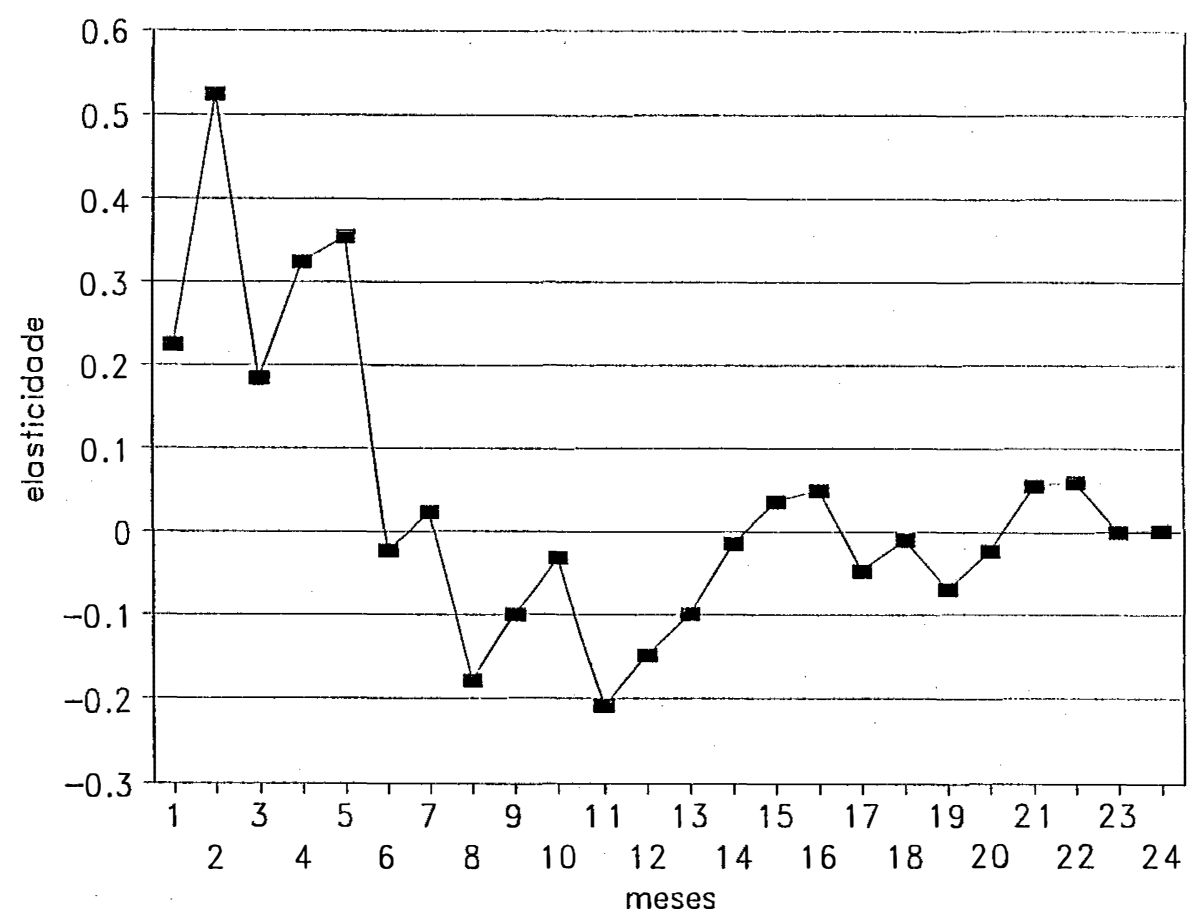

Figura 2.3 - Elasticidades de impulso do salário-mínimo sobre a margem de comercialização de arroz - modelo VAR identificável. 


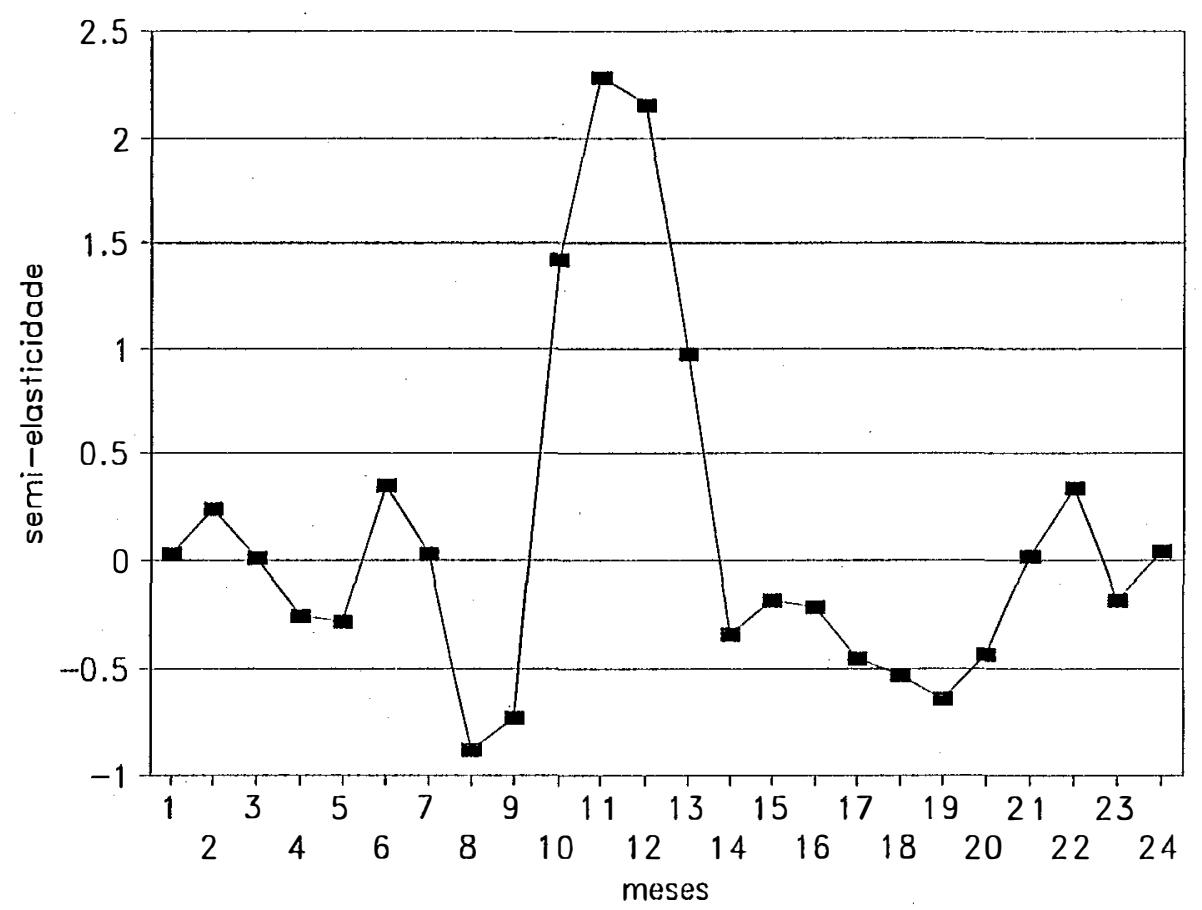

Figura 2.4 - Semi-elasticidades de impulso da taxa de juros sobre a margem de comercialização de arroz - modelo VAR identificável. 


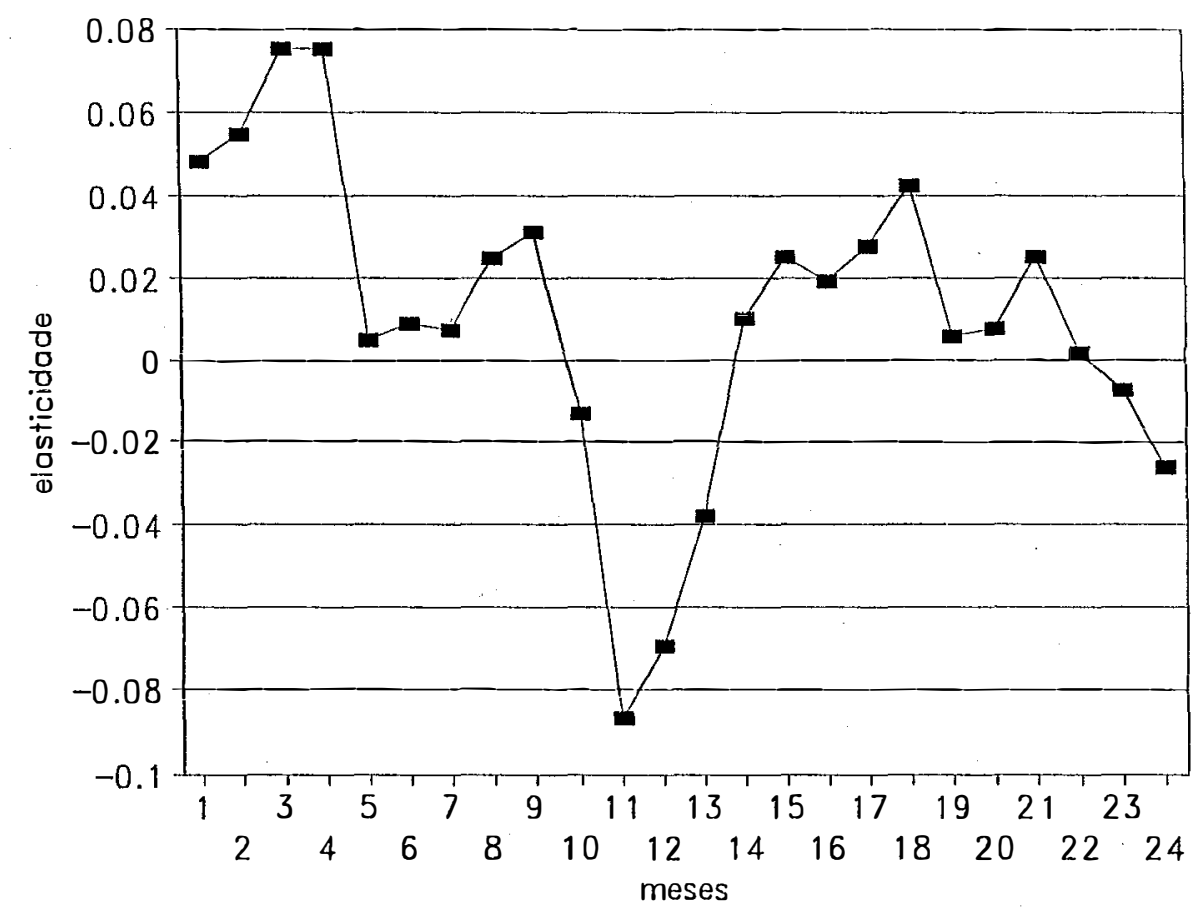

Figura 2.5 - Elasticidades de impulso do risco de preço sobre a margem de comercialização de arroz - modelo VAR identificável. 


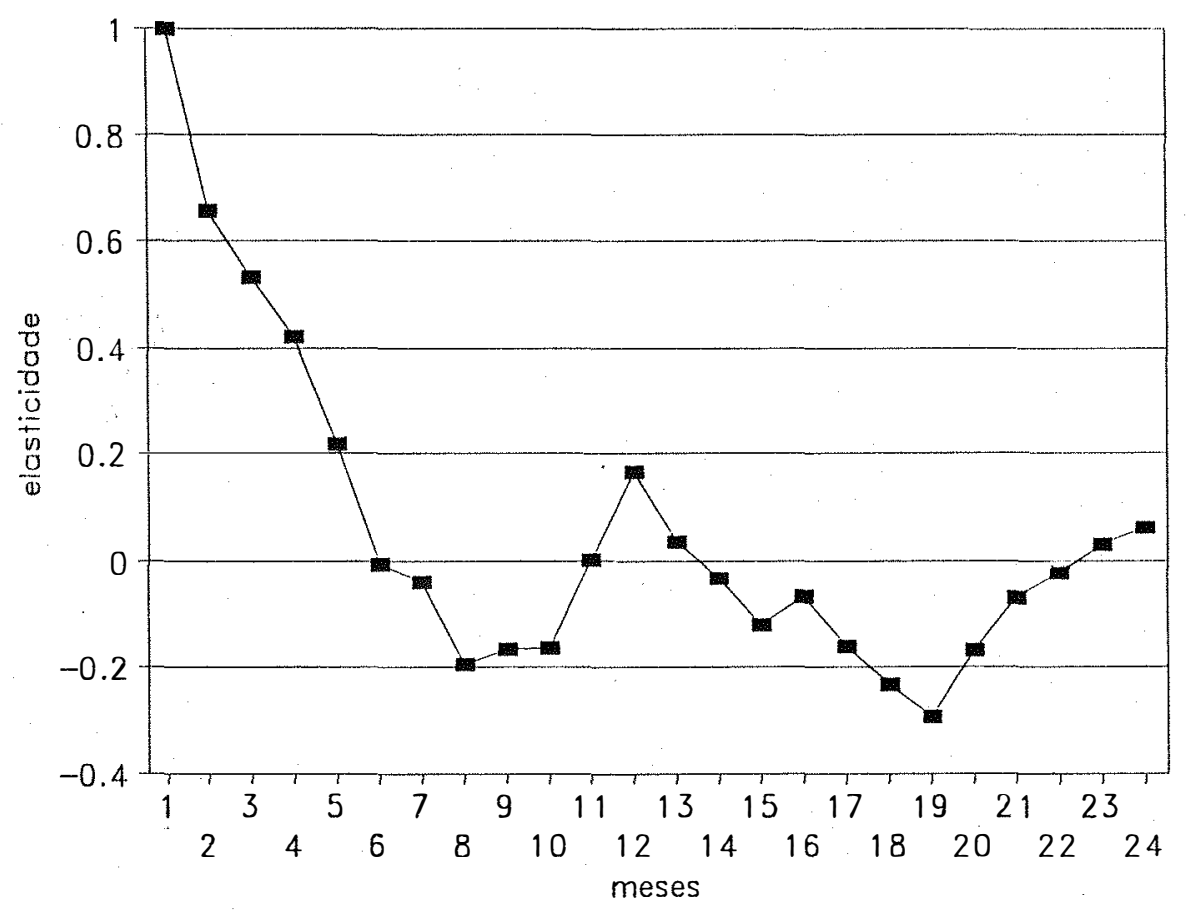

Figura 2.6 - Elasticidades de impulso da margem de comercialização de arroz sobre ela mesma - modelo VAR identificável. 


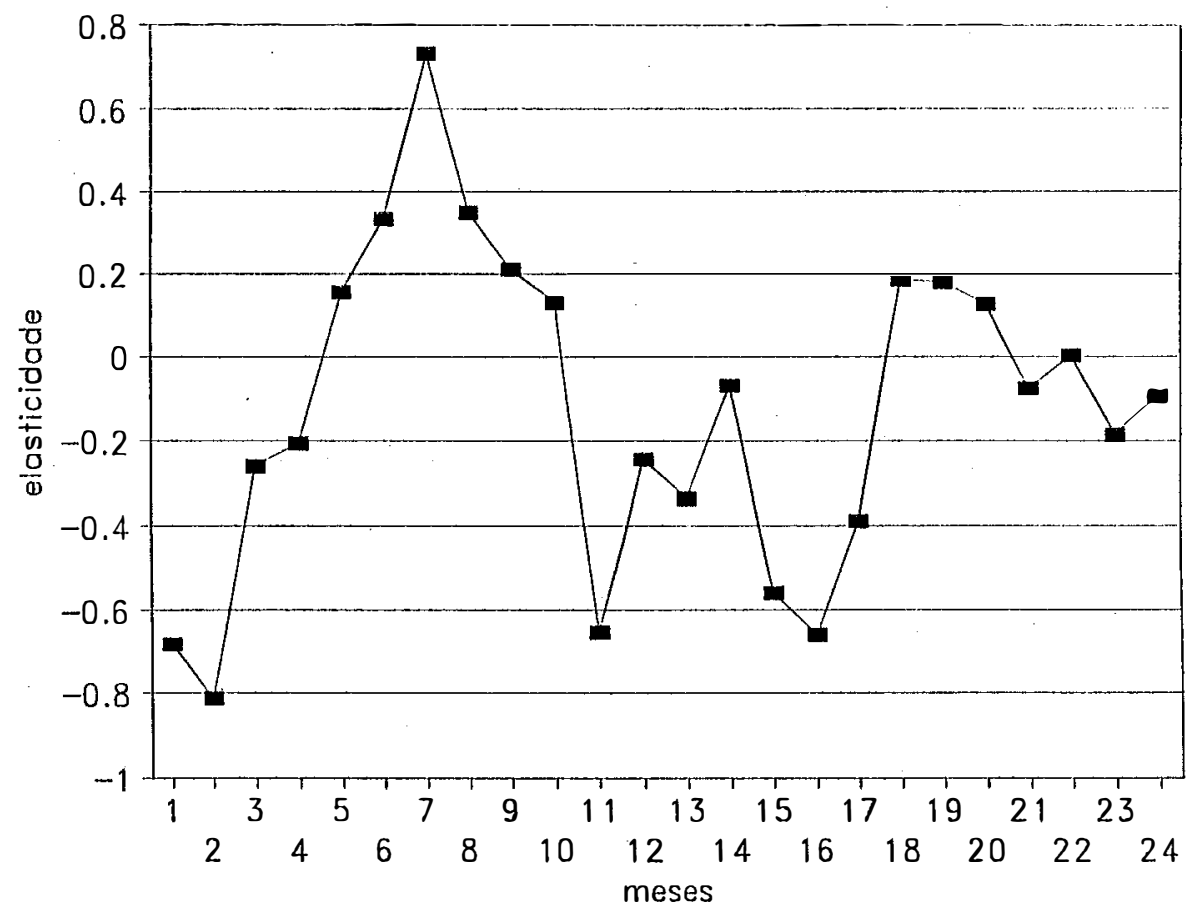

Figura 2.7 - Elasticidades de impulso do preço do óleo diesel sobre a margem de comercialização de feijão - modelo VAR identificável. 


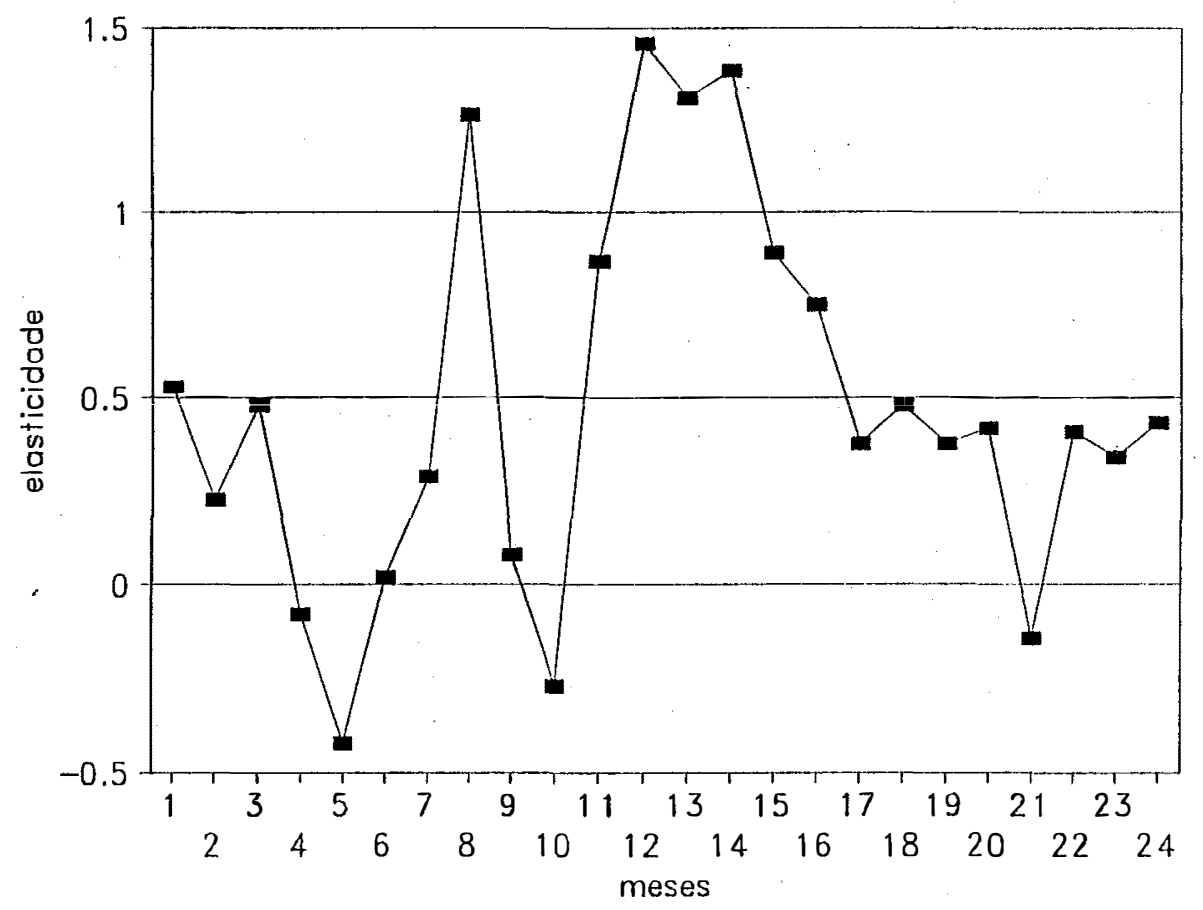

Figura 2.8 - Elasticidades de impulso do preço de fertilizantes sobre a margem de comercialização de feijão - modelo VAR identificável. 


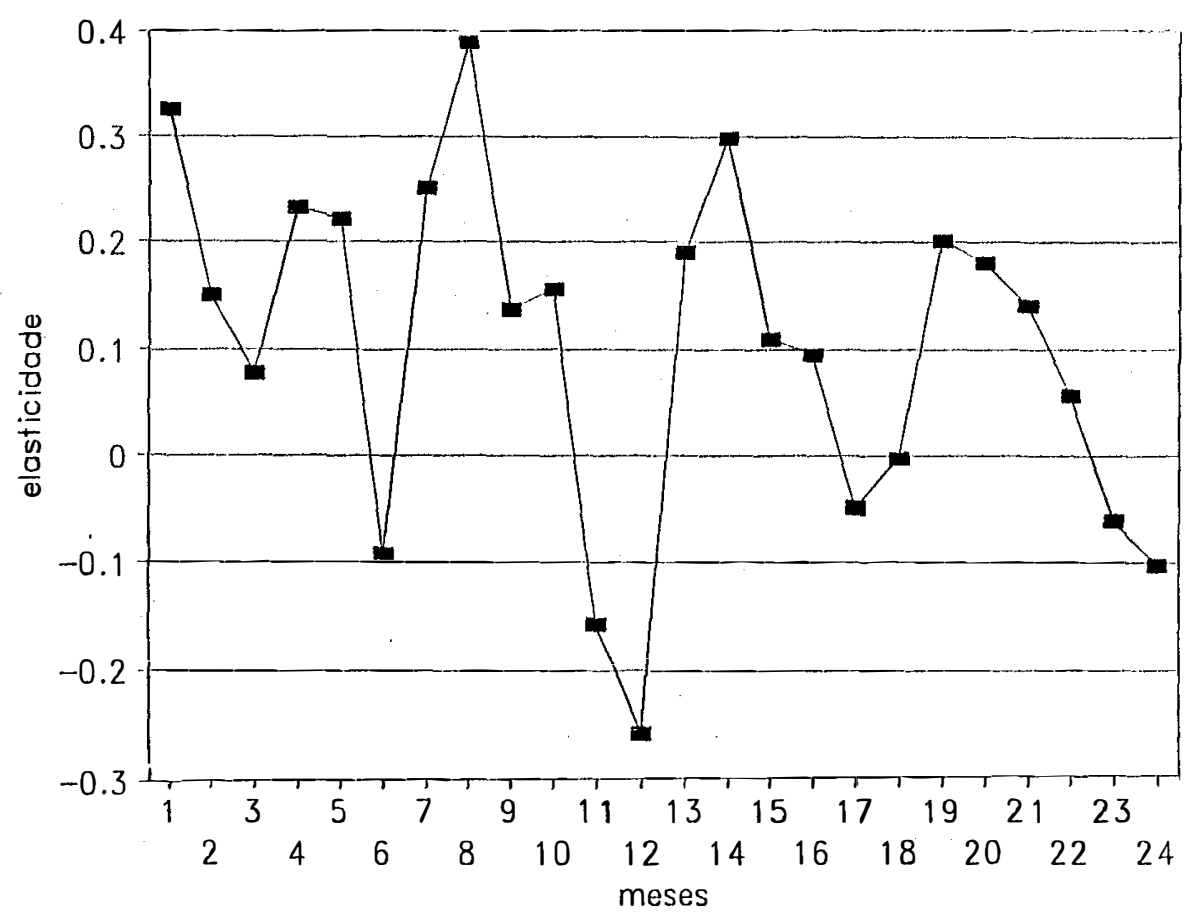

Figura 2.9 - Elasticidades de impulso do salário-mínimo sobre a margem de comercialização de feijão - modelo VAR identificável. 


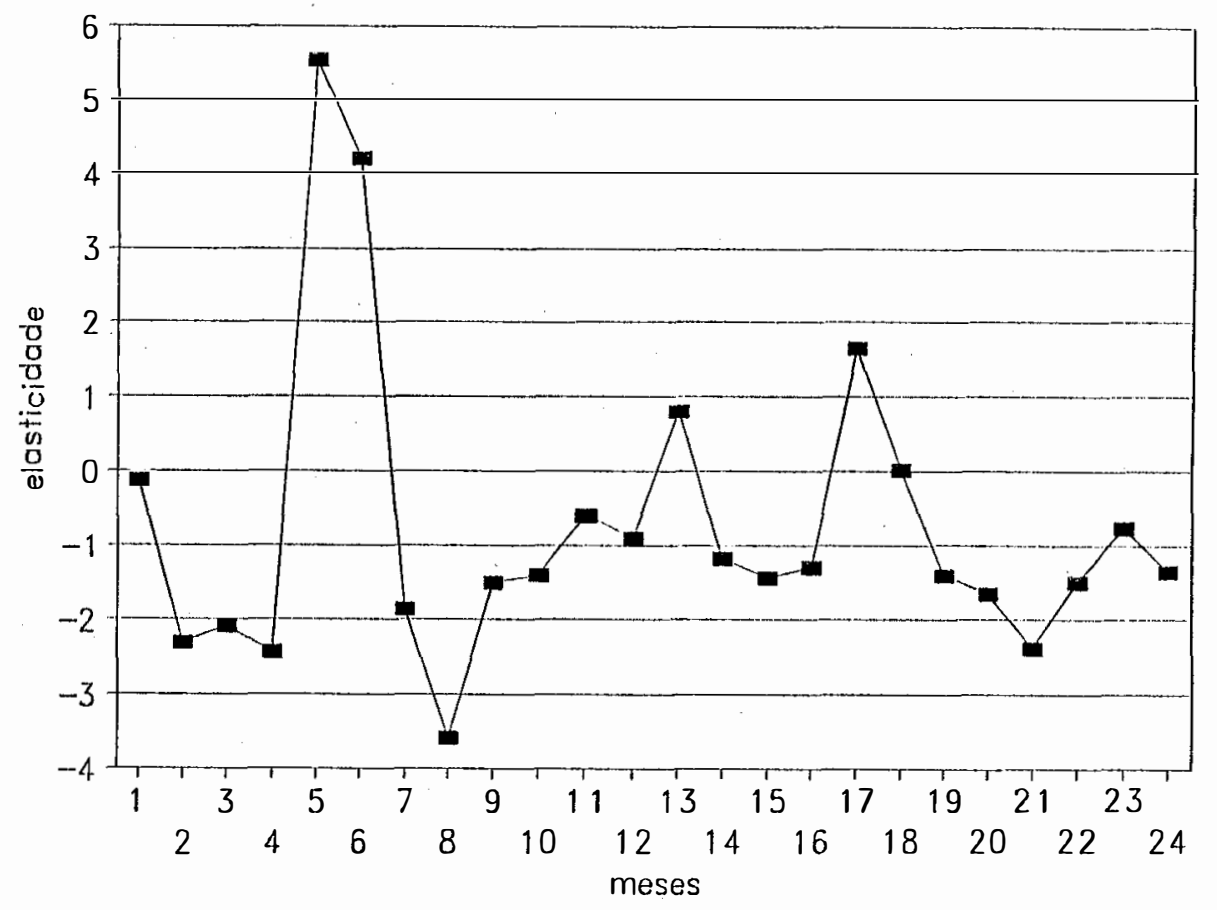

Figura 2.10 - Semi-elasticidades de impulso da taxa de juros sobre a margem de comercialização de feijão - modelo VAR identificável. 


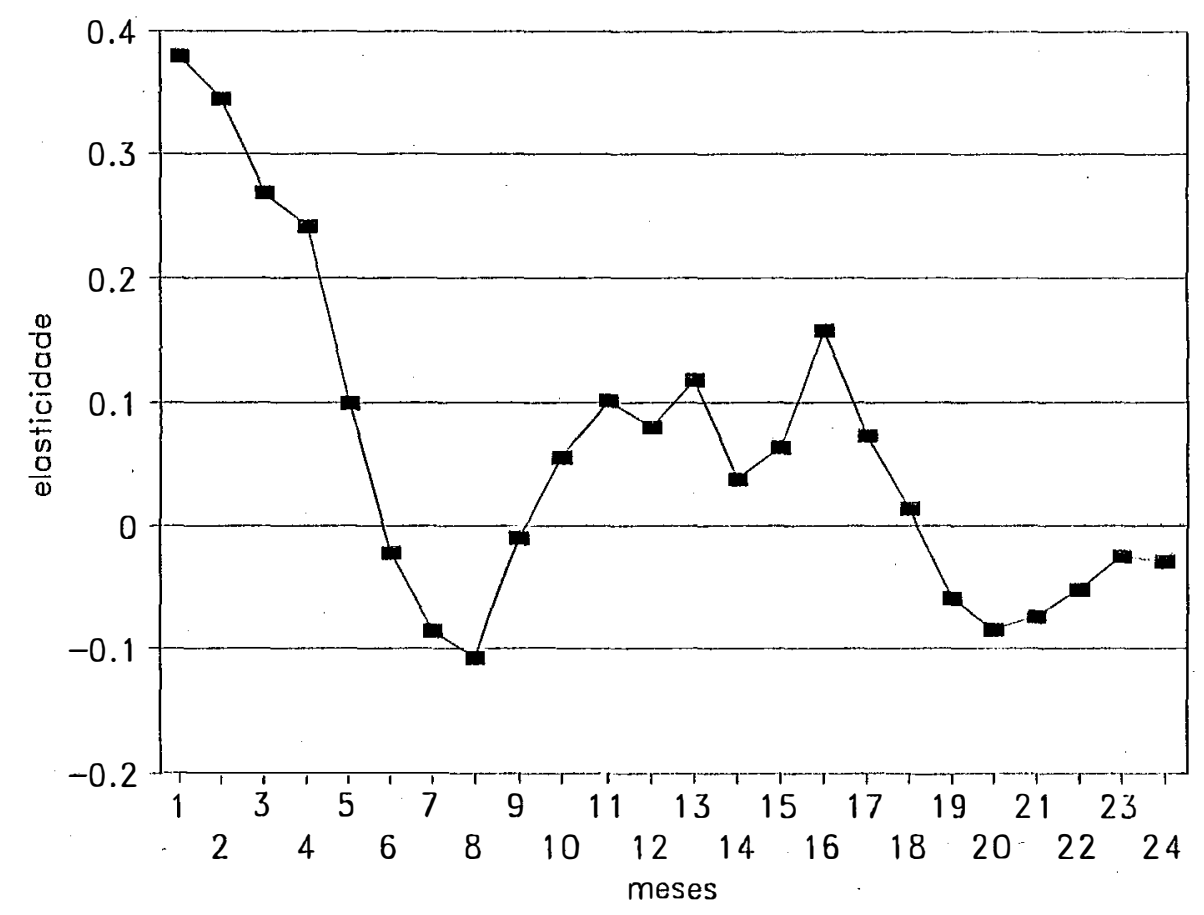

Figura 2.11 - Elasticidades de impulso do risco de preço sobre a margem de comercialização de feijão - modelo VAR identificável. 


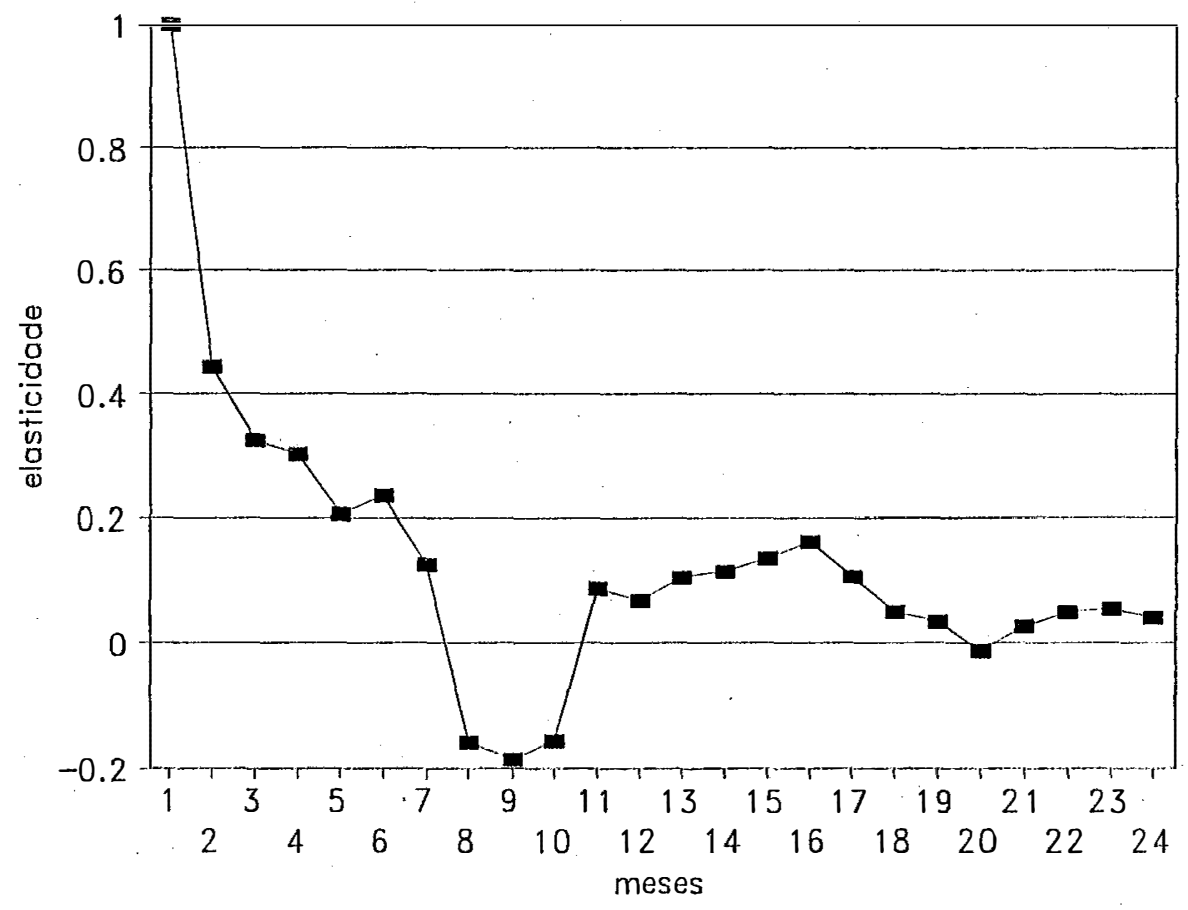

Figura 2.12 - Elasticidades de impulso da margem de comercialização de feijão sobre ela mes'ma- modelo $\mathbb{V A R}$ identificável. 